\title{
REINALDO GIUDICI
}

\author{
MOdELAGEM DE REATOR DE OXIDACXO DE ETILENO: \\ ESTUDO DE PARAMETROS TÉRMICOS \\ E \\ ESTRATÉgIA DE DILUIC\&O dE CATALISADOR
}

\begin{abstract}
Tese apresentada à
Escola Politécnica da USP para a obtencảo do titulo de Doutor em Engenharia.
\end{abstract}

São Paulo, 1990. 


\begin{abstract}
REINALDO GIUDICI
Engenheiro Químico, Escola Politécnica da USP, 1983. Mestre em Engenharia Quíaica, Escola Politécnica da USP, 1986.
\end{abstract}

MODELAGEM DE REATOR DE OXIDACAO DE ETILENO: ESTUDO DE PARAMETROS TÉRMICOS

E

ESTRATÉGIA DE DILUICÁO DE CATALISADOR

\begin{abstract}
Tese apresentada à Escola Politécnica da USP para a obtenção do litulo de Doutor em Engenharia.
\end{abstract}

\begin{abstract}
Orientador: Prof. Dr. Cláudio Augusto Oller do Nascimento Professor Associado, Depto. Engenharia Química
\end{abstract}

Säo Paulo, 1990. 
para meus pais e minhas irmãs, Para meus sogras.

e Para Maria Regina e Kelly 


\section{AGRADECIMENTOS}

Ao Prof. Dr. Cládio Augusto oller do Nascimento, pela orientacão deste trabalio, pelo constante incentivo é pela valiosa amizade.

Ao Eng- Carlos Itsuo Yamamoto, pelo inest imável auxílio nos trabalhos de simulaçáu.

Aos Engs. André L. Fregolente $e$ Antonio Carlos S. C. Teixeira, e à técnica de laboratório srta. Cristina J. Ziminiani, pelo auxilio na montagem do equipamento experimental, e aos. técnicos mecânicos Srs. Jorge Antonio Frutuoso e Tadeu Frutuoso, pelo auxilio na construcáo do equipamento experimental.

A Prof. Ana Maria da silveira, da ufscar, pelas úteis discussốes e trocas de informafóes relativas ao estudo de: transferência de calor.

Ao Quím. João Guilherme R. Poko, do Laboratório de Catálise do IPT, Pelo empréstimo de alguns materiaiś cerámicos utilizados nos Ensaios.

A FAPESP, ao CNPq a a FINEP, pelo auxílio financeiro prestado através de bolsas de iniciação cientifica projetos de pesquisa. relacionados a este trabalho.

Ao Departamento de Engenharia Química da Escola Politécnica da Universidade de Săo Paulo.

Aos amigos do LSCP - Laboratório de Simulacáo e Controle de Processos, pelo constante incentivo pelo propicio ambiente de trabalho proporcionados no convívio diário. 


\section{RESUMO}

Neste trabalho foram estudados aspectos relacionados à modelagem matemática de reator catalitico de leito fixo.

Foi realizado um estudo experimental sobre transferência de calor em leitos fixos, em que é proposto um novo tipo de sensor anelar de temperatura, de fácil construcão, que permite filtrar as flutuacöes aleatorias de temperatura observada:s quando saxo usados sensores pontuais. 0 sensor teve seu funcionamento estudado experimental e teoricamente, e mostrou-se capaz de eliminar a influência da posifäo angular na medida de temperatura.

O5 parâmetros efetivos condutividade térmica radial e coeficiente de transferência parede-leito foram estimados usandose o modelo bidimensional com dispersäo axial. Uma análise de sensibilidade paramétrica deste modelo mostrou que a sensibilidade ao coeficiente de dispersäo térmica axial é bastante pequena, o que explica o ajuste pobre que este parâmetro costuma apresentar.

Os estudos de simulagão aplicados au reator le úxido de eteno mostraram que estratégias de diluicão de atividade catalítica do leito podem aumentar significativamente a faixa de operabilidade do reator, diminuindo a sensibilidade às condicốes de operaçấ. A dijuicão por simples mistura de particulas cataliticas e inertes pode, entretanto, levar a ocorrencia de pontos quentes localizados, devido a eventuais aglomerados de particulats at ivas.

Os estudos de simulacão evidenciam. a importáncia de um bom conhecimento de certos parâmetros do modelo, romo os parânetros térmicos e cinéticos. A identificafão do modelo unidimensional frente a medidas experimentais possibilitou reprosentiar adequadamente o comportamento de: um reator industrial. 


\section{ABSTRACT}

Mathématical modeling of fixed-bed catalytic reactor was the main scope of this work.

A new type of ring-shaped temperature sensor in experimental studies on fixed-bed heat transfer is proposed. This ring-shaped sensor is easy-to-build and allows to filter randomic temperature fluctuations observed when point sensors are used. This technique has the advantage to eliminate the effect of angular position on temperature measurements. This property has also verified by theoretical studies.

Effective radial thermal conductivities and wall heat transfer coefficients were estimated by using an axially dispersed bidimensional model. A parametric sensitivity analysis of this model showed that sensitivity to axial thermal dispersion coefficient is very small, a result which explains the poor estimation of this parameter.

Simulation studies on ethylene oxide reactor demonstrated that catalyst dilution strategies may extend significantiy the reactor operability range by reducing reactor sensitivity. However, when a catalytic bed is diluted by isimple mixture of inert and catalytic particles, local hot spots may occur at the agglomerations of active particle:z.

Simulation studies clearly show how important is the knowledge of some model parameters, as thermal and kinetic ones. The behaviour of an industrial reactor could be adequately represented by adjusting the unidimentional model - 


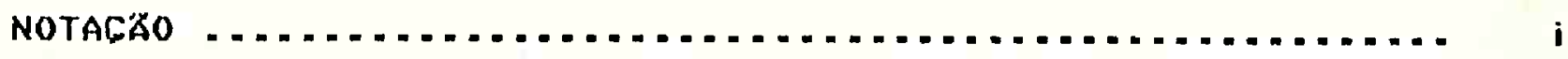

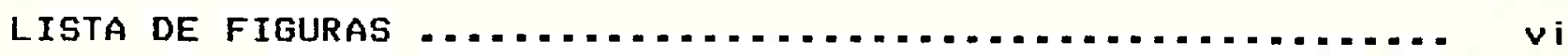

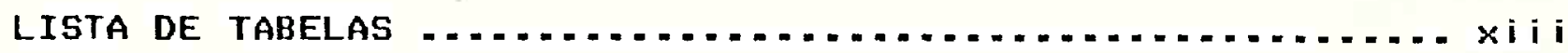

Capitulo 1 - INTRODUCZO ........................... 1

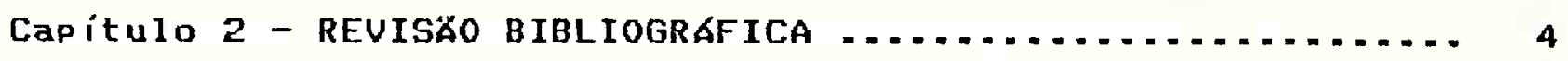

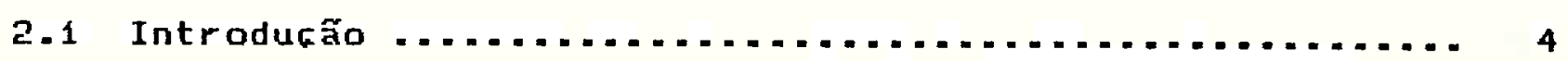

2.2 Modelagem de reatores de leito fixu ................. 4

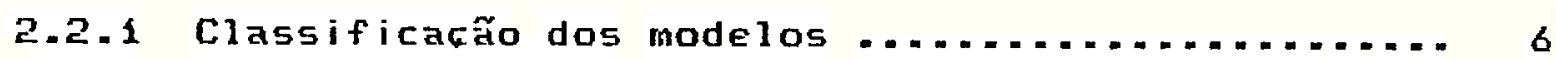

2.2.1 Nétodos numéricos para a solucão dos modelos ..... 9

2.2.3 Modelos de reatores de oxidacăo ém leito fixo .... 10

2.2.4 Modelos que incluem perfis radias de velocidade.. 13

2.2.5 Modelos que analisam estratégias de diluicếo

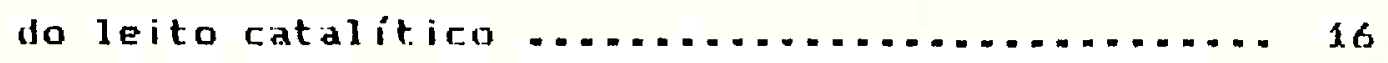

2.2.6 Modelos que consideram a interacão do reator com o meio refrigerante .................. 17

2.3 Transferência de calor em reatores de leito fixo ....... 19

2.3.1 Sobre a determinacũo experimental de parämetrou

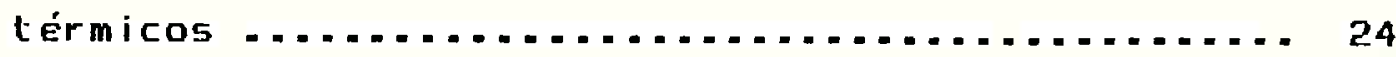

2.3.2 Controvérsias, aspectos pouco explorados

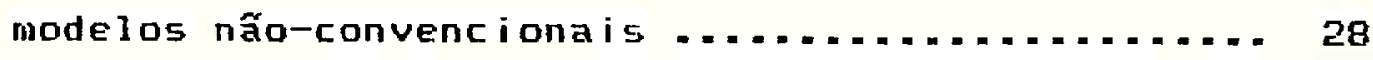

2.4 Descricão do processo de producão de óxido de eteno ..... 30 
Capitulo 3 - ESTUDO EXPERIMENTAL DE TRANSFERÉNCIA DE CALOR EM REATOR CATALITICO DE LEITO FIXO ........... 35

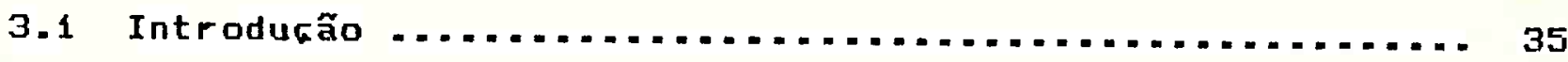

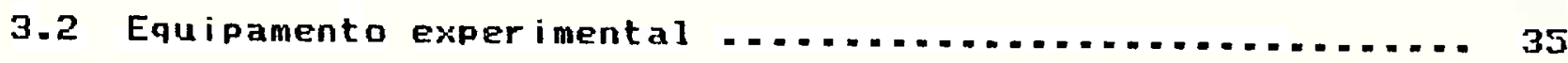

3.2.1 Medidas de temperatura no leito ..................... 39

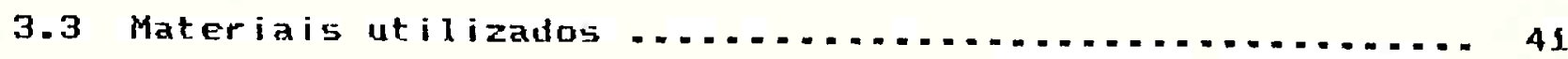

3.4 Ensaios experimentais ........................... 42

3.5 Tratamento de dados e estimacăo dos paràmetros ........ 42

3.6 Resultados experimentais e discussão ................... 44

3.7 Est imacão de parämetros usando outros modelos ......... s6 3.7.1 Comparaão entre os modelos I E IV (com e sem dispersão axial ) ...................... 74

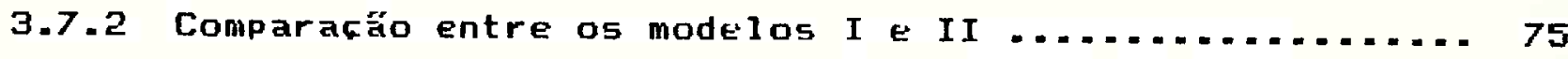

3.7.3 Comparacăo entre os modelos I e III ............ 78

3.8 Estudo de sensibilidade paramétrica do modelo I ....... 80 3.8.1 Resultados e discussão do estudo de sensibilidade. 82

3.9 Modelo teórico para o sensor anelar de temperatura ..... 90

3.10 Conclusóes do estudo de transferencia de calor ........ 95

Capitulo 4 - MODELAGEM MATEMATICA DO REATOR CATALítTCO

DE LEITO FIXO .............................. 96

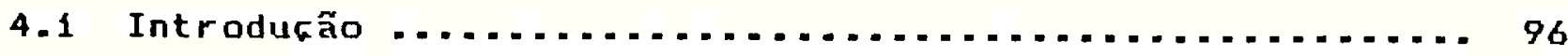

4.2 Modelo 1 - Unidimensional, pseudo-homogëneo, estático ... 97

4.3 Resultados da simulacão obtidos com o modelo $1 . . . . . . .161$ 4.3.1 Influância da temperatura de alimentaçăo $T_{0} E$ da temperatura da parede do tubu $T_{\infty} \ldots . . . . . . . . . .101$

4.3.2 Influência da concentraçăo de reagentes ......... 104 4.3.3 Influência da vazão de alimentacão ............. 104 
4.3.4 Influência da pressâo ...................... 108

4.3.5 Influência da atividade catalitica do leito ...... 110

4.3.6 Influência da cinética da reacấo ................ 110

4.4 Modelo 2 - Bidimensional, pseudo-homogêneo, Estatico .... 112

4.5 Resultados obtidos com o modelo bidimensional .......... 115

4.6 Inclusão do perfil radial de velocidade no modelo $2 \ldots 117$

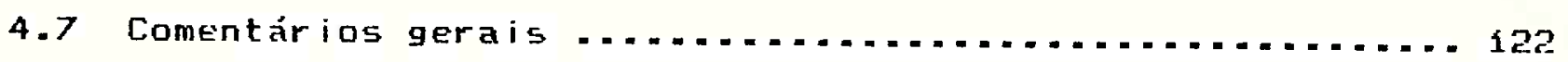

Capitulo 5 - ESTUDO DE ESTRATÉGIAS DE DILUTCÁO DO

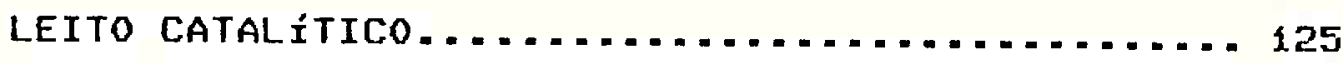

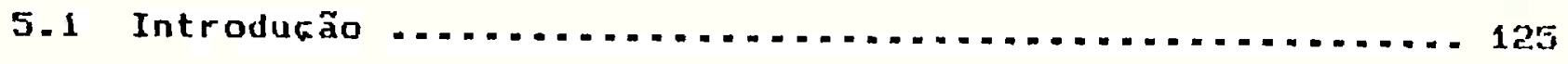

5.2 Modelo matemát ico empregado ........................ 125

5.3 Resultados da simulacão ........................... 127

5.4 Verificaçáo da ocorrencia de pontos quentes locais quando a diluifão de atividade catalitica é feita por mistura de particulas ativas e inertes .............. 137

5.5 Comentários gerais e conclusöes .......................

Capítulo 6 - IDENTIFICACZOO DE MODELO DE REATOR DE LETTO FIXO - 143

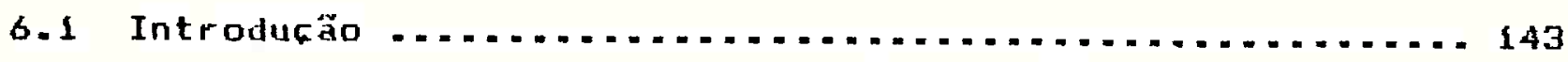

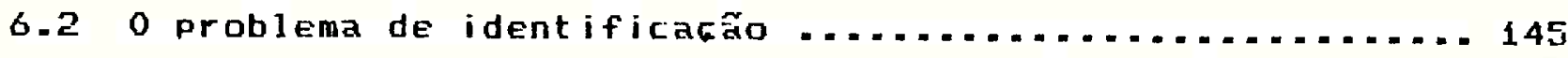

6.3 Aplicaçáo ao reator de óxido de eteno ................ 146

6.3.1 Identificagão usando apenas a temperatura $e$ conversöes na saída do reator ............... 149

6.3.2 Identificagão usando o perfil de temperatura e as conversổes na saida do reator ............. 15it

6.3.3 Influência dos pesos no ajuste pelo critério de mínimos quadrados absolutos ponderados ......... 154

6.4 Comentários e discussão ........................... 155 
Capítulo 7 - CONCLUSófs E RECOMENDACóEs

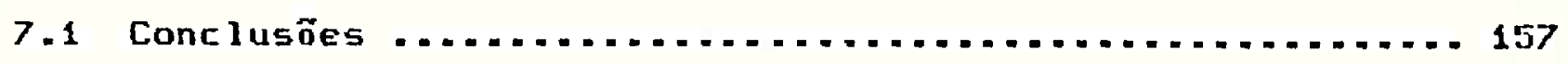

7.2 Sugestőes para cont inuação dos trabalhos ............. 159

Apêndice A - MÉTODO DE OTIMTZACÄO DE MARQUARDT ........... 161

Apêndice B - SOLUCZOO NUMÉRICA DO MODELO DO SENSOR ANELAR .... 163

Apêndice C - SOBRE OS PROGRAMAS UTILIZADOS ............... 165

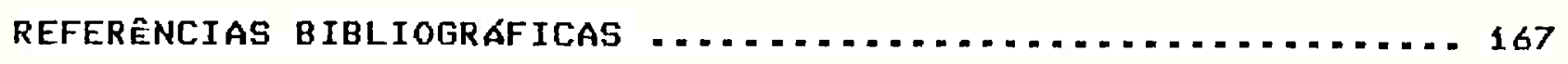




\section{NOTACĀO}

a

a

ar

A

$A_{x}=$

$a_{1}, a_{2}$

b

J

bx

B

BI..

B i

C

$C_{p}$

$d_{p}$

d.

D

Dr

EJ

$f$

$F$

9

G

ha

h.m
- Parâmetro definido na equaçäo $(4.48 .5)$

- atividade catalítica

- área interfacial gás-5ólido especifica $\left(\mathrm{m}^{2} \mathrm{~m}^{-3}\right)$

- área transversal $(=3,1416 \mathrm{~d} \approx / 4)(\mathrm{m})$

- elementos da matriz para o cálculo da cierivada primeira, do mítodo de colocacắ ortogunal

- parâmetros de equaço (5.3)

- constante da equacäo (2.17)

- parâmetros genérico na equacão (3.20)

- vetor dos parâmetros ajustáveis na itêraḉo k

- parâmetro definido na equafão (4.44)

- elementos da matriz para o cálculo do Laplaciano, do método de colocagấ ortoyonal

- número de $B$ iot $\left(=h_{m} R_{\omega} / k_{r}\right)$

- concentracáo da espécie i (kmol $\mathrm{m}^{-3}$ )

- calor específico do fluido (J $\mathrm{kg}^{-1} \mathrm{OC}^{-1}$ )

- diâmetro de partícula (m)

- diametro do reator (m)

- dianetro do fio que constitui o sensor anelar (n)

- difusividade radial efetiva (m $\mathrm{s}^{-2}$ )

- energia de ativacão da reaç̃o j (J kmol'-1)

- fator de atrito para escoamento em leitu fixu

- vazão molar do componente i (kmol $s^{-k}$ )

- fator de amortecimento

- densidade de fluxo mássico (kg $\mathrm{m}^{-2} \mathrm{~s}^{-x}$ )

- coeficiente de transferência de calor gás-anel metálico (W $m^{-2} o C^{-1}$ )

- coeficiente de transferencia de calor entre gás e particula ( $W \mathrm{~m}^{-2}{ }^{-2} \mathrm{C}^{-1}$ ) 


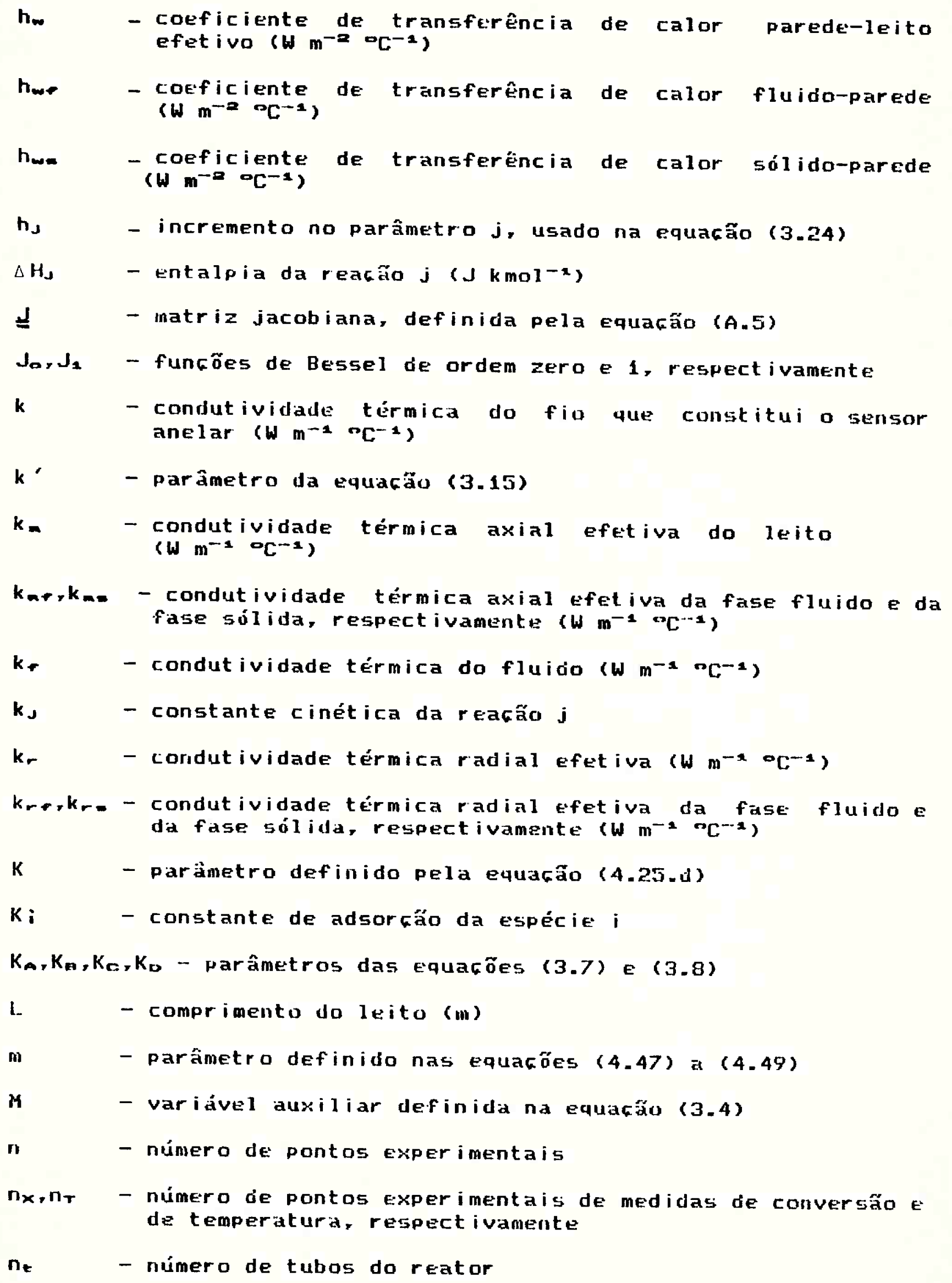


N - número de pontos de colocacão ortouonal internos; também número de pontos de discretizaç̃o do domínio por diferencas finitas

Nu - número de Nusselt $\left(=h_{w} d_{p} / k_{*}\right)$

Nun - número de Nusselt gás-sensor anelar $\left(=\ln D / k_{\uparrow}\right)$

p - número de paràmetrus

pi - pressão parcial do componente i (atm)

P - pressäo (atm)

Pe. - nimero de Peclet axial ( $=G c_{m m} d_{m} / k_{m}$ )

Per - número de Peiclet radial ( $\left.=G c_{p m} d_{p} / k_{r}\right)$

Perm - número de Peclet radial de transporte de massa (=ud, $\left./ D_{-}\right)$

Q - parâmetro definido pela equacióo (4.45)

r - posicáo radial (in)

R - posicáo radial adimenisional $\left(=r / R_{w}\right)$

$R_{n} \quad$ - raio do sensor anelar de temperatura (m)

RJ - velocidade da reacfio $\mathrm{j}\left(\mathrm{kmol} \mathrm{kg}^{-x} \mathrm{~s}^{-x}\right)$

R. - constante dos gases ideais

$R_{w} \quad$ - raio do reator (m)

Re - número de Reynoldi $\left(=G d_{p} / u_{r}\right)$

Ren - número de Reynolds (= G D/ U*)

$5^{2} \quad$ - estimativa da variáncia

Sx.- - sensibilidade da variável I em relaçáo ao parâmetro J, definida pela equacăo $(3.20)$

$S_{m}, S_{m}, S_{w}$ - sensibilióade da temperatura a $k_{m} k_{r} E^{\prime} l_{m}$ respectivemente

Sor - seletividade da reacáo, definida como número cie moles de eteno convertido a oxido de eteno dividido pelo número de moles de eteno reagido

$t$ - temperatura no anel (oc)

$T$ - temperatura ( ${ }^{\circ} \mathrm{C}$ ou $K$ )

T. - temperatura da fase fluido ( $\left.{ }^{\circ}\right)$ 


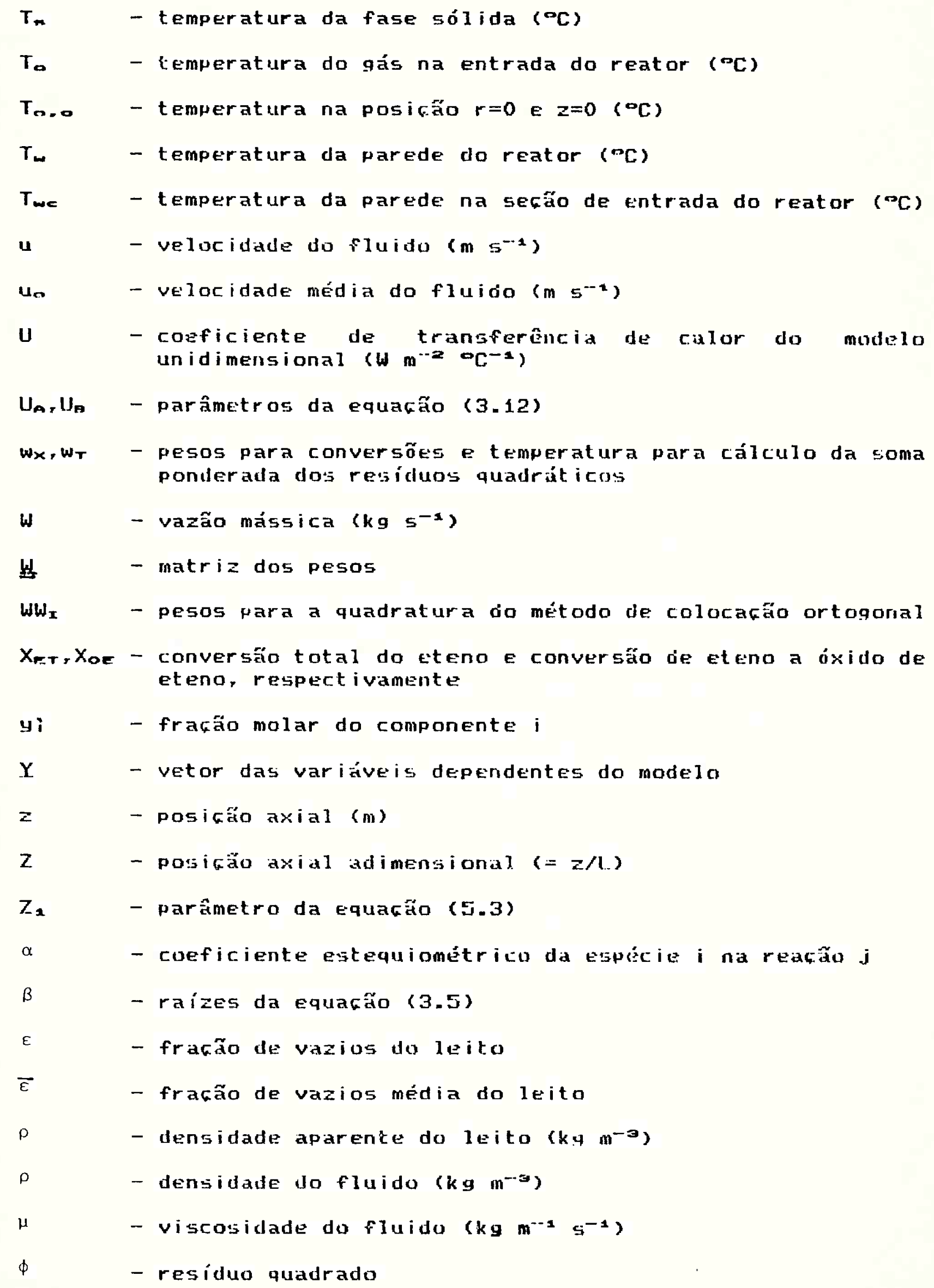




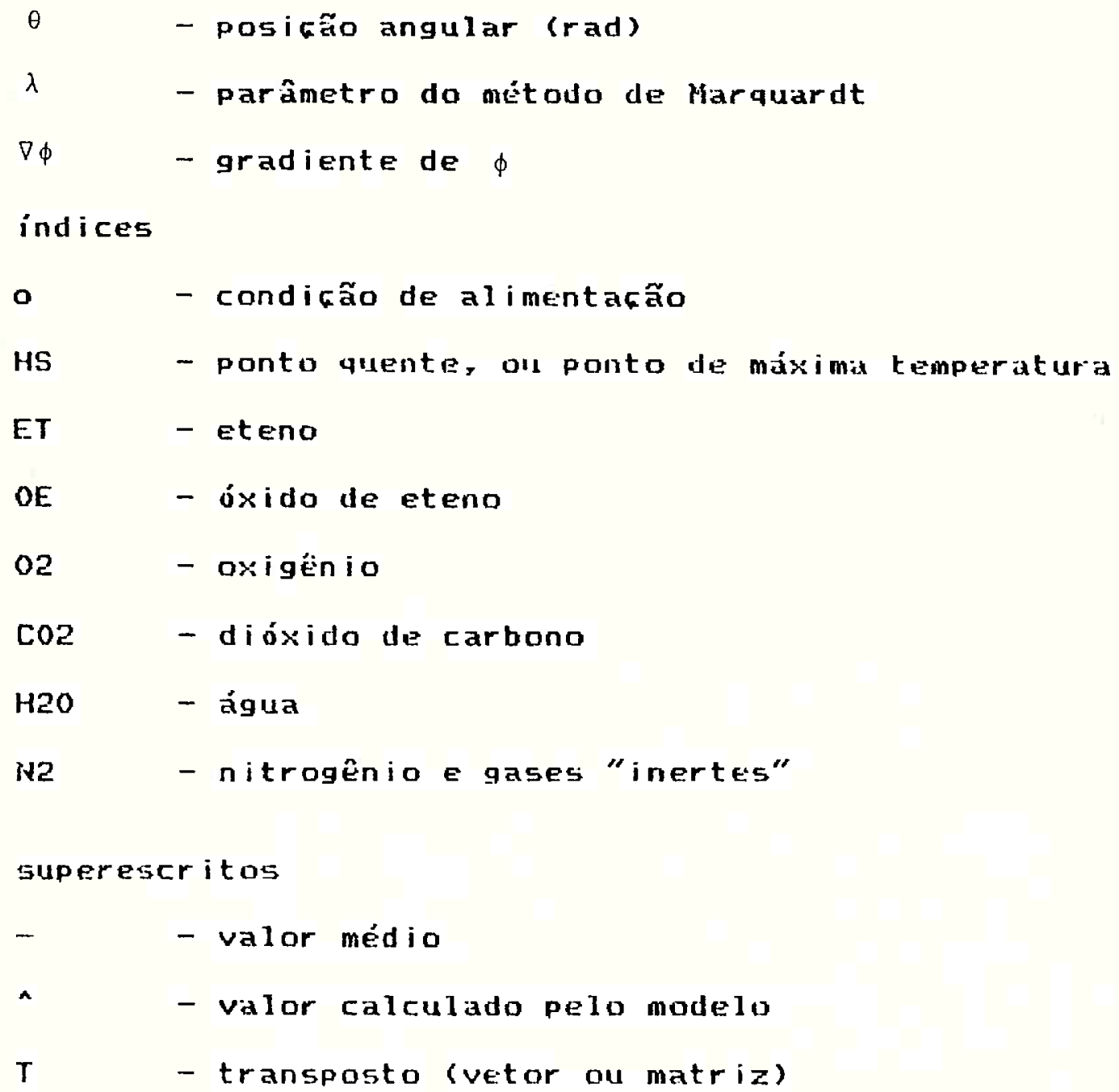




\section{LISTA DE FIGURAS}

pág.

FIgURA 2.1. Esqueaa de configuraçâo experimental para estudo de transferência de calor em reatores de leito fixo ...... 21

FIgURA 2.2. Efeito da condugão pela parede sobre o ajuste do modelo sem dispersão axial: (a) modelo com $k_{r}$ verdadeiro; (b) modelo com $k_{r}$ maior (extraido de

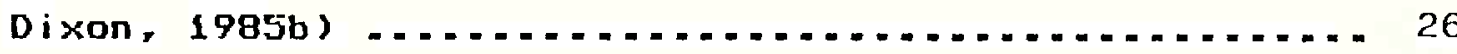

FIGURA 2.3. Fluxograma simplificado do processo de producão de óxido de eteno (extraido de Piccinini \& Levy, 1984) .. 34

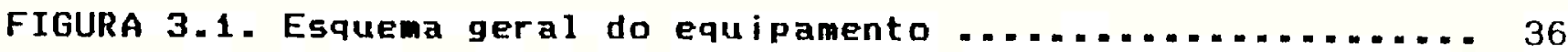

FIgURA 3.2. Esquema dos sensores de temperatura: (a) sensor anelar; (b) sensor pontual convencional .......... 36

FIGURA 3.3. Comparacão das diversas medidas pontuais em diferentes posicöes angulares com as medidas feitas com os sensores anelares, para o material $n^{\circ} 5 \ldots . . .45$

FIGURA 3.4. Perfis de temperatura medidos com os sensores anelares, com os sensores pontuais (média de seis medidas) e calculados pelo modelo. Material no5 ..... 46

FIguRA 3.5. Perfis de temperatura na parede da secăo de entrada. 49

FIGURA 3.6. Reprodutibilidade dos perfis de temepratura (a) $e$ dos parâmetros estimados (b). Material no 5 (anéis de

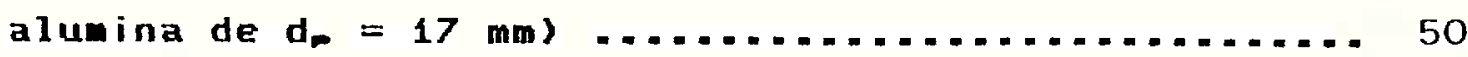

FIgURA 3.7.a. Comparacăo entre os perfis de temperatura medidos e calculados. Material no $1 \ldots \ldots \ldots . . \ldots \ldots \ldots$ 
FIGURA 3.7.b. Comparaçäo entre os perfis de temperatura

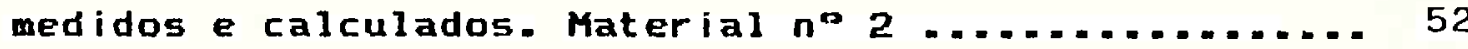

FIGURA 3.7.C. Comparacão entre os perfis de temperatura medidos e calculados. Material no $3 \ldots . . . . . . . . . .$.

FIGURA 3.7.d. Comparacão entre os perfis de temperatura medidos e calculados. Material no $4 \ldots \ldots . \ldots . \ldots . \ldots 4$

FIGURA 3.7.e. Comparacão entre os perfis de temperatura medidos e calculados. Material no $6 \ldots \ldots \ldots 5$

FIGURA 3.8. Comparacão dos resultados deste trabalho com dados da literatura, para esferas de aco inox de $9,5 \mathrm{~mm}$ (material $n^{\circ} 3$ )

FIGURA 3.9. Resultados abtidos para us parâmetros hw e kr para

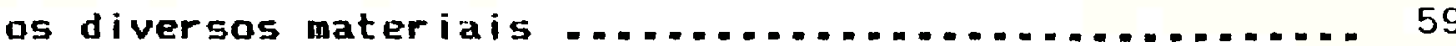

FIgURA 3.10. Comparafäo dos resultados de Per e Nu obtidos neste trabalho com a regiåo de pontos experimentais da literatura (extraido de Gunn et alii, 1987) ..........

FIguRA 3.11- Comparacăo dos resultados de Pé obtidos neste trabalho com a regiäo de pontos experimentais da literatura (extraido de Dixon \& Cresswell, 1979) ..... 62

FIGURA 3.12. Comparacão dos resultados de Bi obtidos neste trabalho com a região de pontos experimentais da literatura e com a correlacäo de Dixon \& Cressmell (1979), equação (3.10) 
FIgURA 3.13. Resultados relativots ao número de Biot: (a) Bi versus Re para os diversos materiais; (b) visualizacão

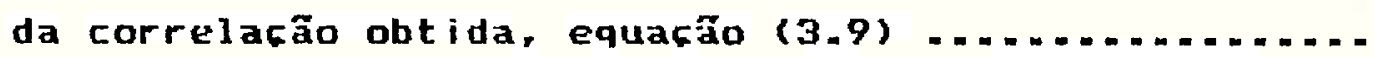

FIGURA 3.14. Resultados relativos ao coeficiente global de transferência de calor $U:$ (a) influéncia da vazão de gás; (b) influência do tamanho da particula ..........

FIGURA 3.15. Comparação entre os resultados obtidos com o modelo com dispersão axial (modelo I) e com o modelo sem dispersão (modelo IV), para três alturas de leito tratadas simultaneamente e individualmente

FIgURA 3.16. Comparacäo entre os resultados obtidos com a modelo com dispersáo axial (modelo I) e com a modelo sem dispersão (modelo IV), para três alturas de leito tratadas simultaneamente $e$ individualmente ..........

FIgURA 3.17. Comparacão dos perfis de temperatura em $z=0$ medidos e calculados pelo modelo I e pelo modelo III .........

FIGURA 3.18. Superfícies de sensibilidade a hw. Casos 1,2 e 3...

FIGURA 3.19. Superfícies de sensibilidade a hw. Casos 4,5 E 6...

FIGURA 3.20. Superficies de sensibilidade a $k_{r}=$ Casos 1,2 E $3 . .$. 85

FIGURA 3.21. Superficies de sensibilidade a kr. Casos 4,5 e 6...

FIguRA 3.22. Superficies de sensibilidade a k=- Casos 1,2 E...

FIGURA 3.23. Superficies de sensibilidade a k.. Casos 4,5 e 6... 
FIGURA 3.24. NuD $\left(=h_{m} D / k_{+}\right)$versus Ren $\left(=p-u D / u_{+}\right)$para escoamento normal a un cilindro cextraido de Welty et.

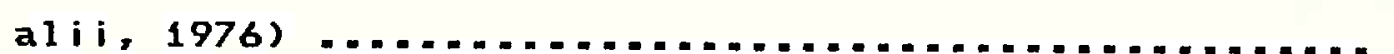

FIgURA 3.25. Resultados do modelo do sensor anelar de temperatura: (a) perfis de temperatura no gás e no

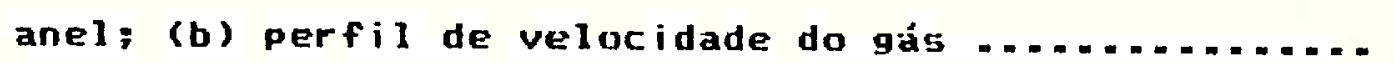

FIGURA 3.26. Resultados do modelo do sensor anelar de temperatura: (a) perfis de temperatura no gás e no anel. (b) perfil de velocidade do gás ............... 94

FIGURA 4.1. Influência da temperatura da alimentacão sobre o comportamento do reator

FIGURA 4.2. Influência da temperatura do fluido refrigerante

FIgURA 4.3. Influência da concentração de oxigênio na al imentặóo

FIGURA 4.4. Influência da vazảo de alimentação. 0 coeficiente de troca térmica é calculado em funcấo da vazão 106

FIGURA 4.5. Influência da vazáo de alimentação quando o coeficiente de transferéncia de calor é considerado

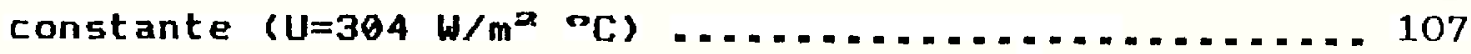

FIgURA 4.6. Influência da pressão de operaçăo .............. 109

FIGURA 4.7. Influência da atividade catalítica do 1eito ...... 111 
FIgURA 4.8. Influência do nimero de pontos de colocacão internos sobre as previsōes do modelo. Condicôes mesmas da Tabela 4.3, caso base. Perfil radial de temperatura na posicão axial de máxima temperatura ... 116

FIGURA 4.9. Comparacão entre previsŏes dos modelos uni $e$ bidimensional: (a) caso base da Tabela 4.3, exceto $T_{0}=T_{\omega}=229^{\circ} \mathrm{C}, \quad d_{t}=31,75 \mathrm{~mm} ; W=25 \mathrm{~kg} / \mathrm{s} ;(\mathrm{b})$ caso base da Tabela 4.3

FIGURA 4.10. Perfis radias de velocidade em leitos fixos de esferas, conforme as previsöes de Vortmeyer \& Schuster (1983), equacỗes (4.47) a (4.49) (extraido de Tsotsas

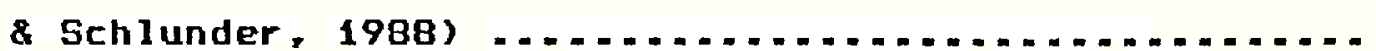

FIGURA 4.11- Comparacão entre previsöes do modelo bidimensional convencional (a) e do modelo comperfis radiais de velocidade $e$ porosidade (b). Condicōes mesmas da Tabela 4.7 , exceto $T_{0}=T_{\infty}=229^{\circ} \mathrm{C}, \omega=25 \mathrm{~kg} / \mathrm{s}$;

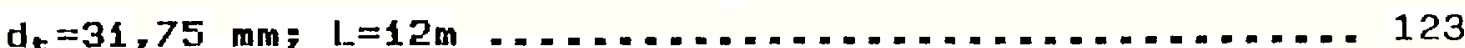

FIGURA 4.12. Comparacão entre previsŏes do modelo bidimensional convencional (a) e do modelo comperfis radiais de velocidade e porosidade (b). Condicôes mesmas da Tabela 4.7 , exceto $T_{0}=T_{m}=231{ }^{\circ} \mathrm{C}, \omega=25 \mathrm{~kg} / \mathrm{s}$;

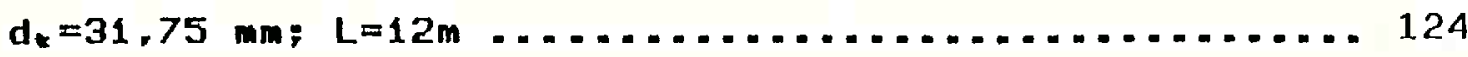

FIgURA 5.1. Influência das temperaturas de alimentacão e de refrigeracáo, e da concentrafä́o de oxigênio na alimentacão sobre o comportamento de um leito de at ividade un iforme .............................. 
FIGURA 5.2. Influência dos parâmetros $a_{1} e Z_{1}$ sobre a pág. comportamento de un leito con estratégia de diluicão.- 130

FIGURA 5.3. Influência das temperaturas de alimentação e de refrigeracão (a), e da concentracto de oxigeñio na alimentação (b) sobre o comportamento de un leito diluido $\left(a_{1}=0,75 ; a_{2}=1,0 ; Z_{1}=0,25\right)$

FIGURA 5.4. Influência das temperaturas de alimentafäo e de refrigeracáo sobre a seletividade a óxido de eteno sobre a conversão do eteno, para leito de atividade uniforme 1,0 e leito diluido $\left(a_{1}=6,75 ; \quad a_{2}=1,0 ;\right.$ $\left.Z_{1}=0,25\right)$

FIGURA 5.5. Influência do número de patamares de atividade catalitica no leito. Condicões mesmas da Tabela 5.7 .. 136

FIGURA 5.6. Comparacão entre previsôes do modelo com distribuicâo discreta e continua de atividade catalitica: (a) resultados com distribuicâo contínua $a(z, r)=0,5$

FIGURA 5.6. Comparação entre previsöes do mudelo com distribuicão discreta e contínua de atividade catalitica: (b) resultados com distribuicão discreta, aleatória, de valores de atividade $a=0$ e $a=1 \ldots . . . . .140$

FIGURA 6.1. Esquema simplificado de controle com otimizacão .... 144 FIgURA 6.2. Perfil de temperatura no reator de óxido de eteno (extraido de Piccinini \& Levy, 1984) ................... 144 
FIGURA 6.3. Comparacão dos perfis ajustados con os pontos pág. experimentais. Ajuste obtido usando apenas a temperatura e conversões na saída do reator ............ 150

FIGURA 6.4. Comparacão dos perfis ajustados com os pontos experimentais. Ajuste obtido usando o perfil de temperatura e as conversões na saida, com o critério

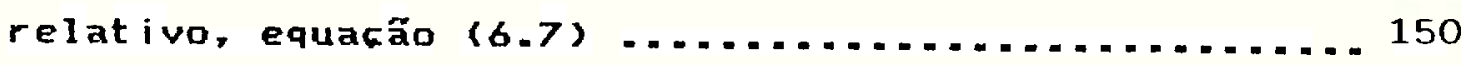

FIGURA 6.5. Comparacão dos perfis ajustados com os pontos experimentais. Ajuste obtido usando o perfil de temperatura e as conversões na saída, com o critério

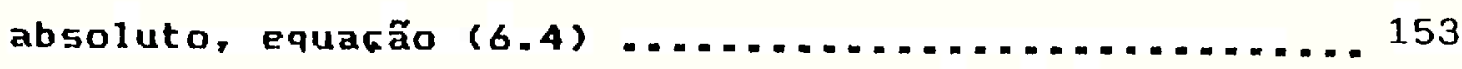

FIGURA 6.6. Influência dos pesos $\omega_{x} E$ w sobre o ajuste usando o

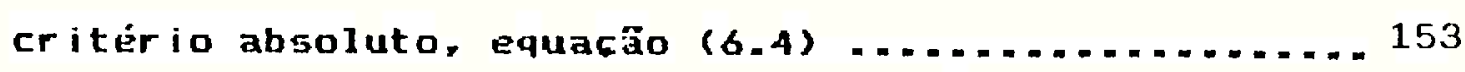

FIGURA A.1. Esquema da numeracão dos pontos de discretização _. 163 


\section{LISTA DE TABELAS}

pág.

TABELA 2.1. Alguns trabalhos sobre simulacão estacionária de reatores de oxidação

TABELA 2.2. Alguns modelos que incluem perfil radial de velocidade e outras não-uniformidades radiais do leito 15

TABELA 2.3. Alguns modelos que consideram a diluicão da

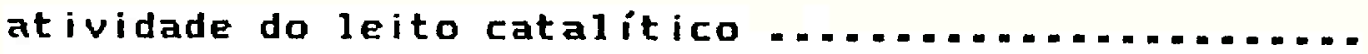

TABELA 2.4. Alguns modelos que consideram o fluido refrigerante en corrente cruzada ................ 18

TABELA 2.5. Alguns estudos sobre a cinetica da oxidacão de eteno 32

TABELA 3.1. Materiais utilizados nos ensaios ............... 41

TABELA 3.2. Resultados obtidos com os diversos materiais ...... 56

TABELA 3.3. Valores típicos dos elementos de correlaça cruzada da matriz variância-covariäncia dos parämetros (Material no5, alturas de leito 100,200 e $300 \mathrm{~mm}$

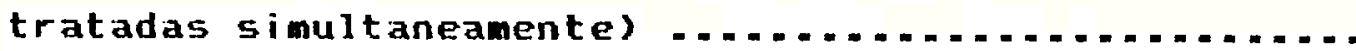

TABELA 3.4. Constantes das equacōes (3.7) e (3.8) ........... 60

TABELA 3.5. Constantes da equação (3.12) .................. 66

TABELA 3.6. Modelos utilizados para o tratamento de dados ..... 69

TABELA 3.7. Resultados obtidos com o modelo II .............. 70

TABELA 3.8. Resultados obtidos com o modelo III ............ 71

TABELA 3.9. Resultados obtidos con o modelo IV .............. 72 
TABELA 3.10. Comparacão entre os residuos quadráticos dos

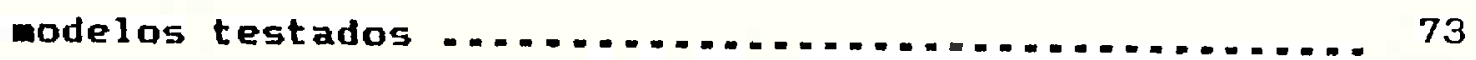

TABELA 3.11. Valores dos parâmetros utilizados para o estudo de

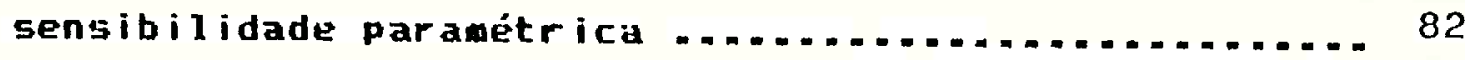

TABELA 3.12. Valores obtidos como o modelo do sensor anelar de

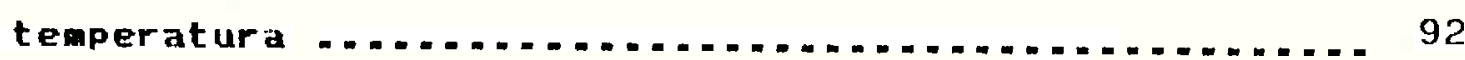

TABELA 4.1. Matriz dos coeficientes estequiométricos .......... 97

TABELA 4.2. Valores dos parâmetros usados na simulaçäo ....... 101

TABELA 4.3. Conjunto base de condicôes operacionais .......... 101

TABELA 5.1. Valores dos parâmetros usados na simulacão e conjunto base de condicões operacionais ............ 126

TABELA 5.2. Efeito da temperatura de alimentacão e do fluido refrigerante $e$ da concentracão de $O_{a}$ na alimentaçấo no desempenho do reator para um leito com atividade

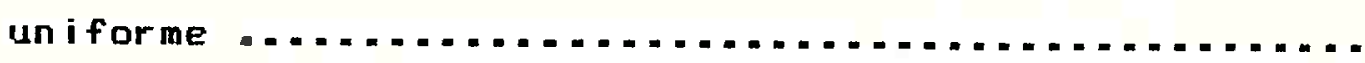

TABELA 5.3. Influência da atividade $a_{x}$ da primeira secão de leito para $Z_{2}=0,25 ; a_{2}=1 ; T_{0}=T_{\infty}=235^{\circ} \mathrm{C} ; y_{E T}=0,17$; $y_{0 x}=0,06$

TABELA 5.4. Influência do tamanho $Z_{1}$ da primeira secão de leito para $a_{1}=0,75 ; a_{2}=1 ; T_{0}=T_{w}=235^{\circ} \mathrm{C} ; y_{E T}=6,17 ; y_{02}=0,06131$

TABELA 5.5. Influência da temperatura da alimentacão sobre o desempento do reator com leito diluido, para temperatura do fluido refrigerante mantida constante em $T_{\omega}=240^{\circ} \mathrm{C} ; Z_{1}=0,25 ; a_{2}=0,75 ; a_{22}=1 ; T_{0}=T_{m}=235^{\circ} \mathrm{C} ;$ yex $=0,17 ; y_{0 z}=0,06$ 
TABELA 5.6. Influência da temperatura da alimentacão do fluido pág. refrigerante e da fracão molar de Oa na alimentacão no desempenho do reator com leito diluido: $a_{2}=0,75$; $a_{z=1}=Z_{1}=0,25 ; y_{E T}=0,17$

TABELA 5.7. Influência do número de patamares com intervalos igualmente espacados e atividade global média unitária sobre o desmpenho do reator: $y_{5 \mathrm{r}}=0,17 ; y_{022}=0,06$; $T_{0}=T_{\omega}=235^{\circ} \mathrm{C}$

TABELA 5.8. Comparacão dos resultados da simulacão usando modelo com distribuicão discreta e modelo com distribuicäo

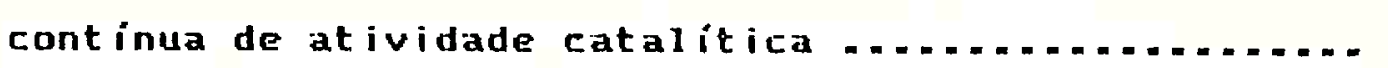

TABELA 6.1. Caracteristicas e condicões de operactio do reator para a producão de oxida de eteno cextraídas de

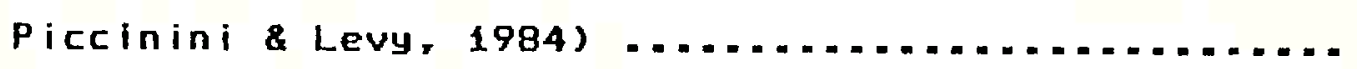

TABELA 6.2. Resultados do ajuste usando apenas a temperatura e

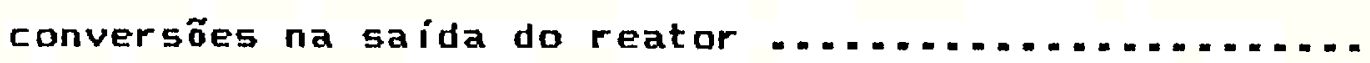

TABela 6.3. Pontos intermediários $e$ de saída utilizados para a

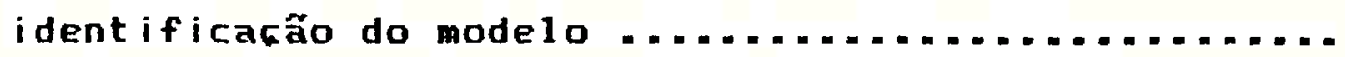

TABELA 6.4. Resultados do ajuste usando perfil de temperatura

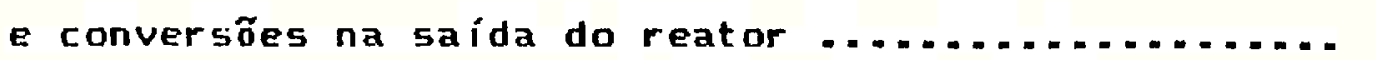

TABELA 6.5. Influência dos pesos wre wr sobre o ajuste usando o critério absoluto 


\section{Capitulo 1}

\section{INTRODUC'KO}

Reatores cataliticos de leito fixo sảo equipamentos de farta utilização na indústria quimica. Para os reatores tubulares cataliticos näo-adiabáticos onde ocorram reacốes fortemente exotérmicas, os principais problemas de operacão estão relacionados à possibilidade de ocorrência de pontos quentes. É especialmente importante prevenir este problema pois leva a consequências indesejáveis, tais como diminuicão de seletividade no caso de reacões competitivas, desativação do catalisador e especialmente o perigo do descontrole ("runaway") da temperatura do reator.

Este tipo de reator é normalmente do tipo multitubular, com um numero elevado de tubos longos e estreitos, refrigerados externamente por um meio de transferência de calor, usualmente um fluido térmico. o comprimento dos tubos é centenas de vezes maior que o diâmetro das particulas, mas o diâmetro do tubo $\dot{\epsilon}$ somente umas poucas vezes maior que o da particula, o que facilita a troca de calor radial através da parede dos tubos. Na última década, grande atencão tem sido voltada para o estuda de transferencia de calor em leitos fixos com baixa relacão diâmetro do tubo/diâmetro da particula.

Para estudar, projetar e analisar o reator, bem como ot imizar sua operacão e propor sistemas adequados de controler é fundamental dispor de um modelo matemático suficientemente representat ivo do processo.

Os modelos matemáticos constituem importantes ferramentas para utilizar as informacöes e dados existentes visando a previsão 
de novas condicões, possibilitando estudar, por exemplo, a viabilidade de mudancas de alimentacão, catalisadores e condicöes de operacão, a previsáo da dinâmica do processo sujeito a dado sistema de controle, a ot imizacão do processo. O grande valor da modelagem simulacão é un melhor entendimento sobre como "funciona" o sistema, e a possibilidade de testar diferentes condicões de uma maneira mais rápida, barata e segura do que se fossem testadas diretamente sobre o processo.

Quando melhorias do processo, ainda que pequenas, são conseguidas, pode-se levar a uma economia significativa, especialmente quando grandes quantidades são processadas. Um exemplo citado na literatura (Chen \& Joseph, 1987) relata que "em uma tipica planta de etileno con capacidade de $1 \times 10^{*} 1$ b/ano, um aumento de 1 (X no rendimento pode resultar en economia da ordem de US\$ $1,5 \times 10^{\circ /} / \mathrm{ano}^{\prime \prime}$.

Na elaboracão de um modelo matemático para reator catalitico, ut ilizam-se equaçöes fundamentais de conservacão de massa. energia e quantidade de movimento. Boas previsões do modelo dependem do adequado conhecimento de certos parâmetros relativos ao processo, tais como parâmetros cinéticos e de transferência de calor.

Alguns parâmetros, entretanto, são pouco conhecidos ou mesmo variáveis ao longo da operacão, requerendo que sejam ajustados frente aos dados do processo para garantir boa representacão do modelo. Este procedimento é conhecido por identificacáo do modelo.

Especificamente, este trabalho tem por objetivo:

- estudar a determinacão experimental de parâmetros térmicos de reatores de leito fixo, usando reator de laboratório:

- estabelecer modelo matemático para o reator de producão de dxido de eteno, e estudar através da simulacão, possiveis estratégias de diluicão da atividade catalitica do reator que 
permitam diminuir a ocorrencia de pontos quentes e aumentar a faixa de operabilidade do reator.

- estudar a identificacão do modelo do reator frente a dados do processo.

- processo de producão de óxido de eteno fol escolhido por ser um exemplo tipico de reacão de oxidacão industrial realizado em reator multitubular catalitico de leito fixo, onde oroblema de ocorrência de pontos quentes é crítico. Além disso tem relevância como processo industrial que produz um importante intermediário da indústria química.

Frente a estes objetivos, no Capitulo 2 é apresentada uma revisão bibliggráfica sobre os assuntos de interesse para o trabalho.

No Capitulo 3 é feito um estudo sobre transferência de calor ew leitos fixos, enfocando aspectos ligados a determinaçäo experimental de parâmetros térmicos.

No Capítulo 4 säo estudados modelos matemáticos para o reator de óxido de eteno, os quais são aplicados, no Capítulo şr para o estudo de estratégias de diluicão da atividade catalitica do leito.

No Capitulo 6 é estudada a identificacão do modelo do reator de leito fixo. Finalmente, no Capitulo 7 são apresentadas as conclusões e algumas sugestổs para a continuaço deste trabalho.

Alguns dos resultados parciais desta tese foram publicados nos trabalhos de Giudici \& Nascimento (1989), Fregolente, Nascimento \& Giudici (1989) e Yamamoto, Nascimento \& Giudici (1990). 


\author{
Capitulo 2
}

REUISXO BIBLIOGRGFICA

\title{
2.1 Introducão
}

Neste Capitulo é apresentada uma revisão bibliográfica sobre assuntos abordados neste trabalho. São tratados os temas modelagem de reatores de leito fixo e transferência de calor neste tipo de equipamento. Além disto feita uma apresentacão do processo de obtencão do óxido de etileno.

\subsection{Modelagem de reatores de leito fixo}

A modelagem matemática e simulacão de reatores de leito fixo tem sida extensivamente estudadas na literatura. Dentre as utilidades da modelagem e simulacão, Martinez et alii(1985) cit am:

- melhor entendimento do sistema, que permita melhorar o projeto do equipamento;

- previsão da dinâmica do sistema para propósitos de controle da operacão:

- ot imizacão das condicốes de operacão:

- análise do comportamento do reator frente a diferentes alimentacões, catalisadores e condicôes de operąåo;

- auxilio na mudanca de escala.

- nivel de sofisticacão adotado na modelagem de reatores depende em muito do uso a que se destina o modelo. Se, por um lado simplificacões muito fortes podem levar o modelo a fornecer previsöes incorretas, por outro um detalhamento excessivo pode tornar a solucão do modelo computacionalmente complexa ou depender de parâmetros cujos valores năo podem ser medidos com precisão a partir dos dados de operacão. 
As previsões de um modelo não podem em geral ser mais precisas que os parâmetros físicos e quimicos introduzidos no modelo. Talvez a maior limitacão no uso dos modelos nos dias atuais esteja no conhecimento preciso dos parámetros. De uma maneira geral, os parâmetros cuja influência seja maior nas previsōes do modelo são aqueles que deven ser conhecidos com maior precisão.

Sendo os modelos fundamentais, isto é, baseados em principios fundamentais (conservacấo de massa, energia e quantidade de movimento), normalmente os parâmetros tem um significado físico. Mo entanto, frequentemente, os parâmetros "carregam" ou "absorvem" as simplificacões e imperfeicões do modelo; isto ocorre quando os parâmetros são usados para ajustar o modelo à realidade física. Assim, uma etapa de estimacão de parâmetros, a partir de dados experimentais, pode ser utilizada para fazer ajustes nos parâmetros, de modo a tornar mais confiáveis as previsões do modelo.

Este aspecto é particularmente litil quando os parâmetros são pouco conhecidos a priori, ou mesmo variáveis com as condicóes de operaça (por exemplo, a atividade de um catalisador que sofra desativacão durante a operacãos. Um exemplo típico em que uma etapa de estimacão é utilizada é em controle otimizado de processos, sendo esta etapa conhecida pur "identificacăo" do modelo. Outro exemplo é o caso de otimizacáo em linha de processos, como ilustrado no trabalho de Chen \& Joseph (1987).

Nos dois exemplos acima citados ccontrole e otimizacão de processos) frequentemente se faz necessairio simular o modelo um número elevado de vezes. Neste caso os modelos mais úteis são preferencialmente aqueles mais simples, com menor carga computacional, e por decorrência destas simplificacões é 
necessário uma identificacão do modelo para assegurar uma boa representaçáo da realidade física.

\subsubsection{Classificacä́o dos modelas}

Os modelos matemáticos de reatores de leito fixo podem ser classificados sob vários aspectos, apresentados e discutidos a seguir. Pode-se separar os modelos en duas grandes categorias:

- os modelos de uma fase ou pseudo-homogêneos;

- os modelos de duas fases ou heterogêneos.

Nos modelas pseudo-homogêneas o leito é considerado como um meio homogêneo hipotético, e as equacöes de balanco de massa e energia são escritas para esta pseudo-única fase. Nestes modelos a natureza bifásica do leito é considerada apenas indiretamente ou implicitamente, através dos parâmetros "efetivos" do leito.

Nos modelos heterogenneas, as fases sólida (catalisador) e fluida são consideradas explicitamente, ou sejä, as equacões de balanco säo escritas para cada fase separadamente, e acopladas por termos que representam as transferéncias de calor e massa entre as fases.

Muito embora os modelos heterogéneos sejam fisicamente mais realistas, eles não tem sido tão utilizados quanto os pseudohomogêneos por duas razōes principais, conforme Khana \& Seinfeld (1987). Primeiro porque a solucão numérica do modelo heterogêneo é consideravelmente mais dificil que a do homogêneo, e segundo porque há muitas situacōes em que o modelo homogêneo é perfeitamente aceitável.

Assim, o modelo homogêneo parace reter os principais caracteristicos do comportamento do reator, sendo que em muitas situacões, o aumento de complexidade matemática ao considerar as 
duas fases separadamente não é compensada pelo ganho de informacôes adicionais do modelo mais detalhado.

Quanto ao número de dimensões consideradas pode-se classificar os modelos em:

- unidimensionais, onde somente são consideradas as variacões ao longo da direcão do escoamento principal (axial) no reator

- bidimensionais, onde as propriedades são consideradas variando ao longo de duas direcões, a axial (do escoamento) $e$ a radial.

No modelo unidimensional, mais simples, considera-se que as variacőes radiais sejam desprezíveis. Quando isto năo é possivel pode-se ainda justificá-10 como uma descricão aproximada das variacões de propriedades médias radiais ao longo do comprimento do reator. Este modelo é adequado para simular condicões de operacão do reator combaixa sensibilidade (Froment \& Bischoff, 1979), isto é, quando o comportamento do reator for pouco sensivel a pequenas mudancas de condicöes operacionais.

o modelo bidimensional fornece uma descricâo mais detalhada do reator, sendo recomendado para a simulação de condicôes mais severas de operacáo, especialmente aquelas mais próximas às condicões de maior sensibilidade.

Algumas raras vezes são encontrados trabalhos $\mathrm{em}$ que se utilizam modelos tridimensionais. Por exemplo, para descrever o comportamento de reatores em que o catalisador sólido está distribuido nẫo dentro de um tubo, aas do lado de fora dơ tubos. como no caso de reator para a sintese de amonia. Exemplos de modelos tridimensionais são dados na revisão de Hlavacek \& Votruba (1977) E no trabalho de Ahmed \& Fahien(1989).

Outra possivel classificacão dos modelos é relativa à inclusão ou não do termo de dispersäo axial nas equacōes. Este 
termo representa os processos de mistura axial (isto é, na direcäo do escoamento) que possam ocorrer superposto ao escoamento.

A inclusão do termo de dispersão axial via de regra aumenta em grande extensão a complexidade da solução numérica das equacôes do modelo.

Com a inclusão deste termo a modelo prevé a possibilidade de ocorrência de multiplicidade de estados estacionários. Como mostrado por exemplo por Froment \& Bischoff (1979) a faixa de valores dos parâmetros em que este importante fenômeno pode ocorrer é bastante restrita; é mostrado que para as condicōes de muitas reacōes industriais este comportamento nâo ocorre.

- termo de dispersão axial é desprezível para a maioria das situacōes típicas de reatores industriais, onde as velocidades de escoamento são elevadas e os leitos são suficientemente longos ( $L$ ) $150 \mathrm{~d}_{\mathrm{p}}$ ). No entanto este termo pode ser importante para reatores de laboratório, frequentemente operados com leitos curtos e vazões moderadas ou pequenas.

Pereira Duarte et alii (1984) apresentaram critérios qualitativos para a escolha de modelos sem dispersão axial. Basicamente a recomendacão $\dot{e}$ de utilizar o modelo bidimensional para condicôes mais severas de operacão laltos gradientes radiais de temperatura e reacões cuja velocidade é muito sensivel à temperatura). enquanto o modelo unidimensional é adequado para condicões de baixa sensibilidade. Para altas relacóes entre o diámetro do reator e o da partícula ( $\left.d_{*} / d_{m}\right)$ recomenda-se o modelo pseudo-homogêneo enquanto para baixos valores de $d_{e} / d_{-}$o modelo heterogêneo seria preferivel.

A despeito dessa recomendacáo, a maior parte dos trabalhos sobre modelagem de reatores de oxidacăo, em que a relação de/dp $\dot{e}$ baixa, trabalham com modelos homogeneos, como se verá adiante. 


\subsubsection{Métodos nunéricos para a solucĩo dos modelos}

Apesar de os modelos de reatores de leito fixo estarem relativamente ben estabelecidos desde a década de 1950, a sua aplicacão estava restrita aos modelos mais simples em virtude das dificuldades em se obter a solucão das equacóes. Com o aumento crescente das facilidades computacionais nas décadas seguintes, foi possível cada vez mais viabilizar a utilizacão de modelos mais sofisticados e novas técnicas de solucão numérica das equacôes foram desenvolvidas.

o estudo destas técnicas é apresentado en várias referências (por exemplo, Finlayson, 1986). A seguir apresentamos resumidamente algumas destas técnicas:

(a) Equacones diferenciais ordinárias de condicão inicial. Aparecem no modelo unidimensional sem dispersão axial. A literatura dispôe de várias métodos para a solucão deste problema, por exemplo o clássico método de Runge-Kutta, os métodos de passo múliplo e suas variantes. Para problemas "stiff" também estäo desenvolvidos pacotes adequados, por exemplo o de Runge-kutta semi-implícito (Michelsen, 1976) e o de Gear (Gear, 1971; Kahaner et $a 1 i i, 1989)$.

(b) Equacões diferenciais ordinárias de condicão de contorno. É o caso das equacốes do modelo unidimensional com dispersăo axial. A solucão é difícil, particularmente para o caso de reacóes exotérmicas e depende muito do valor do numero de Peclet, de acordo com Hlavacek \& Rompay (1981). Dependendo do problema pode ser resolvido por integracão passo a passo associado a técnicas de convergência. Diferencas finitas e colocacão ortogonal podem ser também ut ilizadas. 
(c) Equacões diferenciais parciais do tipo parabólico. Surgem por exemplo do modelo bidimensional sem dispersão axial. podem ser usados os métodos de diferencas finitas, o das linhas $e$ de colocaçâo ortogonal. Usualmente emprega-se diferencas finitas em esquema implicito de Crank-iticholson ou discretizacão das derivadas radiais por colocacão ortogonal com integracão do sistema de equacões difierencias ordinárias resultante por métodos passo a passo.

(d) Equacoes diferenciais parciais do tipo eliptica. Surgem do modelo bidimensional com dispersâo axial. Sua solucão é considerada um dos problemas mais difíceis. Algumas técnicas são discutidas no trabalho de Puszynski et alii(1981), Cabendo citar o método de dupla colocacào utilizado por Yong \& Finlayson (1973) e o método do falso transiente [Hlavacek \& Rompay (1981)].

\subsubsection{Modelas de reatores de oxidacão en leito fixo}

Na literatura são encontrados vários trabalhos soire modelagem da operacão estacionária de reatores de leito fixo com reacöes de oxidação. Ma Tabela 2.1 são 1 istados alguns destes trabalhos. Outros casos de simulação de reatores de leito fixo são mostrados nos 1 ivros de Froment \& Bischoff (1979) E Doraiswamy \& Sharma (1984). Pode-se observar que os modelos utilizados são, em sua grande maioria, pseudohomogêneos e sem dispersăo axial.

Os principais sistemas reativos estudados são a oxidacäo de orto-xileno a anidrido ftálico, a de naftaleno a anidrido ftálico, a de eteno a óxido de eteno,a de dióxido a trióxido de enxofre.

Os principais estudos realizados referem-se a previsão de pontos quentes $e$ de situacões de sensibilidade paramétrica, que devem ser evitadas na escolina das condicones de projeto e de operacão do reator fFroment, 1967; Carberry \& White, 1969; Smith \& 
Carberry, 1974; Westerterp \& Ptasinski, 1984; Makh1in et alii, 1987). Há também estudo sobre otimizacão em linha do reator (Chen \& Joseph, 1987).

Poucas vezes são apresentadas comparacões das previsões do modelo cow dados experimentais de reatores industriais. Uma excecão é o trabalho de Montalvo-Robles (1973) que simulou o reator de oxidacão de eteno e comparou com dados de planta industrial, mostrando boa concordância cno entanto, os dados relativos às dimensões do reator näo foram apresentadas, impedindo uma ver ificacão dos resultados).

Tabela 2.1. Alguns trabalhos sobre simulacão estacionária de reatores de oxidacão.

\begin{tabular}{|c|c|c|c|}
\hline aut or (es) & $\begin{array}{l}\text { reacão de } \\
\text { oxidacáo }\end{array}$ & $\begin{array}{l}\text { modelo } \\
\text { empregado }\end{array}$ & $\begin{array}{l}\text { observacôes e } \\
\text { comentários }\end{array}$ \\
\hline $\begin{array}{l}\text { Young } 8 \\
\text { Finlayson } \\
(1973)\end{array}$ & $50_{2}$ a $50_{2}$ & $\begin{array}{l}\text {-bidimensional } \\
\text {-homogêneo } \\
\text {-com disp-axial }\end{array}$ & $\begin{array}{l}\text { comparacão com dados de } \\
\text { reator de laboratório }\end{array}$ \\
\hline $\begin{array}{l}\text { Minhas } 8 \\
\text { Carberry } \\
(1974)\end{array}$ & $5 O_{2}$ a $50_{0}$ & $\begin{array}{l}\text {-un idimensional } \\
\text {-homogêneo } \\
\text { - sem disp - axial }\end{array}$ & $\begin{array}{l}\text { comparafão do desempenho } \\
\text { de dois tipos de } \\
\text { catalisadores }\end{array}$ \\
\hline $\begin{array}{l}\text { Smith } 8 \\
\text { Carberry } \\
(1974)\end{array}$ & $\begin{array}{l}\text { naftaleno } \\
\text { a anidrido } \\
\text { ftálico }\end{array}$ & $\begin{array}{l}\text {-bidimensional } \\
\text {-homogênea } \\
\text {-sem disp-axial }\end{array}$ & $\begin{array}{l}\text { estudo de or imizaçáa da } \\
\text { conversão e da produti- } \\
\text { vidade do reator }\end{array}$ \\
\hline $\begin{array}{l}\text { Carberry } \\
8 \text { White } \\
(1969)\end{array}$ & $\begin{array}{l}\text { naftaleno } \\
\text { a anidrido } \\
\text { ftálico }\end{array}$ & $\begin{array}{l}\text {-bidimensional } \\
\text {-heterogêneo } \\
\text {-sem disp-axial }\end{array}$ & $\begin{array}{l}\text { com } d_{p}=0,5 \mathrm{~cm} \text { particulas } \\
\text { são isotérmicas, was os } \\
\text { gradientes de concentra- } \\
\text { căo internos säo impor- } \\
\text { tantes }\end{array}$ \\
\hline $\begin{array}{l}\text { Froment } \\
(1967)\end{array}$ & $\begin{array}{l}\text { o-xileno a } \\
\text { anidrido } \\
\text { ftálico }\end{array}$ & $\begin{array}{l}\text {-bi e unidim } \\
\text {-homogêneo } \\
\text {-sem disp-axial }\end{array}$ & $\begin{array}{l}\text { estudo de sensibilidade } \\
\text { paramétrica }\end{array}$ \\
\hline $\begin{array}{l}\text { Westerterp } \\
\text { \& Ptasinski } \\
(1984)\end{array}$ & $\begin{array}{l}\text { eteno a } \\
\text { óxido de } \\
\text { eteno }\end{array}$ & $\begin{array}{l}\text {-unidimensional } \\
\text {-homogêneo } \\
\text {-sem disp.axial }\end{array}$ & $\begin{array}{l}\text { Estudo de critério para } \\
\text { projeto de reator com } \\
\text { reacốs exotérmicas em } \\
\text { paralelo }\end{array}$ \\
\hline
\end{tabular}


Tabela 2.1. Alguns trabalhos sobre simulaça estacionária de reatores de oxidacåo (Continuacão).

\begin{tabular}{|c|c|c|c|}
\hline aut or (es) & $\begin{array}{l}\text { reacão de } \\
\text { oxidacáo }\end{array}$ & $\begin{array}{l}\text { modelo } \\
\text { empregado }\end{array}$ & $\begin{array}{l}\text { observacőes e } \\
\text { comentários }\end{array}$ \\
\hline $\begin{array}{l}\text { Makhl in } \\
\text { et al i i } \\
\text { (1987) }\end{array}$ & $\begin{array}{l}\text { eteno a } \\
\text { óxido de } \\
\text { eteno }\end{array}$ & $\begin{array}{l}\text {-unidimensional } \\
\text {-homogêneo } \\
\text {-sem disp-axial }\end{array}$ & $\begin{array}{l}\text { estudo de sensibilidade } \\
\text { paramétrica }\end{array}$ \\
\hline $\begin{array}{l}\text { Chen \& } \\
\text { Joseph } \\
(1987)\end{array}$ & $\begin{array}{l}\text { eteno a } \\
\text { óxido de } \\
\text { eteno }\end{array}$ & $\begin{array}{l}\text {-unidimensional } \\
\text {-homogêneo } \\
\text {-sem disp-axial }\end{array}$ & $\begin{array}{l}\text { utilizou o modelo para } \\
\text { ilustrar a técnica de } \\
\text { otimizacăo "on-line" }\end{array}$ \\
\hline $\begin{array}{l}\text { Montalvo } \\
\text { Robles } \\
(1973)\end{array}$ & $\begin{array}{l}\text { eteno a } \\
\text { óxido de } \\
\text { eteno }\end{array}$ & $\begin{array}{l}\text {-unidimensional } \\
\text {-heterogeneo } \\
\text {-sem disp-axial }\end{array}$ & $\begin{array}{l}\text { simulacấo da planta de } \\
\text { óxido de eteno, compara- } \\
\text { cáo com dados de reator } \\
\text { industrial }\end{array}$ \\
\hline $\begin{array}{l}\text { D'Avila } \\
\text { (1971) }\end{array}$ & $\begin{array}{l}\text { crotonal- } \\
\text { deido a } \\
\text { anidrido } \\
\text { ftálico }\end{array}$ & $\begin{array}{l}\text {-unidimensional } \\
\text {-homogêneo } \\
\text {-sem disp -axial }\end{array}$ & $\begin{array}{l}\text { estudo da influência de } \\
\text { variáveis de operacăo } \\
\text { sobre comportamento do } \\
\text { reator }\end{array}$ \\
\hline $\begin{array}{l}\text { Moura } \\
(1984)\end{array}$ & $\begin{array}{l}\text { etanol a } \\
\text { acetal- } \\
\text { deido }\end{array}$ & $\begin{array}{l}\text {-un idimensional } \\
\text {-homogêneo } \\
\text {-sem disp - axial }\end{array}$ & $\begin{array}{l}\text { estudo da influencia de } \\
\text { variáveis de operacáo } \\
\text { sobre comportamento do } \\
\text { reator }\end{array}$ \\
\hline $\begin{array}{l}\text { Soares } \\
\& \text { Mor i } \\
(1986)\end{array}$ & $\begin{array}{l}\text { etanol a } \\
\text { acetal- } \\
\text { deido }\end{array}$ & $\begin{array}{l}\text {-bidimensional } \\
\text {-homogêneo } \\
\text {-sem disp-axial }\end{array}$ & $\begin{array}{l}\text { estudo da influéncia de } \\
\text { variáveis de operaçáa } \\
\text { sobre o comportamento do } \\
\text { reator }\end{array}$ \\
\hline $\begin{array}{l}\text { McGreavy } \\
\text { et ali } i \\
(1988)\end{array}$ & $\begin{array}{l}\text { etanol a } \\
\text { acetal } \\
\text { deido }\end{array}$ & $\begin{array}{l}\text {-bidimensional } \\
\text {-heterogéneo } \\
\text {-sem disp-axial }\end{array}$ & $\begin{array}{l}\text { estudo de sensibilidade } \\
\text { paramétrica }\end{array}$ \\
\hline
\end{tabular}

Em alguns trabalhos os resultados da simulacão são comparados com dados de reatores de laboratório. Young \& Finlayson (1973) simularam um reator de laboratório de oxidacäo de $50_{2}$ a $50_{3}$ - Foi necessário incluir no modelo o termo de dispersão axial para um melhor ajuste a dados experimentais existentes na literatura. Os autores discutiram critérios para a importancia da dispersäo axial Em reatores não isotérmicos. 
2.2.4 Modelos que incluem perfls radiais de velocidade

Mais recentemente alguns trabalhos tem mostrado que a hipótese de escoamento pistonado (perfil radial plano de velocidade) frequentemente adotada nos modelus de reatores de leito fixo pode, na verdade, levar a erros consideráveis na previsão de pontos quente's.

É conhecido que o perfil radial de velocidade em leitos fixos não é perfeitamente plano, e que, dependendo da relacão entre o diâmetro da partícula e o do reator, tal perfil pode apresentar variacóes radiais bastante pronunciadas. Os perfis resultan de uma variacáo radial de porosidade (fraçáo de vazios) do leito. A porosidade é maior próximo a parede menor no centro do leito devido a um grau de empacotamento diferente causado pela presenca fisica da parede do reator ("efeito de parede"). Decorre usa distribuicão radial de porosidade, que faz com que a velocidade de passagew do gás seja maior próximo a parede.

Diversos pesquisadores tem procurado estudar estes efeitos, podendo-se citar, por exemp $10=$

- medicão experimental do perfil de fracão de vazios [Benenati \& Brosilow (1962), Zotin (1985)];

- madelagem teórica do perfil de fracão de vazios cMartin (1978); Govindarao \& Froment (1986)];

- medicão experimental do perfil de velocidade cMorales et alii (1951); Schwartz \& Smith (1953); Marivoet et alii (1974); Drahos et alii (1982), McGreavy et alii (1986)];

- modelo térico para a perfil de velocidade CVortmeyer \& Schuster (1983), McGreavy et ali i (1986)].

Revisões sobre o assunto são encontradas nos trabalhos de Lycskowsky (1982), Drahos \& Cermak (1986), Zotin \& Freire (1986) E Ziolkowska \& Ziolkowsky (1988). 
Na Tabela 2.2 são apresentados alguns trabalhos en cujos modelos se incluiu o perfil radial de velocidade. Embora ut ilizando equacões diferentes para o perfil de velocidade os trabalhos de Lerou \& Froment (1977), Kalthoff \& Vortmeger (1980) e Eigenberg (1984) mostraram que o modelo incluindo perfil resulta em pontos quentes mais pronunciados que o modelo de escoamento pistonado, chegando em casos mais criticos a prever disparos de temperatura em situacões em que o modelo convencional não o prevé. Segundo Kalthoff \& Vortmeyer (1980), esta observacão só é válida para os casos de conversảo incompleta de reagente.

Assin, o modelo de escoamento pistonado é menos conservativo que aquele que inclui o perfil de velocidade. Este aspecto é muito importante para os reatores de oxidaç̃o parcial, onde por serem tipicamente altas as relacōes $d_{m} / d_{t}$, säo esperados perfis de velocidade mais pronunciados.

Também variacões radiais de propriedades de transporte tem sido incluidas em alguns modelos. Ahmed 8 Fahien (1980) consideraram variacões de condutividade térmica radial e difusividade radial efetiva com a posicäo radial, além do perfil de velocidades descrito pela equacão empírica de Fahien \& Stankovic (1979). Ahmed a Fahien (1980) introduziram ainda a interessante idéia de que é possivel considerar a efeito da dispersão axial apenas na região de entrada do reator. Isto permite trabalhar com um modelo sem dispersão axial para a zona ativa do reator, implicando em menor esforco computacional. A dispersão axial é considerada na zona de pré-aquécimento de modo a corrigir os valores de temperatura e conversão na entrada na zona ativa. Aplicando estas idéias foi possivel simular com sucesso o mesmo reator simulado por Young \& Finlayson (1973) que haviam mostrado ser necessário considerar o termo de dispersão axial. 
Tabela 2.2. Alguns modelos que incluem perfil radial de velocidade e outras não-uniformidades radiais do leito.

\begin{tabular}{|c|c|c|c|}
\hline aut or (Es) & $\begin{array}{l}\text { reacão de } \\
\text { oxidacáa }\end{array}$ & $\begin{array}{l}\text { modelo } \\
\text { empregado }\end{array}$ & $\begin{array}{l}\text { observacōes e } \\
\text { comentários }\end{array}$ \\
\hline $\begin{array}{l}\text { Finlayson } \\
\text { (1971) }\end{array}$ & genérica & $\begin{array}{l}\text {-bidimensional } \\
\text {-homagêneo } \\
\text {-sem disp- axial } \\
\text {-u(r) de medidas } \\
\text { exp. de Schwartz } \\
\text { \& Smith (1953) }\end{array}$ & $\begin{array}{l}\text { diferencas de previsões } \\
\text { pequenas em relacão ao } \\
\text { modelo convencional }\end{array}$ \\
\hline $\begin{array}{l}\text { Lerou } 8 \\
\text { Froment } \\
(1977)\end{array}$ & $\begin{array}{l}\text { o-xileno } \\
\text { a } \\
\text { anidrido } \\
\text { ftálico }\end{array}$ & $\begin{array}{l}\text {-bidimensional } \\
\text {-homogêneo } \\
\text {-sem disp-axial } \\
\text {-u(r) suposto } \\
\text { inversamente } \\
\text { proporcional } \\
\text { a } \varepsilon(r)\end{array}$ & $\begin{array}{l}\text { previsöes de ponto } \\
\text { quente maiares que do } \\
\text { modelo "plug-flow" } \\
\text { necessar io incluir u(r) } \\
\text { para representar osci- } \\
\text { lacóes experimentais de } \\
T(r)\end{array}$ \\
\hline $\begin{array}{l}\text { Kalthoff \& } \\
\text { Vortmeyer } \\
(1980)\end{array}$ & $\begin{array}{l}\text { etano a } \\
\mathrm{CO}_{2} \mathrm{H} \mathrm{H}_{2} \mathrm{O}\end{array}$ & $\begin{array}{l}\text {-bidimensional } \\
\text {-homogêneo } \\
\text {-com disp-axial } \\
\text {-u(r) e }(r) \\
\text { segundo Vortmeyer } \\
\text { \& Schuster ( } 1983 \text { ) }\end{array}$ & $\begin{array}{l}\text { incluça de } u(r) \text { e } E(r) \\
\text { melhorou previsóes em } \\
\text { relacão a dados expe- } \\
\text { rimentais de reator de } \\
\text { bancada }\end{array}$ \\
\hline $\begin{array}{l}\text { Ahmed \& } \\
\text { Fahien } \\
(1980)\end{array}$ & $50_{2}$ a $\mathrm{SO}_{2}$ & $\begin{array}{l}\text {-bidimensional } \\
\text {-homogêneo } \\
\text {-sem disp-axial no } \\
\text { leito ativo, mas } \\
\text { considerada na } \\
\text { secăo de entrada } \\
\text {-u(r) pela eq. em- } \\
\text { pírica de Faisien } \\
\text { \& stankovic(1979) } \\
\text {-kr (r) E Dr (r) } \\
\text { também inclusos }\end{array}$ & $\begin{array}{l}\text { boa concordancia com } \\
\text { dados experimentais de } \\
\text { reator de laboratório }\end{array}$ \\
\hline $\begin{array}{l}\text { Delmas \& } \\
\text { Froment } \\
\text { (1988) }\end{array}$ & $\begin{array}{l}\text { o-xileno } \\
\text { a } \\
\text { an idr ido } \\
\text { ftálico }\end{array}$ & $\begin{array}{l}\text {-bidimensional } \\
\text {-homogêneo } \\
\text {-sem disp.axial } \\
\text {-u(r) pela eq- de } \\
\text { Ergun modificada } \\
\text { come(r) } \\
\text {-testadas três } \\
\text { formas funcio- } \\
\text { nais parakr-(r) } \\
\text { e Dr (r) }\end{array}$ & $\begin{array}{l}\text { resultados encontrados } \\
\text { com modelo diferem bas- } \\
\text { tante dos previstos por } \\
\text { modelos convencionais }\end{array}$ \\
\hline
\end{tabular}

Hais recentemente Delmas \& Froment(1988) discutiram as nãouniformidades estruturais radiais do leito. Devido ao perfil de porosidade, tem-se que a velocidade, a condutividade térmica $e$ a 
difusividade efetivas radiais variarão com a posicão radial. Os autores testaram sugestöes de como introduzir tais variafóes no modelo. As previsōes deste modelo diferem significativamente das do modelo convencional.

Estas não-uniformidades requerem mais estudos para uma melhor compreensão da fluidodinâmica e das propriedades de leitos fixati. As incertezas são particularmente pronunciadas para os casos de maiores relacōes $d_{m} / d_{t}$, que säo aquelas tipicamente encontradas nos reatores de oxidacão parcial. No presente momento, pode-se afirmar que este conhecimento é ainda pequeno e que a grande maioria das correlacões para os parâmetros efetivos foram obtidas sob a hipótese de escoamento pistonado, o que tem dificultado a maior uti lizacão destes modelos mais realistas.

\subsubsection{Modelos que analisam estratéqias de diluicão do leito catalitico}

Em reatores de leito fixo com reacôes exatérmicas, uma das maiores preocupacões na sua operafão é a descontrole de temperatura, podendo surgir pontos quentes acentuados. Para prevenir este problema, alguns autores tem proposto uma diluicão do leito catalítico com particulas inertes.

Calderbank et ali i (1968) analisaram a diluicåo do leito com um modelo de arranjo tetraédrico de particulas inertes e ativas, estudando a reacãa de oxidacão de orto-xileno a anidrido ftálico. Posteriormente outros autores analisaram a diluifáo do leito utilizando modelos homogêneos uni e bidimensional CRase (1977); Eigenberg (1984); Pirkle \& Wachs (1987)]. Estes trabalhos, resuaidamente apresentados na Tabela 2.3, mostraram ser possivel reduzir a sensibilidade do reator ao descontrole de temperatura 
nos leitos diluidos em relacão aos leitos con atividade catalitica un iforme.

Tabela 2.3. Alguns modelos que consideram a diluicão da atividade do leito catalitico

\begin{tabular}{|c|c|c|c|}
\hline aut or (es) & $\begin{array}{l}\text { reacão de } \\
\text { oxidacão }\end{array}$ & $\begin{array}{l}\text { modelo } \\
\text { empregado }\end{array}$ & $\begin{array}{l}\text { abservacöes e } \\
\text { comentärios }\end{array}$ \\
\hline $\begin{array}{l}\text { Calderbank } \\
\text { et alii } \\
(1968)\end{array}$ & $\begin{array}{l}\text { o-xileno } \\
\text { a } \\
\text { anidrido } \\
\text { ftálico }\end{array}$ & $\begin{array}{l}\text {-modelo de ma- } \\
\text { triz tridimen- } \\
\text { sional para a } \\
\text { distribuifão } \\
\text { aleatoria das } \\
\text { particulas ati- } \\
\text { vase inertes } \\
\text { no leito }\end{array}$ & $\begin{array}{l}\text { estratégia de diluicão } \\
\text { do leito mostrou reducăo } \\
\text { da sensibilidade }\end{array}$ \\
\hline $\begin{array}{l}\text { Rase } \\
(1977)\end{array}$ & $\begin{array}{l}\text { o-xileno } \\
\text { a } \\
\text { anidrido } \\
\text { ftálico }\end{array}$ & $\begin{array}{l}\text {-bi e unidim- } \\
\text {-homogêneo } \\
\text {-sem disp-axial }\end{array}$ & $\begin{array}{l}\text { estratégia de diluicão } \\
\text { do leito mostrou reducão } \\
\text { da sensibilidade }\end{array}$ \\
\hline $\begin{array}{l}\text { Eigenberg } \\
\text { (1984) }\end{array}$ & $\begin{array}{l}\text { reacão } \\
\text { exotérmica } \\
\text { nãoespe- } \\
\text { cificada }\end{array}$ & $\begin{array}{l}\text {-un idimensional } \\
\text {-homogêneo } \\
\text {-sem disp -axial }\end{array}$ & $\begin{array}{l}\text { apresenta verificacão } \\
\text { experimental da estra- } \\
\text { tégia de diluicáo do } \\
\text { leito }\end{array}$ \\
\hline $\begin{array}{l}\text { Pirkle } 8 \\
\text { Wachs } \\
(1987)\end{array}$ & $\begin{array}{l}a-x i l e n o \\
\text { a } \\
\text { anidrido } \\
\text { ftálico }\end{array}$ & $\begin{array}{l}\text {-bidimensional } \\
\text {-homogêneo } \\
\text {-sem isp - axial }\end{array}$ & $\begin{array}{l}\text { reducáo de sensibilidade } \\
\text { pode ser conseguida por } \\
\text { diluicão, mas há casos de } \\
\text { sensibilidade reversa }\end{array}$ \\
\hline
\end{tabular}

\subsubsection{Kodelos que consideram a interacão do reator com o meio refrigerante}

Alguns estudos analisaram as interacőes térmicas do tubo do reator con o meio de refrigeracão. Por exemplo, Borio et ali (1987), utilizando um modelo homogêneo unidimensional, observaram que a refrigeracão no sentido concorrente resulta em menor sensibilidade que no contracorrente. Sob condicões de baixas vazões de refrigerante o contato contracorrente pode levar a múltiplos estados estacionários, devido à retroalimentacáo de calor provocada pelo refrigerante. Esta multiplicidade näo ocorre 
para o caso de contato concorrente, nem para a condicão de altas vazões de refrigerante en contracorrente.

Para os reatores multitubulares tipicamente usados em reatores de oxidacão, o contato entre o refrigerante e os tubos é do tipo corrente cruzada. Neste caso os efeitos da variafão de temperatura do refrigerante ao longo do comprimento dos tubos säo mais complexos, estando os diversos tubos submetidos a diferentes tempereturas de refrigerafão. Modelos que consideram estes aspectos foram empregados por McGreavy \& Dunbbobin (1978), Lasa et alii (1981), Adamska-Rutkowska et alii (1988) e Stankiewicz (1989). Como mostrado na Tabela 2.4, para os tubos pode ser usado um modelo homogêneo unidimensional ou, quando necessário bidimensional, E para o casco é considerado un modelo de células de wistura, ou um modelo continuo, considerando a contato em corrente cruzada con os tubos.

Tabela 2.4. Alguns modelos que consideram o fluido refrigerante em corrente cruzada.

\begin{tabular}{|c|c|c|c|}
\hline autor (Es) & $\begin{array}{l}\text { reacão de } \\
\text { oxidacão }\end{array}$ & $\begin{array}{l}\text { modelo } \\
\text { empregado }\end{array}$ & $\begin{array}{l}\text { observafões e } \\
\text { comentáriosi }\end{array}$ \\
\hline $\begin{array}{l}\text { Lasa et } \\
\text { a1 i i } \\
(1981)\end{array}$ & $\begin{array}{l}\text { o-xileno } \\
\text { a } \\
\text { anidrido } \\
\text { ftálico }\end{array}$ & $\begin{array}{l}\text {-unidimensional } \\
\text {-homogêneo } \\
\text {-sem disp-axial }\end{array}$ & $\begin{array}{l}\text { modelo do casco por } \\
\text { células de mistura, } \\
\text { em corrente cruzada } \\
\text { com os tubos }\end{array}$ \\
\hline $\begin{array}{l}\text { Adanska- } \\
\text { Rutkowska } \\
\text { et a1 i i } \\
\text { (1988) }\end{array}$ & $\begin{array}{l}\text { benzeno a } \\
\text { anidrido } \\
\text { maleico }\end{array}$ & $\begin{array}{l}\text {-un idimensional } \\
\text {-homogêneo } \\
\text {-sem disp-axial }\end{array}$ & $\begin{array}{l}\text { modelo do casco por } \\
\text { células de mistura. } \\
\text { em corrente cruzada } \\
\text { com os tubos }\end{array}$ \\
\hline $\begin{array}{l}\text { Stank iewicz } \\
\text { (1989) }\end{array}$ & $\begin{array}{l}\text { benzeno a } \\
\text { anldrido } \\
\text { maleico }\end{array}$ & $\begin{array}{l}\text {-bidimensional } \\
\text {-homogêneo } \\
\text {-sem disp-axial }\end{array}$ & $\begin{array}{l}\text { modelo do casco por } \\
\text { células de mistura, } \\
\text { em corrente cruzada } \\
\text { com os tubos }\end{array}$ \\
\hline $\begin{array}{l}\text { Biscaia Jr - } \\
\text { e Dieguez } \\
(1983)\end{array}$ & $\begin{array}{l}\text { benzeno a } \\
\text { anidrido } \\
\text { maleico }\end{array}$ & $\begin{array}{l}\text {-unidimensional } \\
\text {-homogêneo } \\
\text {-sem disp - axial }\end{array}$ & $\begin{array}{l}\text { modelo do casco por } \\
\text { células de mistura,e } \\
\text { por modelo contínuo, } \\
\text { em corrente cruzada } \\
\text { com os tubos }\end{array}$ \\
\hline
\end{tabular}


Neste sistema os tubos situados em diferentes posicōes no casco terão diferentes valores e posicão de pontos quentes, pode-se verificar a existência de filas de tubos críticos, isto é, sujeitos às condicões de refrigeracão menos favoráveis. A maior dificuldade na solucão do modelo está na dimensão do sistema de equacões a resolver, que é larganente aumentada. Uma análise da sensibilidade deste sistema foi apresentada por Biscaia \& Dieguez (1983).

\subsection{Iransferência de calor en reatores de leito fixo}

- conhecimento dos parâmetros térmicos que governam a transferência de calor é muito importante no projeto e análise de reatores de leito fixo, especialmente nos casos em que a velocidade de reaça for muito sensivel à temperatura.

Vários mecanismos podem estar envolvidos na transferencia de calor em leitos fixos (Yagi \& Kunii, 1957; Balakrishna \& Pei, (978):

(1) condução de calor através das partículas sólidas;

(2) conducão de calor entre as particulas em contato:

(3) conducão de calor através de fluido estagnado em contato com as particulas;

(4) condução de calor através do fluido nos poros;

(5) radiacão entre as superficies das particulas (no caso do fluido ser gás);

(6) absorcão de radiagão pelo fluido;

(7) conveccão sólido-fluido e fluido-sólido;

(8) dispersão térmica na fase fluido.

A transferencia de calor envolvendo radiacão é importante quando o fluido é um gás é significativa apenas sob temperaturas elevadas, superiores a $300^{\circ} \mathrm{C}$. 
Nas condicôes práticas de pperacão dos reatores industriais de leito fixo vários destes mecanismos atuan simultaneamente interagew entre si. Dada a dificuldade do tratamento individual de cada um destes mecanismos, estes podem ter seus efeitos representados conjuntamente por parâmetros "efetivos" de transferência de calor. A formulacäo de tais parâeetros decorre do modelo matemático utilizado para representar o fenômeno.

Mos modelos heterogéneos, o leito E dividido em uma fase em escoamento (fluido) e uma fase estacionária (sólido mais fluido estagnado). Todo transporte de calor radial é considerado nos parâmetros condutividade térmica radial efetiva do sólido (krme do fluido $\left(k_{r}\right)$. Analogamente, todo transporte axial não associado con a vazão de escoamento é considerado nos parâmetros condutividade axial efetiva do sólido $\left(k_{m}\right)$ e do fluido (km). A transferencia de calor entre as fases expressa pelo coeficiente de transferência fluido-partículas (hos).

A resistência adicional ao transporte radial de calor que se verifica ocorrer próximo à parede do reator é considerada nos parâmetros coeficiente de transferência parede-fluido (hwe) e parede-sólido (hw). Esta resistência adicional está relacionada a uma maior fracão de vazios nas proximidades da parede, devido a uma diferente geometria de empacotamento das particulas cefeito de parede), que diminui kr=, e também a um amortecimento das flutuacôes turbilhonares próximo à parede, o que diminui k... No modelo pseudo-homogêneo, estas contribuicōes de cada fase são consideradas de forma conjunta, pelos parâmetros pseudohomogêneos condutividade radial efetiva $\left(k_{r}\right)$, condutividade axial efetiva ( $\left.k_{m}\right)$ e coeficiente de transferência de calor parede-leito (h) . 
No modelo pseudo-homogêneo unidimensional, o transporte de calor radial é representado por um único parâmetro, o coeficiente global de transferência de calor (u).

Com o objetivo de ilustrar os aspectos apresentados dar subsidios à discussão a seguir, considere a configuracâo esquematizada na figura 2.1, tipicamente utilizada para experimentos de transferência de calor. Consta de um leito cilindrico, com escoamento axial, com as particulas preenchendo duas secões: uma região de entrada (ou secão calma), em que se espera que o perfil de velocidade se estabeleca, e uma secão térmica, dotada de uma camisa que mantém a parede a uma temperatura $T_{\omega}$ diferente daquela na secão de entrada.

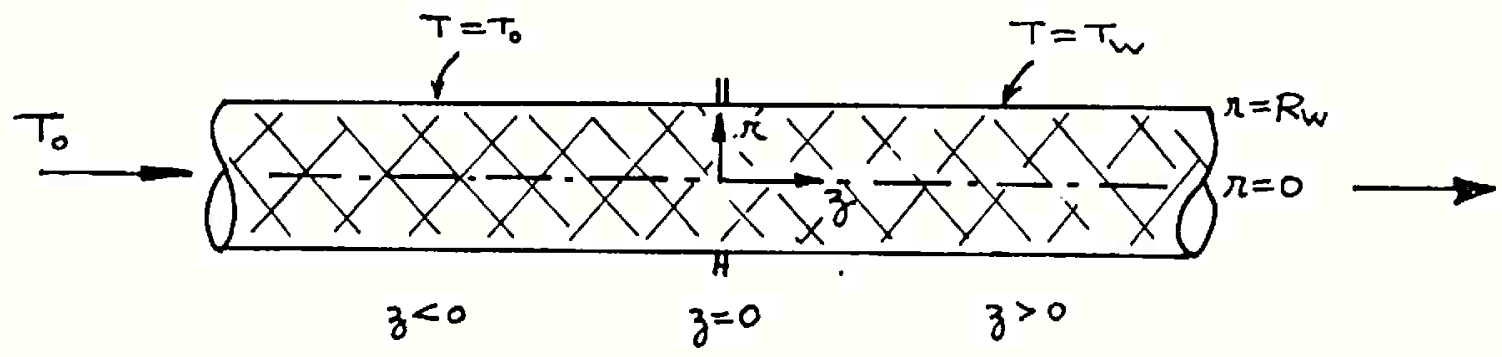

Figura 2.1. Esquema da configuracâo experimental para estudo de transferência de calor em reatores de leito fixo.

Considerando a modelo bidimensional heterogêneo, as equacóes podem ser escritas na forma (Dixon \& Cresswel1, 1979):

$$
\begin{aligned}
& G C_{m} \frac{\partial T_{r}}{\partial z}=k_{r}-\left(\frac{\partial^{2} T_{r}}{\partial r^{2}}+\frac{1}{r} \frac{\partial T_{r}}{\partial r}\right)+k=\frac{\partial^{2} T_{r}}{\partial z^{2}}-a_{-m} h_{-m}\left(T_{-}-T_{m}\right) \text { (2.1) } \\
& 0=k_{r}=\left(\frac{\partial^{2} T_{m}}{\partial r^{2}}+\frac{1}{r} \frac{\partial T_{m}}{\partial r}\right)+k=\frac{\partial^{2} T_{m}}{\partial z^{2}}+a_{m}-h_{m}\left(T_{-}-T_{m}\right) \quad(2.2)
\end{aligned}
$$

com condiçöes de contorno: 


$$
\begin{aligned}
& \left(\partial T_{\sigma} / \partial r\right)=\left(\partial T_{0} / \partial r\right)=0 \\
& r=0 \\
& -k_{r+} \frac{\partial T_{+}}{\partial r}=\left\{\begin{array}{ll}
h_{\omega+}\left(T_{+}-T_{\infty}\right) & z>0 \\
h_{\omega+}\left(T_{+}-T_{-}\right) & z<\theta
\end{array} \quad r=R_{\infty}\right. \\
& -k_{r}=\frac{\partial T_{m}}{\partial r}=\left\{\begin{array}{ll}
h_{\infty}\left(T_{-}-T_{\omega}\right) & z>0 \\
h_{\omega=}\left(T_{-}-T_{\infty}\right) & z<\theta
\end{array} \quad r=R_{\omega}\right. \\
& \mathrm{T}_{\boldsymbol{H}} \rightarrow \mathrm{T}_{\bullet}, \mathrm{T}_{\boldsymbol{H}} \rightarrow \mathrm{T}_{\bullet} \\
& T_{-} \rightarrow T_{\infty}, T_{\infty} \rightarrow T_{\infty} \\
& z \rightarrow-\infty \\
& z \rightarrow+\infty \\
& \partial \mathrm{T}_{+} / \mathrm{d} z\left(0^{+}\right)=\partial_{+} / \partial z\left(0^{-}\right) \\
& \text {a } \mathrm{T}=/ \mathrm{dz}\left(\mathrm{O}^{+}\right)=\partial \mathrm{T}=/ \partial z\left(0^{-}\right)
\end{aligned}
$$

Para a mesma situacão, o modelo bidimensional pseudohomogêneo é representado por

$$
\text { G } C_{r} r \frac{\partial T}{\partial z}=k_{r}\left(\frac{\partial z T}{\partial r^{2}}+\frac{1}{r} \frac{\partial T}{\partial r}\right)+k_{m} \frac{\partial z T}{\partial z^{2}}
$$

com condicóes de contorno:

$$
\begin{aligned}
& (d T / d r)=0 \\
& r=0 \\
& -k_{r} \frac{d T}{d r}=\left\{\begin{array}{ll}
h_{\infty}\left(T-T_{\infty}\right) & z>\theta \\
h_{\infty}\left(T-T_{\infty}\right) & z<\theta
\end{array} \quad r=R_{\omega}\right. \\
& T \rightarrow T \text {. } \\
& T \rightarrow T_{\infty} \\
& z-\infty \\
& z \rightarrow+\infty \\
& \mathrm{T}\left(0^{+}\right)=\mathrm{T}\left(\mathrm{O}^{-}\right) \\
& \partial T / \partial z\left(0^{+}\right)=\partial T / \partial z\left(0^{-}\right)
\end{aligned}
$$

No modelo mais simples, pseudohomogêneo unidimensional sem dispersão axial, a equaçõo correspondente seria:

$$
G C_{m}+\frac{d T}{d z}=U \frac{4}{d_{t}}\left(T-T_{\infty}\right)
$$

com condicão inicial:

$$
T=T_{0} \quad z=0
$$


A medida em que se diminui o nível de complexidade dos modelos, diminui também o número de parâmetros de transferência de calor. Por outro lado os parámetros de modelos mais simples representam un número maior de mecanismos de transferência.

Isto torna perigosa a extrapolaçăo de correlacões de tais parâmetros das condicões de laboratório para as de um reator industrial, uma vez que os diferentes mecanismos representados pelo paranmetro podem variar em diferentes graus na extrapolacão (Dixon \& Cresswel1, 1979).

Para modelos de estado estacionário, Dixon \& Cresswell (1979) mostraram ser possivel obter relacổes entre os parâmetros efet ivos pseudo-homogêneos $e$ os parâmetros do modelo heterogêneo bidimensional, os quais, por serem mais fundamentais, podem ser correlacionados extrapolados de maneira mais confiável. Estas relacões foram obtidas comparando-se as soluçöes analiticas simplificadas dos modelos bidimensionais pseudo-homogêneo e heterogêneo. Posteriormente, Dixon (1985a) obteve relacōes semelhantes a partir de combinação de resistências à transferência de calor.

A interrelacão entre os parâmetros pseudo-homogêneos dos modelos uni- e bidimensional säo discutidos no trabalho de Martinez et alii (1985), e pode ser colocada na forma:

$$
1 / U=1 / h_{\infty}+R_{\omega} /\left(b k_{-}\right)
$$

Se se supõe que a perfil radial de temperatura é parabolico, obtém-se o valor b=4 (Beek \& Singer, 1951). Crider \& Foss (1965) encontraram b=3,0665 por minimizacão das diferencas entre as solucões dos modelos uni- e bidimensional. Finlayson (1980) estabeleceu a equivalencia a partir do método de colocacão 
ortogonal con um ponto radial, obtendo o valor b=3 ao utilizar os polinômios de Jacobi e $b=4$ cos os polinômios de Legendre. Para um valor finito de Bi $\left(=h_{m} R_{m} / k_{-}\right)$, Villadsen \& Michelsen (1978) mostraram que a melhor escolha $\dot{e}$ a que leva a $b=4$.

\subsubsection{Sobre a determinacän experimental de parâmetros térmicos}

Para a estimafão de parâmetros térmicos é feito um ajuste do modelo aos valores de temperatura medidos experimentalmente. 0 modelo utilizado tipicamente é o bidimensional pseudo-homogêneo. Apesar de representar uma descrifão mais detalhada e mais "realista" dos reatores de leito fixo, os modelos heterogêneos tem seu emprego restrito na análise da transferência de calor devido à dificuldade de determinacáo experimental da temperatura de cada fase separadamente. Além disso, a despeito de suas inerentes simplificacóes $e$ da ausência de um significado físico bem estabelecido para a temperatura pseudo-homogênea, o modelo homogêneo mostra-se capaz de representar adequadamente o comportamento essencial do reator.

No tratamento de dados convencionalmente utilizado pela maioria dos trabalhos, considera-se desprezível o termo de dispersão axial na equacão (2.9). Quando não é considerada a dispersão axial, o termo $k-\left(\partial 2 T / \partial z^{2}\right)$ não aparece, e as correspondentes condicöes de contorno "axiais" (2.12), (2.13) (2.14) são substituídas por uma condicão do tipo:

$$
T=T(\theta, r) \quad z=0
$$

e frequentemente se adota $T(0, r)=T_{0}$. Os valores de $k_{r}$ e $h_{w}$ assim obtidos apresentaram uma dependencia sistemática da altura de 
leito utilizada nos ensaios (por exemplo, Dewasch \& Froment, 1972; Ziolkowski e Legawiec, 1987).

Uma análise das técnicas experimentais e do tratamento de dados de diversos autores foi feita por Li \& Finlayson (1977). Estes autores recomendaram que somente dados obtidos com leitos suficientemente longas deveriam ser usados para se obter valores assintóticos de $k_{r} e h_{m}$, os quais seriam adequados para utilizacão em projeto de reatores.

Mais recentemente, os trabalhos de Dixon et alii (1978) e Dixon (1985b) defende que tal dependência da altura de leito năo existe, surgindo devido à utilizacão de um modelo inadequado para a estimacão dos parâmetros. Dixon (1985b) utilizou o modelo com dispersão axial, ajustando seus três parâmetros hm, kr e kmQuando o termo de dispersão axial foi considerado, obteve-se valores de $k_{r} e h_{\infty}$ isentos da dependência da altura de leito.

Ao se ajustar os três parâmetros térmicos simultaneamente, observou-se que $k_{\text {a }} \dot{e}$ mal estimado, isto $\dot{E}$, seu valor apresenta-se cow grandes intervalos de confianca e com grande dispersäo estatistica de valores. Isto também foi observado por Gunn \& Khalid (1975) e Stanek \& Vychodyl (1984). o ajuste, no entanto, mostrou-se pouco sensivel ao valor de $k m$, isto é, mudancas significativas no seu valor não afetam muito as previsóes do modelo.

Assim, km parece ser muito mais um parâmetro de ajuste do que um parametro com un significado físico claro neste tipo de experimento (Lerou \& Froment, 1979), senda entretanto necessário para uma estimacão adequada de $k_{r} e h_{\infty}$ sem dependência do comprimento do leito.

Na argumentação de Dixon (1985b), os fenômenos que estariam sendo compensados no ajuste de $k_{n}$ estariam ligados à condicão de 
contorno na entrada da secão térmica $(z=0)$. Foi observado que o perfil de temperatura $T(r)$ em $z=0$ também é afetado pela conducão de calor da secão térmica para a seçao calma através da parede do reator. A temperatura en $z=0$ é diferente de To, mostrando que a condicão de contorno do modelo se dispersão não está sendo satisfeita. Para que o modelo sem dispersão seja ajustado em um determinado ponto $z^{*}$, é preciso usar um valor de $k_{r}$ maior que o real, como ilustra a figura 2.2 . Euanto menor o valor de $z^{*}$, maior o valor de $k_{r}$ que se precisa impor para o ajuste, explicando assim a dependência da altura de leito.
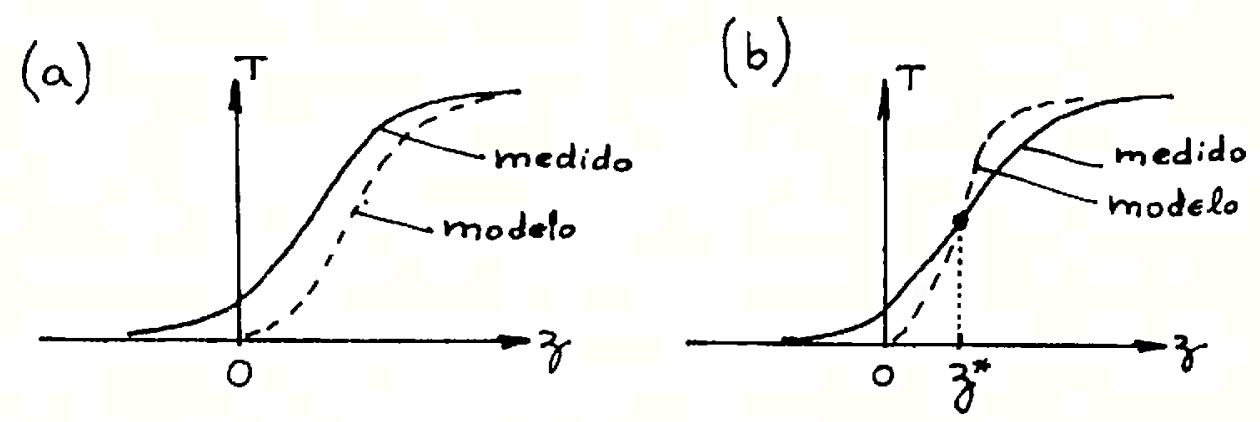

Figura 2.2. Efeito da conducáo pela parede sobre o ajuste do modelo sem dispersão axial: (a) modelo com $k_{r}$ verdadeiro; (b) modelo com kr maior lextraído de Dixon, 1985b ).

Thoméo \& Freire (1989) e Thoméo (1990) verificaram experimentalmente que a conducăo de calor pela parede afeta o perfil radial de temperatura na secão de entrada. Este efeito é significativo para o escoamento de gás, porém sua intensidade é 
bem menor para o caso de o fluido ser um liquido (silveira et al i i, 1989).

Para levar em conta o fenómeno de conducáo pela parede do reator, Dixon (1985b) propás um modelo alternativo para o tratamento de dados; a condicão de contorno na parede é trocada por:

$$
-k_{\sigma} \frac{\partial T}{\partial r}=\left\{\begin{array}{ll}
h_{\infty}\left(T-T_{\infty}\right) & z>0 \\
h_{\omega}\left[T-T_{\omega}(z)\right] & z<0
\end{array} \quad r=R_{\omega}\right.
$$

onde $T_{w e}(z)$ representa o perfil de temperatura na parede da secão calma, medido experimentalmente. A solucäo do modelo com esta condicão de contorno foi obtida numericamente (Dixon, 1981). Este modelo também produziu ajustes satisfatórios de $k_{r} e h_{w}$ (isto ér isentos da dependência da altura de leito), sem necessidade de ajustar $k_{\text {- }}$ Os valores de $k_{-} e$ hw obtidos por este modelo não diferem significativamente dos obtidos com o modelo a 3 parämetros $\left(k_{-}, h_{w} k_{m}\right)$, porém a carga computacional é maior.

outro modelo, baseado na equacão (2.9) mas con diferente condicáo de contorno na saida do leito, isto é substituindo a condicão (2.13) por:

$$
z=L \quad \partial T / \partial z=0
$$

foi testado por Dixon et ali (1978). Por comparacão frente a dados experimentais este modelo mostrou ser menos adequado que aquele com a condiçäo $(2.13)$

Quanto às técnicas experimentais usadas na obtencão de parâmetros térmicos, podem ser encontradas nos trabalhos de Freire (1979), Soomro (1981) e Thoméo (1990). 


\subsubsection{Controvérsias aspectos pouco explorados e modelos}

\section{não-convencionais}

Há algumas controvérsias na literatura quanto à avaliacão dos parametros térmicos ser feita de maneira independente como defendem Paterson \& Carberry (1983), ou conjuntamente como proposto por Clement \& Jorgensen (1983). O principal problema refere-se à existência de interdependências entre os parâmetros de transferência de calor e outros parâmetro do oodelo, tais como Parâmetras cinéticos.

Recentemente Wyngaarden \& Hesterterp (1989) apresentaram uma explicacáo para o fato observado por alguns autores na literatura, de que os valores de $k_{r}$ ho obtidos em ensaios com reacà quimica sâo diferentes daqueles obtidos em ensaios sem reacão. Fundamentalmente a explicaçá baseada na idéia de que, quando há reacão química, pode haver uma diferenca de temperatura significativa entre as fases sólida e gasosa; dessa forma os valores de $k_{r}$ e $h_{w}$ estimados por ajuste do modelo homogêneo sofreriam um desvio sistemático, levando a uma falsa dependência Entre os parâmetros térmicos e cinéticos.

A questão, portanto, parece estar ligada a simplificaçöes inerentes ao modelo utilizado, que são absorvidas nos parâmetros ajustáveis.

Outro problema importante é com respeito à pertinência de se utilizar nos modelos dinâmicos os parâmetros térmicos obtidos a partir de modelas e experimentos estáticos. Segundo Dixon \& Cresswell (1986) esta aproximacão, apesar de muito usada, é válida somente para escoamentos com Re $<10$, tipicamente encontrados em estudos de laboratório. Entretanto, para condicóes de reatores industriais tem-se Re, 100, o que compromete o uso da referida aproximąão. 
Un aspecto pouco abordado na literatura $\dot{e} 0$ relativo aos limites de aplicabilidade dos modelos pseudo-homogêneos. Whitaker (1966) desenvolveu um critério matemático para a homogeneidade de meios porosos. Do ponto de vista matemático un meio pode ser considerado homogêneo se algum comprimento caracteristico microscópico for muito menor que outro comprimento caracteristico sobre o qual se tomam valores médios. Se considerarmos em um reator de leito fixo serem o diâmetros da partícula $d_{p} E$ o diâmetro do reator de estes comprimentos caracteristicos, a condição de homogeneidade seria

$$
d_{\mathbf{p}}<<d_{e}
$$

Se se considera que de deva ser ao menos uma ordem de grandeza maior que $d_{p}$, a condicão limite seria a correspondente $a d_{t} / d_{p}=10$ (Vortmeyer \& Winter, 1984). Mo entanto, para estudos de transferência de calor, os modelos homogêneos tem sido usados mesmo para relacões de/d, tão pequenas quanto 4,06 colbrich \& Potter, 1972), 5 (Dixon et alii, 1978), 5.6 (Ziolkowiski \& Legawiec, 1987) e 3,7 e mesmo 2,3 (Gunn et alii, 1987).

Para situacões com reacão, Vortmeger \& Winter (1984) mostraram ser razoável aplicar o modelo homogêneo para de/dp até 4. porém não se obteve bons resultados para $d_{t} / d_{p}=2,8$ e 2,1 .

É razoável esperar que em experimentos sem reacão $e$ estáticos, o critério possa ser menos restritivo. No entanto não há até o momento un critério quantitativo nelhor estabelecido.

outro ponto que merece comentários se refere à variacão de propriedades ao longo do raio do reator. Já fora citado que os modelos "clássicos" representam a maior resistência à transferência de calor próxima à parede por un coeficiente de 
transferência (hw, ou hose hme). Algumas abordagens diferentes tem sido reportadas.

Usando uma abordagem relativamente simples, Gunn et alii (1987) consideraram o leito dividido radialmente em duas regións: um núcleo central, onde as propriedades térmicas $k_{-} e k_{m}$ são constantes, e uma região estreita próxima à parede onde estas propriedades variam, sendo a temperatura 0 gradiente constantes através das regiões. Os autores compararam este modelo de duas regiões com a modelo bidimensional pseudo-homogêneo com dispersão axial. Observou-se que para particulas pequenas com alta condut ividade térmica ambos os modelos mostraram-se adequados, mas para particulas grandes de baixa condutividade o modelo de duas regiôes apresentou um ajuste muito melhor.

Abordagens mais sofisticadats, que propōe representar
variacões radiais de propriedades como funcão das não-
uniformidades do leito, també são encontradas na literatura sobre transferência de calor. Por exemplo, Lerou \& Froment (1977) observaram oscilacôes pronunciadas nos perfis radiais de temperatura experimentais. Para representar tais oscilaföes foram incluidas no modelo variacöes radiais de velocidade $e$ de $k_{\text {r. }}$ Outras abordagens deste tipo para sistemas com reacão foram apresentadas por Ahmed \& Fahien (1986) e Delmas \& Froment (1988).

\subsection{Descricä́n do processo de aroducäo do óxido de eteno}

A oxidacão de eteno para a producão de óxido de eteno é una importante reacão em virtude da sua aplicacão industrial e da vasta utilizacão do produto como intermediário na indústria química. São apresentadas a seguir algumas consideracóes sobre o processo, para o qual foi realizado estudo de simulação do reator, desenvolvido nos Capitulos 4 e 5 deste trabalho. 
A oxidacão de eteno para a producão de óxido de eteno é realizada industrialmente com oxigênio ou ar fazendo uso de catalisadores à base de prata em suporte de alumina. As particulas de catalisador são esferas, cilindros ou anéis de dimensões entre $0,003=0,010 \mathrm{~m}$.

o reator é do tipo leito fixo multitubular, operando com temperatura entre 220 e $300^{\circ} \mathrm{C}$ e pressão entre 10 e 30 atm. Tipicamente, o reator pode ter entre 2000 e 10000 tubos, com diâmetro de 0,02 a 0,05 me comprimento de 6 a 12 m. 0 fluido refrigerante que circula por fora dos tubos no casco é óleo térmico, e nos reatores mais modernos égua em ebulicão.

As principais reacöes do processo são:

$$
\begin{aligned}
& \mathrm{C}_{2} \mathrm{H}_{4}+1 / 2 \mathrm{O} \longrightarrow \mathrm{C}_{2} \mathrm{H}_{1} \mathrm{O} \text { ( } 1 \text { 1) } \\
& \mathrm{C}_{2} \mathrm{H}_{4}+3 \mathrm{O}+2 \mathrm{CO}_{2}+2 \mathrm{H}_{22} \mathrm{O}\left(\mathrm{r}_{2}\right) \\
& \mathrm{C}_{2} \mathrm{H}_{4} \mathrm{O}+5 / 2 \mathrm{O} \longrightarrow 2 \mathrm{CO}_{2}+2 \mathrm{H}_{2} \mathrm{O} \text { (r3) }
\end{aligned}
$$

formando um esquema triangular ou série-paralelo. Dependendo do nivel de conversão a reacão (ra) pode ou não ser importante.

Una revisão da literatura aberta sobre a cinética dessas reacôes mostra que, a despeito do grande número de trabalhos publicados, não há um consenso geral sobre a cinética nem sobre o mecanismo da reacão. Os dados cinéticos de seletividade, conversão total de eteno e parämetros cinéticos cenergias de ativacäo, ordens aparentes, efeitos dos produtos da reacão) reportados na literatura são frequentemente conflitantes e não conclusivos. A Tabela 2.5 apresenta uma compilacảo de alguns destes estudos.

As variacões de valores dos parâmetros cinéticos poden ser atribuídas às diferentes formulacões de catalisador utilizadas pelos diversos autores, em particular quanto a aditivos promotores que aumentam a estabilidade e a atividade como tais como césio, potássio, cálcio, bário, estróncio e moderadores que 
melhoram a seletividade tais como cloro, bromo, selênio, telúrio, enxofre, bismuto.

Tabela 2.5. Alguns estudos sobre a cinética da oxidaçáo de eteno.

\begin{tabular}{|c|c|c|c|c|c|}
\hline aut or (Es) & $\begin{array}{l}\text { catal isador } \\
\text { suporte } \\
\text { aditivos }\end{array}$ & $\begin{array}{l}\text { tipo de } \\
\text { expressäo } \\
\text { para a } \\
\text { cinética }\end{array}$ & $\begin{array}{l}\text { en } \\
\text { Ex }\end{array}$ & $\begin{array}{l}\text { rgia } \\
\text { tiva } \\
J / m o \\
E_{n}\end{array}$ & $\begin{array}{l}\text { s } \\
\text { cão } \\
\text { 1) } \\
\mathrm{E}_{\mathbf{\Omega}}\end{array}$ \\
\hline Twigg (1946) & $\begin{array}{l}\text { Ag/fibras de } \\
\text { vidro }\end{array}$ & $\begin{array}{l}\text { lei de } \\
\text { potências }\end{array}$ & 67 & 67 & 84 \\
\hline Murray (1950) & $\begin{array}{l}\text { Ag/suparte näo } \\
\text { especificado } \\
\text { con Ba }\end{array}$ & $\begin{array}{l}\text { lei de } \\
\text { potências }\end{array}$ & 50 & 63 & -- \\
\hline Wan (1953) & $\begin{array}{l}\text { Ag/alumina } \\
\text { Preparado } \\
\text { com Ba }\end{array}$ & $\begin{array}{l}\text { lei de } \\
\text { potencias }\end{array}$ & 81 & -- & - \\
\hline $\begin{array}{l}\text { Kurilenko } \\
\text { et alii (1958) }\end{array}$ & $\begin{array}{l}\text { Ag/suporte não } \\
\text { especificado }\end{array}$ & Tenak in & 64 & 83 & -- \\
\hline $\begin{array}{l}\text { Fognani } \& \\
\text { Montarnal } \\
(1959)\end{array}$ & $\begin{array}{l}\text { Ag/corundo } \\
\text { com Ba }\end{array}$ & LHHW & 82 & 138 & 54 \\
\hline Bunt in (1962) & $\begin{array}{l}\text { Ag/alumina } \\
\text { Preparado }\end{array}$ & LHHW & 57 & 63 & -- \\
\hline Imre (1970) & $\begin{array}{l}\text { Ag/suporte não } \\
\text { espec if icado } \\
\text { com Cd }\end{array}$ & $\begin{array}{l}\text { lei de } \\
\text { potencias }\end{array}$ & 32 & 39 & - \\
\hline $\begin{array}{l}\text { Alfani \& } \\
\text { Carberry } \\
\text { (1970) }\end{array}$ & $\begin{array}{l}\text { Ag/alumina } \\
\text { comercial } \\
\text { (Engelhard) } \\
\text { sem moderador }\end{array}$ & $\begin{array}{l}\text { lei de } \\
\text { potências }\end{array}$ & 35 & 31 & 48 \\
\hline $\begin{array}{l}\text { Klugherz } 8 \\
\text { Harriot }(1970)\end{array}$ & $\begin{array}{l}\text { Ag/alfa-alumina } \\
\text { preparado }\end{array}$ & LHHW & -- & -- & -- \\
\hline $\begin{array}{l}\text { Valle }(1978) \\
\text { Valle \& } \\
\text { Schmall }(1978)\end{array}$ & $\begin{array}{l}\text { Ag/alumina } \\
\text { comercial } \\
\text { (Oxiteno) }\end{array}$ & LHHW & - & -- & -- \\
\hline $\begin{array}{l}\text { Dettwiler et } \\
\text { alii. (1979) }\end{array}$ & $\begin{array}{l}\text { Ag/pumice } \\
\text { preparado }\end{array}$ & LHHW & 77 & 63 & 85 \\
\hline Temk in (1979) & $\begin{array}{l}\text { Ag/alumina } \\
\text { preparado } \\
\text { Com Se, C1, Te }\end{array}$ & Temk in & 80 & 90 & -- \\
\hline
\end{tabular}

LHHW = expressão tipo Langmuir-Hinshelwood-Hougen-Watson 
Tabela 2.5. Alguns estudos sobre a cinética da oxidacão de eteno (cont inuaç̃o).

\begin{tabular}{|c|c|c|c|c|c|}
\hline \multirow[t]{2}{*}{ autor (es) } & \multirow[t]{2}{*}{$\begin{array}{l}\text { catal isador } \\
\text { suporte } \\
\text { aditivos }\end{array}$} & \multirow{2}{*}{$\begin{array}{l}\text { tipo de } \\
\text { expressão } \\
\text { para a } \\
\text { cinét ica }\end{array}$} & \multicolumn{3}{|c|}{$\begin{array}{c}\text { energias } \\
\text { de at ivacão } \\
(k J / m o l)\end{array}$} \\
\hline & & & $E_{2}$ & $E_{x}$ & $E_{\mathbf{m}}$ \\
\hline $\begin{array}{l}\text { Heggs \& } \\
\text { Assaf (1981) }\end{array}$ & $\begin{array}{l}\text { Ag/alfa-alumina } \\
\text { comercial(ICI) }\end{array}$ & $\begin{array}{l}\text { lei de } \\
\text { potências }\end{array}$ & 62 & 73 & - \\
\hline Dogu (1981) & $\begin{array}{l}\text { Ag/pumice } \\
\text { Preparado }\end{array}$ & $\begin{array}{l}\text { lei de } \\
\text { potências }\end{array}$ & 83 & 117 & -- \\
\hline $\begin{array}{l}\text { Stouk ides } 8 \\
\text { Vayenas } \\
(1980,1981)\end{array}$ & Ag/zircônia & LHНH & 61 & 92 & 85 \\
\hline $\begin{array}{l}\text { Al-Saleh et } \\
\text { ali i. (1988) }\end{array}$ & $\begin{array}{l}\text { Ag/alfa-alumina } \\
\text { comercial } \\
\text { (Harshaw- } \\
\text { Filtrol) } \\
\text { com Fe, C1,s }\end{array}$ & LHHW & 75 & 90 & -- \\
\hline
\end{tabular}

LHHH = expressão tipo Langmuir-Hinshelwood-Hougen-Watson

Há poucos estudos publicados sobre o efeito de inibidores gasosos industrialmente utilizados emistura con os reagentes (por exemplo dicloroetano, compostos clorados, metano, etano). Uma excecão é a trabalho de Petrov et alii (1986) e de Eligas et alii (1989) que analizaram o efeito do dicloetano sobre a cinética de oxidacão de eteno e de dxido de eteno, respectivamente.

A figura 2.3 mostra simplificadamente um fluxograma do processo de producão de óxido de eteno. O reator é al imentado com uma mistura dos reagentes $E$ do gás proveniente do compressor de reciclo. Nos reatores resfriados a óleo térmico, este é circulado resfriado em um trocador externo onde é gerado vapor. Os gases que saem do reator pré-aquecem a al imentacão ew um trocador de calor e passam por um sistema de absorvedoras com água onde se retira o óxido de eteno, que segue para o setor de purificacão. Uma parte do gás passa por absorvedor onde parte do dióxido de carbono é 
retido. o gás, após uma purga e reposicão de reagentes, é reciclado ao reator.

A cinética, os processos de adsarcaio e os possíveis mecanismos associados com a reacão de oxidacián de eteno estão descritas na revisão de Sachter et alii (1981). Aspectos referentes à tecnologia de fabricacão do óxido de eteno são descritos por Zommerdijk \& Hall (1981). Nas revisões de Landau \& Lidov (1969) e de Berty (1983) são discutidos tanto aspectos fundamentais (cinética, mecanismos) como os tecnológicos ligados ao processo de obtenção do óxido de eteno.

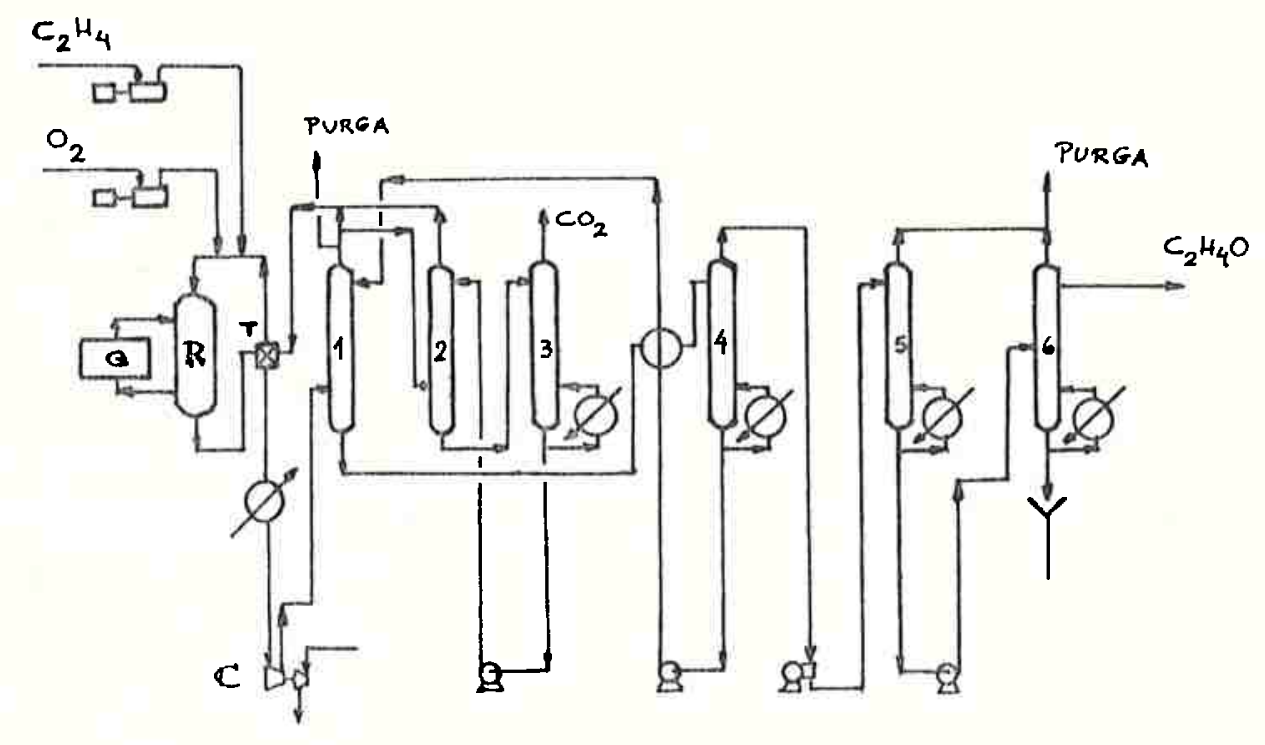

$$
\begin{aligned}
& G \text { - sisterna gerador de vapor } \\
& R \text { - reator multitubular } \\
& T \text { - trocador de calor gás-gás } \\
& 1 \text { - absorvedora de óxido de eteno } \\
& 2 \text { - absorvedera de } \mathrm{CO}_{2} \\
& 3 \text { - dessorvedora de } \mathrm{CO}_{2}
\end{aligned}
$$

Figura 2.3. Fluxograma simplificado do processo de produçäo de óxido de eteno (extraído de Piccinini \& Levy, 1984) 


\section{Capitulo 3}

\section{ESTUDO EXPER IMENTAL DE TRANGFERÊACIA DE CALOR}

EM REATOR CATALITICO DE LEITO FIXO

\subsection{Introducão}

Neste Capitulo apresenta-se un estudo sobre a determinacão experimental de parâmetros de transferencia de calor em reator de leito fixo.

Procurando ampliar a gama do estudo, foram utilizados além de materiais cerãmicos tipicamente usados como suporte de catalisadores, também outros materiais (metálicos), com distintas formas e tamanhos de partícula. Entretanto em funcão da disponibilidade dos materiais, não foi possível variar estes três aspectos (tipo de material, forma e tamanho) independentemente.

Procurou-se nesta parte do trabalho contribuir para um melhor entendimento dos modelos utilizados para a estimacão dos parâmetros térmicos, e também contribuir para um melhoramento de certos aspectos experimentais 1 igados a esta determinacá.

\subsection{Equipamento Exper imental}

o equipamento experimental, esquematizado na figura 3.1, é similar ao utilizado por outros pesquisadores Gunn \& Khalid, 1975; Dixon et a11i, 1978; Dixon, 1985b; Gunn et alli., 1987; Dixon, 1988).

- reator consta de uma secáo térmica (aquecida pela parede) e uma secão de entrada ou seçăo calma (para desenvolvimento e estabilizacão do perfil de velocidade), ambas de mesmo diâmetro e preenchidas com a mesmo material. 


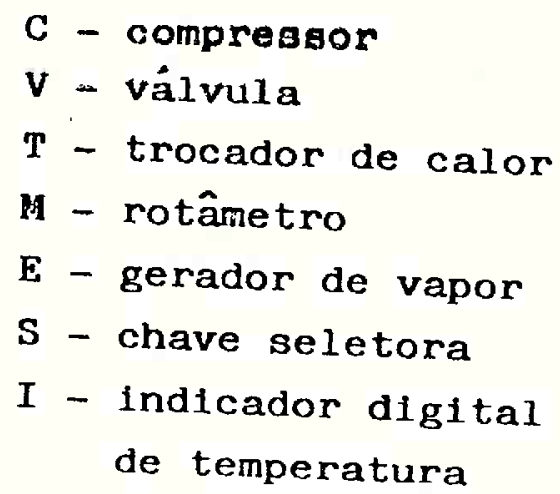

C - compressor

T valvula

$T$ - trocador de calor

A - rotâmetro

- gerador de vapor

chave seletora

de temperatura

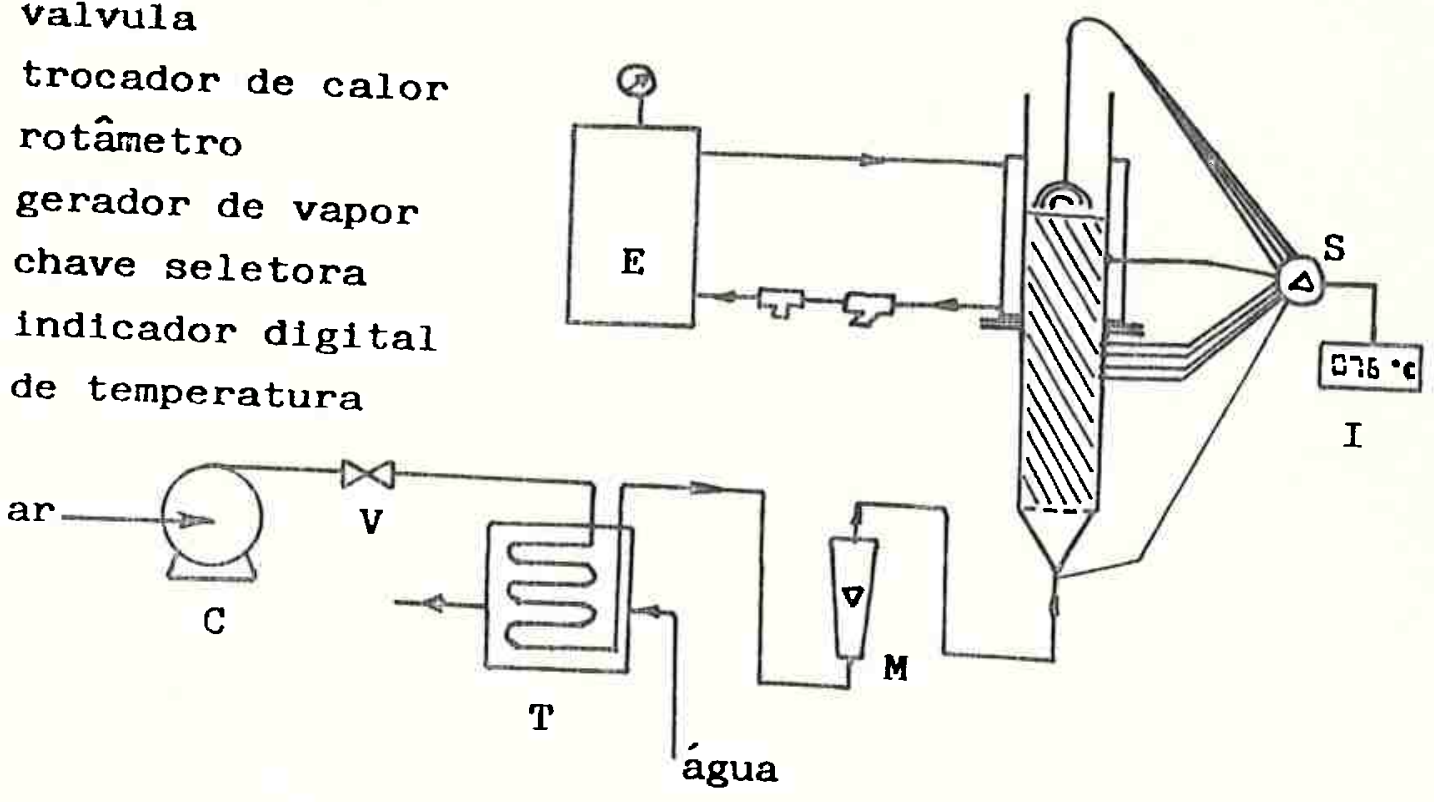

Figura 3.1. Esquema geral do equipamento.

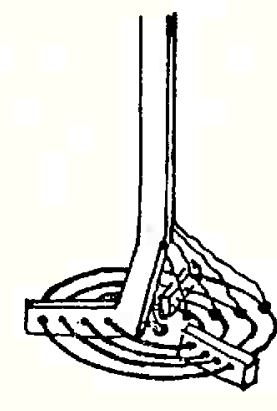

(a)

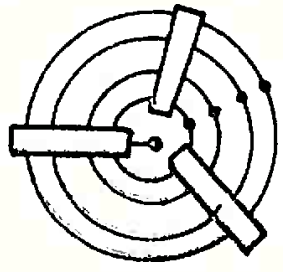

$75^{\circ} \mathrm{c}$ 

A secão térmica é formada por um tubo de aco inox de $60 \mathrm{~mm}$ de diâmetro interno 400 de comprimento, dotado de canisa de aquecimento onde condensa vapor de água proveniente de uma pequena caldeira elétrica. A temperatura da parede do reator é medida por termopar.

Abaixo do reator, a secão de entrada é formada por um tubo de PUC de $60 \mathrm{~mm}$ de diâmetro interno e $250 \mathrm{~mm}$ de comprimento, estando acoplada ao reator por flange de nylon. Na parede da secão de entrada foram colados cinco termopares (nas posicäes $z=-5$, -12 , -25 e $-65 \mathrm{~mm}$ ) para verificar a ocorrência de conducáo de calor pela parede entre as duas secóes do reator.

Ar, o fluido utilizado nas experiências, $\dot{E}$ suprido por um compressor centrifugo; passa por uma válvula e por um erocador de calor e por um rotâmetro. É entáo alimentado no fundo da seçáo de entrada do reator, onde sua temperatura é medida por termopar soloado a uma pequena chapa metálica, a que melhora sensivelmente a precisão da medida (Freire, 1986).

- trocador de calor é formado de uma serpentina de cobre de 15 ma de diametro interno comprimento total de aproximadamente 3 metros, mergulhada em um pequeno tanque onde a água é constantemente renovada. Neste trocador o ar entra aquecido devido a sua passagem pelo compressor centrifugo, é resfriado para uma temperatura próxima da ambiente, para então ter sua vazão medida pelo rotámetro.

Para a medicáo do perfil radial de temperatura na saída do leito foram utilizados dois tipos de dispositivos, os quais estão ilustrados na figura 3.2 .

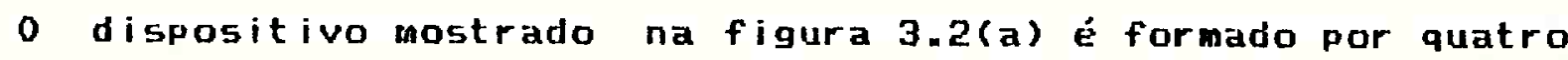
anéis metálicos concêntricos (raios $r=8,15,21$ e 27 ma), suspensos por um suporte de nylori. Em cada anel, feito com fio de 
cobre de $2.5 \mathrm{~mm}$ de espessura, estä soldado um termopar. Un quinto termopar foi soldado a um pequeno pedaco de fio de cobre o qual foi fixado no centro do suporte $(r=0)$. A idéia que levou à proposta deste dispositivo formado por sensores anelares é discutida no item 3.2.1.

- outro tipo de dispositivo ilustrado na figura $3.2(b)$ formado por nove termopares suspensos por um suporte em forma de cruz, feito de riglon. Este conjunto mede a temperatura pontual em nove posiföes radiais diferentes $(r=0,10,11,17,18,22,24$, $26 \mathrm{~mm}$, havendo repeticão $\mathrm{em} r=22 \mathrm{~mm}$, como ilustra a figura 2(a). Os termopares foram colocados dentro de pequenos tubos de a6o, os quais estáo presos ao suporte. Estes tubos servem para manter o termopar na posicăo desejada, impedindo deslocamentos em reląão ao suporte. Este tipo de dispositivo é de uso consagrado na literatura (Dixon, 1978; Dewasch \& Froment, 1972; Soomro, 1981, entre outros), e foi usado neste trabalho para testar experimentalmente as medidas do dispositivo anelar acima descrito.

Cada um destes dispositivos, quando utilizado, é colocado afastado a uma pequena distancia acima do leito caproximadamente 3 mm), Emede operfil radial de temperatura do gás ao sair do leito. Testes experimentais feitos por Soomro (1981) wostraram que não há diferencas significativas entre medidas realizadas com os termopares colocados pouco acima do leito e aquelas realizadas com os sensores cobertos por sucessivas camadas de partículas.

Os termopares utilizados são de chromel-alumel e estão ligados por chaves seletoras a um pirômetro inóicador digital.

- equipamento foi projetado seguindo as recomendacōes dadas no trabalho de Dixon (1985b) no sentido de (a) usar material de baixa condutividade térmica no suporte dos termopares para evitar conduç̃o entre os sensores; (b) usar material de baixa 
condutividade na secáo de entrada, diainuindo a conducăo pela parede; (c) medir o perfil de temperatura fora do leito para evitar perturbacão no empacotamento pela insercáo de termopares.

\subsubsection{Medidas de temperatura no leito}

- perfil radial de temperatura em un experimento de transferência de calor pode ser medido de diversas maneiras, como por exemplo:

(a) insercão de termopares dentro do leito, técnica que apesar de relativamente simples e muito utilizada, tem como desvantagem a possibilidade de perturbar o empacotamento do leito. Além disso, há a possibilidade de perturbar a medida de temperatura devido à condugão de calor pelo termopar, quanoio este atravessa a parede aquecida do reator, como constatado por Thoméo e Freire (1988) e Dixon (1985b), consequentemente pode afetar os parâmetros térmicos obtidos dessa forma.

(b) dispor un único termopar no topo do leito e deslocá-10 em diferentes posicôes radiais e angulares por sobre o leito (Thoméo \& Freire, 1988);

(c) termopares suspensos por suporte em forma de cruz, colocados a uma pequena distância acima do leito, para medir a temperatura de saida do gás. Esta técnica tem sido muito utilizada, por exemplo nos trabalhos de Dewasch \& Froment (1972), Dixon et alii(1978), e vários outros. Dixon (1985b) recomenda que - suporte seja feito de material de baixa condutividade térmica para evitar que a conducão pelo suporte possa alterar as medidas de temperatura.

(d) colocaçáo de cilindros concêntricos no topo do leito para separacão do gás, dispondo termopares em cada seção anular para 
tomar uma temperatura média em cada região, como utilizado por Gunn \& Khalid (1975) Eunn et alii (1987).

Quando medidas são feitas em diferentes posicőes angulares, tem sido observado por diversos pesquisadores que existem flutuacões significativas, mas aparentemente aleatórias, de temperatura em leitos porosos. Tais flutuaçöes são devido a nãouniformidades locais de empacotamento inerentes ao próprio leito, e Parecem ser mais acentuadas quanto maior for a relacão $d_{m} / d_{t}$. Os modelos normalmente utilizados näo consideram estas flutuacöes. Assin torna-se necessário "filtrar" tais flutuacöes no tratamento de dados, pois de outra forma estas säo incorporadas no tratamento estatistico de dados como erro experimental e os parâmetros térmicos seräo estimados com largos intervalos de confianca, ou seja, com pequena precisäo.

Uma forma de abordar este problema é tomar medidas de temperatura em diversas posicões angulares, por exemplo pela técnica (c), e usar uma média dos valores medidos como a temperatura em cada posicão radial considerada. Outro modo seria utilizar sensores de temperatura em forma de anéis, como proposto por Ziolkowski \& Legawiec (1987), os quais medem uma temperacura média ao longo da posicão radial sobre a qual o sensor é colocado.

Neste trabalho são propostos sensores baseados nesta idéia, porén construidos de uma forma bastante simples, utilizando termopares. Cada sensor consiste de um anel metálico ao qual foi soldado um termopar. Sendo o material do anel (cobre) de alta condutividade térmica, o termopar registra uma média das temperaturas a que cada ponto do anel está submetida. Un modelo teórico para o funcionamento deste sensor descrito no item 3.10. 0 desempenho deste tipo de sensor foi testado experimentalmente, comparando suas medicôes com as de uma 
dispositivo do tipo (c), já descrito anteriormente, de uso consagrado na literatura, o qual formado por un conjunto de 10 termopares suspensos próximo ao topo do leito por um suporte de nylon en forma de cruz, conforme ilustra a figura 3.2(b). Quando este dispositivo foi usado, o suporte foi colocado en seis diferentes posinões angulares, e en cada uma das posicôes foram feitas medicões. A temperatura de cada posicão radial usada no tratamento de dados é a média das seis medidas realizadas em cada Posigão angular da cruz.

\subsection{Materiais utilizados}

Os materiais ensaiados estão apresentados na Tabela 3.1

Tabela 3.1. Materiais utilizados nos ensaios.

\begin{tabular}{|c|c|c|c|c|c|}
\hline$n^{\infty}$ & $\begin{array}{l}\text { tipo do } \\
\text { material }\end{array}$ & $\begin{array}{l}\text { uso ou } \\
\text { origem }\end{array}$ & $\begin{array}{l}\text { forma } e \\
\text { dimensö́es }\end{array}$ & $d_{p}(m)$ & $d_{p} / d_{t}$ \\
\hline 1 & $\begin{array}{l}\text { silica- } \\
\text {-alumina }\end{array}$ & $\begin{array}{l}\text { Catal isador } \\
\text { de craquea- } \\
\text { mento de } \\
\text { petróleo }\end{array}$ & $\begin{array}{l}\text { aproximad. } \\
\text { esféricas, } \\
\text { entre pe- } \\
\text { neiras }-5+6\end{array}$ & 3,7 & 0,062 \\
\hline 2 & $\begin{array}{l}\text { óxido de } \\
\text { zinco }\end{array}$ & $\begin{array}{l}\text { absorvente } \\
\text { para } \\
\text { remocão de } \\
\mathrm{H}_{2} \mathrm{~S}\end{array}$ & $\begin{array}{l}\text { cilindros } \\
\text { de } 7 \mathrm{~mm} \text { com } \\
\text { diâm. de } \\
4 \mathrm{~mm}\end{array}$ & 5.5 & 0,092 \\
\hline 3 & aco inox & $\begin{array}{l}\text { usadas em } \\
\text { mancais }\end{array}$ & esferas & 9,5 & 0,158 \\
\hline 4 & pedras & $\begin{array}{l}\text { cascalho } \\
\text { natural de } \\
\text { fundo de rio }\end{array}$ & $\begin{array}{l}\text { forma } \\
\text { tipica }\end{array}$ & 10,0 & 0,167 \\
\hline 5 & $\begin{array}{l}\text { alumina } \\
\text { impregnada } \\
\text { com } 15 \% \text { de } \\
\text { niquel }\end{array}$ & $\begin{array}{l}\text { catal isador } \\
\text { de reforma } \\
\text { a vapor }\end{array}$ & $\begin{array}{l}\text { anéis } \\
\text { cilindricos } \\
\text { de } 17 \times 17 \\
\text { mm com furo } \\
\text { coxial de } \\
6 \text { mm }\end{array}$ & 17,0 & 0,283 \\
\hline 6 & ferro & $\begin{array}{l}\text { usadas em } \\
\text { moinhos de } \\
\text { bolas }\end{array}$ & $\begin{array}{l}\text { apraximad. } \\
\text { esfér icas }\end{array}$ & 20,0 & 0.333 \\
\hline
\end{tabular}




\subsection{Ensaios experimentais}

Os experimentos foram realizados da seguinte maneira: uma vez carregado o reator com um material até uma certa altura, o sensor de medida do perfil radial de temperatura era aproximado pelo topo do leito e fixajo. Cinco valores pré-ajustados de vazôes de ar (190, 160, 120, 80 e $40 \mathrm{~L} / \mathrm{min}$ CNTP) eram entáo ensaiadas, correspondendo a cinco valores de número de Reynolds para cada materia 1.

Três alturas de leito (usualmente 100,200 e $300 \mathrm{~mm}$ ) foram empregadas en cada ensaio, isto é. para cada vazão de ar e material ensaiado.

\subsection{Iratamento de Dados e Estimacão de Parâmetros}

- tratamento de dados foi realizado usando o modelo bidimensional pseudohomogêneo com dispersâo axial, representado matemat icamente por:

$$
k_{r}\left(\frac{\partial^{2} T}{\partial r^{2}}+\frac{1}{r} \frac{\partial T}{\partial r}\right)+k-\frac{\partial^{22} T}{\partial Z^{2}}=G c_{P} \frac{\partial T}{\partial z}
$$

com as seguintes condicôes de contorno:

$$
\begin{aligned}
& r=0 \quad(\partial T / \partial r)=0 \\
& (3.2 . a) \\
& r=R \quad-k_{r}(\partial T / d r)= \begin{cases}h_{\omega}\left(T-T_{\omega}\right) & z>0 \\
h_{\omega}\left(T-T_{0}\right) & z<0\end{cases} \\
& z \rightarrow-\infty \quad T \rightarrow T_{0} \\
& z \rightarrow+\infty \quad T \rightarrow T_{-} \\
& z=\theta \quad T\left(\theta^{+}\right)=T\left(\theta^{-}\right) \\
& \partial T / \partial Z\left(\theta^{+}\right)=\partial T / \partial Z\left(\theta^{-}\right)
\end{aligned}
$$

A solução desta equacão para $z$ ) é (Dixon et alii, 1978)= 


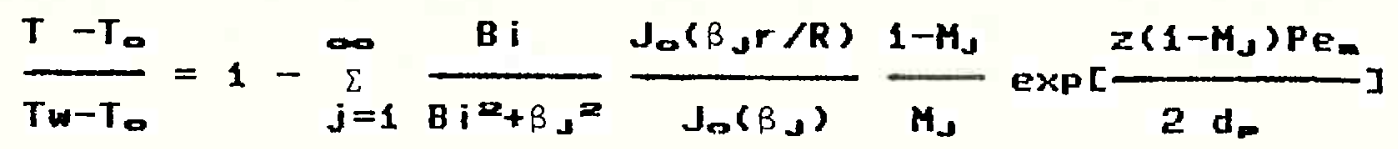

onde

$$
M_{J}=\left[1+4 B J^{2} d_{-}^{2} /\left(R^{2 P} P e_{-m} P E_{r}\right)\right] 1 / 22
$$

e $\beta$ J são as raízes da equação:

$$
\beta J_{1}(\beta)-B i J_{0}(\beta)=0
$$

A partir das medidas em estado estacionário da distribuicão radial de temperatura na saída do leito (para 3 alturas de leitoe 5 medidas radiais en cada altura), das temperaturas da parede T. $E$ do ar na entrada do leito To, os parâmetros Bi, Per e Pea são ajustados pelo critério dos mínimos quadradosr ou seja, para minimizar a funçäo:

$$
\phi=\sum_{I=1}^{3} \sum_{K=1}^{5}\left(T_{x-k}-T_{x=k}\right)=
$$

onde $\hat{\mathrm{T}} \dot{e}$ a temperatura calculada pelo modelo, no caso pela equacăo (3.3) - O método de ot imizaça ut ilizado foi o de Marquardt (1963), descrito no Apêndice A.

As raizes da equacăo (3.5) foram obtidas automaticamente pelo método de biparticão do intervalo de procura $e$ as funcōes de Bessel foram calculadas por aproximacóes polinomiais adequadas (Abramowitz \& Stegun, 1965). A somatória da equacão (3.3) foi feita com os primeiros 20 termos da série, número julgado suficiente para uma boa precisão a partir de testes previamente realizados (no entanto, quando se necessita calcular temperaturas en $z=0$, Eecessário incluir no minimo 100 termos da somatória para uma razoável precisão, da ordem de $0,5 \circ \mathrm{C}$ ). 


\subsection{Resultados Experimentais e Discussão}

Durante os ensaios realizados, o tempo para o sistema atingir - Estado estacionário esteve tipicamente entre 80 e 100 minutos após a fixação das condicooes do ensaio, a partir de uma condicão estacionária anterior. Aproximadamente o dobro deste tempo era necessário para atingir o regime quando o equipamento era colocado em furcionamento pela primeira vez no dia.

A comparacão entre os perfis de temperatura medidos pelos sensores anelares $E$ pelos sensores pontuais convencionais (cruz) está mostrado na figura 3.3 para o makerial $n^{\circ} 5_{n}$ Observa-se que as flutuações angulares de temperatura são bastante grandes, muitas vezes da ordem de grandeza da variacão de temperatura média ao longo do raio, como também relatado por Dixon et ali $\mathrm{i}$ (1978). Observa-se também que os sensores anelares permitem obter medidas de temperatura isentas das flutuacôes aleatórias observadas com as medidas pontuais, concordando razoavelmente bem com os valores médios das seis medidas pontuais em diferentes posicóes anqulares, como ilustra a figura 3.4. Com os sensores anelares não é necessário deslocar o dispositivo angularmente- Quando isto foi feito, as flutuacões de medidas observadas náo ultrapassaram $1^{\circ} \mathrm{C}$ que é a valor da sensibilidade do indicador de temperatura utilizado - isto é, a menor diferenca de temperatura que o indicador pode acusar. As medidas com os sensores anelares são portanto adequadas para o tratamento de dados.

0s sensores anelares apresentam entretanto uma pequena desvantagem quanto ao número de medidas radiais em relacão aos sensores pontuais convencionais. Para que os anéis de cobre tenham boa resistência mecânica o fio empregado para a construçăo dos anéis não pode ser muito fino. Isto impede a montagem de um 

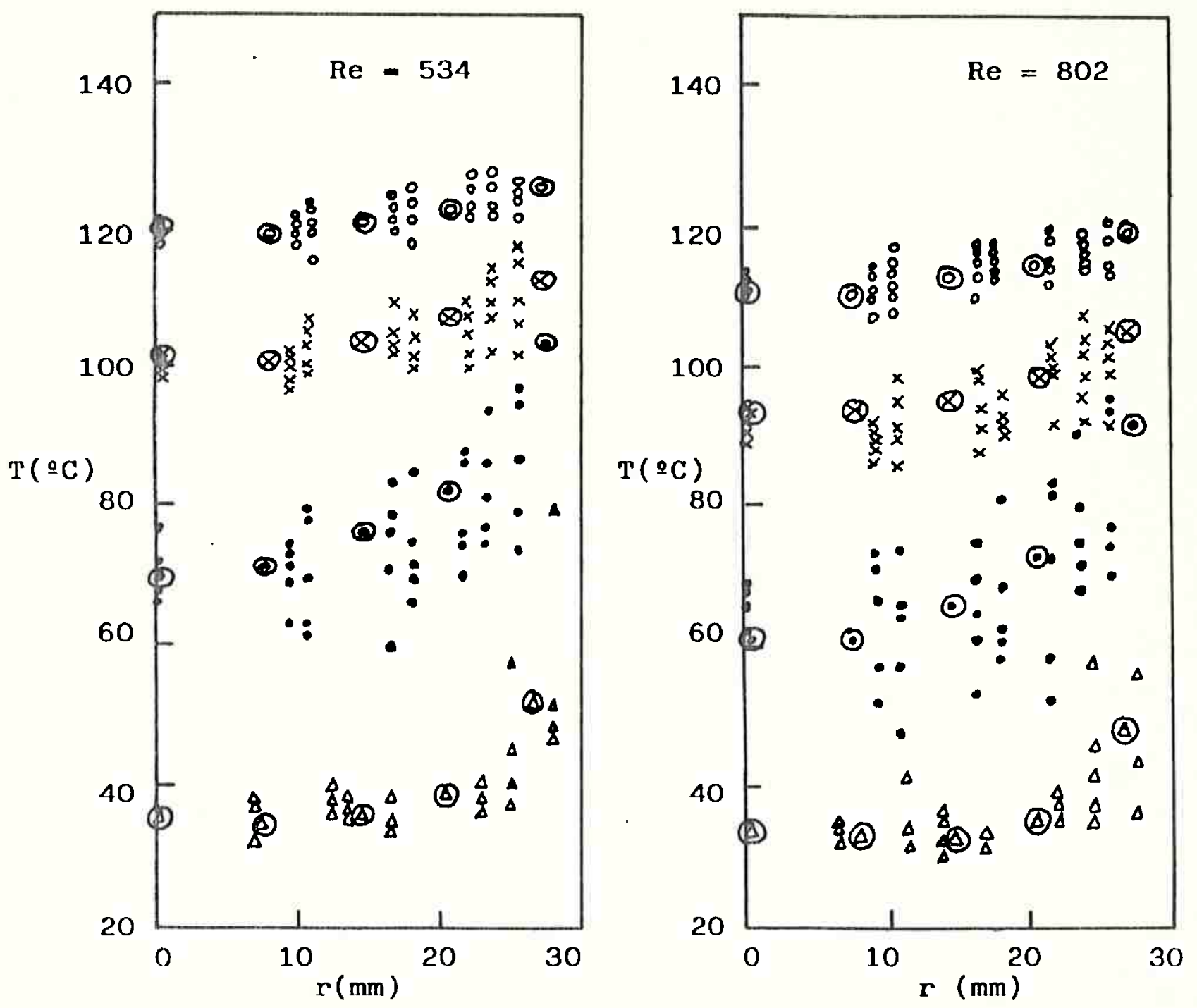

Figura 3.3. Comparação das diversas medidas pontuais em diferentes posições angulares com as medidas feitas com os sensores anelares, para o material no 5 .

Legenda: ( ) $1=300 \mathrm{~mm} ;(x) \mathrm{L}=200 \mathrm{~mm}$; ( ) $\mathrm{L}=100 \mathrm{~mm}$

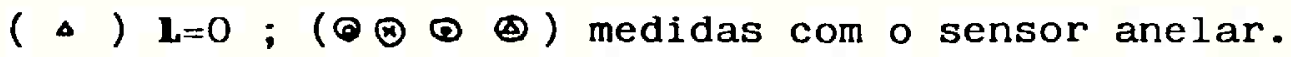




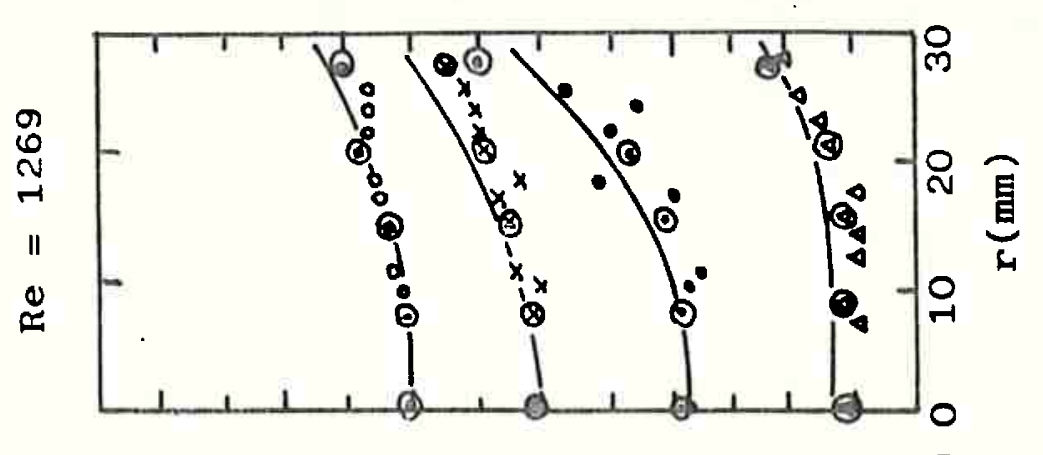

1
0
0
0
0
4
0
0
0
0
0
0
0
0
0
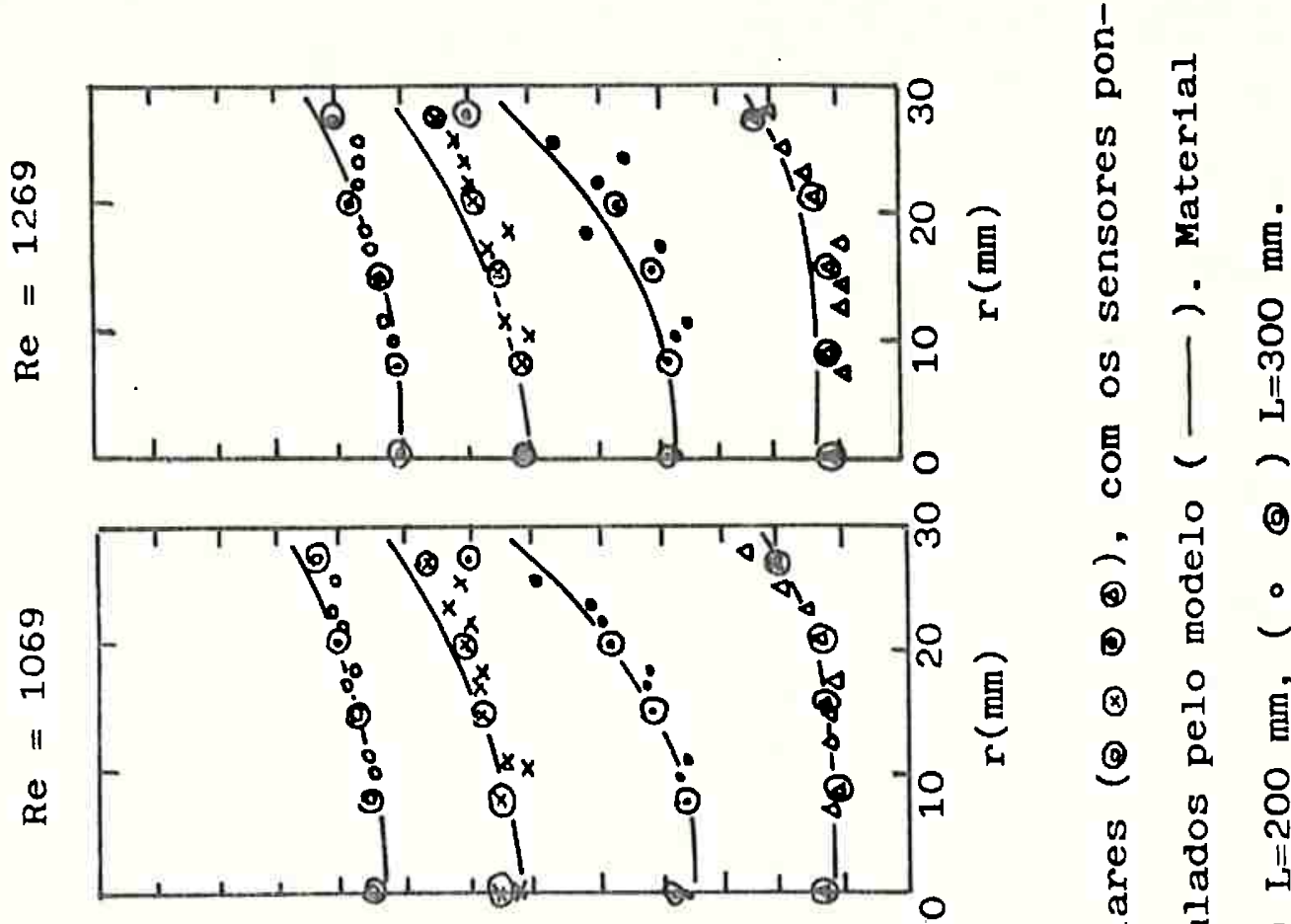

$\therefore \quad \stackrel{0}{0} 0$

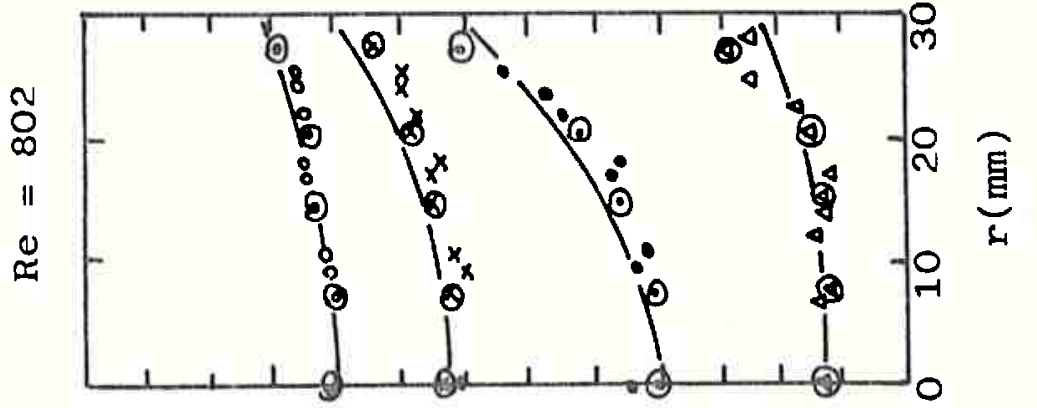

๑)

囚 $\stackrel{0}{\circ}$ ह

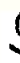

2
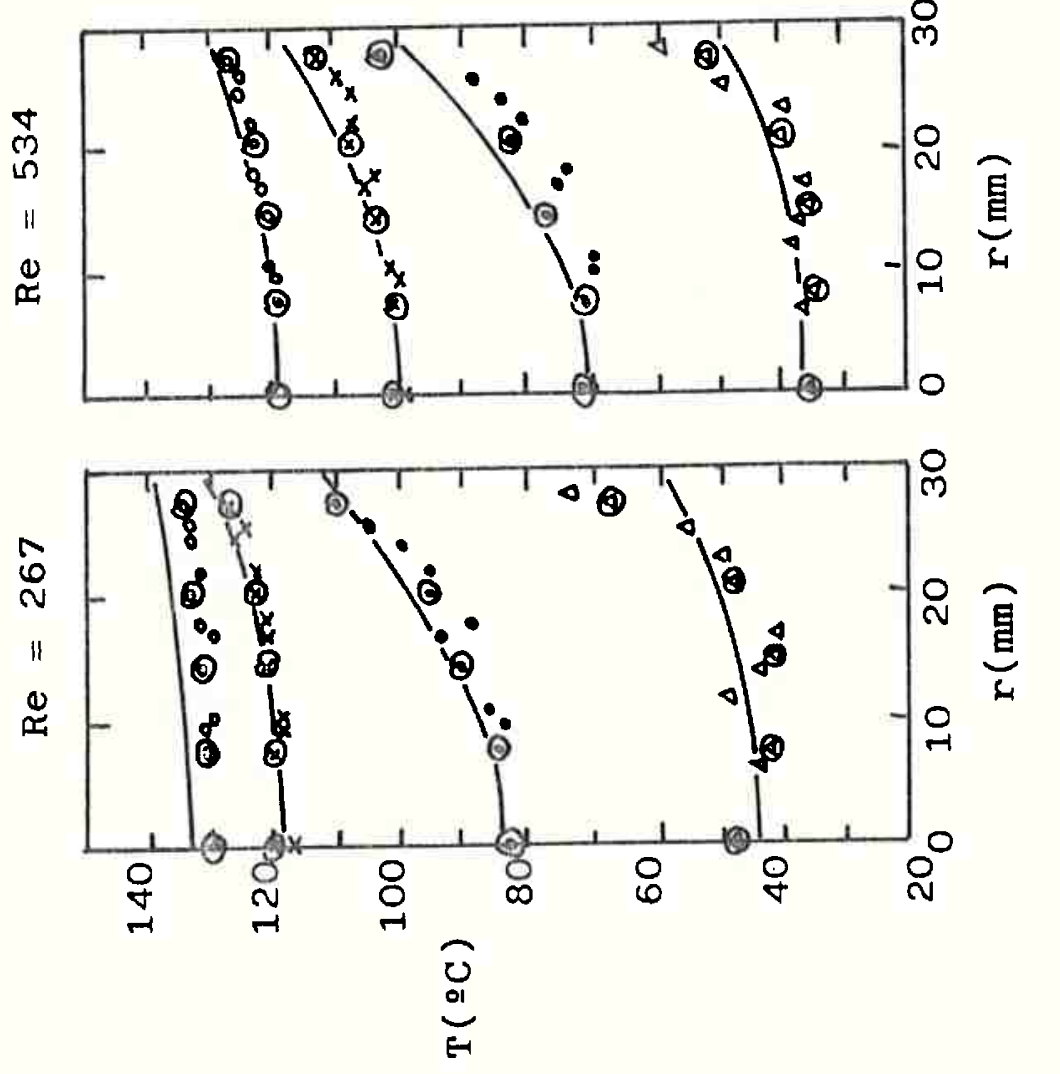

5

สู

$\begin{array}{lll}2 & 0 & x \\ 0 & 0 & -\end{array}$

品

- 8

ह $x$

0

ช

导导

\& 0

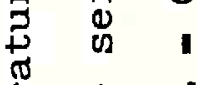

เै

員 需

$+8$

品

望 
dispositivo com muitos anéis, os quais näo podem ficar muito próximos entresi pois, de outra forma restaria pouca área de passagem do gás, o que perturbaria o escoamento. Este problema não ocorre com os sensores pontuais, que podem ser distribuídos em diferentes bracos do suporte.

No caso do dispositivo aqui utilizado, o diâmetro do fio foi de $2,5 \mathrm{~mm} e$ a distancia livre entre dois anéis vizinhos foi tipicamente 3,5 a $4,0 \mathrm{~mm}, \operatorname{com}$ a uso de quatro anéis no suporte.

Particularmente para o material $n^{-} 5$, também foram tentadas medicôes do perfil radial de temperatura em $z=0$. Isto foi feito do mesmo modo que as medidas para outras alturas de leito, isto $\dot{\epsilon}$, carregou-se o leito até a altura $z=0$ cisto é, só na secäo de entrada) e aproximou-se o dispositivo sensor pelo topo, ligeiramente acima do leito. Para medir o perfil em $z=0$ com os sensores pontuais foi usado um outro dispositivo, semelhante ao da figura 3.2(b), porém feita em pUC e com a localizacão dos sensores feita de modo um pouco diferente cposicóes radiais $r=7,12,14$, 17, 23, 25 e $28 \mathrm{~mm}$, devido a aspectos construtivos. Pode-se observar pela figura 3.4 que as medidas nesta cota apresentam-se sensivelmente mais dispersas. A mesma dificuldade de medicão em $z=0$ foi relatada por Dixon (1985b), que a atribuiu a certa imprecisão em preencher o leito exatamente até $z=0$, e em posicionar a dispositivo sensor. Dixon et alii (1978) haviam tentado medir este perfil inserindo termopares radialmente através da flange de separacão entre as secōes térmica e de entrada, e também observaram grande dispersão, atribuida à perturbacăo do empacotamento do leito e à conducão pelos termopares.

Devido a esta imprecisão de medidas os dados em $z=0$ não foram utilizados no tratamento de dados para a estimacáo dos parâmetros térmicos. Estas medidas, mesmo que sob aspecto apenas 
"qualitativo", são de utilidade na discriminacão entre os modelos, que discutida no item 3.8 .

outro aspecto experimental observado refere-se ao fenômeno de conducão de calor da parede da secão térmica para a parede de secão de entrada. Pelas medidas de temperatura ao longo da parede da sefão de entrada é possivel verificar que ocorre tal fenómeno. como também fora observado por Dixon (1985b). Devido à utilizacão de material de baixa condutividade térmica na secão de entrada (Puc ligado por flange de nylon), este efeito é pequeno, embora seja mensurável, como ilustra a figura 3.5 .

Alguns ensaios foram realizados para verificar a reprodutibilidade das medidas e um caso típico e mostrado na figura 3.6. Estes ensaios de reprodutibidade foram feitos com novo carregamento de material, para incluir variafões decorrentes de eventuais diferencas de grau de empacotamento do leito, que é reconhecido na literatura (Ziolkowski \& Legawiec, 1987) como um dos principais fatores de dispersáo de resultados. Observou-se uma boa reprodutibilidade dos perfis de temperatura e por decorrencia também dos parâmetros térmicos radiais obtidos.

Os perfis de temperatura medidos com as sensores anelares para os materiais ensaiados sáo apresentados na figura 3.7. Também são mostradas as curvas obtidas através do ajuste do modelo, onde se pode observar a qualidade do ajuste. Para o material no 5 os perfis estão mostrados na figura 3.4 .

A Tabela 3.2 resume o conjunto dos resultados obtidos. Os parametros diretamente ajustados no tratamento de dados são os adimensionais Bi(número de Biot). Per (número de Peclet radial) e Pencinumo de Peclet axial), sendo que os demais parâmetros são calculados a partir destes. 


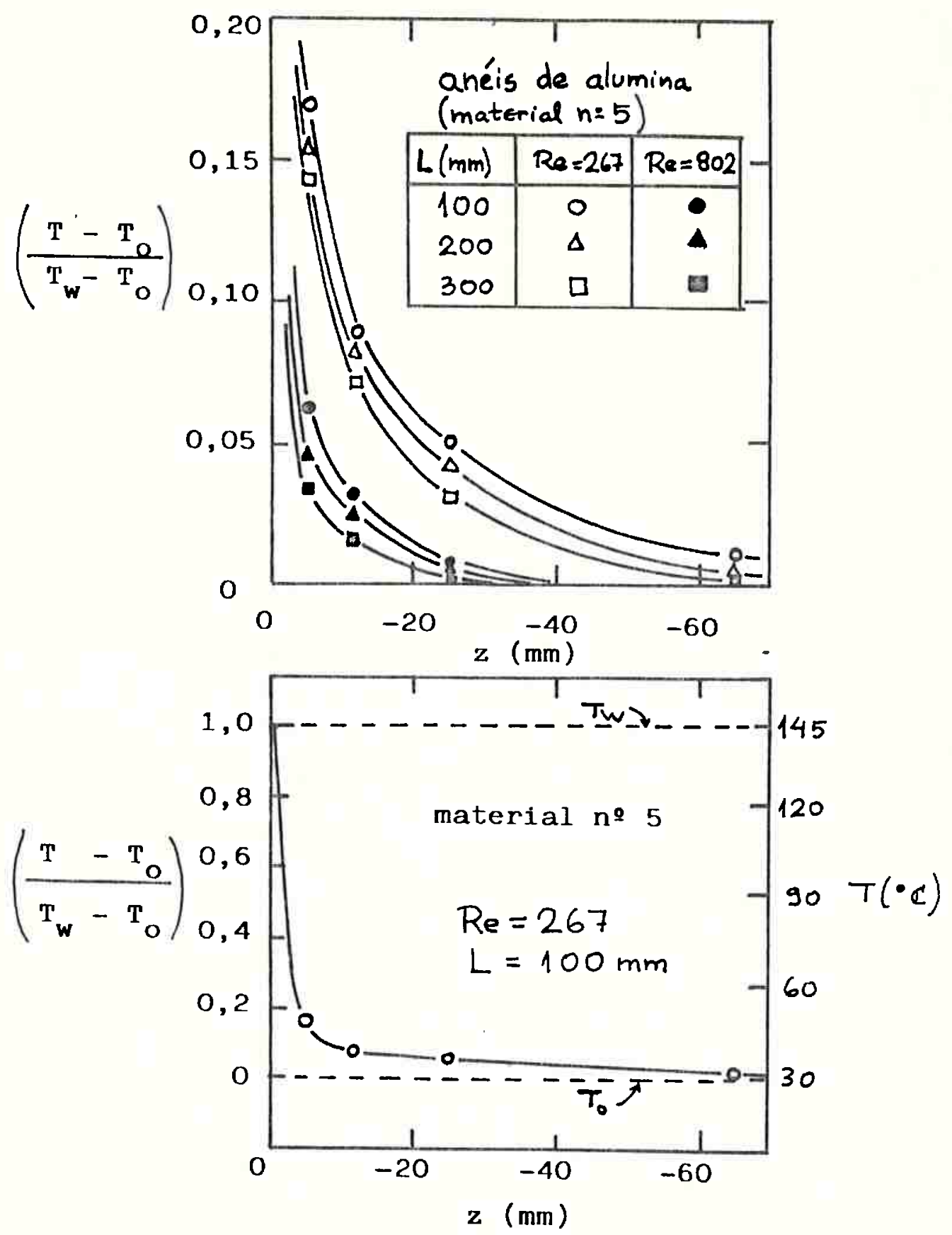

Figura 3.5. Perfis de temperatura na parede da seção de entrada. 


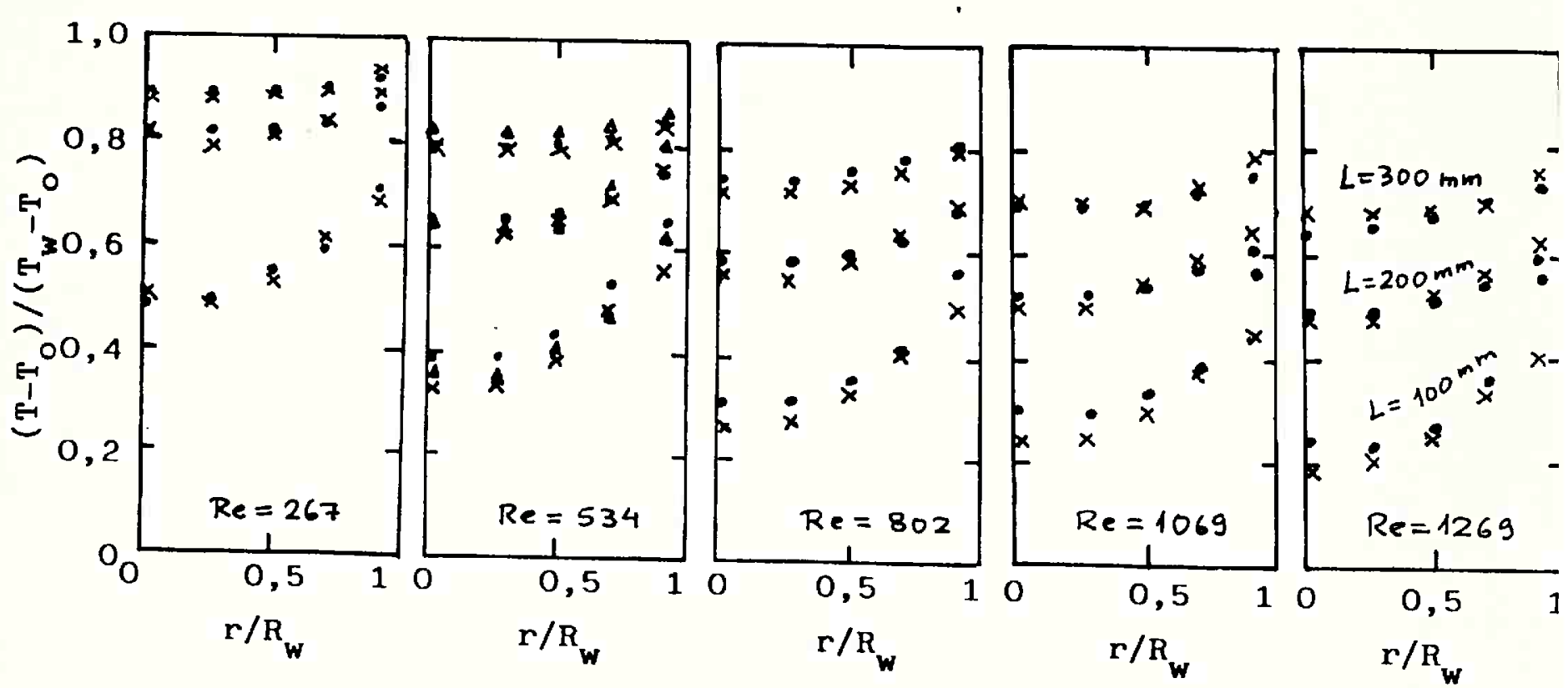

(a)
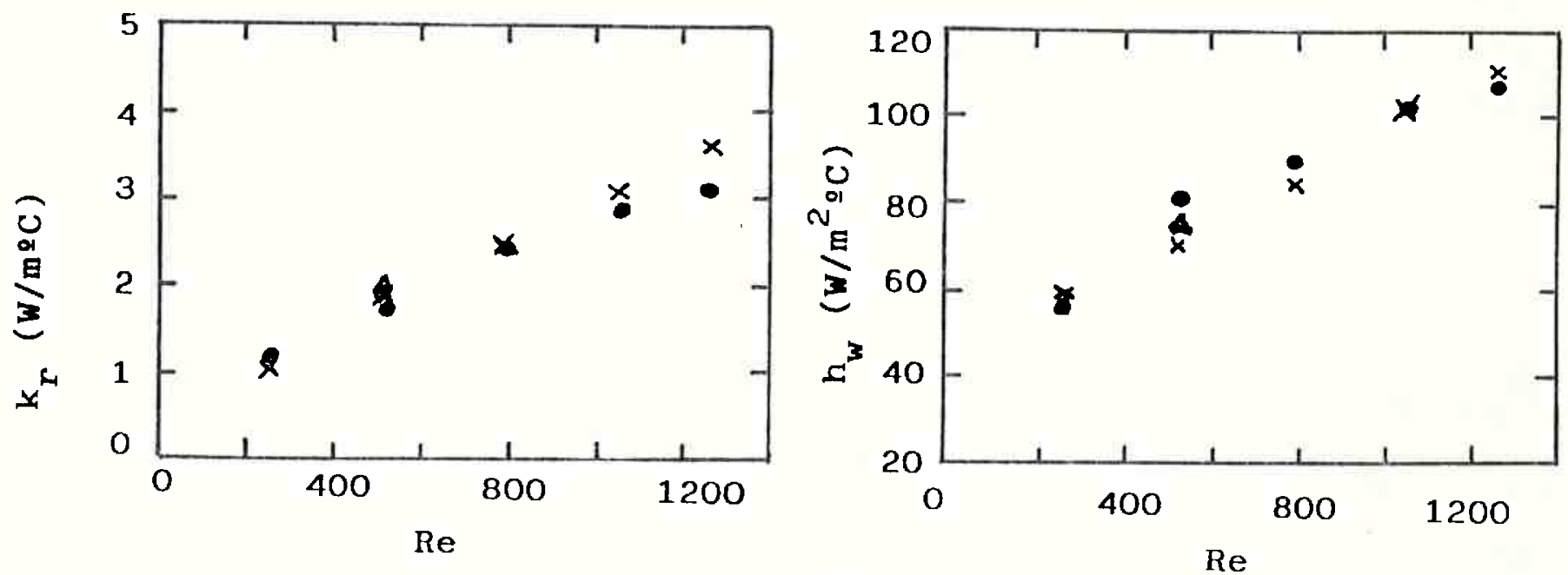

(b)

Figura 3.6. Reprodutibilidade dos perfis de temperatura (a) e dos parâmetros estimados (b). Material no 5 (anéis de alumina de $\left.d_{p}=17 \mathrm{~mm}\right)$ 

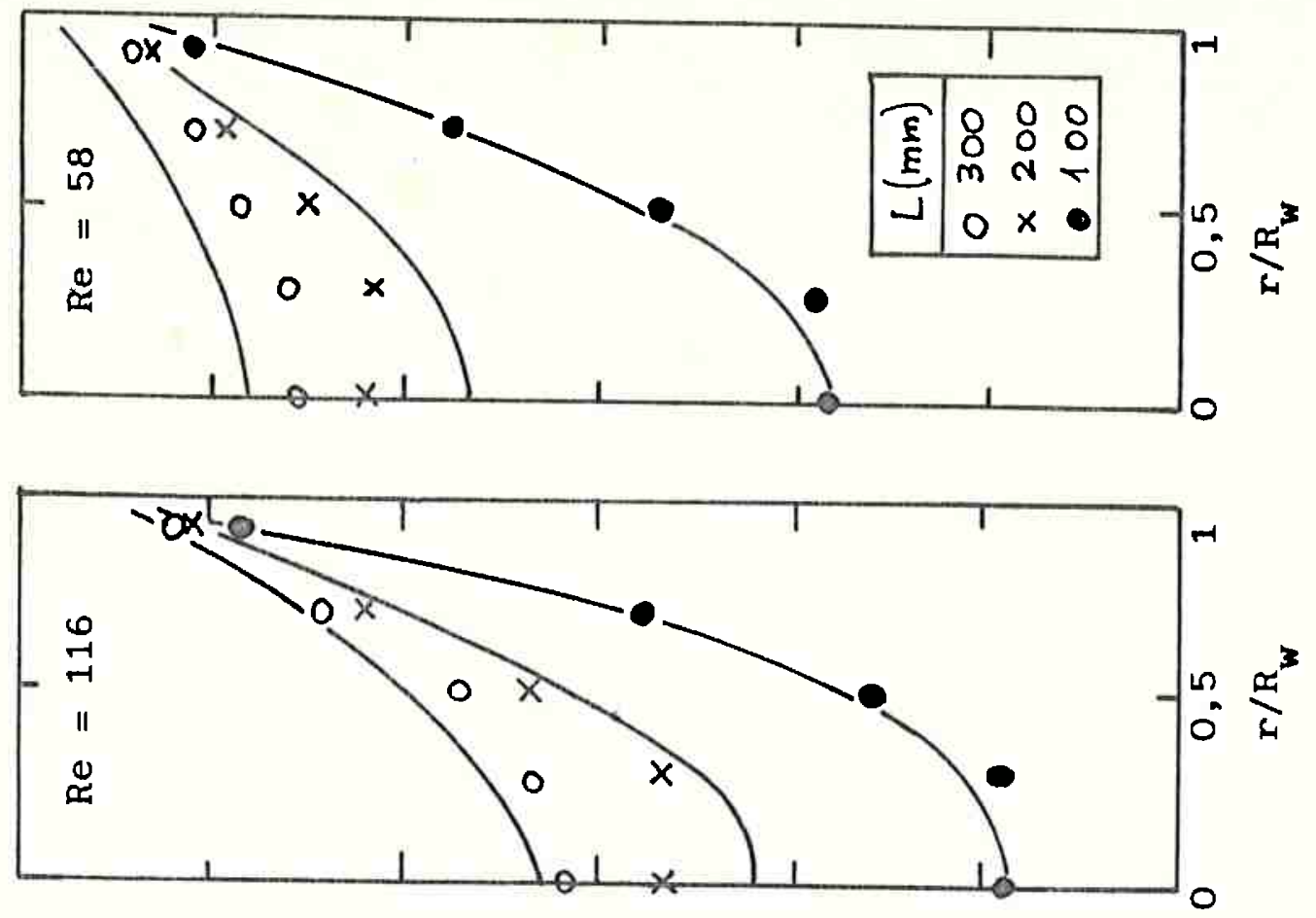

-
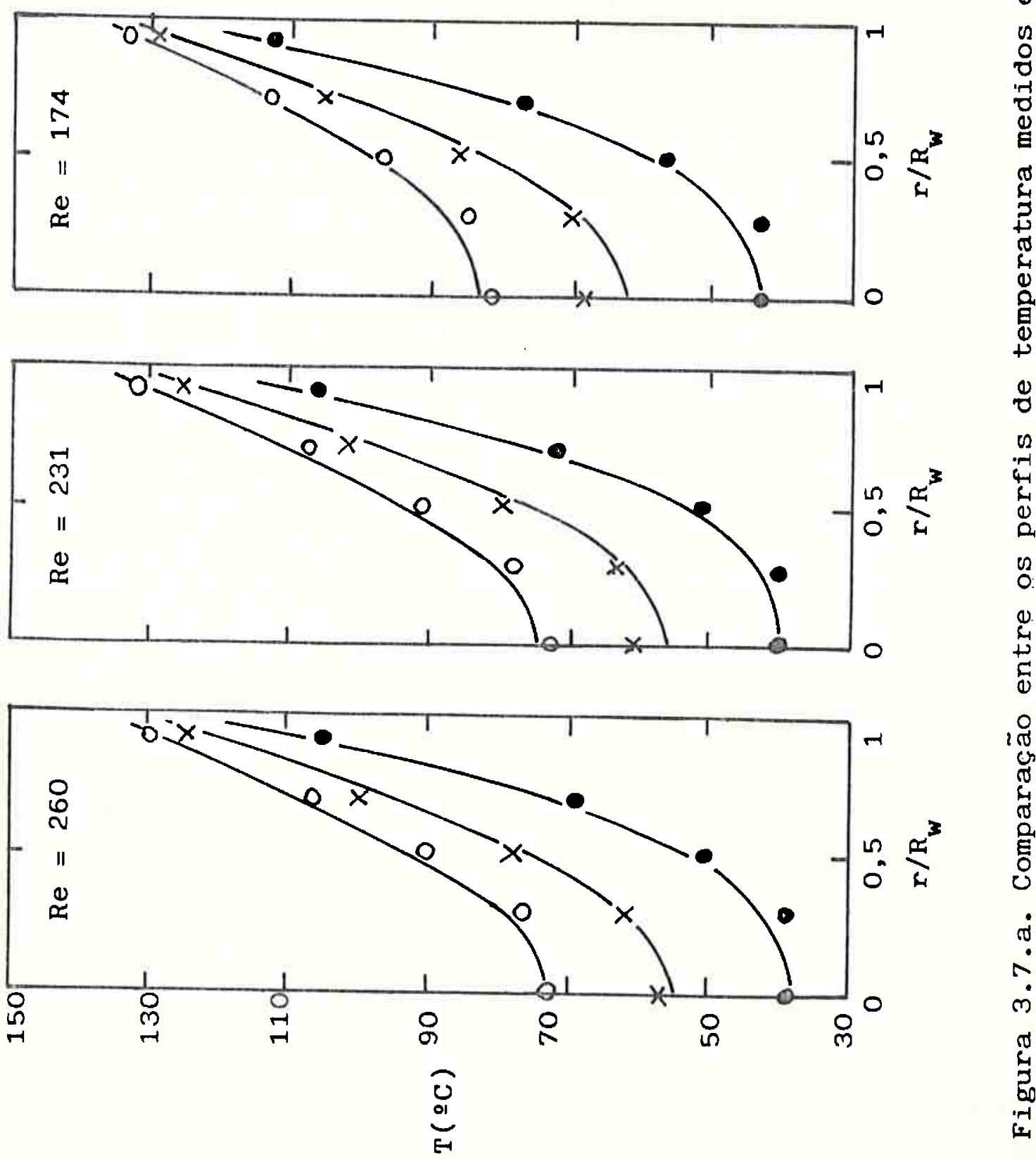

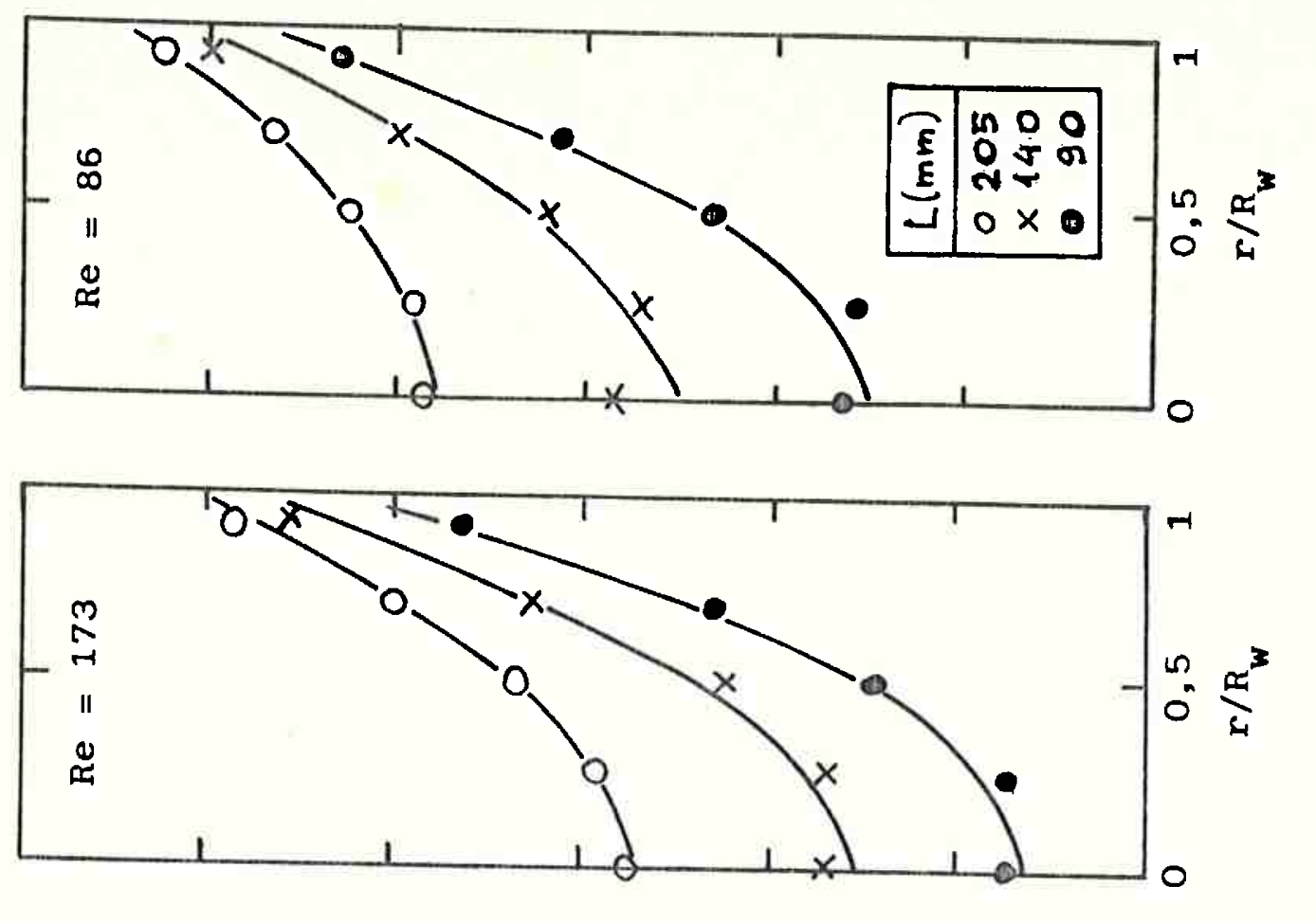

O
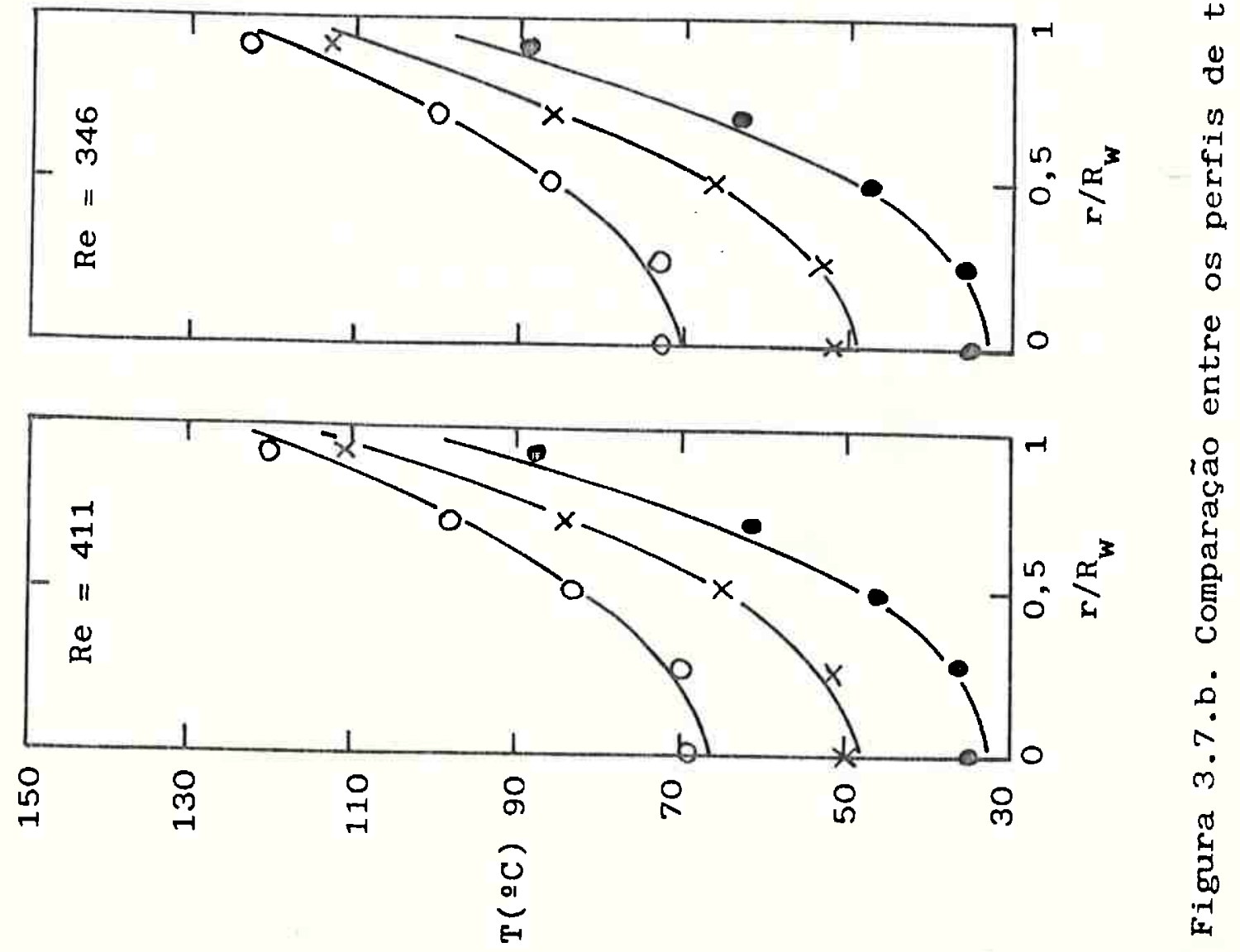


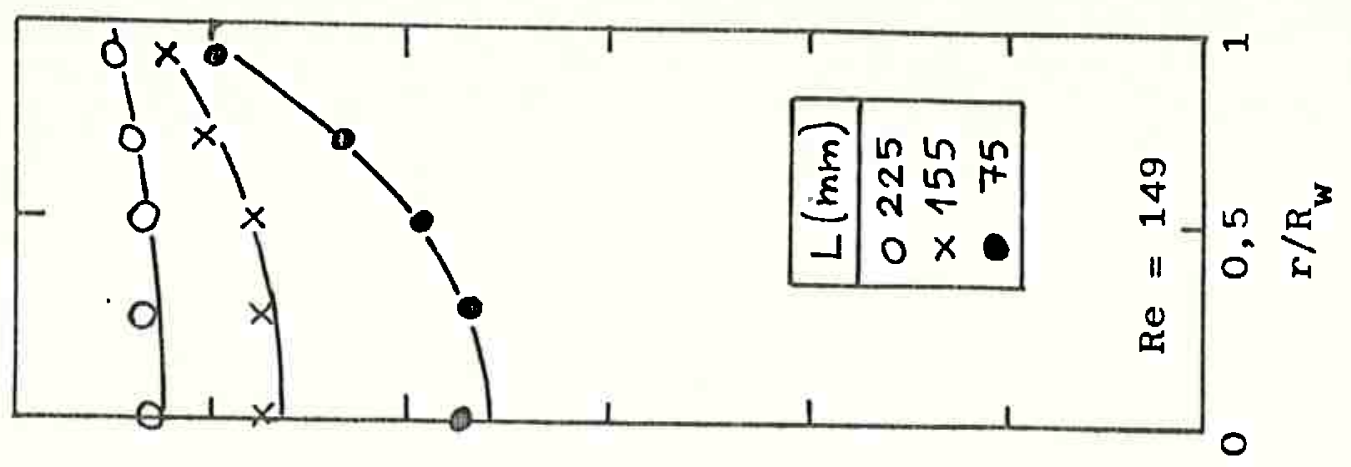

53
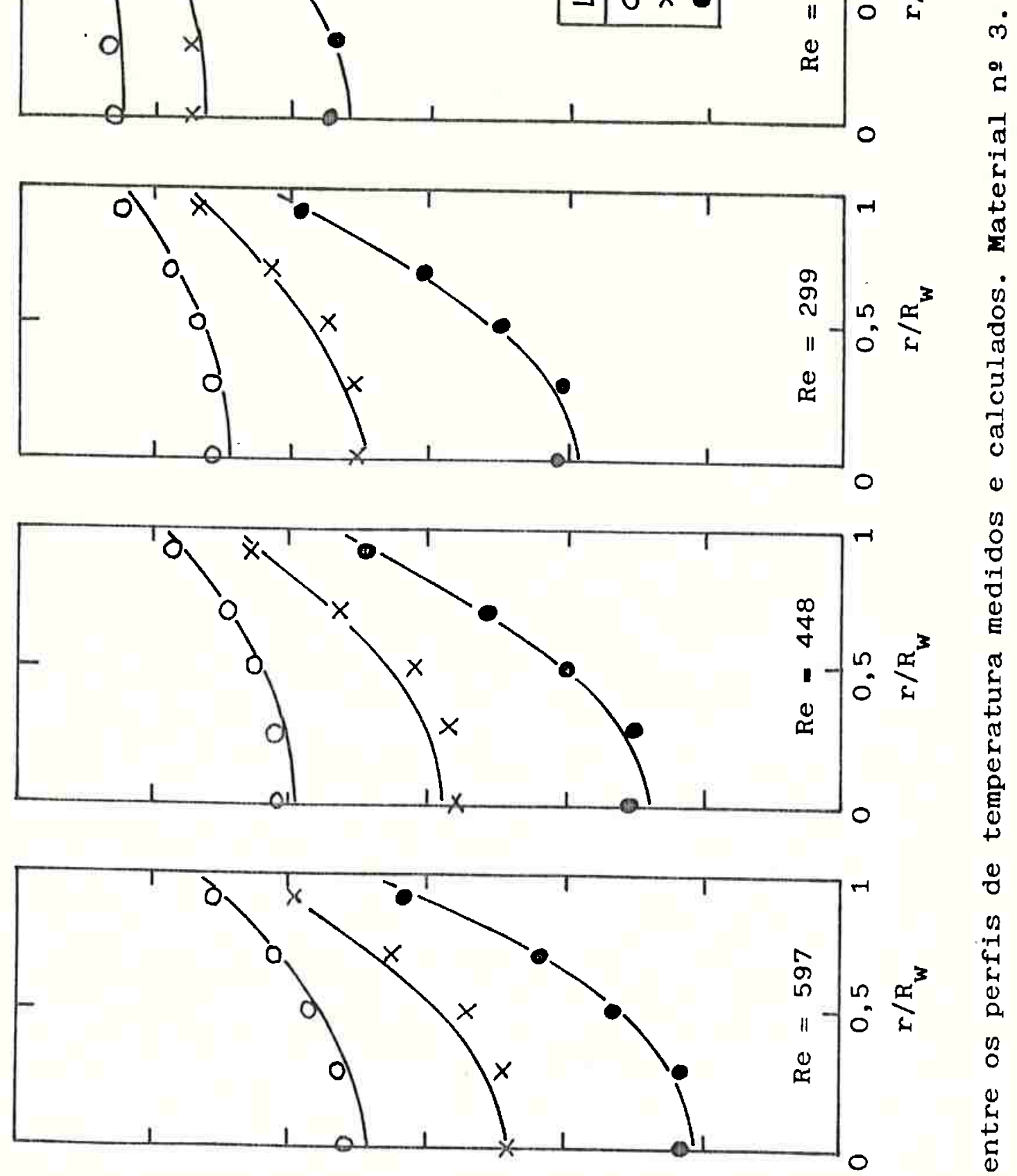

0
0
0
0
4
4
0
0
0
0
0
0
0
4
5
0

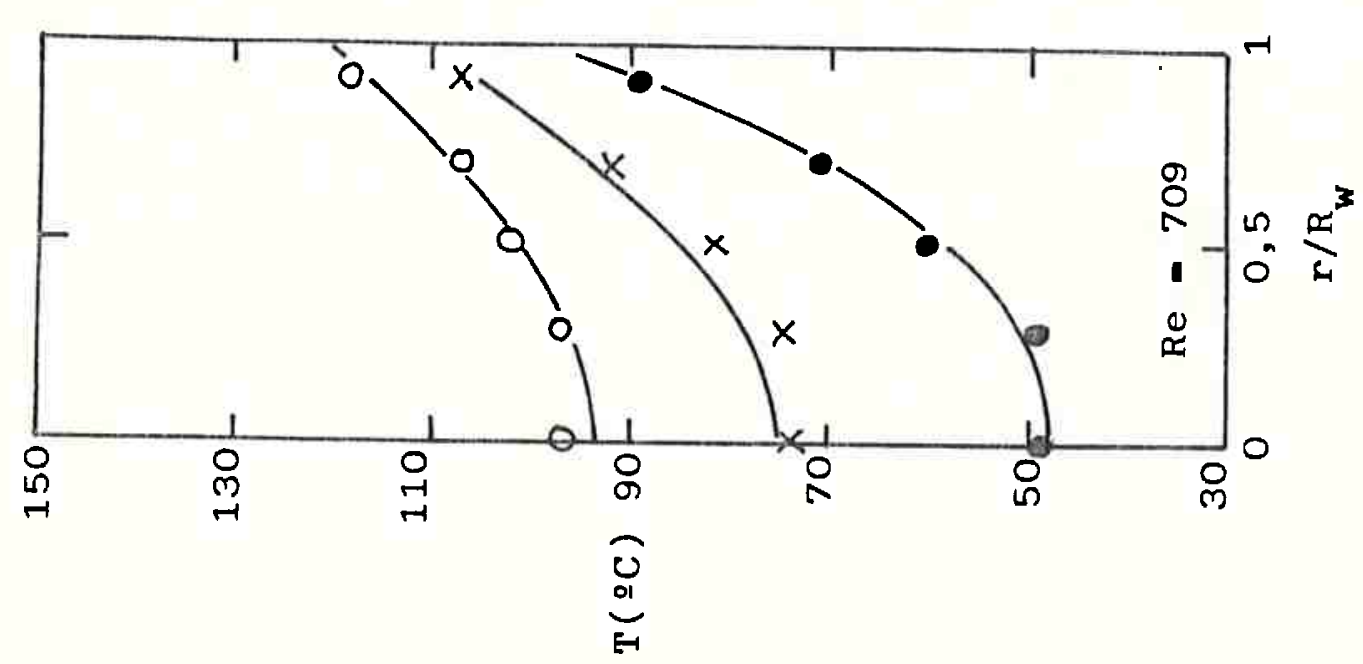

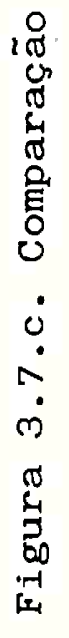



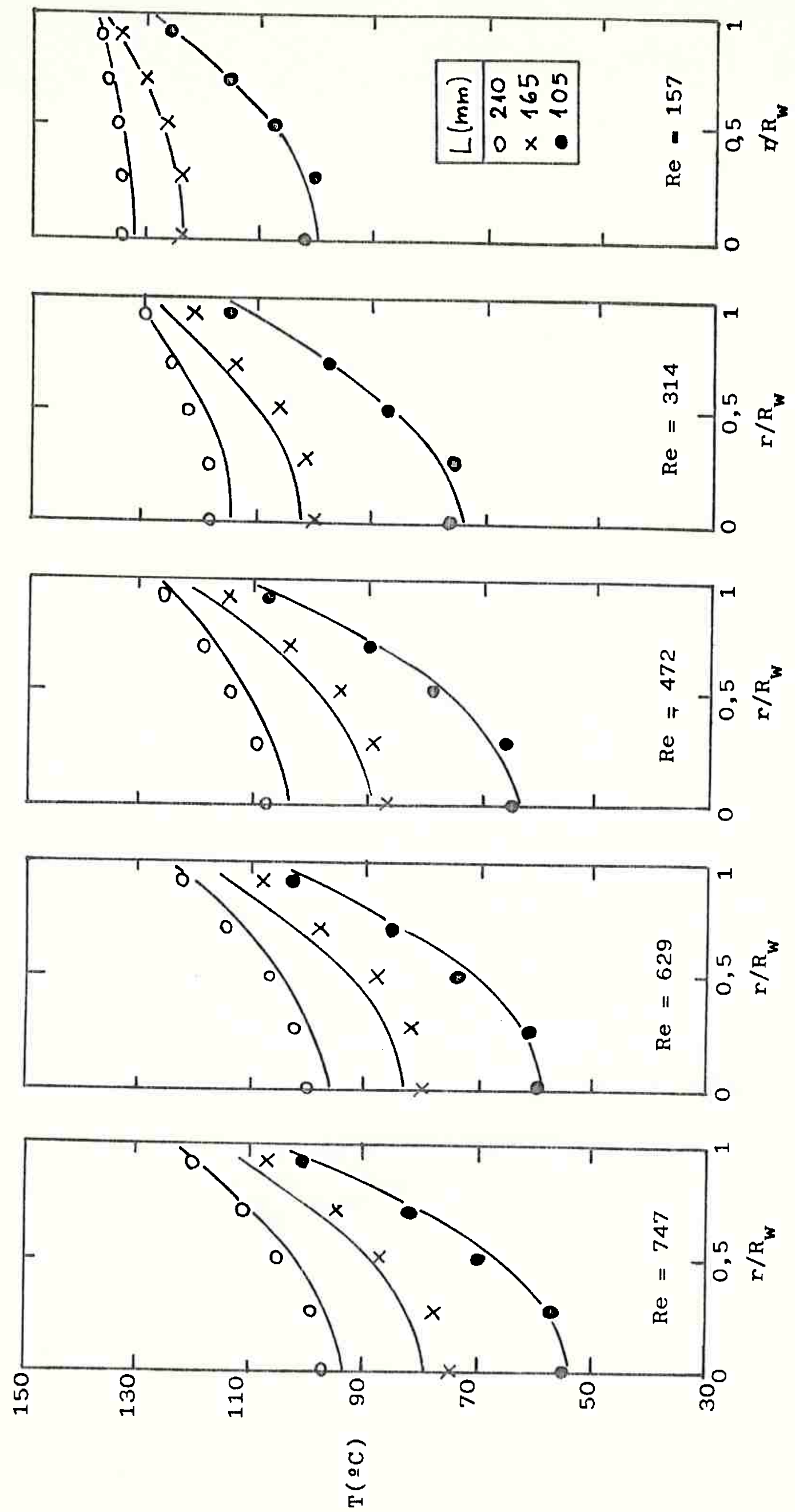

:

7
$\pi$
0
0
0
0
0
0
0
0
7
0
7
0
0

0
0
0
$0-1$
0
0
0
0
0
0
0
0
0
0
0
0
0

8

0
-1
+1
0
0
0
0

in 


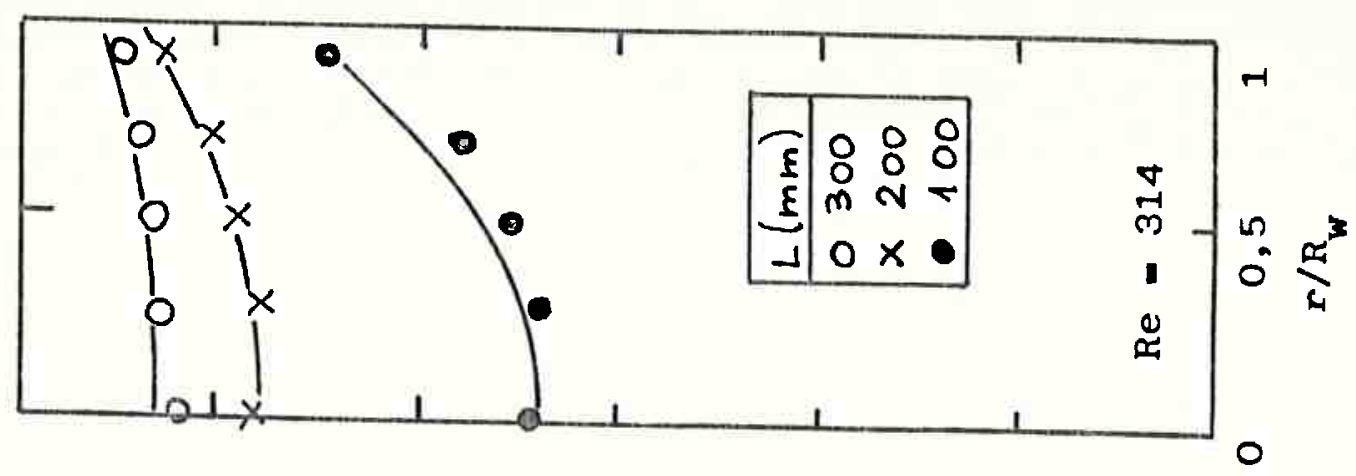

55
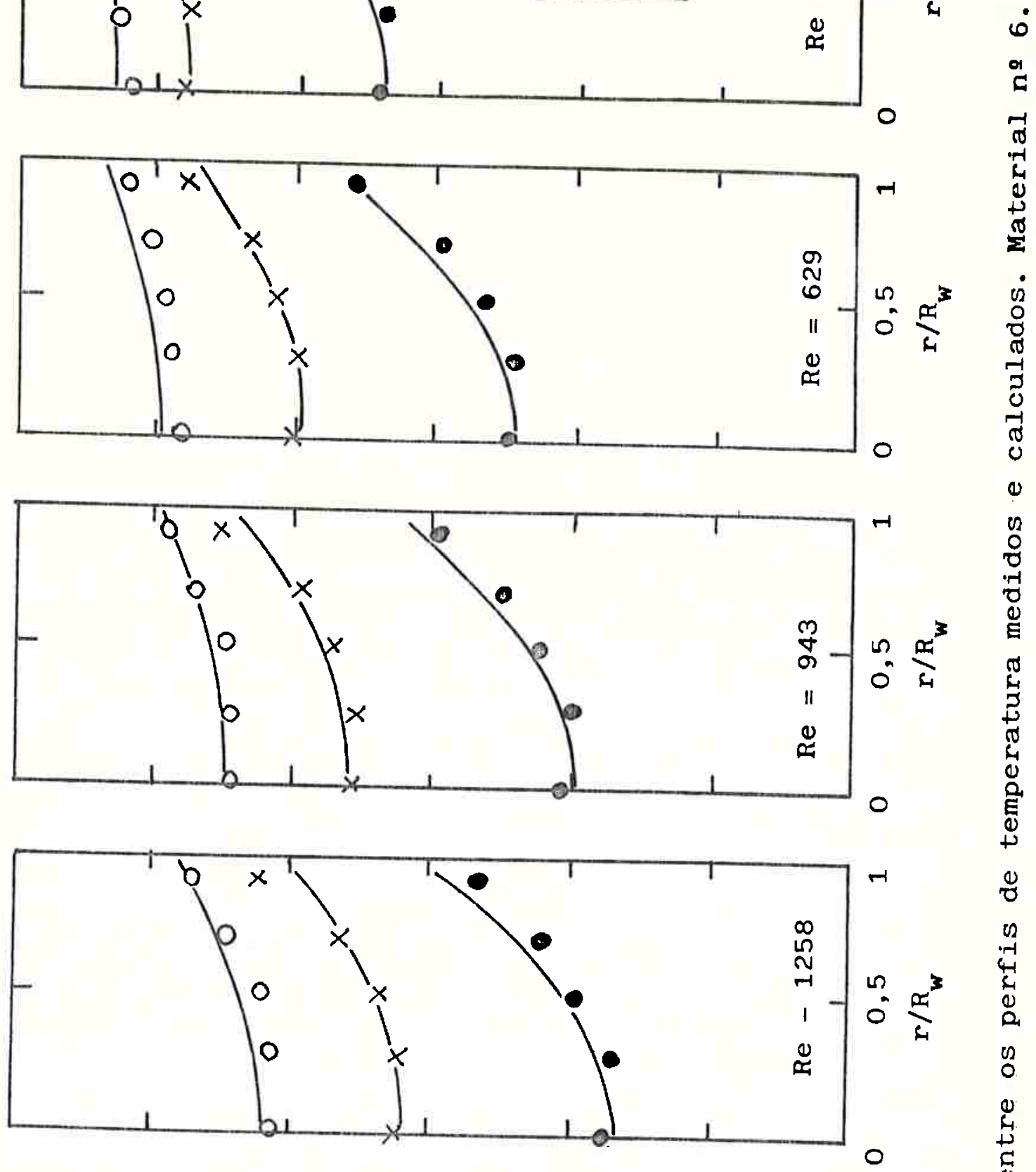

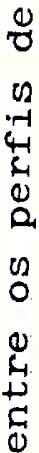

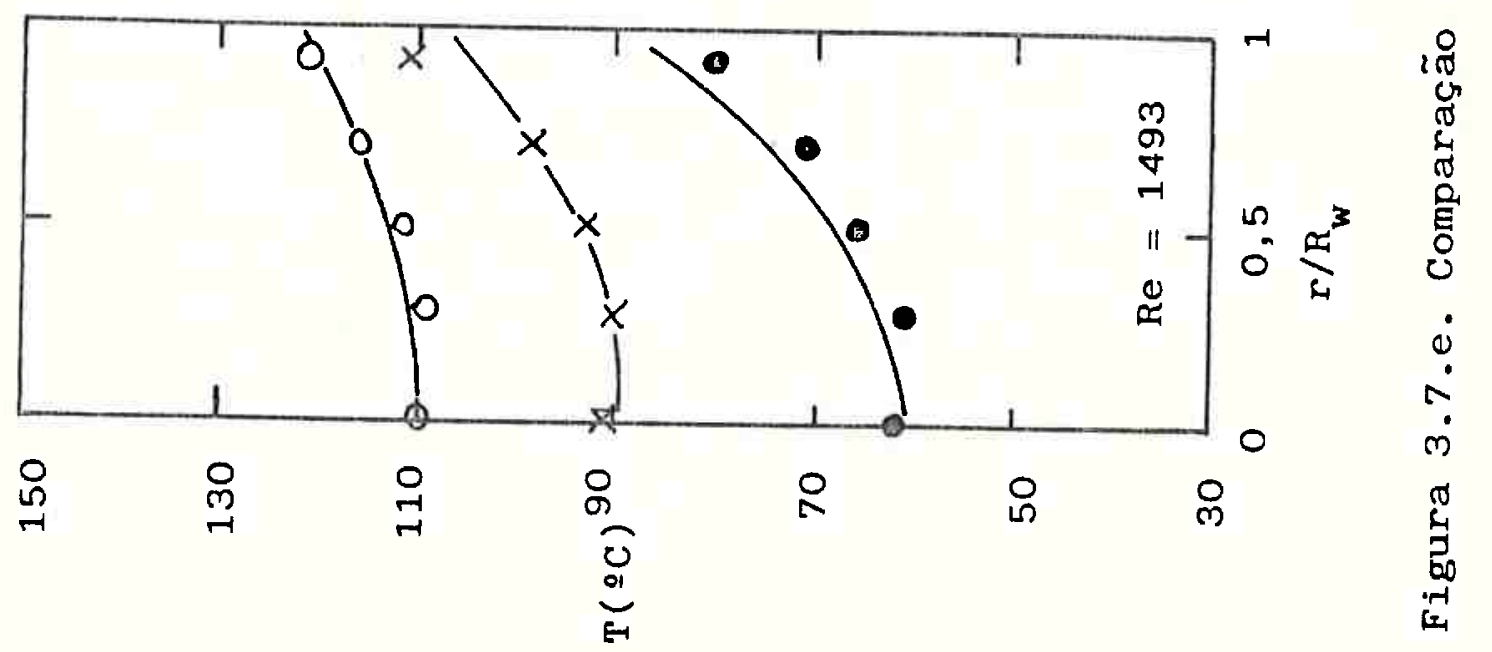


Tabela 3.2. Resultados obtidos com os diversos materiais.

\begin{tabular}{|c|c|c|c|c|c|c|c|c|}
\hline $\operatorname{Re}$ & $\mathbf{B} \mathbf{i}$ & $\mathrm{Pe}_{r}$ & $\mathrm{Pe}_{-}$ & $N_{u}$ & $\underset{m}{h_{m}}=$ & $k_{r} / m^{\circ} \mathrm{C}$ & $\underset{W / m^{200} C}{U}$ & $\stackrel{G}{\mathrm{~kg} / \mathrm{m}^{2} \mathrm{~s}}$ \\
\hline \multicolumn{9}{|c|}{-- - - esferas de } \\
\hline $\begin{array}{r}314 \\
629 \\
943 \\
1258 \\
1493\end{array}$ & $\begin{array}{l}1,80 \\
1,26 \\
0,99 \\
0,94 \\
0,86\end{array}$ & $\begin{array}{l}4,34 \\
5,88 \\
6,06 \\
6,80 \\
7,06\end{array}$ & $\begin{array}{r}0,36 \\
1,34 \\
2,61 \\
4,86 \\
311,00 \\
\end{array}$ & $\begin{array}{l}61 \\
63 \\
72 \\
81 \\
85 \\
\end{array}$ & $\begin{array}{r}82 \\
85 \\
97 \\
109 \\
115 \\
\end{array}$ & $\begin{array}{l}1,37 \\
2,02 \\
2,94 \\
3,49 \\
4,00\end{array}$ & $\begin{array}{l}57 \\
65 \\
78 \\
88 \\
95\end{array}$ & $\begin{array}{l}0,28 \\
0,56 \\
0,85 \\
1,13 \\
1,34 \\
\end{array}$ \\
\hline \multicolumn{9}{|c|}{ - anéis cilindricos de alumina - - $-d_{-}=17 \mathrm{~mm}$} \\
\hline $\begin{array}{r}267 \\
534 \\
802 \\
1669 \\
1269 \\
\end{array}$ & $\begin{array}{l}1,47 \\
1.41 \\
1.10 \\
1.08 \\
1.04\end{array}$ & $\begin{array}{l}4,36 \\
5,86 \\
6,16 \\
7,11 \\
7,78\end{array}$ & $\begin{array}{l}2,92 \\
0,43 \\
0,85 \\
0,41 \\
0,39\end{array}$ & $\begin{array}{l}36 \\
51 \\
57 \\
64 \\
68\end{array}$ & $\begin{array}{r}57 \\
81 \\
96 \\
102 \\
107 \\
\end{array}$ & $\begin{array}{l}1,16 \\
1,72 \\
2,46 \\
2,84 \\
3,08\end{array}$ & $\begin{array}{l}42 \\
60 \\
71 \\
80 \\
85\end{array}$ & $\begin{array}{l}0,28 \\
0,56 \\
0,85 \\
1,13 \\
1,34\end{array}$ \\
\hline \multicolumn{9}{|c|}{ pedras (areia) } \\
\hline $\begin{array}{l}157 \\
314 \\
472 \\
629 \\
747\end{array}$ & $\begin{array}{l}2,91 \\
2,68 \\
2,56 \\
2,28 \\
2,32 \\
\end{array}$ & $\begin{array}{l}2,67 \\
4,06 \\
4,78 \\
5,24 \\
5,66 \\
\end{array}$ & $\begin{array}{r}1,85 \\
3,66 \\
2,43 \\
2,16 \\
27,60 \\
\end{array}$ & $\begin{array}{l}40 \\
49 \\
59 \\
64 \\
71\end{array}$ & $\begin{array}{l}108 \\
131 \\
159 \\
173 \\
192\end{array}$ & $\begin{array}{l}1,11 \\
1,46 \\
1,87 \\
2,27 \\
2,49 \\
\end{array}$ & $\begin{array}{r}62 \\
78 \\
97 \\
110 \\
122\end{array}$ & $\begin{array}{l}0,28 \\
0,56 \\
0,85 \\
1,13 \\
1,34 \\
\end{array}$ \\
\hline \multicolumn{9}{|c|}{ esferas de aco inox } \\
\hline $\begin{array}{l}149 \\
299 \\
448 \\
597 \\
709 \\
\end{array}$ & $\begin{array}{l}3,17 \\
2,58 \\
2,31 \\
2,11 \\
2,04 \\
\end{array}$ & $\begin{array}{l}1,89 \\
3,43 \\
4,17 \\
4,77 \\
5,17 \\
\end{array}$ & $\begin{array}{l}0,24 \\
0,73 \\
1,26 \\
1,11 \\
1,42 \\
\end{array}$ & $\begin{array}{l}55 \\
50 \\
55 \\
59 \\
62\end{array}$ & $\begin{array}{l}157 \\
142 \\
156 \\
166 \\
176\end{array}$ & $\begin{array}{l}1,49 \\
1,65 \\
2,63 \\
2,37 \\
2,59 \\
\end{array}$ & $\begin{array}{r}88 \\
86 \\
99 \\
109 \\
117 \\
\end{array}$ & $\begin{array}{l}0,28 \\
0,56 \\
0,85 \\
1,13 \\
1,34 \\
\end{array}$ \\
\hline \multicolumn{9}{|c|}{ cilindros de óxido de zinco - $----d_{p}=5,5 \mathrm{~mm}$} \\
\hline $\begin{array}{r}86 \\
173 \\
259 \\
346 \\
411\end{array}$ & $\begin{array}{l}7,20 \\
5,61 \\
5,37 \\
4,39 \\
4,48\end{array}$ & $\begin{array}{l}3,39 \\
4,65 \\
5,39 \\
5,66 \\
6,13\end{array}$ & $\begin{array}{l}0,33 \\
0,42 \\
0,52 \\
0,58 \\
0,47\end{array}$ & $\begin{array}{l}23 \\
27 \\
33 \\
34 \\
39\end{array}$ & $\begin{array}{l}115 \\
132 \\
162 \\
169 \\
189\end{array}$ & $\begin{array}{l}0,48 \\
0,70 \\
0,91 \\
1,15 \\
1,27 \\
\end{array}$ & $\begin{array}{l}41 \\
55 \\
69 \\
80 \\
89\end{array}$ & $\begin{array}{l}0,28 \\
0,56 \\
0,85 \\
1,13 \\
1,34 \\
\end{array}$ \\
\hline \multicolumn{9}{|c|}{ Esferas de silica-alumina - $\ldots-\ldots d_{\infty}=3.7 \mathrm{~mm} \ldots$} \\
\hline $\begin{array}{r}58 \\
116 \\
174 \\
231 \\
260\end{array}$ & $\begin{array}{l}19,0 \\
13,3 \\
14,2 \\
11,7 \\
10,7\end{array}$ & $\begin{array}{l}2,73 \\
4,51 \\
5,76 \\
6,60 \\
6,52\end{array}$ & $\begin{array}{l}0,26 \\
0,15 \\
0,13 \\
0,12 \\
0,20\end{array}$ & $\begin{array}{l}35 \\
29 \\
37 \\
35 \\
37\end{array}$ & $\begin{array}{l}254 \\
215 \\
271 \\
258 \\
269\end{array}$ & $\begin{array}{l}0.40 \\
0.49 \\
0.57 \\
0.66 \\
0.75\end{array}$ & $\begin{array}{l}44 \\
50 \\
59 \\
66 \\
73\end{array}$ & $\begin{array}{l}0,28 \\
0,56 \\
0,85 \\
1,13 \\
1,27\end{array}$ \\
\hline
\end{tabular}


Valores típicos das elementos de intercorrelaça da matriz variância-covariância são apresentados na Tabela 3.3. Pode-se observar que praticamente não há correlacão entre Peme Per e entre Pea $E$ i, exceto talvez para numeros de Reunolds pequenos. Por outro lado ha correlacão apreciaivel entre os parâmetros "radiais" Per e Bi, como seria esperado. Estes resultados são semelhantes aos apresentados por Dixon et ali $(1978)$.

Tabela 3.3. Valores típicos dos elementos de correlacão cruzada da matriz variancia-covariância dos parâmetros ( Material n:5, alturas de leito 100,200 e $300 \mathrm{~mm}$, tratadas simultaneamente)

\begin{tabular}{|cccc|}
\hline & \multicolumn{2}{c|}{ Pares de parâmetros de intercorrelacão } \\
\hline Re & Bi e Per & Bi e Pe & Per e Pem \\
\hline 267 & 0,12 & $-0,19$ & $-0,14$ \\
534 & 0,13 & $-0,007$ & $-0,01$ \\
802 & 0,08 & $-0,012$ & $-0,05$ \\
1069 & 0,24 & $-0,009$ & $-0,05$ \\
1269 & 0,25 & $-0,008$ & $-0,06$ \\
\hline
\end{tabular}

Dentre os materiais ensaiados, 0 de no3 cesferas de aco de 9,5 mos pode ter seus resultados comparados diretamente com os da literatura por ter sido estudado também por outros autores. A comparacão dos parâmetros térmicos Per e Bi está mostrada na figura 3.8, onde se observa uma concordância relativamente boa.

0s resultados relativos aos parâmetros de transferência radial obtidos com os seis materiais são mostrados na figura 3.9(a) e 3.9(b). Foi possivel, para cada material, obter relacỏes

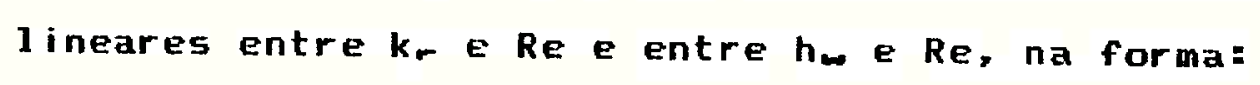

$$
\begin{aligned}
& k_{r}=k_{A}+K_{D} R E \\
& h_{\omega}=K_{C}+K_{D} R E
\end{aligned}
$$

As constantes $K_{A}, K_{m}$. $K_{C} e K_{0}$ são mostradas na Tabela 3.4. 

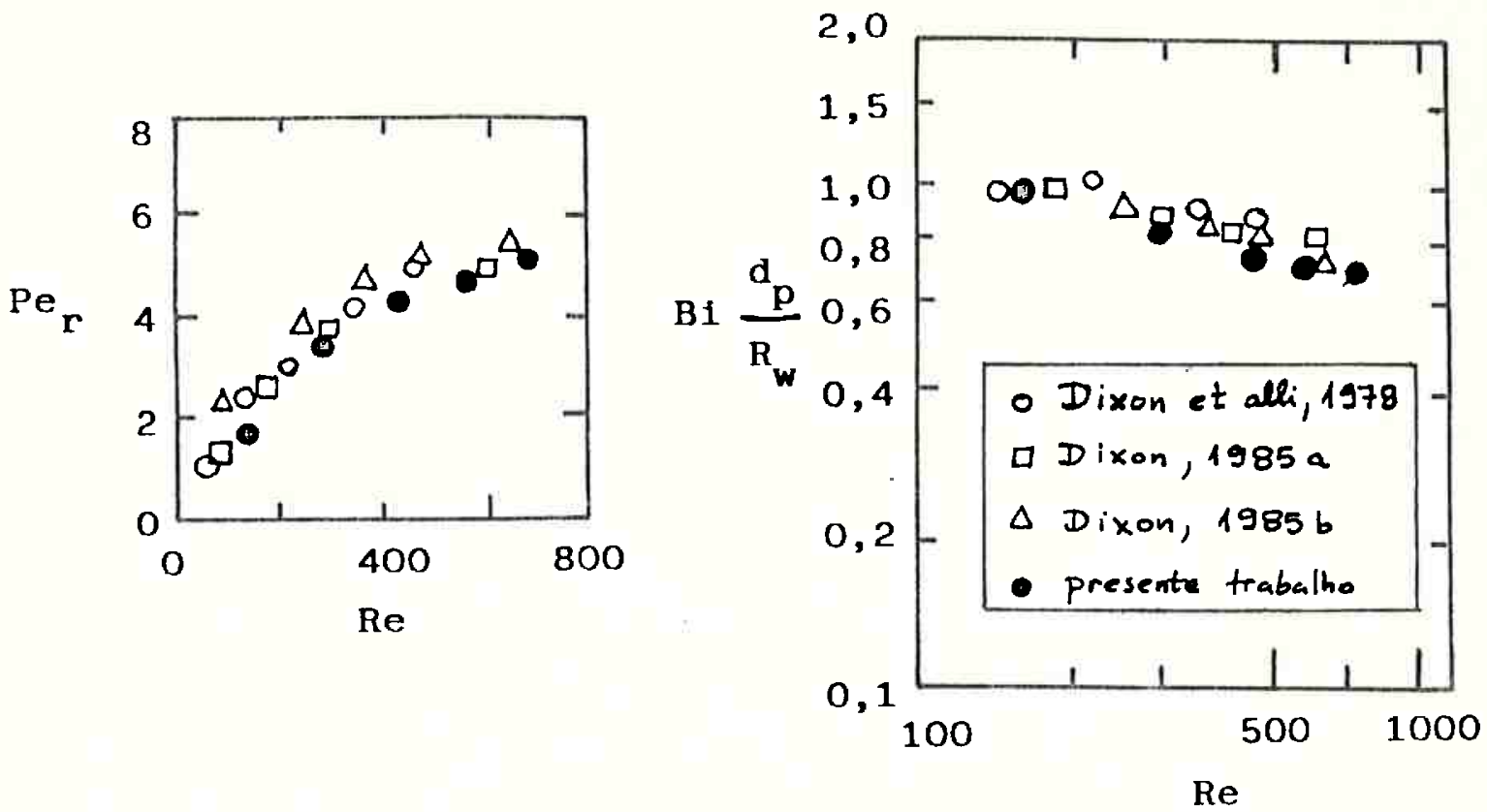

Figura 3.8. Comparação dos resultados deste trabalho com dados da literatura, para esferas de aço inox de $9,5 \mathrm{~mm}$ (material $\mathrm{n}^{2} 3$ ). 

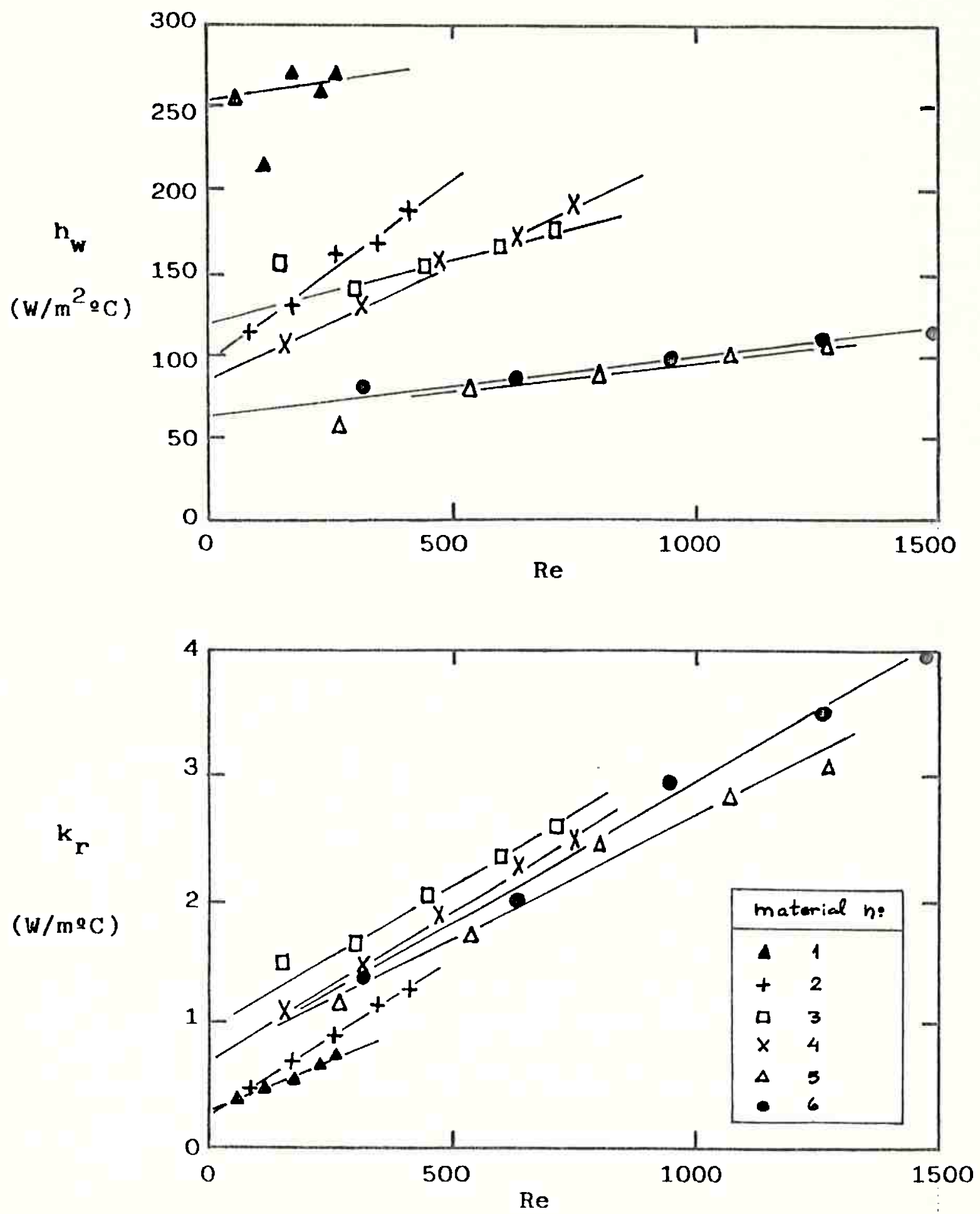

Figura 3.9. Resultados obtidos para os parâmetros $h_{w} e k_{r}$ para os diversos materiais. 
Tabela 3.4. Constantes das equacões (3.7) e (3.8).

\begin{tabular}{|c|c|c|c|c|c|}
\hline & & \multicolumn{2}{|c|}{$k_{r}=K_{A}+K_{0}-R e$} & \multicolumn{2}{|c|}{$h_{\omega}=K_{e}+K_{D} \cdot R_{e}$} \\
\hline $\begin{array}{c}\text { material } \\
n^{\circ}\end{array}$ & $d_{p} / d_{t}$ & $\underset{(W / m \cdot K)}{K / m}$ & $\underset{(W / m-K)}{K o}$ & $\begin{array}{c}K E_{n} \\
\left(W / m^{2} K\right)\end{array}$ & $\begin{array}{c}K_{D} \\
\left(H / m^{22} K\right)\end{array}$ \\
\hline 1 & 0,062 & 0,29 & 0,0017 & 253 & 0.053 \\
\hline 2 & 0.092 & 0.27 & 0,0025 & 99 & 0.23 \\
\hline $\mathbf{3}$ & 0,158 & 0,98 & 0.0023 & 118 & 0.081 \\
\hline 4 & 0,167 & 0,73 & 0.0024 & 87 & 0,14 \\
\hline 5 & 0,283 & 0,70 & 0.0020 & 61 & 0,037 \\
\hline 6 & 0,333 & 0,667 & 0.0023 & 63 & 0,035 \\
\hline
\end{tabular}

- conjunto dos seis materiais ensaiados apresenta diferentes tamanhos de partícula $\left(3,7 \mathrm{~mm}<d_{p}<20 \mathrm{~mm}\right.$ ), formas (esferas, cilindros, anéis) e materiais (metálicos e cerámicos). Devido ao fato de que tais fatores näo foram variados independentemente, torna-se dificil tirar conclusốes inequívocas sobre a influência de cada um destes fatores sobre os parâmetros térmicos. Para alguns parämetros, no entanto, é possivel perceber um fator cu,ja influência seja preponderante.

Da análise da figura $3.9(b)$ pode-se perceber que a influência do diämetro da particula sobre o coeficiente ho é bem mais pronunciada que a do material ou da forma da partícula. Quanto à condutividade térmica radial efetiva, os resultados não permitem estabelecer um fator preponderante de maneira conclusiva, embora se tenham indicacões de que o material seja um fator importante.

As relacōes entre Per e Re, entre Nu e Re, entre Bi e Re e entre Pe. $e$ Re säo ilustradas nas figuras $3.10,3.11$ e 3.12. Estas figuras mostram que os resultados obtidos neste trabalho estấo dentro das regiôes de pontos experimentais de diversos autores obtidas na literatura. 

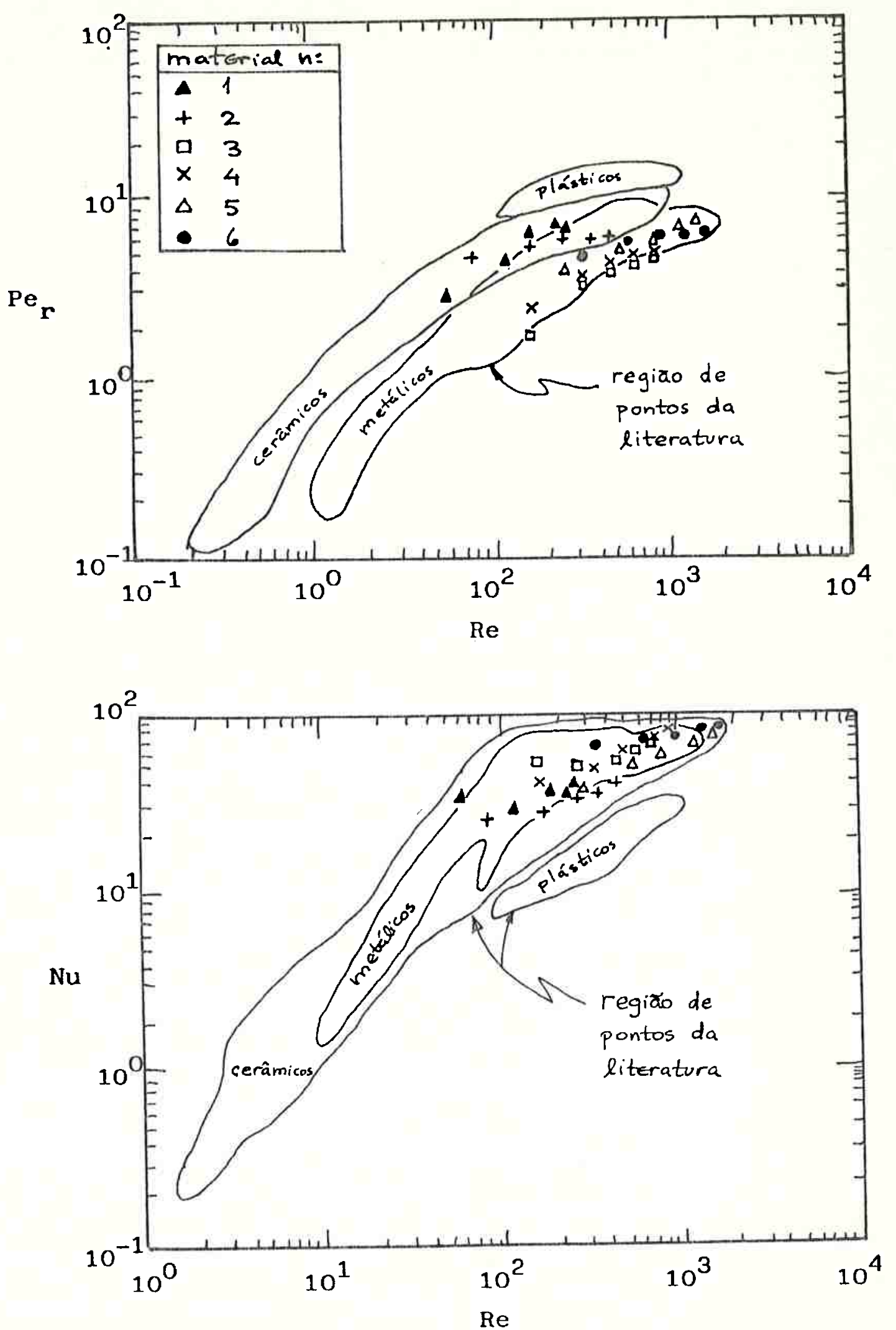

Figura 3.10. Comparação dos resultados de $\mathrm{Pe}_{\mathrm{r}} \mathrm{e} \mathrm{Nu}$ obtidos neste trabalho com a região de pontos experimentais da 1 iteratura (extraido de Gunn et alii, 1987). 


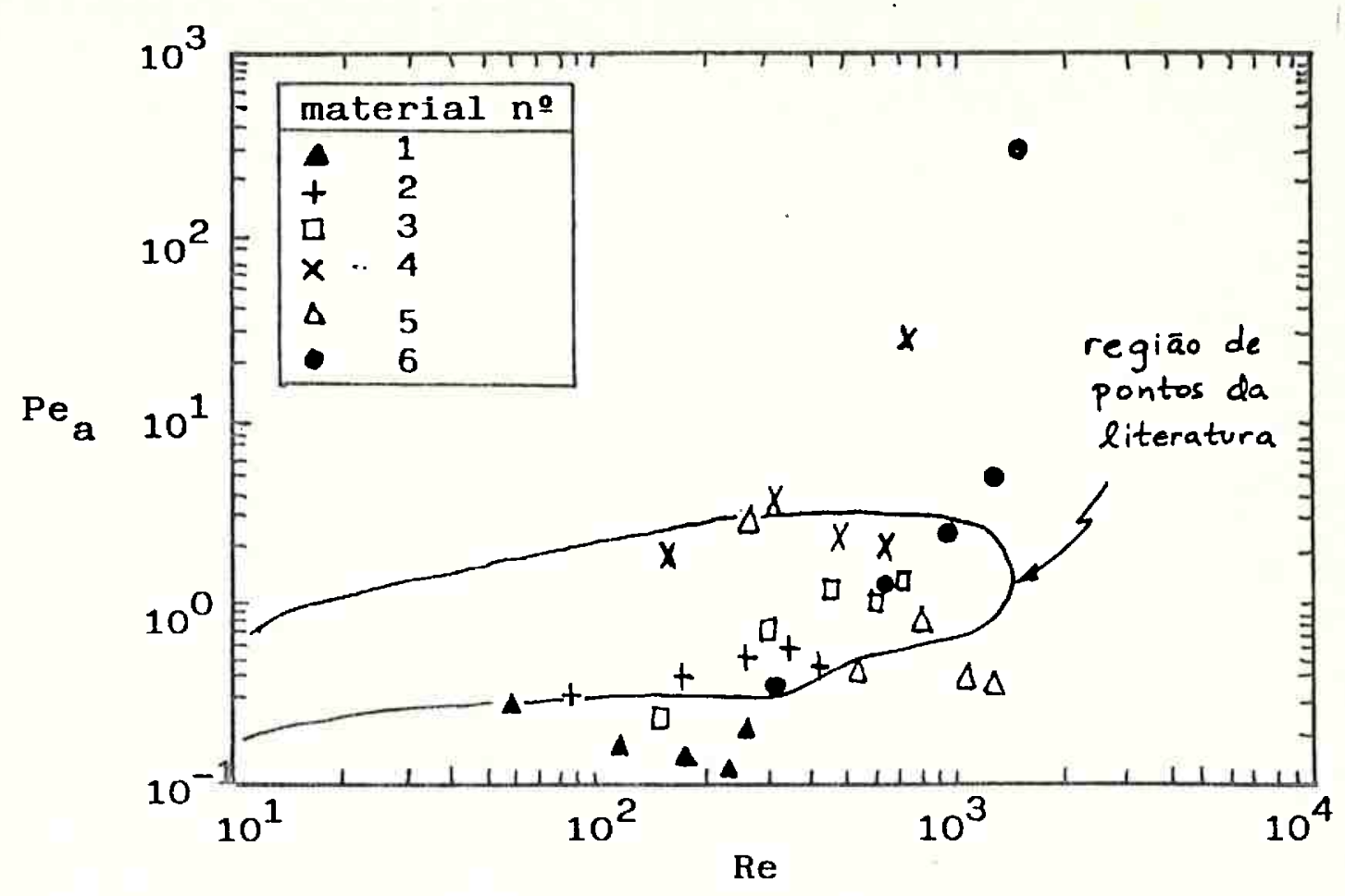

Figura 3.11. Comparação dos resultados de $\mathrm{Pe}_{\mathrm{a}}$ obtidos neste trabalho com a região de pontos da literatura (extraído de Dixon \& Cresswe11, 1979).

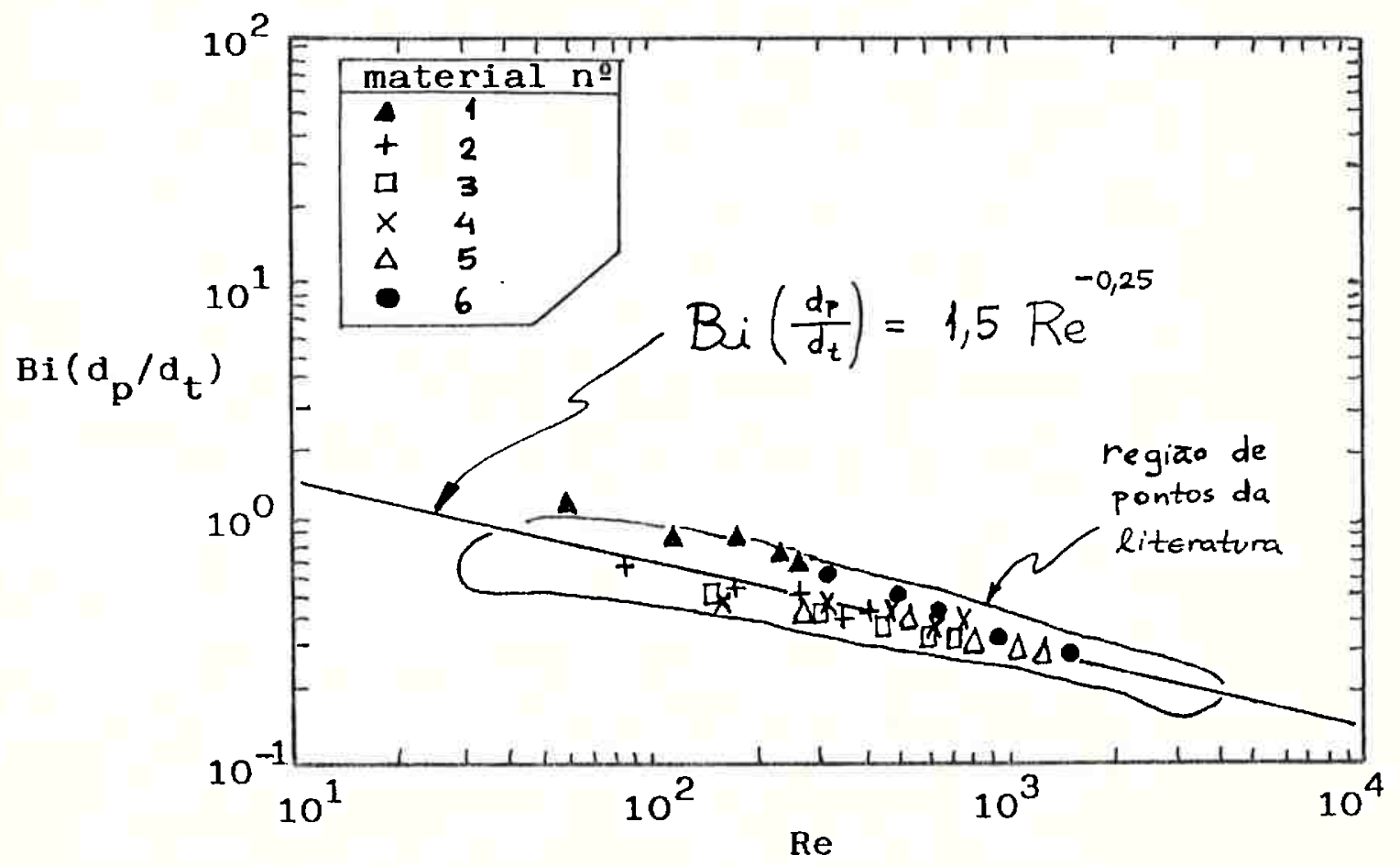

Figura 3.12. Comparação dos resultados de Bi obtidos neste trabalho com a regiaão de pontos da literatura e com a correlação de Dixon \& Cresswell (1979), equação (3.10). 
Para o número de Biot, a figura 3.13(a) mostra uma clara dependência do tamanho da particula e praticamente não há dependência da condutividade do material. Uma correlação dos dados de todos os materiais estudados neste trabalho levou à correlacão empirica:

$$
B i=2,18 \quad\left(d_{p} / d_{t}\right)-2-13 \quad R e^{-0.3 x}
$$

cowo ilustra a figura $3.12(b)=0$ expoente do grupo (dp/dt) concorda razoavelmente com o da correlaçäo proposta por Dixon $\&$ Cresswel1 (1979):

$$
B i=1,5\left(d_{1} / d_{t}\right)^{-1} \quad R^{-\infty .203}
$$

Esta equacão também representa de modo aceitável os dadas obtidos neste trabaliho, como ilustra a figura 3.12.

Em conformidade com a literatura CGunn \& Khalid,1975; Dixon et al1i,f1978; Dixon,1985b) foi observado que o coeficiente de dispersão axial é mal ajustado neste tipo de experimento, sendo a minimizacão pouco sensivel a este parâmetro. Este fato pode ser explicado a partir do estudo de sensibilidade paramétrica do modelo utilizado no tratamento de dados, como mostrado adiante. os resultados para o número de Peclet axial, mostrados na figura 3.11, apresentam grande dispersão, ficando a maior parte dos pontos na região entre 0,1 e 3,0 , em concordância com a faixa de resultados da 1 iteratura.

Os valores do coeficiente global de transferéncia de calor do modelo unidimensional obtidos por

$$
1 / U=1 / h_{-}+R_{W} /\left(4 k_{-}\right)
$$

säo mostrados na figura 3.14 para os diversos materiais e vazöes ensaiados. Os resultados na figura $3.14(a)$ mostram uma rélacáo linear entre $U$ e a densidade de fluxo mássico $G:$ 

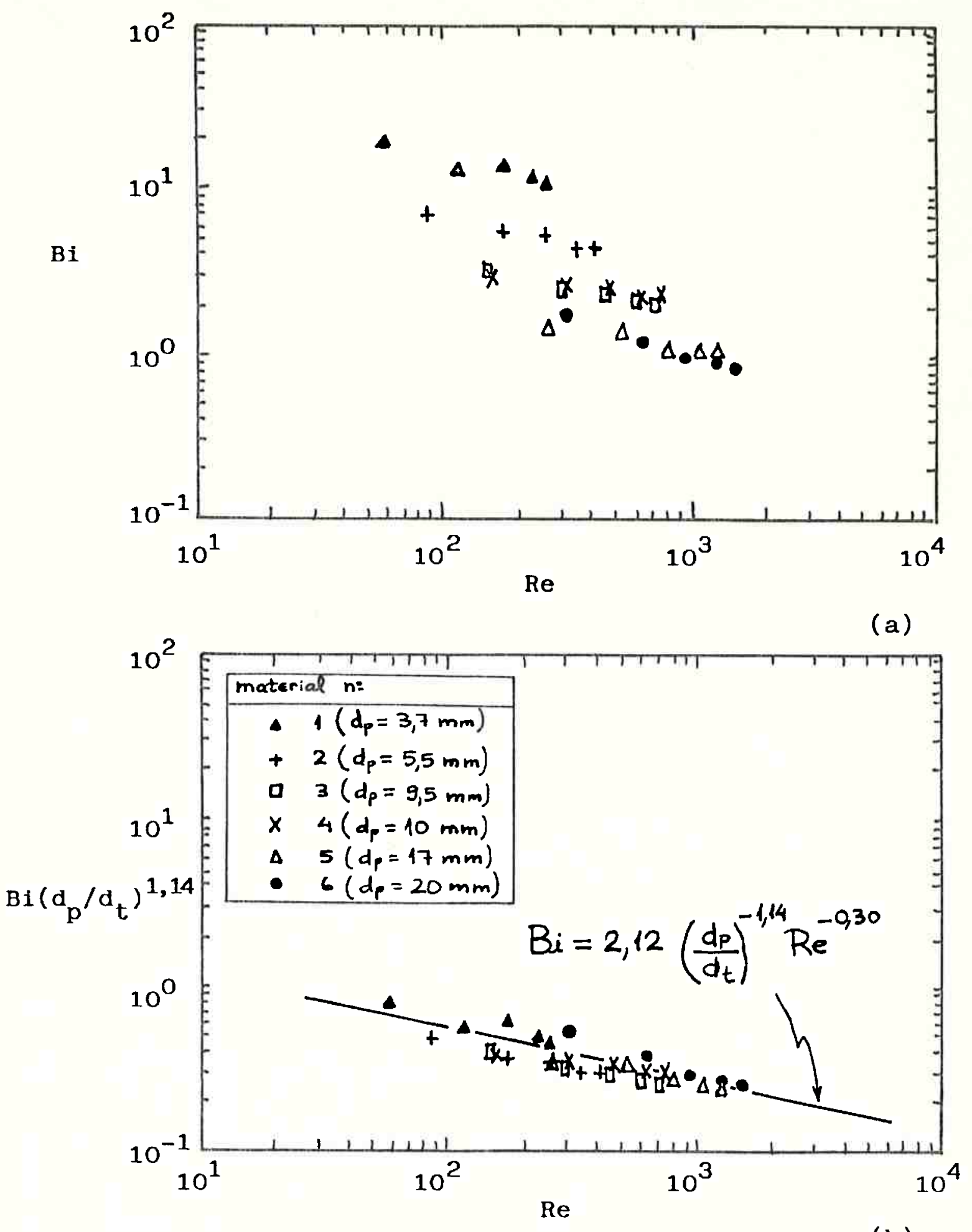

(b)

Figura 3.13. Resultados relativos ao número de Biot: (a) Bi versus Re para os diversos materiais; (b) visualização da correlação obtida, equação (3.9) . 


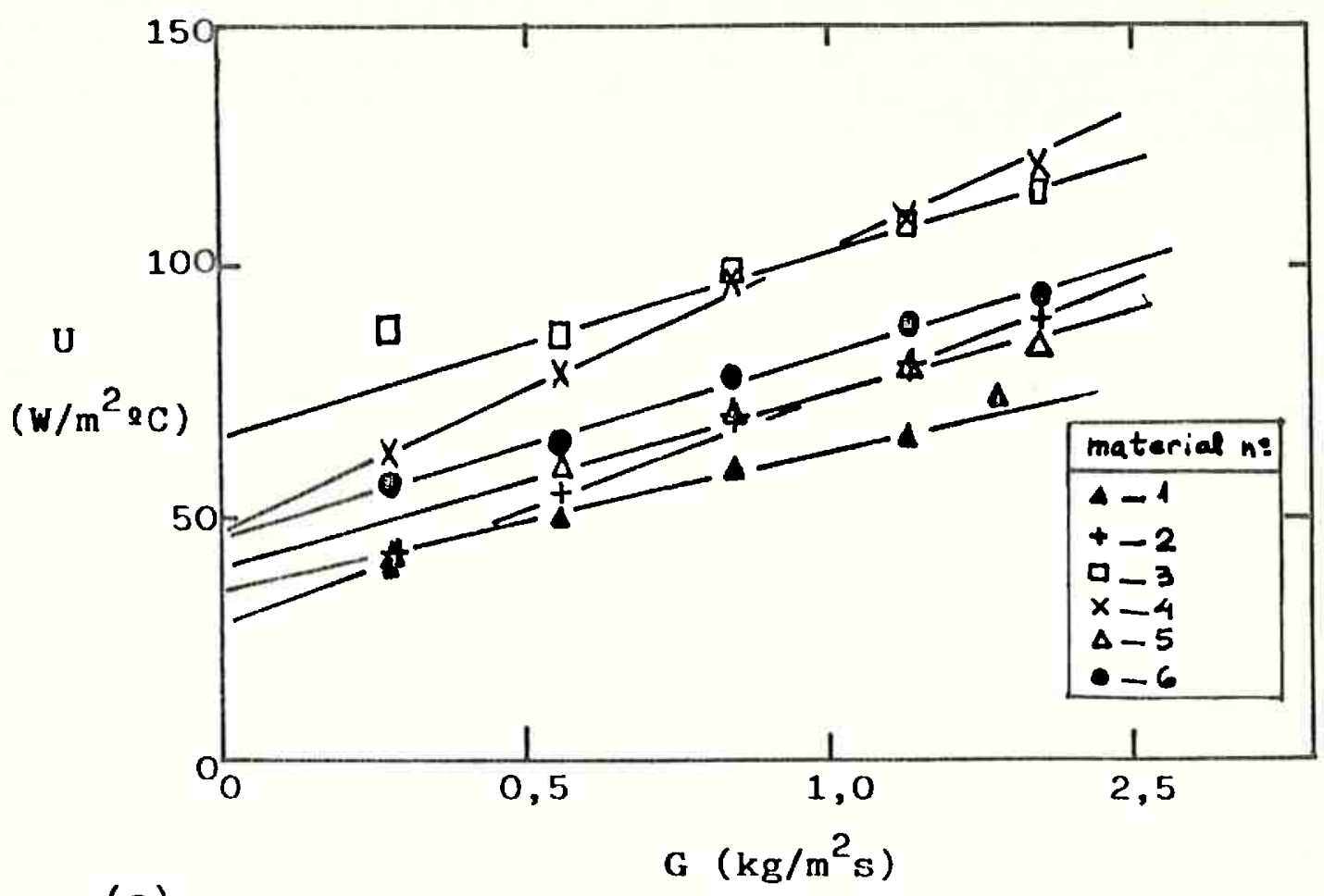

(a)

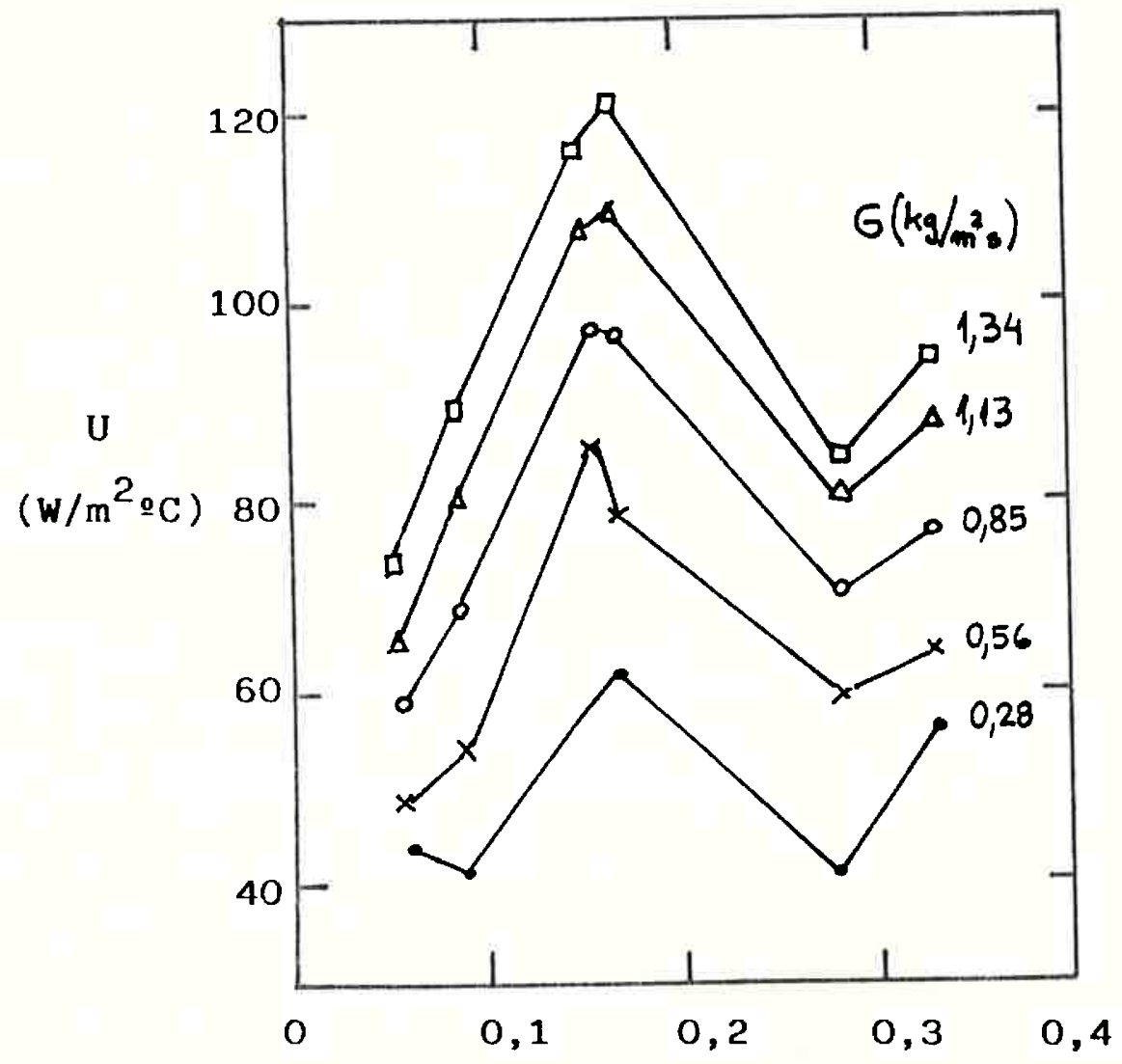

(b)

$d_{p} / d_{t}$

Figura 3.14. Resultados relativos ao coeficiente global de transferência de calor $U:$ (a) influência da vazão de gás; (b) influência do tamanho da partícula. 


$$
\mathbf{U}=U_{\boldsymbol{A}}+\mathbf{U}_{\mathbf{a}-\mathbf{G}}
$$

como também fora observado por Dixon (1988). Na Tabela 3.5 são apresentados os parâmetros $U_{A} e$ Ua para os seis materiais (foi utilizado G no lugar de Re para retirar a influência do diâmetro da particula que aparece em Re).

\begin{tabular}{|c|c|c|c|}
\hline \multicolumn{4}{|c|}{$\mathbf{u}=\mathbf{u}_{\boldsymbol{A}}+\mathbf{u}_{\mathbf{E}-\mathbf{G}}$} \\
\hline $\begin{array}{c}\text { material } \\
n^{\circ}\end{array}$ & $d_{p} / d_{t}$ & $\underset{\left(W / m^{2}-K\right)}{U_{A}}$ & $\frac{U_{0}}{(J / k g-K)}$ \\
\hline 1 & 0.062 & 35 & 28 \\
\hline 2 & 0.092 & 29 & 45 \\
\hline $\mathbf{3}$ & 0,158 & 65 & 38 \\
\hline 4 & 0.167 & 47 & 57 \\
\hline 5 & 0,283 & 42 & 33 \\
\hline 6 & 0,333 & 45 & 37 \\
\hline
\end{tabular}

Foi observado que o máximo valor de $U$ cáxima transferência de calor) ocorre para $d_{p} / d_{e}$ ao redor de 0,15 . conforme ilustra a figura $3.14(b)$. Este resultado está en concordancia com aqueles obtidos por Leva (1953), Ziolkowski \& Legawiec (1987) e Chalbi et a11 i. (1987).

\subsection{Estimaã̃o de parámetros usando outros modelos}

Além do modelo bidimensional pseudohomogêneo com dispersão axial representado pela equacăo (3.3), foram realizados testes com outras variantes deste modelo cisto é considerando autras candicões de contorno) e com o modelo sem dispersão axial. Estes testes foram realizados para verificar se algum outro modelo representaria melhor os dados experimentais. 
Os seguintes modelos foram testados:

(I) 0 modelo bidimensional pseudohomogêneo com dispersão axial com condicöes de contorno no infinito, descrito no item 3.5, representado matematicamente pela equacão (3.1) com condicôes de contorno (3.2.a) a (3.2.e), cuja solucäo é representada pela equacão (3.3). Este modelo foi usado para estimar os parâmetros térmicos cujos resultados foram apresentados no item 3.6.

(II) Idem ao madelo (I), porém com condicão de contorno finita correspondente à saida do leito, onde se substituiu a condifão (3.2.d) por outra do tipo:

$$
z=L \quad(\partial T / \partial z)=0
$$

ou seja, considera-se um escoamento sem dispersão axial no espaco acima do leito. Sob esta condicão, a solucão da equacão diferencial (3.1) se apresenta na forma (Dixon et alii, 1978):

$$
\begin{aligned}
\frac{T-T_{0}}{T w-T_{0}}= & 1-\sum_{j=1}^{\infty} \frac{B i}{B i z+\beta J} \frac{J_{0}(\beta J r / R)}{J_{0}(\beta J)} \frac{1-M_{J}}{M_{J}} \operatorname{cexp}\left[\frac{z\left(1-M_{J}\right) P E_{-}}{2 d_{D}}\right]+ \\
& \left.+\frac{M_{J}+1}{M_{J}-1} \exp \left[\frac{\left(1-M_{J}\right) P E_{m}}{2 d_{P}}\left[M_{J}(2 L-z)-z\right]\right]\right)
\end{aligned}
$$

(III) Un terceiro modelo que foi testado frente aos pontos experimentais foi baseado no proposto por olbrich \& Potter (1972), Em que se considera como condicão de contorno na saida do leito a condicão (3.13) e adicionalmente se substitui a condicão na entrada do leito por uma do tipo:

$$
z=0\left(T-T_{0.0}\right) /\left(T_{w}-T_{0.0}\right)=k '\left[1-J_{0}(2,4648 \mathrm{r} / R)\right]
$$

ou seja, supõe-se um perfil radial de temperatura em $z=0$ com a forma dada pela equacão (3.15). O parâmetrok'representa o grau 
de näo-uniformidade do perfil radial de temperatura em $z=0$ e $T_{0,0}$ é a temperatura em $z=0$ e $r=0$. Com essa condicão, a solucão fica:

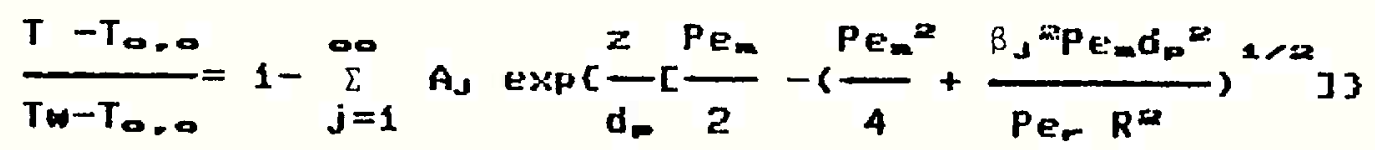

onde

$$
A_{J}=\frac{2\left[B i\left(1-k^{\prime}\right)+n J_{x}(n) k^{\prime} \beta_{J} 2 /\left(n^{2}-\beta, 2\right)\right]}{\left(\beta_{J}^{2}+B i\right) J_{0}(n)}
$$

sendo $n=2,4648$. Olbrich \& Potter (1972) usaram esta equaç̃o para tratar seus dados, porém estimando apenas Per $e k$, e fixando valores para Pem e Bi. Neste trabalho preferiu-se fixar $\mathrm{Pe}_{\mathbf{m}}=2$, como sugerido por olbrich \& Patter (1972), e foram estimados os parâmetros $k$ ', Per e Bi. Entretanto, como o valor experimental de To.o näo estava disponivel para todos os materiais (as medidas em $z=0$ foram feitas apenas com o material $n^{\circ} s$ ) foi utilizado como uma aproximafão $T_{0.0}=T_{0}$, ou seja, a temperatura de entrada no leito.

(IV) 0 modelo sem dispersão axial pode ser obtido como caso limite da equacão (3.3) para $\mathrm{PE}_{m} \rightarrow \infty$, obtendo-se:

$$
\frac{T-T_{0}}{T w-T_{0}}=1-2 \sum_{j=1}^{\infty} \frac{B i}{B i z+\beta_{J} z} \frac{J_{0}\left(\beta_{J} r / R\right)}{J_{0}\left(\beta_{J}\right)} \exp \left[\frac{-\beta_{j}=d_{r} z}{P E_{r} R^{2}}\right]
$$

A Tabela 3.6 mostra os quatro modelos apresentados que foram empregados para estimar os parâmetros térmicos.

A partir da distribuicäo radial de temperatura na saída do leito, das temperaturas da parede Twe do ar na entrada do leito $T_{0}$, os parámetros de todos os quatro modelos apresentados foram ajustados pelo critério dos mínimos quadrados, equaçăo (3-6), usando o método de Marquardt (1963). 
Tabela 3.6. Modelos utilizados para o tratamento de dados.

\begin{tabular}{|c|c|c|c|}
\hline mode 10 & caracteristicas & equação & $\begin{array}{l}\text { parâmetros } \\
\text { ajustáveis }\end{array}$ \\
\hline $\mathbf{I}$ & $\begin{array}{l}\text { com dispersão axial e } \\
\text { cond. de cont. infinito (3.2) }\end{array}$ & $(3.3)$ & $\mathrm{Bi}, \mathrm{Pe}, \mathrm{Pe}_{-}$ \\
\hline I I & $\begin{array}{l}\text { com dispersão axial e } \\
\text { cond. de cont. finita }(3.13)\end{array}$ & $(3.14)$ & $\mathrm{Bi}, \mathrm{Pe}_{\mathrm{r}}, \mathrm{Pe}_{\mathrm{m}}$ \\
\hline III & $\begin{array}{l}\text { com dispersäo axial e } \\
\text { cond. cont com perfil radial } \\
\text { na entrada dado pela eq. (3.17) }\end{array}$ & $(3.16)$ & $B i, P_{r}, k$ \\
\hline rv & sen dispersão axial & $(3.18)$ & $B$ i e $P e_{-}$ \\
\hline
\end{tabular}

Os resultados obtidos com o modelo (I) - com dispersão axial e condifões de contorno no infinito - foram apresentados na Tabela 3.2 e discutidos no item 3.7 . Os resultados obtidos com os demais modelos são apresentados nas Tabelas 3.7 a 3.9.

Os valores do resíduo quadrático, calculados pela equacão (3.6), para trinta minimizaçós realizadas (cinco vazōes para cada um dos seis materiais, com dados de três alturas de leito ajustadas simultaneamente), para cada um dos modelos testados, eståo apresentados na Tabela 3.10 .

Observa-se que há apreciável flutuacáo de valores de 0 . decorrentes dos erros experimentais. Para comparar a qualidade do ajuste foi utilizado como critério o valor médio de $\phi$ para todas as minimizacōes de cada modelo. Observa-se que o modelo I foi o que apresentou menor residuo quadrático médio $(124,6)$ en relacão aos modelos II $(139,3)$, III $(128,3)$ e IV $(181,4)$.

o modelo IU, sem dispersão axial, foi o que apresentou maior desvio médio frente aos pontos experimentais. Como este modelo tem apenas dois parâmetros ajustáveis (Bi e Per) e os demais tem três parâmetros, um critério mais adequado de comparacão é a variancia do modelo frente aos pontos experimentais, dada por: 
Tabela 3.7. Resultados obtidos com o modelo II.

\begin{tabular}{|c|c|c|c|c|c|c|c|c|}
\hline $\mathrm{Re}$ & $\mathrm{Bi}$ & Per & $\mathrm{Pe}_{\mathbf{m}}$ & $\mathrm{Nu}$ & 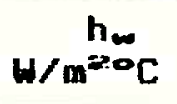 & 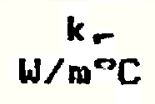 & $\underset{W / m^{2 m} \mathrm{C}}{U}$ & $\underset{\mathrm{kg} / \mathrm{m}^{2} \mathrm{~s}}{\mathrm{G}}$ \\
\hline \multicolumn{9}{|c|}{------- esferas de } \\
\hline $\begin{array}{r}314 \\
629 \\
943 \\
1258 \\
1493\end{array}$ & $\begin{array}{l}1,90 \\
1,59 \\
1,29 \\
1,29 \\
1,62\end{array}$ & $\begin{array}{l}1,52 \\
2,27 \\
3,13 \\
3,23 \\
5,92\end{array}$ & $\begin{array}{l}0,085 \\
0,066 \\
0,083 \\
0,052 \\
0,023\end{array}$ & $\begin{array}{l}182 \\
207 \\
182 \\
234 \\
120\end{array}$ & $\begin{array}{l}247 \\
279 \\
245 \\
316 \\
162\end{array}$ & $\begin{array}{l}3,90 \\
5,25 \\
5,69 \\
7,36 \\
4,76\end{array}$ & $\begin{array}{l}167 \\
199 \\
185 \\
239 \\
129\end{array}$ & $\begin{array}{l}0,28 \\
0,56 \\
0,85 \\
1,13 \\
1,34\end{array}$ \\
\hline \multicolumn{9}{|c|}{------ anéis cilindricos de alumina----- $d_{m}=17 \mathrm{~mm}--------$} \\
\hline $\begin{array}{r}267 \\
534 \\
802 \\
1069 \\
1269\end{array}$ & $\begin{array}{l}1,49 \\
1,62 \\
1,21 \\
1,25 \\
1,28\end{array}$ & $\begin{array}{l}3,56 \\
3,03 \\
4,25 \\
3,82 \\
3,72\end{array}$ & $\begin{array}{l}0,061 \\
0,092 \\
0,16 \\
0,074 \\
0,051\end{array}$ & $\begin{array}{r}44 \\
113 \\
90 \\
138 \\
172\end{array}$ & $\begin{array}{r}70 \\
173 \\
143 \\
220 \\
273\end{array}$ & $\begin{array}{l}1,42 \\
3,32 \\
3,56 \\
5,36 \\
6,44\end{array}$ & $\begin{array}{r}51 \\
127 \\
110 \\
168 \\
207\end{array}$ & $\begin{array}{l}0,28 \\
0,56 \\
0,85 \\
1,13 \\
1,34\end{array}$ \\
\hline \multicolumn{9}{|c|}{$-\cdots-$ pedras (areia) - } \\
\hline $\begin{array}{l}157 \\
314 \\
472 \\
629 \\
747\end{array}$ & $\begin{array}{l}2,94 \\
2,66 \\
2,52 \\
2,23 \\
2,31\end{array}$ & $\begin{array}{l}2,40 \\
4,63 \\
4,68 \\
5,14 \\
5,65\end{array}$ & $\begin{array}{c}0,87 \\
16 \\
3,8 \\
21 \\
196\end{array}$ & $\begin{array}{l}45 \\
48 \\
59 \\
64 \\
71\end{array}$ & $\begin{array}{l}121 \\
130 \\
160 \\
172 \\
192\end{array}$ & $\begin{array}{l}1,23 \\
1,47 \\
1,91 \\
2,31 \\
2,50\end{array}$ & $\begin{array}{r}119 \\
78 \\
98 \\
110 \\
122\end{array}$ & $\begin{array}{l}0,28 \\
0,56 \\
0,85 \\
1,13 \\
1,34\end{array}$ \\
\hline \multicolumn{9}{|c|}{ esferas de aco inox - } \\
\hline $\begin{array}{l}149 \\
299 \\
448 \\
597 \\
709\end{array}$ & $\begin{array}{l}--- \\
3,85 \\
2,74 \\
2,36 \\
2,22\end{array}$ & $\begin{array}{l}--- \\
1,39 \\
3,52 \\
4,28 \\
4,84\end{array}$ & $\begin{array}{l}0,041 \\
0,22 \\
0,30 \\
0,45\end{array}$ & $\begin{array}{r}-183 \\
77 \\
73 \\
72\end{array}$ & $\begin{array}{l}--- \\
521 \\
220 \\
207 \\
205\end{array}$ & $\begin{array}{l}--- \\
4,06 \\
2,41 \\
2,63 \\
2,77\end{array}$ & $\begin{array}{l}--1 \\
265 \\
131 \\
130 \\
132\end{array}$ & $\begin{array}{l}0,28 \\
0,56 \\
0,85 \\
1,13 \\
1,34\end{array}$ \\
\hline \multicolumn{9}{|c|}{ - cilindros de óxido de zinco - $-d_{p}=5,5 \mathrm{~mm}$} \\
\hline $\begin{array}{r}86 \\
173 \\
259 \\
346 \\
411\end{array}$ & $\begin{array}{c}11,9 \\
8,21 \\
7,69 \\
5,86 \\
5,84\end{array}$ & $\begin{array}{l}2,17 \\
3,94 \\
4,90 \\
5,32 \\
5,71\end{array}$ & $\begin{array}{l}0,052 \\
0,089 \\
0,019 \\
0.12 \\
0.13\end{array}$ & $\begin{array}{l}61 \\
46 \\
52 \\
49 \\
54\end{array}$ & $\begin{array}{l}298 \\
227 \\
256 \\
241 \\
265\end{array}$ & $\begin{array}{l}0,75 \\
0,83 \\
1,00 \\
1,23 \\
1,36\end{array}$ & $\begin{array}{r}75 \\
74 \\
88 \\
98 \\
106\end{array}$ & $\begin{array}{l}0,28 \\
0,56 \\
0,85 \\
1,13 \\
1,34\end{array}$ \\
\hline \multicolumn{9}{|c|}{----- esferas de silica-alumina - - - - $d_{p}=3,7 \mathrm{~mm}$} \\
\hline $\begin{array}{r}58 \\
116 \\
174 \\
231 \\
260\end{array}$ & $\begin{array}{l}29,9 \\
22,3 \\
25,8 \\
17,1 \\
14,4\end{array}$ & $\begin{array}{l}2,39 \\
3,80 \\
4,91 \\
5,77 \\
6,06\end{array}$ & $\begin{array}{l}0.12 \\
0.060 \\
0.053 \\
0.062 \\
0.094\end{array}$ & $\begin{array}{l}62 \\
58 \\
79 \\
59 \\
53\end{array}$ & $\begin{array}{l}458 \\
429 \\
576 \\
433 \\
389\end{array}$ & $\begin{array}{l}0,46 \\
0,58 \\
0,67 \\
0,76 \\
0,81\end{array}$ & $\begin{array}{l}54 \\
65 \\
77 \\
82 \\
85\end{array}$ & $\begin{array}{l}0,28 \\
0,56 \\
0,85 \\
1,13 \\
1,27\end{array}$ \\
\hline
\end{tabular}


Tabela 3.8. Resultados obtidos com modelo III.

\begin{tabular}{|c|c|c|c|c|c|c|c|c|}
\hline Re & $\mathrm{B} \mathrm{i}$ & $P e_{r}$ & $k^{\prime}$ & $\mathrm{Nu}$ & $h_{W / m^{2}} h_{C}$ & $k^{k} / m^{\circ} C$ & $\underset{W / m=0}{u}$ & $\underset{\mathrm{kg} / \mathrm{m}^{2} \mathrm{~s}}{\mathrm{G}}$ \\
\hline \multicolumn{9}{|c|}{ esferas de ferro - } \\
\hline $\begin{array}{r}314 \\
629 \\
943 \\
1258 \\
1493\end{array}$ & $\begin{array}{l}1,62 \\
1,24 \\
1,00 \\
0,95 \\
0,89\end{array}$ & $\begin{array}{l}5,46 \\
5,92 \\
6,01 \\
6,66 \\
6,91\end{array}$ & $\begin{array}{l}0.47 \\
0,14 \\
0.064 \\
0.028 \\
0.00001\end{array}$ & $\begin{array}{l}43 \\
62 \\
73 \\
84 \\
89\end{array}$ & $\begin{array}{r}59 \\
83 \\
99 \\
113 \\
121\end{array}$ & $\begin{array}{l}1,09 \\
2,01 \\
2,96 \\
3,57 \\
4,08\end{array}$ & $\begin{array}{l}42 \\
63 \\
79 \\
91 \\
99\end{array}$ & $\begin{array}{l}0,28 \\
0,56 \\
0,85 \\
1,13 \\
1,34\end{array}$ \\
\hline \multicolumn{9}{|c|}{ - anéis cilíndricos de alumina - - $d_{p}=17 \mathrm{~mm}-$} \\
\hline $\begin{array}{r}267 \\
534 \\
802 \\
1069 \\
1269\end{array}$ & $\begin{array}{l}1,48 \\
1,32 \\
1,08 \\
1,01 \\
0,97\end{array}$ & $\begin{array}{l}4,28 \\
6,61 \\
6,43 \\
7,82 \\
8,43\end{array}$ & $\begin{array}{l}0,091 \\
0,31 \\
0,16 \\
0,26 \\
0,25\end{array}$ & $\begin{array}{l}37 \\
42 \\
53 \\
55 \\
58\end{array}$ & $\begin{array}{l}58 \\
67 \\
85 \\
87 \\
92\end{array}$ & $\begin{array}{l}1,18 \\
1,52 \\
2,36 \\
2,58 \\
2,85\end{array}$ & $\begin{array}{l}42 \\
50 \\
67 \\
69 \\
74\end{array}$ & $\begin{array}{l}0,28 \\
0,56 \\
0,85 \\
1,13 \\
1,34\end{array}$ \\
\hline \multicolumn{9}{|c|}{ pedras (areia) - } \\
\hline $\begin{array}{l}157 \\
314 \\
472 \\
629 \\
747\end{array}$ & $\begin{array}{l}2,91 \\
2,69 \\
2,55 \\
2,28 \\
2,36\end{array}$ & $\begin{array}{l}2,69 \\
4,01 \\
4,86 \\
5,28 \\
5,58\end{array}$ & $\begin{array}{l}0,12 \\
0,049 \\
0,070 \\
0,066 \\
0,00001\end{array}$ & $\begin{array}{l}40 \\
49 \\
58 \\
63 \\
73\end{array}$ & $\begin{array}{l}107 \\
133 \\
158 \\
171 \\
200\end{array}$ & $\begin{array}{l}1,11 \\
1,48 \\
1,86 \\
2,25 \\
2,53\end{array}$ & $\begin{array}{r}62 \\
79 \\
97 \\
109 \\
126\end{array}$ & $\begin{array}{l}0,28 \\
0,56 \\
0,85 \\
1,13 \\
1,34\end{array}$ \\
\hline \multicolumn{9}{|c|}{ esferas de ato inox - } \\
\hline $\begin{array}{l}149 \\
299 \\
448 \\
597 \\
709\end{array}$ & $\begin{array}{l}2,73 \\
2,46 \\
2,28 \\
2,06 \\
2,02\end{array}$ & $\begin{array}{l}2,47 \\
3,55 \\
4,18 \\
4,79 \\
5,16\end{array}$ & $\begin{array}{l}0,52 \\
0,18 \\
0,078 \\
0,032 \\
0,057\end{array}$ & $\begin{array}{l}37 \\
46 \\
54 \\
57 \\
62\end{array}$ & $\begin{array}{l}104 \\
131 \\
154 \\
162 \\
175\end{array}$ & $\begin{array}{l}1,14 \\
1,59 \\
2,03 \\
2,36 \\
2,60\end{array}$ & $\begin{array}{r}62 \\
81 \\
98 \\
107 \\
116\end{array}$ & $\begin{array}{l}0,28 \\
0,56 \\
0,85 \\
1,13 \\
1,34\end{array}$ \\
\hline \multicolumn{9}{|c|}{ - cilindros de óxido de zinco ----- $d_{p}=5,5 \mathrm{~mm}$} \\
\hline $\begin{array}{r}86 \\
173 \\
259 \\
346 \\
411\end{array}$ & $\begin{array}{l}6,33 \\
5,12 \\
5,05 \\
4,13 \\
4,19\end{array}$ & $\begin{array}{l}3,58 \\
4,72 \\
5,24 \\
5,45 \\
5,79\end{array}$ & $\begin{array}{l}0,23 \\
0,13 \\
0,049 \\
0,031 \\
0,033\end{array}$ & $\begin{array}{l}20 \\
24 \\
32 \\
34 \\
38\end{array}$ & $\begin{array}{r}96 \\
119 \\
157 \\
165 \\
187\end{array}$ & $\begin{array}{l}0,45 \\
0,69 \\
0,93 \\
1,20 \\
1,34\end{array}$ & $\begin{array}{l}37 \\
52 \\
69 \\
81 \\
91\end{array}$ & $\begin{array}{l}0,28 \\
0,56 \\
0,85 \\
1,13 \\
1,34\end{array}$ \\
\hline \multicolumn{9}{|c|}{ - } \\
\hline $\begin{array}{r}58 \\
116 \\
174 \\
231 \\
260\end{array}$ & $\begin{array}{c}14,5 \\
9,91 \\
10,4 \\
8,71 \\
9,05\end{array}$ & $\begin{array}{l}2,98 \\
4,78 \\
5,96 \\
6,74 \\
6,57\end{array}$ & $\begin{array}{l}0,31 \\
0,26 \\
0,22 \\
0,20 \\
0,12\end{array}$ & $\begin{array}{l}24 \\
21 \\
26 \\
26 \\
31\end{array}$ & $\begin{array}{l}178 \\
152 \\
190 \\
188 \\
225\end{array}$ & $\begin{array}{l}0,37 \\
0,46 \\
0,55 \\
0,65 \\
0,75\end{array}$ & $\begin{array}{l}39 \\
44 \\
53 \\
59 \\
69\end{array}$ & $\begin{array}{l}0,28 \\
0,56 \\
0,85 \\
1,13 \\
1,27\end{array}$ \\
\hline
\end{tabular}


Tabela 3.9. Resultados obtidos com modelo sem dispersäo axial, modelo IV.

\begin{tabular}{|c|c|c|c|c|c|c|c|}
\hline $\mathbf{R e}$ & $\mathrm{B} \mathrm{i}$ & Per & $\mathrm{Nu}$ & $\stackrel{h}{h+m}$ & $\mathrm{k}_{\mathrm{m}}^{\mathrm{O}} \mathrm{C}$ & $\stackrel{U}{H / m^{20}}$ & $\mathrm{~kg} / \mathrm{m}^{22} \mathrm{~s}$ \\
\hline \multicolumn{8}{|c|}{--D--- esferas de } \\
\hline $\begin{array}{r}314 \\
629 \\
943 \\
1258 \\
1493 \\
\end{array}$ & $\begin{array}{l}1,45 \\
1,16 \\
0.95 \\
0,91 \\
0.86\end{array}$ & $\begin{array}{l}4,39 \\
5,60 \\
5,86 \\
6,63 \\
7,04\end{array}$ & $\begin{array}{l}48 \\
61 \\
71 \\
80 \\
85\end{array}$ & $\begin{array}{r}65 \\
82 \\
96 \\
109 \\
115\end{array}$ & $\begin{array}{l}1,35 \\
2,12 \\
3,04 \\
3,59 \\
4,01\end{array}$ & $\begin{array}{l}48 \\
64 \\
78 \\
88 \\
95\end{array}$ & $\begin{array}{l}0,28 \\
0,56 \\
0,85 \\
1,13 \\
1,34\end{array}$ \\
\hline \multicolumn{8}{|c|}{ - anéis cilindricos de alumina - - - $\mathrm{d}_{\mathbb{P}}=17 \mathrm{~mm}-$} \\
\hline $\begin{array}{r}267 \\
534 \\
802 \\
1069 \\
1269\end{array}$ & $\begin{array}{l}1,44 \\
1,20 \\
1,01 \\
0,92 \\
0,87\end{array}$ & $\begin{array}{l}4,33 \\
5,35 \\
5,71 \\
6,17 \\
6,56 \\
\end{array}$ & $\begin{array}{l}35 \\
47 \\
56 \\
63 \\
67 \\
\end{array}$ & $\begin{array}{r}56 \\
75 \\
89 \\
100 \\
107\end{array}$ & $\begin{array}{l}1,17 \\
1,89 \\
2,65 \\
3,27 \\
3,66 \\
\end{array}$ & $\begin{array}{l}41 \\
58 \\
71 \\
81 \\
88\end{array}$ & $\begin{array}{l}0,28 \\
0,56 \\
0,85 \\
1,13 \\
1,34 \\
\end{array}$ \\
\hline \multicolumn{8}{|c|}{ - pedras (areia) - } \\
\hline $\begin{array}{l}157 \\
314 \\
472 \\
629 \\
747\end{array}$ & $\begin{array}{l}2,89 \\
2,66 \\
2,50 \\
2,22 \\
2,31 \\
\end{array}$ & $\begin{array}{l}2,73 \\
4,05 \\
4,73 \\
5,14 \\
5,64 \\
\end{array}$ & $\begin{array}{l}38 \\
48 \\
58 \\
63 \\
71\end{array}$ & $\begin{array}{l}105 \\
130 \\
157 \\
171 \\
192\end{array}$ & $\begin{array}{l}1,09 \\
1,47 \\
1,89 \\
2,31 \\
2,50 \\
\end{array}$ & $\begin{array}{r}61 \\
78 \\
97 \\
116 \\
122\end{array}$ & $\begin{array}{l}0,28 \\
0,56 \\
0,85 \\
1,13 \\
1,34 \\
\end{array}$ \\
\hline \multicolumn{8}{|c|}{ esferas de aco inox - } \\
\hline $\begin{array}{l}149 \\
299 \\
448 \\
597 \\
709 \\
\end{array}$ & $\begin{array}{l}2,53 \\
2,29 \\
2,16 \\
1,95 \\
1,93 \\
\end{array}$ & $\begin{array}{l}2,01 \\
3,25 \\
4,01 \\
4,53 \\
4,94 \\
\end{array}$ & $\begin{array}{l}42 \\
47 \\
54 \\
57 \\
61 \\
\end{array}$ & $\begin{array}{l}118 \\
133 \\
152 \\
162 \\
174 \\
\end{array}$ & $\begin{array}{l}1,40 \\
1,74 \\
2,11 \\
2,49 \\
2,71\end{array}$ & $\begin{array}{r}72 \\
85 \\
99 \\
109 \\
117 \\
\end{array}$ & $\begin{array}{l}0,28 \\
0,56 \\
0,85 \\
1,13 \\
1,34\end{array}$ \\
\hline \multicolumn{8}{|c|}{ cilindros de óxido de zinco $\ldots-\cdots, d_{-}=5,5 \mathrm{~mm}$} \\
\hline $\begin{array}{r}86 \\
173 \\
259 \\
346 \\
411\end{array}$ & $\begin{array}{l}6,08 \\
4,89 \\
4,83 \\
3,98 \\
4,02 \\
\end{array}$ & $\begin{array}{l}3,22 \\
4,32 \\
5,03 \\
5,27 \\
5,58 \\
\end{array}$ & $\begin{array}{l}21 \\
25 \\
32 \\
34 \\
38\end{array}$ & $\begin{array}{l}102 \\
123 \\
157 \\
165 \\
186\end{array}$ & $\begin{array}{l}0,51 \\
0,75 \\
0,97 \\
1,21 \\
1,39\end{array}$ & $\begin{array}{l}41 \\
55 \\
71 \\
83 \\
93\end{array}$ & $\begin{array}{l}0,28 \\
0,56 \\
0,85 \\
1,13 \\
1,34 \\
\end{array}$ \\
\hline \multicolumn{8}{|c|}{ esferas de silica-alumina - } \\
\hline $\begin{array}{r}58 \\
116 \\
174 \\
231 \\
260\end{array}$ & $\begin{array}{r}15,6 \\
10,3 \\
10,5 \\
8,82 \\
8,98\end{array}$ & $\begin{array}{l}2,68 \\
4,18 \\
5,20 \\
5,84 \\
6,03\end{array}$ & $\begin{array}{l}29 \\
25 \\
30 \\
30 \\
33\end{array}$ & $\begin{array}{l}212 \\
180 \\
222 \\
220 \\
243\end{array}$ & $\begin{array}{l}0,41 \\
0,53 \\
0,63 \\
0,75 \\
0,82\end{array}$ & $\begin{array}{l}43 \\
51 \\
61 \\
69 \\
75\end{array}$ & $\begin{array}{l}0,28 \\
0,56 \\
0,85 \\
1,13 \\
1,27\end{array}$ \\
\hline
\end{tabular}


Tabela 3.10. Comparacão entre os residuos quadráticos dos modelos testados.

\begin{tabular}{|c|c|c|c|c|c|}
\hline \multirow[b]{2}{*}{$d p(\mathrm{~mm})$} & \multirow[b]{2}{*}{ Re } & \multicolumn{4}{|c|}{ valores de $\phi$ para os modelos } \\
\hline & & $\mathbf{I}$ & I I & III & $x y$ \\
\hline 20 & $\begin{array}{r}314 \\
629 \\
943 \\
1258 \\
1493\end{array}$ & $\begin{array}{r}29,3 \\
73,6 \\
70,4 \\
102,1 \\
101,3\end{array}$ & $\begin{array}{r}116,2 \\
71,5 \\
47,5 \\
74,0 \\
89,7\end{array}$ & $\begin{array}{r}33,6 \\
74,1 \\
69,7 \\
100,2 \\
89,5\end{array}$ & $\begin{array}{r}128.4 \\
96.1 \\
79.0 \\
105.2 \\
101.2\end{array}$ \\
\hline 17 & $\begin{array}{r}267 \\
534 \\
802 \\
1069 \\
1269\end{array}$ & $\begin{array}{r}83,1 \\
94,7 \\
79,1 \\
190,1 \\
197,0\end{array}$ & $\begin{array}{r}88,5 \\
227,5 \\
129,6 \\
340,5 \\
345,6\end{array}$ & $\begin{array}{r}83,3 \\
88,7 \\
77,9 \\
178,3 \\
183,3\end{array}$ & $\begin{array}{r}87.6 \\
254.7 \\
137.2 \\
361.2 \\
379.5\end{array}$ \\
\hline 10 & $\begin{array}{l}157 \\
3 \pm 4 \\
472 \\
629 \\
747\end{array}$ & $\begin{array}{r}31,3 \\
123,2 \\
152,5 \\
181,4 \\
125,0\end{array}$ & $\begin{array}{r}33,0 \\
124,4 \\
156,0 \\
185,6 \\
124,9\end{array}$ & $\begin{array}{r}31,3 \\
123,6 \\
152,6 \\
181,4 \\
126,9\end{array}$ & $\begin{array}{r}33,4 \\
124,4 \\
156,0 \\
185,7 \\
124,9\end{array}$ \\
\hline 9,5 & $\begin{array}{l}149 \\
299 \\
448 \\
597 \\
769\end{array}$ & $\begin{array}{l}17,7 \\
48,1 \\
75,0 \\
85,9 \\
55,5\end{array}$ & $\begin{array}{l}72,8 \\
46,1 \\
66,8 \\
88,6 \\
56,1\end{array}$ & $\begin{array}{l}21,8 \\
53,0 \\
76,3 \\
87,4 \\
55,9\end{array}$ & $\begin{array}{r}107.0 \\
102.5 \\
97.4 \\
107.9 \\
74.1\end{array}$ \\
\hline 5,5 & $\begin{array}{r}86 \\
173 \\
259 \\
346 \\
411\end{array}$ & $\begin{array}{r}91,0 \\
78,3 \\
131,9 \\
126,5 \\
103,2\end{array}$ & $\begin{array}{l}78,5 \\
43,7 \\
77.1 \\
76,5 \\
57,3\end{array}$ & $\begin{array}{r}164,5 \\
99,8 \\
146,6 \\
135,8 \\
112,8\end{array}$ & $\begin{array}{l}153.9 \\
143.6 \\
169.2 \\
154,9 \\
132.3\end{array}$ \\
\hline 3,7 & $\begin{array}{l}58 \\
116 \\
174 \\
231 \\
260\end{array}$ & $\begin{array}{l}395,6 \\
235,3 \\
177,0 \\
228,8 \\
237,0\end{array}$ & $\begin{array}{l}426,3 \\
269,4 \\
187,7 \\
253,5 \\
230,3\end{array}$ & $\begin{array}{l}386,2 \\
247,3 \\
211,6 \\
256,5 \\
254,6\end{array}$ & $\begin{array}{l}445.0 \\
376,9 \\
337,5 \\
304,8 \\
380.9\end{array}$ \\
\hline \multicolumn{2}{|l|}{$\sum \phi$} & 3720,9 & 4179,2 & 3848,0 & 5441.8 \\
\hline \multicolumn{2}{|l|}{$\bar{\phi}$} & 124,6 & 139,3 & 128,3 & 181,4 \\
\hline \multicolumn{2}{|c|}{$s^{2}=\bar{\phi} /(n-p)$} & 19,34 & 11,61 & 10.69 & 13,75 \\
\hline \multicolumn{2}{|l|}{$\mathbf{p}$} & 3 & 3 & 3 & 2 \\
\hline
\end{tabular}




$$
\mathbf{s}^{2}=\phi /(n-p)
$$

onde $p$ é o numero de parâmetros ajustáveis e n a numero de pontos experimentais usados no cálculo do residuo $\phi$. Mesmo usando este critério de comparacão, observa-se que a variância média do modelo sem dispersão IV $(13,95) \dot{e}$ maior que a dos modelos I $(10,34)$, II $(11,61)$ e III $(10,69)$.

\subsubsection{Comparacäo entre as modelos I e IU ccom e sem}

dispecsão axial

Uma discussão sobre a conveniência de se incluir o termo de dispersão axial no tratamento de dados pode ser feita a partir dos resultados obtidos.

Quando o ajuste foi feito para trés alturas de leito tratadas simulaneamente, foi observado ematicamente todos os casos que o resíduo para o modelo sem dispersão foi maior que o do modelo com o termo de dispersão, embora não se possa afirmar que o modelo com dispersäo seja estatisticamente superior ao sem dispersäo, frente aos erros experimentais.

No entanto, quando $5 e$ analisou os dados medidos ew $z=0$ (medidas feitas com o material $n^{*} 5$ ), rigorosamente o modelo sem dispersão axial näo pode ser considerado adequado. 0 modelo sem dispersão prevê $T=T_{0}$ em $z=0$, enquanto o modelo com dispersão prevé a existencia de um perfil radial de temperatura não plano nesta cota, sendo mais coerente com as observacôes experimentais mostradas na figura 3.4. A despeito da existência de imprecisóes nas medicões feitas em $z=0$, já discutidas previamente no item 3.6 , estas medidas mostram, ao menos qualitativamente, que o perfil de temperatura nesta cota nåo é plano, nem tampouco igual à temperatura de entrada do ar no leito Tor como previsto pelo modelo sem dispersäo axial. 


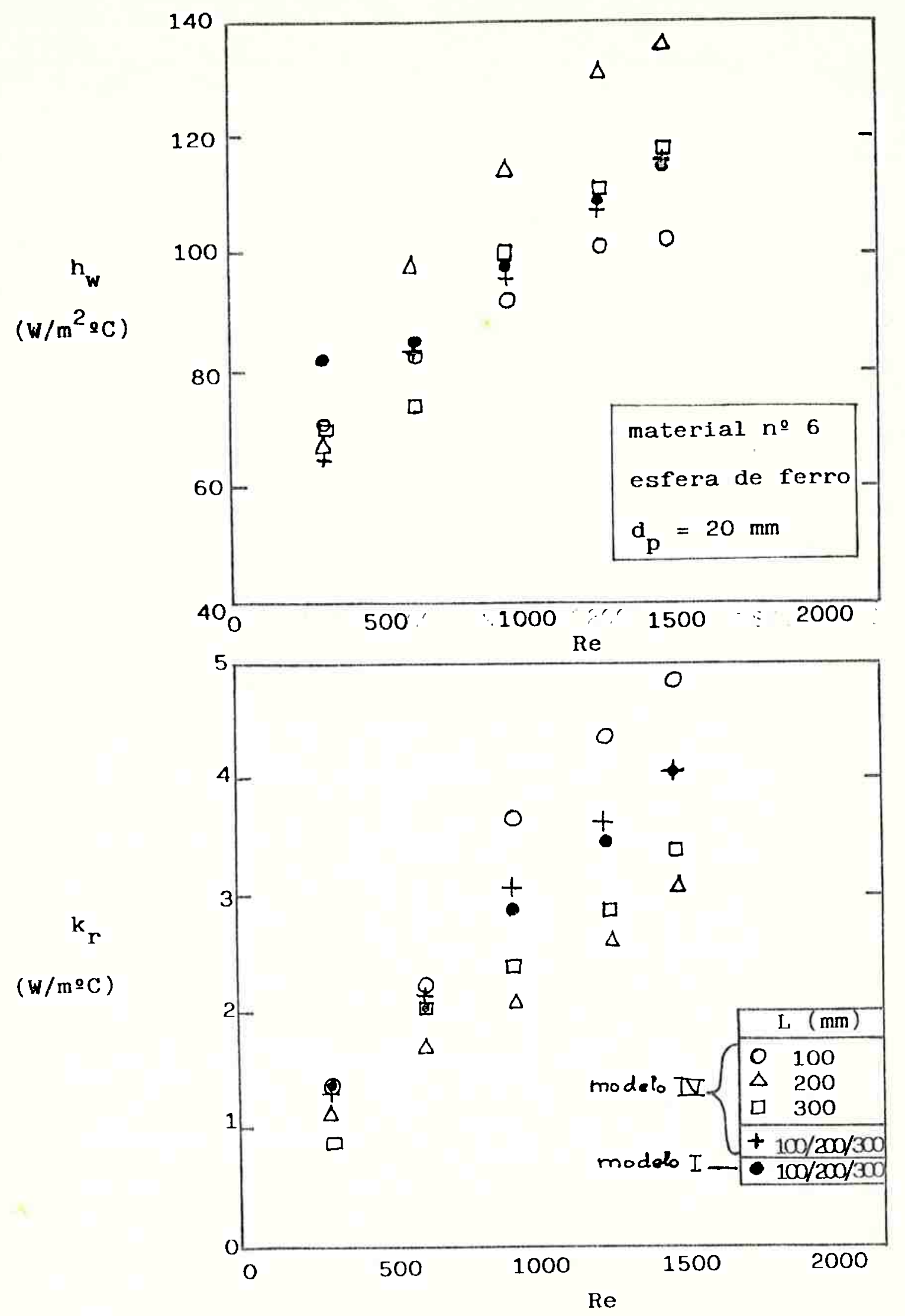

Figura 3.16. Comparação entre os resultados obtidos com o modelo com dispersão axial (modelo I) e com o modelo sem dispersão (modelo IV), para as três alturas de leito tratadas simultaneamente e individualmente. 
As diferencas entre os parâmetros radiais obtidos com os modelos (I) e (IU) não são excessivas, situando-se no máximo em 10x nos valores de Per e $20 x$ nos valores de Bi.

0 modelo sem dispersão foi empregado também para ajustar dados de alturas individuais. Alguns resultados são ilustrados nas figuras 3.15 e 3.16 . A dependência do comprimento de leito que poderia ser esperada ocorrer sobre os parâmetros do modelo (IU) quando ajustado a alturas individuais nem sempre foi claramente observada. Estes resultados säo similares aos de Dixon (1985b), que observou que a dependência do comprimento do leito é bem menos evidente quando se utiliza um suporte dos termopares feito em material de baixa condutividade térmica, como ucilizado no presente trabalho.

\subsubsection{Comparacäo entre as modelos I E II}

Ambos os modelos I e II incluem o termo de dispersão axial, e tem como parâmetros ajustáveis Bi. Per e Pemr diferindo nas condicões de contorno adotadas.

As diferengas entre os valores dos parâmetros obtidos com o modelo II (condicão de contorno finita) e aqueles ootidos com o modelo I (condicão de contorno no infinito) foram bem maiores que aquelas entre os modelos $I$ E $I$. Com o modelo II ocorreu, em alguns casos, dificuldade na minimização do residuo quadrático.

As diferencas de previsöes entre estes modelos é menor que entre I $E$ IV, como se pode ver pelo residuo quacirático médio ou pela variância. Novamente as maiores diferencas de previsôes entre as modelos ocorre $E m z=0$. O modelo II prevê $T(z=\theta)=T_{a}$, a que discorda das observacōes experimentais, e assim, frente a uma consideracão mais rigorosa, também pode ser considerado inadequado. 


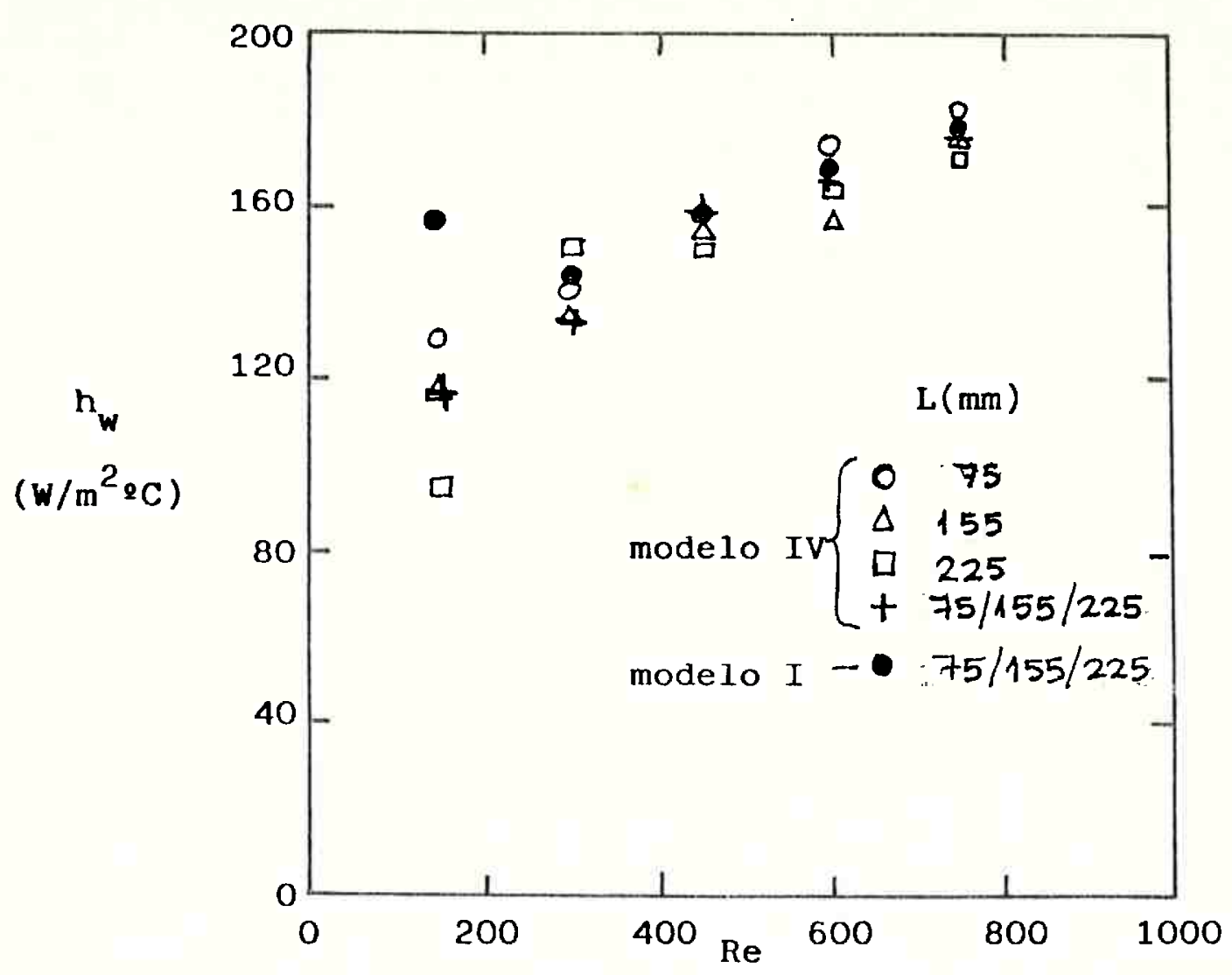

76

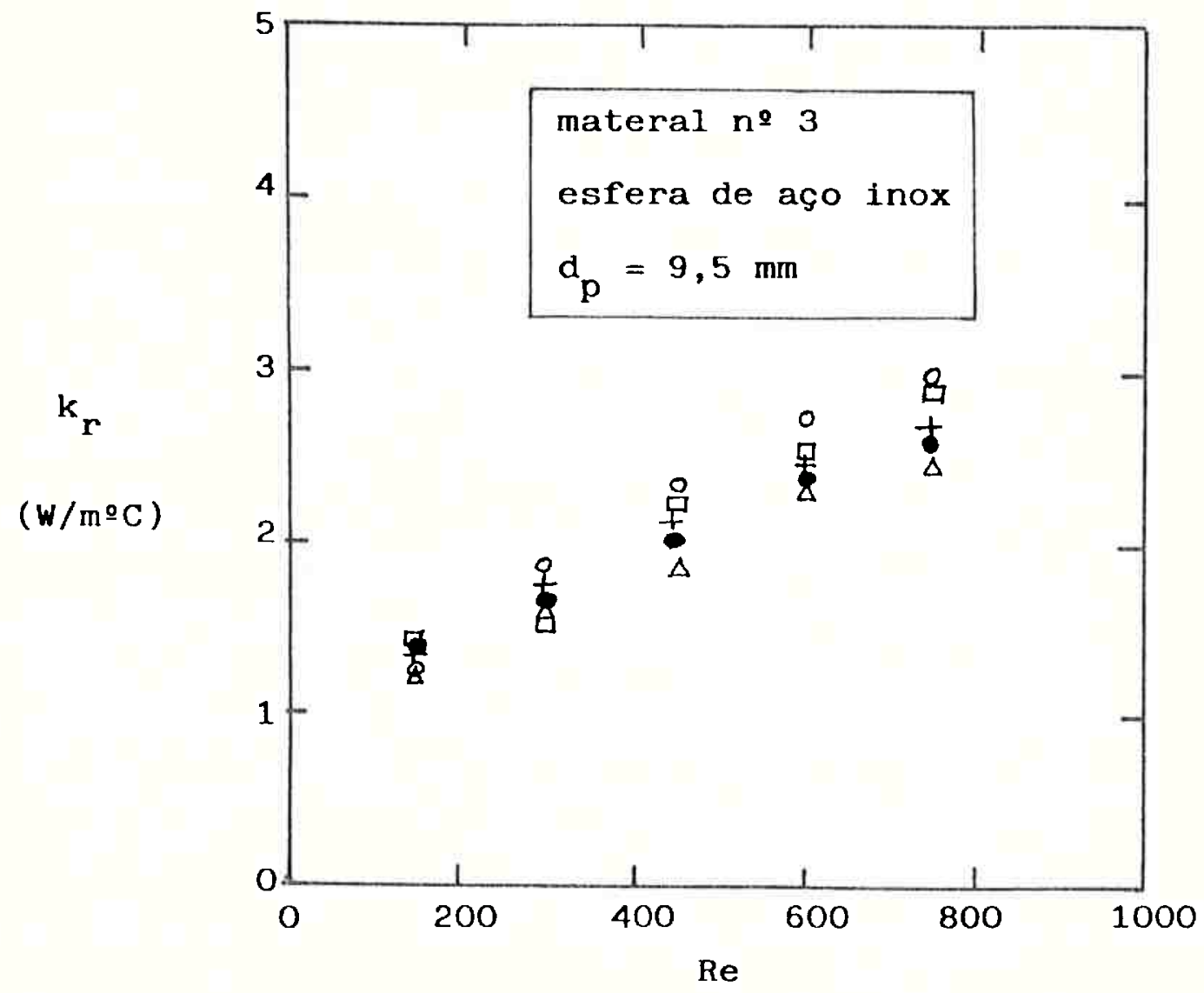

Figura 3.15. Comparação entre os resultados obtidos com o modelo com dispersão axial (modelo I) e com o modelo sem dispersão (modelo IV). para três alturas de leito tratadas simultaneamente e individualmente. 


\subsubsection{Compacacão entre os modelos I e III}

- modelo III considera o termo de dispersão axial mas, ao invés de ajustar Pem, este parâmetro teve seu valor fixado em 2,0 e os efeitos de contorno na entrada da seçäo téraica são representados no perfil radial nesta cota, dado pela equacão (3.17), sendo o parâmetro k'ajustável.

Este modelo fai o que melhor se aproximou das previsöes do modelo I, tendo praticamente o mesmo valor de variância média deste.

Mais uma vez, para uma discriminação mais segura entre os modelos, deve-se comparar os valores de previsôes em $z=0$, local de máxima divergência entre os modelos. Apesar dé prever a existência de un perfil radial de temperatura en $z=0$ as previsóes do modelo III para este perfil foram algo piores que as do modelo $I$, especialmente para baixos valores de Re, conforme ilustra a figura 3.17. No entanto, é preciso lembrar que o modelo II foi testado usando-se a aproximafão $T_{0}=0 T_{n}, 0$ que sabe-se não ser perfeitamente realista, conforme dados de silveira et alii (1989).

Dessa forma, o modelo III apresenta uma interessante alternativa para se evitar o ajuste de Pem a valores fisicamente irreais que pode ocorrer no modelo I. No modelo I o coeficiente de dispersão axial é muito mais um parâmetro de ajuste do que propriamente um parametro com um significado fisico bem definido, e seu ajuste parece servir para compensar certas diferencas entre - experimento e a formulacão do modelo. Este parâmecro de ajuste no modelo III é $k$ '. que expressa o grau de não uniformidade do perfil em $z=0$, o que pode ser ma is facilmente interpretado.

As maiores diferencas de previsăo entre o modelo III $e$ a realidade física parece estar na própria definicão da condicão de contorno (perfi1) em $z=0$, e parece ter sido decorrente da 

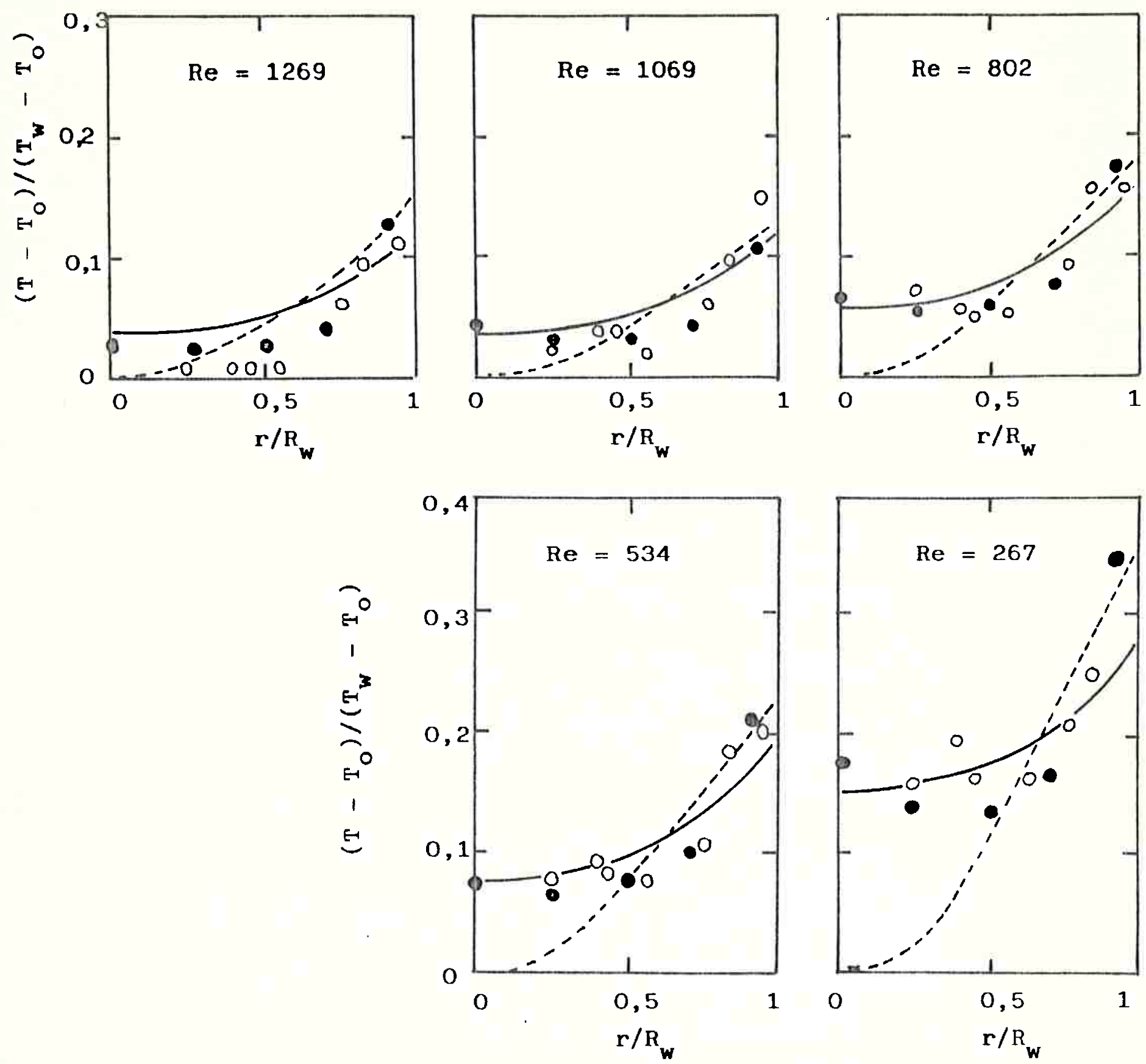

Fgura 3.17. Comparação dos perfis de temperatura em z=0 medidos ( sensor anelar, o média de seis medidas com sensor pontual) e calculados pelo modelo I ( - ) e pelo modelo III (-- ) Material $n=5$. 
aproximacão $T_{0.0}=T_{0}$ utilizada. Parece ser possivel melhorar este modelo com uma proposicão mais adequada do perfil radial em $z=0$, 0 que passa necessariamente por uma medicão experimental mais precisa deste perfil do que as técnicas atuais tem permitido.

\subsection{Estudo de Seasibilidade Paramétrica do modelo I}

Na estimacão de parâmetros de um modelo a partir de medidas experimentais é importante saber em que regiăo do dominio dos experimentos é mais conveniente localizar os sensores. Esta informaç̃o está relacionada com a sensibilidade paramétrica do modelo utilizado aos parâmetros que se deseja estimar.

Sklivaniotis et alii (1988) apresentaram um estudo de sensibilidade paramétrica do modelo bidimensional sem dispersão axial. Neste item apresenta-se uma extensão daquele estudo ao modelo com dispersão axial (modelo $I$ ), utilizado no presente trabalho.

Define-se sensibilidade de uma variável de estado a um parâmetro do sistema como sendo a mudanca do valor da variajel causada por uma pequena mudanca no valor do parámetro. Assim. sendo $Y_{I}$ a variável $I$ do vetor do estado $Y(I=1,2,3, \ldots N)$ E $b, 0$ parâmetro $J$ do sistema, a sensibilidade da variável $Y_{I}$ ao parâmetro bue

$$
S_{x=U}=\left(\partial Y_{x} / \partial b_{J}\right)
$$

Aplicando esta definicão ao problema de transferência de calor em leito fixo, a variável medida experimentalmente $\dot{E} a$ temperatura e os parámetros do modelo bidimensional pseudohomogêneo considerado sáo hm ccoeficiente de transferência de calor parede-leito), $k_{r}$ (condutividade térmica radial efetiva) e k. (condutividade térmica axial efetiva). Dessa forma pode-se definir très sensibilidades: 


$$
\begin{aligned}
& \mathbf{S}_{\infty}=\left(\partial T / \partial \mathrm{h}_{m}\right) \\
& \mathbf{S}_{\boldsymbol{r}}=\left(\partial T / \partial \mathrm{k}_{r}\right) \\
& \mathbf{S}_{m}=\left(\partial \mathrm{T} / \partial \mathrm{k}_{m}\right)
\end{aligned}
$$

A sensibilidade é uma informacão citil pois se for conhecida como varia ao longo do leito, pode-se locar os sensores de temperatura nas posicões onde a sensibilidade $\dot{e}$ maior, obtendo-se com isso, melhores estimativas dos parâmetros (melhores no sentido estatistico, istoé, os parâmetros seräo estimados com maior precisão, ou seja com menores intervalos de confianfa).

As sensibilidades $S_{m}$. $S_{r}$ Sm foram calculadas por fórmulas de aproximaçăo de diferença central=

$$
\frac{\partial T}{\partial b_{J}}=\frac{T\left(b_{1}, \ldots, b_{J}+h_{J}, \ldots, b_{m}\right)-T\left(b_{1}, \ldots, b_{J}-h_{J}, \ldots b_{m}\right)}{2 h_{J}}
$$

com $h_{\lrcorner}=10^{-3} b_{\lrcorner}$, e $T$ calculado pela equacäo (3.3). 0 mapeanento das sensibilidades foi feito calculando seus valores em diversos pontos ao longo da secão térmica. A região correspondente à secão térmica $\theta(z<L, \theta<r<R$ ) foi dividida em uma grade com 11 divisões axiais $e$ divisöes radiais, igualmente espafadas, 6 os valores de $S_{r} S_{m} e S_{m}$ foram calculados em cada ponto da grade.

0 cálculo foi feito para um reator com as dimensōes $L=0,3 \mathrm{~m}$ E $R=0,03 \mathrm{~m}$, adotando-se $T_{0}=25^{\circ} \mathrm{C}$ E $T_{\omega}=144^{\circ} \mathrm{C}$, e números de Reynolds iguais a 10,100 e 1000 . As dimensônes escolhidas correspondem basicamente àquelas do equipamento usado neste trabalho. Para se calcular as sensibilidades é preciso conhecer a prior i o valor dos parámetros. Para isso valores típicos de $k_{-}, h_{-}$ e K. foram estimados a partir de correlacôes da literatura CDixon \& Cresswe11, 1979, Gunn et a1ii, 1987), obrendo-se os valores mostrados na Tabela 3.11. 
Tabela 3.11. Valores dos parâmetros utilizados para o estudo de sensibilidade paramétrica.

\begin{tabular}{|rrrrrrrr|}
\hline Caso & $R e$ & $\begin{array}{c}h_{m} \\
\left(W / m^{2} K\right)\end{array}$ & $\begin{array}{c}k_{r} \\
(W / m K)\end{array}$ & $\begin{array}{c}k_{m} \\
(W / m K)\end{array}$ & $B i$ & $P E_{-}$ & $P e_{m}$ \\
\hline 1 & 10 & 197 & 0,394 & 1,05 & 15,0 & 0,8 & 0,3 \\
2 & 100 & 210 & 0,630 & 4,50 & 10,0 & 5,0 & 0,7 \\
3 & 1000 & 656 & 3,94 & 31,50 & 5,0 & 8,0 & 1,0 \\
\hline 4 & 10 & 39 & 0,394 & 1,05 & 3,0 & 0,8 & 0,3 \\
5 & 100 & 42 & 0,630 & 4,50 & 2,0 & 5,0 & 0,7 \\
6 & 1000 & 131 & 3,94 & 31,50 & 1,0 & 8,0 & 1,0 \\
\hline
\end{tabular}

\subsubsection{Resultados e discussão do estudo de sensibilidade}

0s mapas de sensibilidade paramétrica obtidos são mostrados nas figuras 3.18 a 3.23.

Observa-se, como esperado, que $S_{w} \in$ maior nat região mais próxima à parede, ou seja, quanto mais próximas da parede as medidas de temperatura melhores estimativas de hu sáo obtidas. Para Re menores 5 aumenta com $z$ e depois diminui à medida que $z$ aumenta; para $\operatorname{Re}=1000$ Sw cresce com $z$ até atingir valor máximo próximo a $z=L$. Curiosamente, nos casos 4,5 , 6 os valores de 5 . para Re=100 sâo significativamente maiores que para Re=10 $\mathrm{E}$ $\operatorname{Re}=1000$.

Quanto a 5 r seus valores säo maiores na região central do leito e menores nas proximidades da parede. A região de máximo $S_{r}$ ocorre perto de $z=6$ para Re=10, deslocando-se para $z$ maiores quando se aumenta Re. Observa-se que para numeros de Regnolds muito elevados $S_{r}$ é significativamente menor.

os valores de $S_{-}$ubservados foram muito pequenos em praticamente todo o domínio da sefăo térmica. Isto está de acordo com Gunn \& Khalid (1975), Dixon et alii (1978) e Dixon (1985b), que observaram ser o modelo muito pouco sensivel a $k=$, por consequência este parámetro é pobremente determinado neste tipo de 

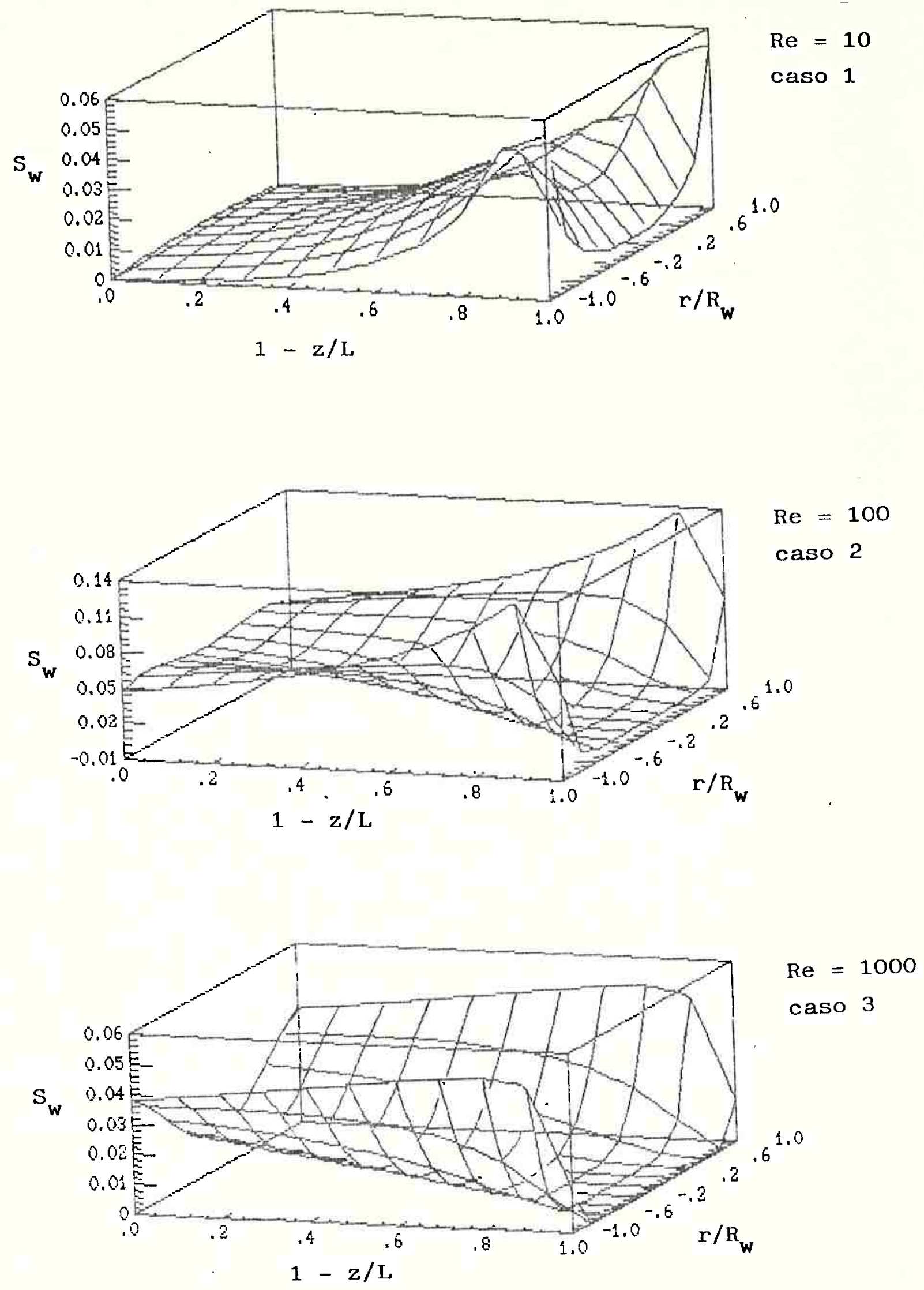

Figura 3.18. Superfícies de sensibilidade

a $h_{w^{*}}$ Casos 1,2 e 3 . 


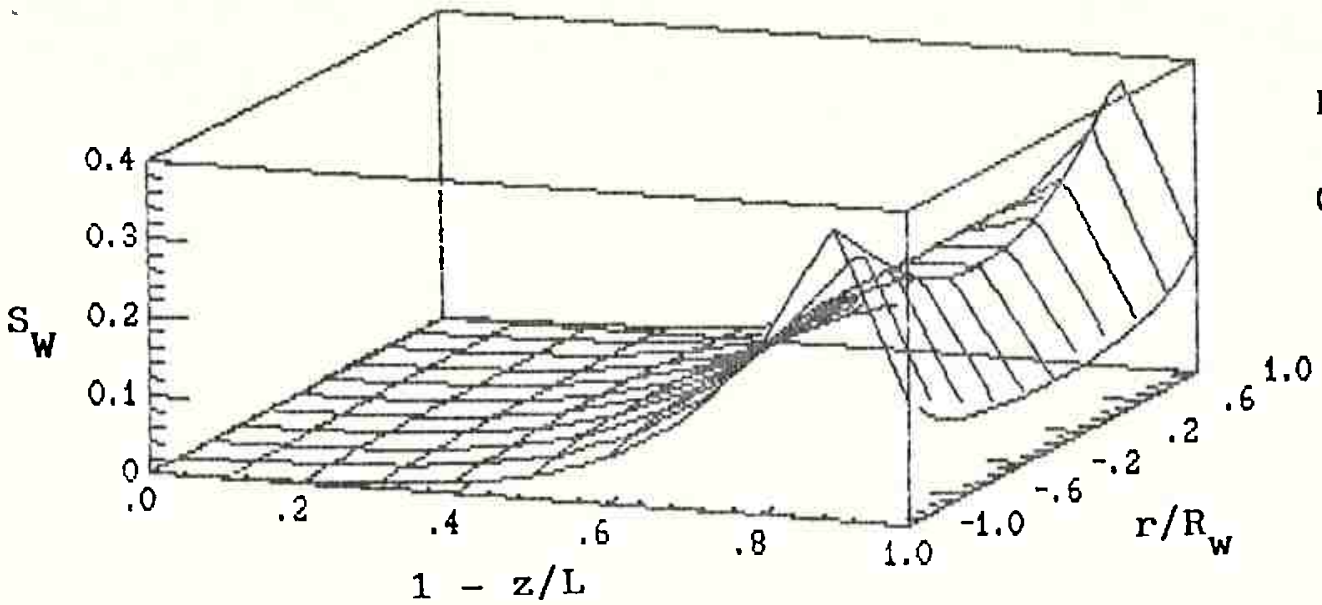

$R e=10$

Caso 4
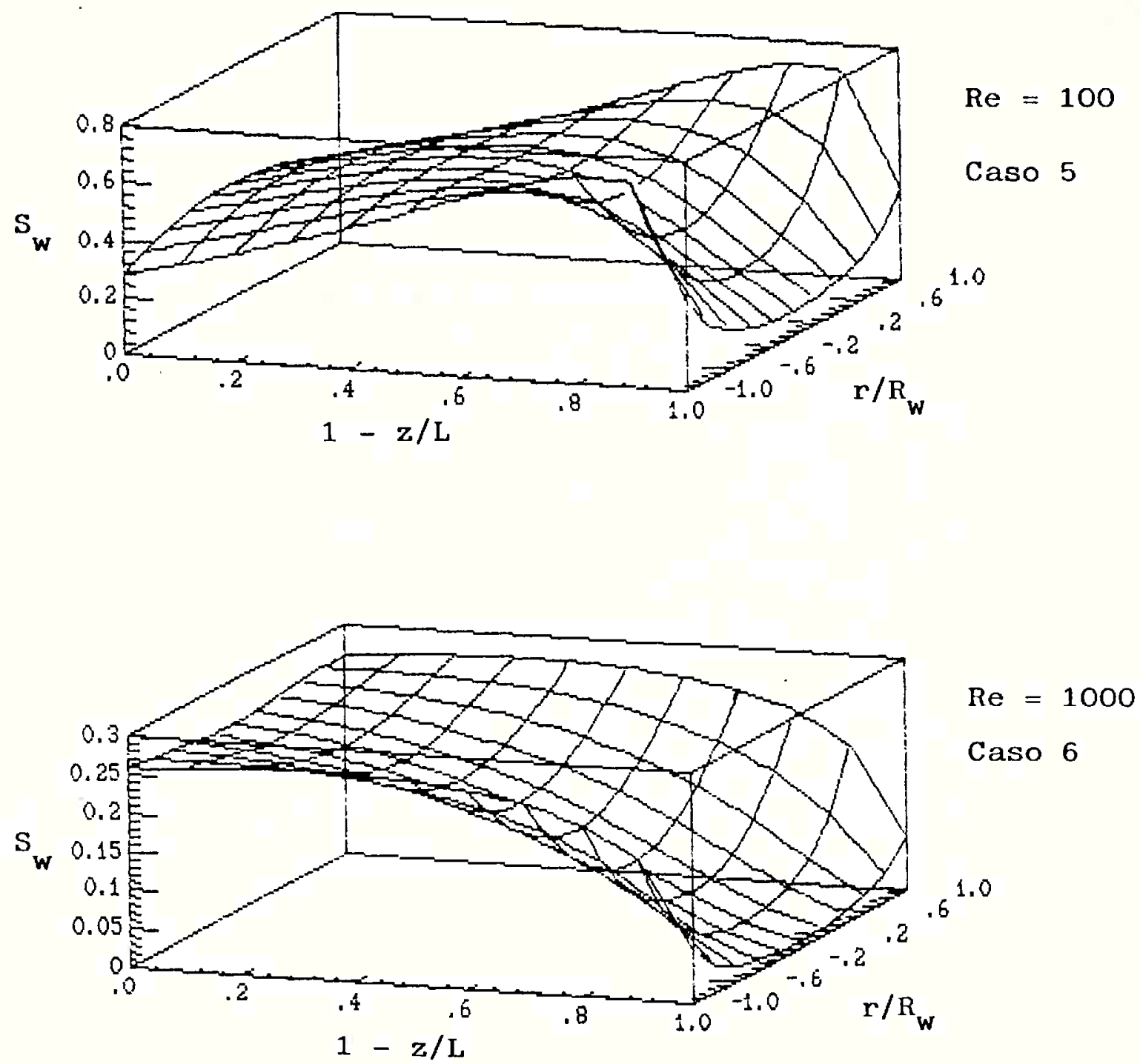

Figura 3.19. Superfícies de sensibilidade a $h_{w} \cdot \operatorname{Casos} 4,5$ e 6 . 

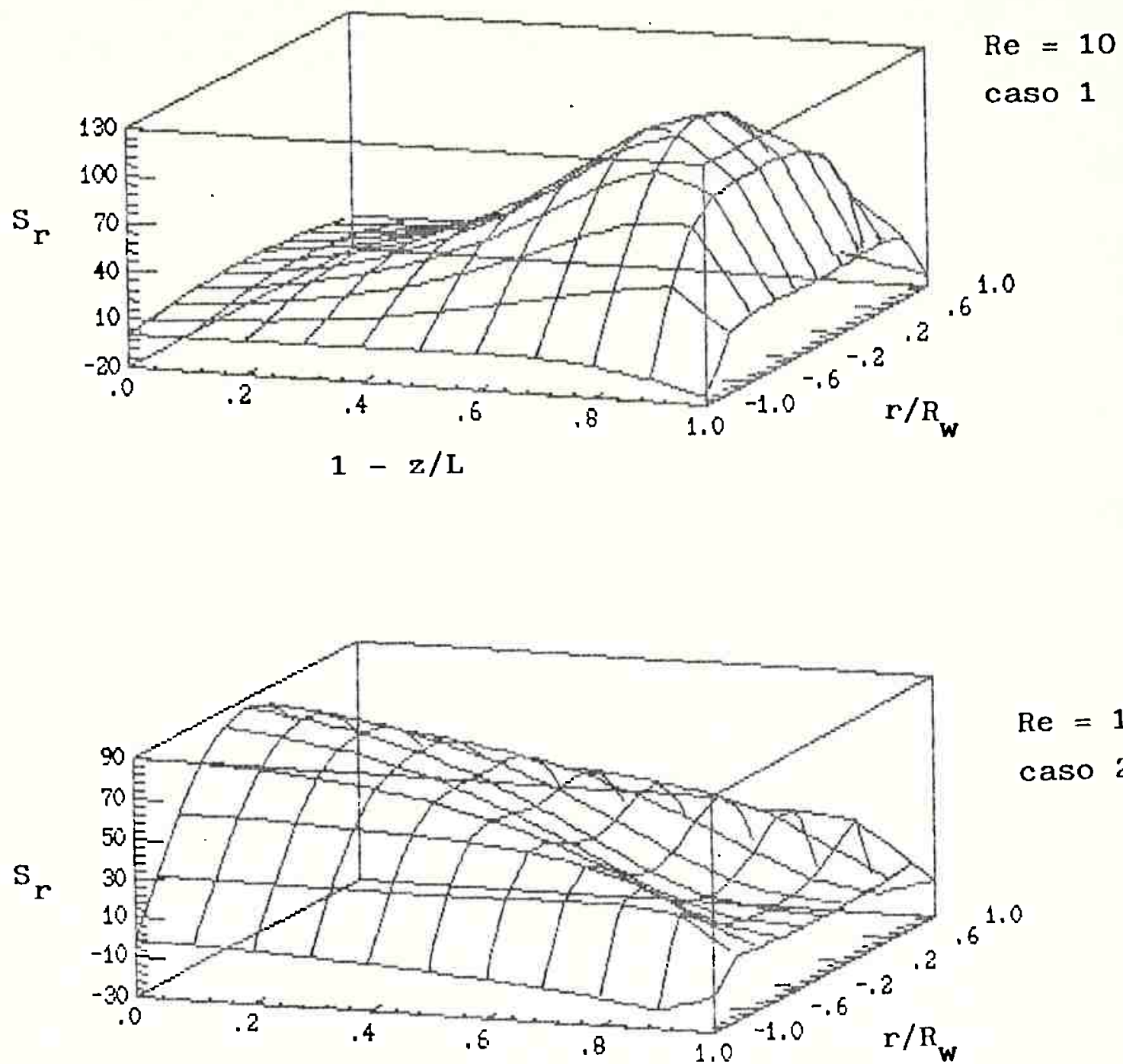

$\mathrm{Re}=100$

caso 2

$1-\mathrm{z} / \mathrm{L}$

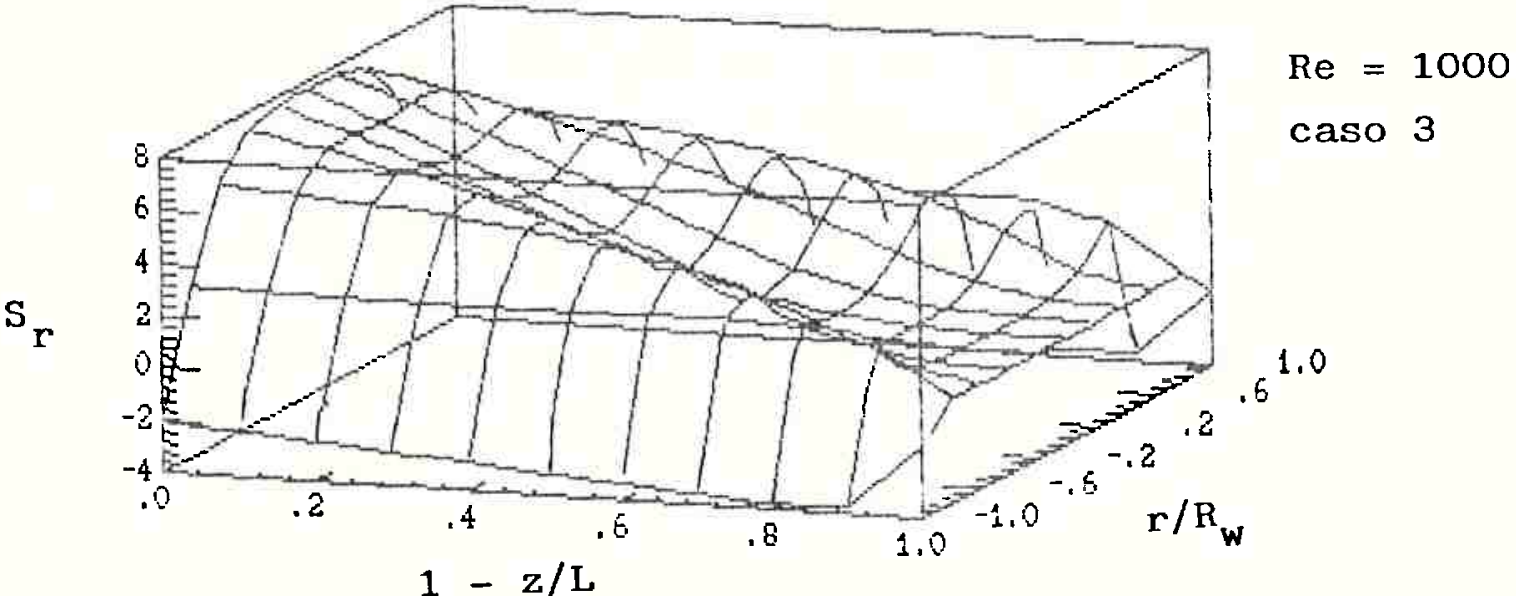

Figura 3.20. Superfícies de sensibilidade a $k_{r}$ - Casos 1,2 e 3 . 

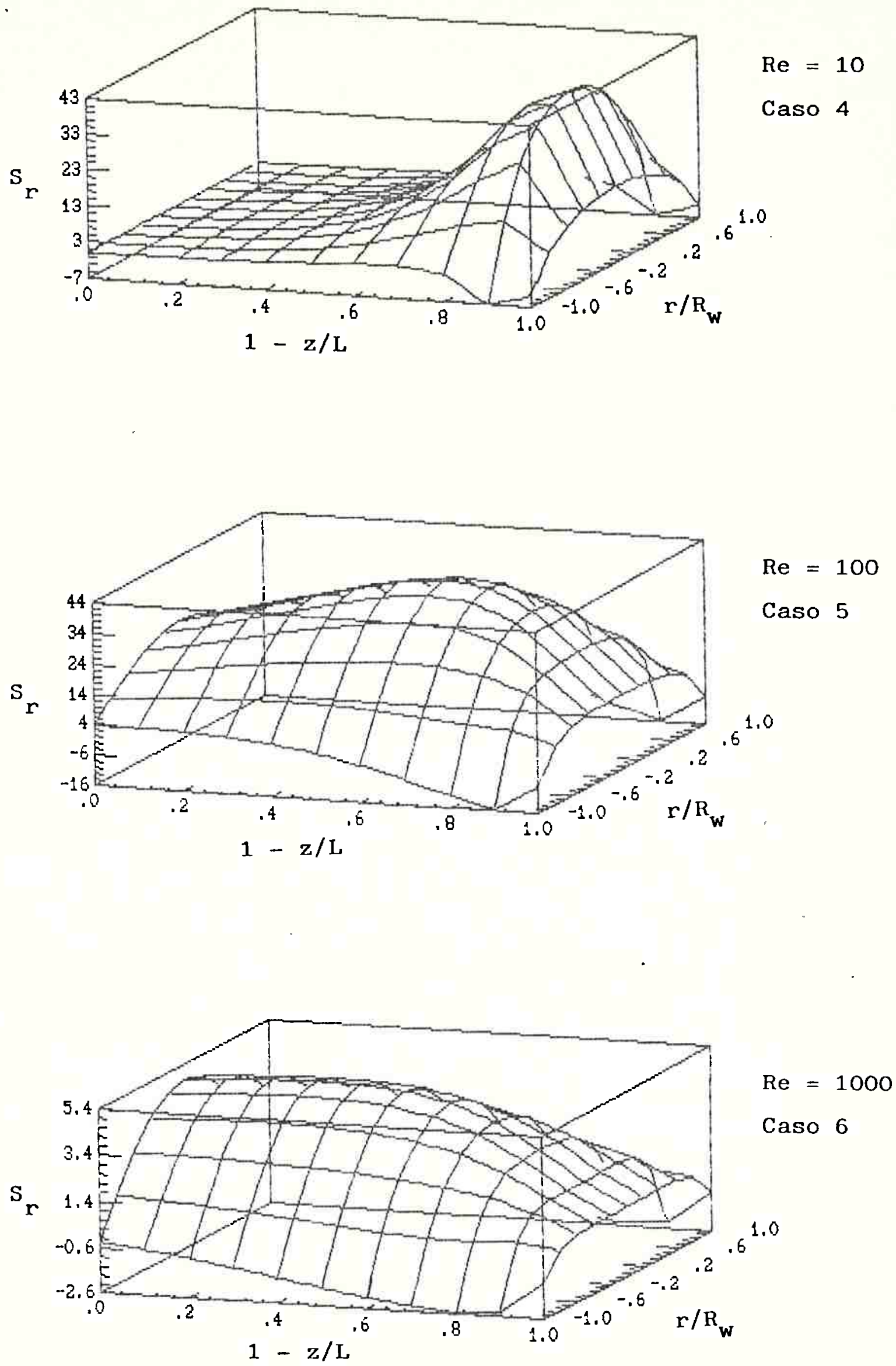

Figura 3.21. Superficies de sensibilidade

a $k_{r}$. Casos 4,5 e 6 . 

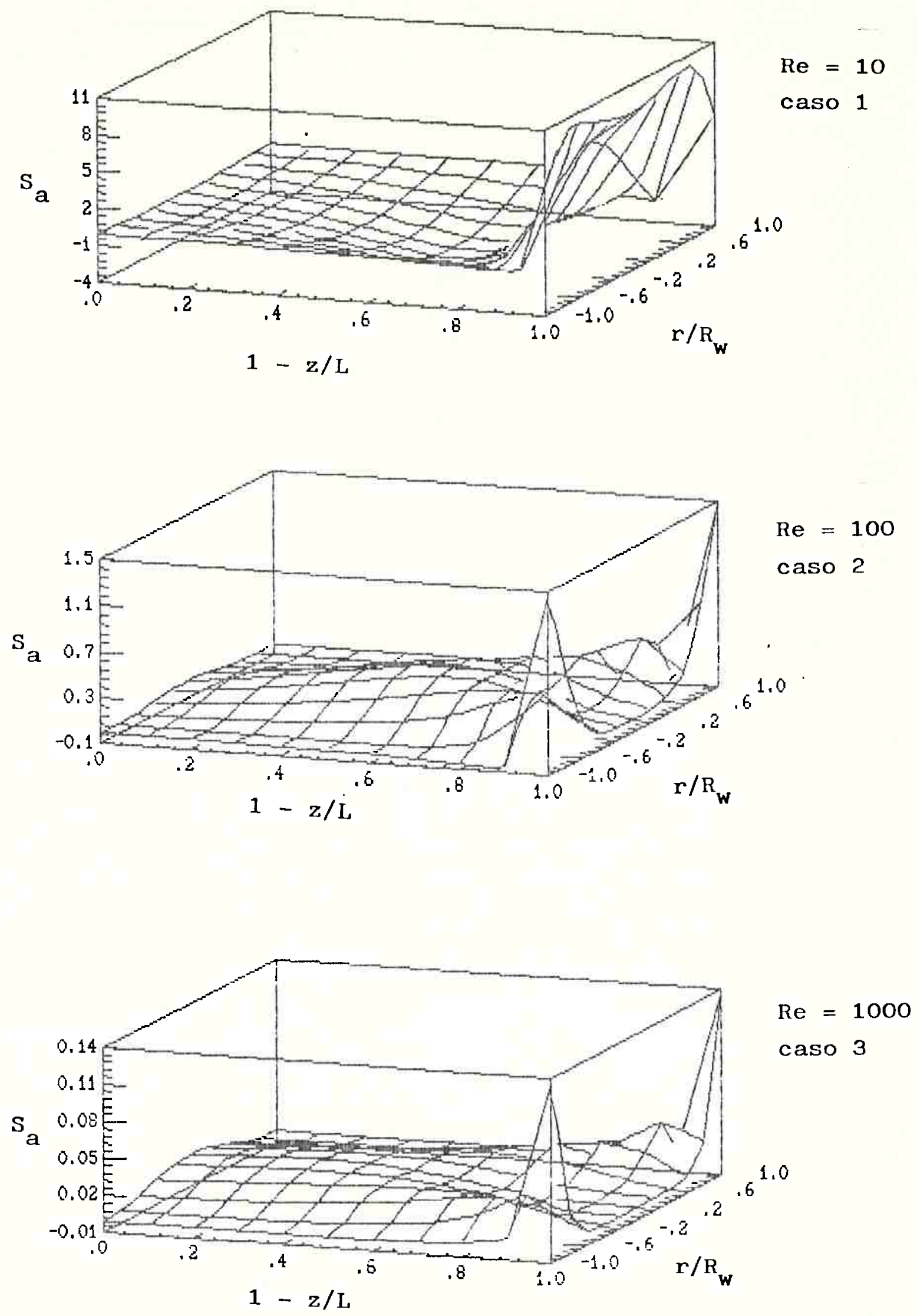

Figura 3.22. Superfícies de sensibilidade a $\mathrm{k}_{\mathrm{a}}$. Casos 1, 2 e 3 . 

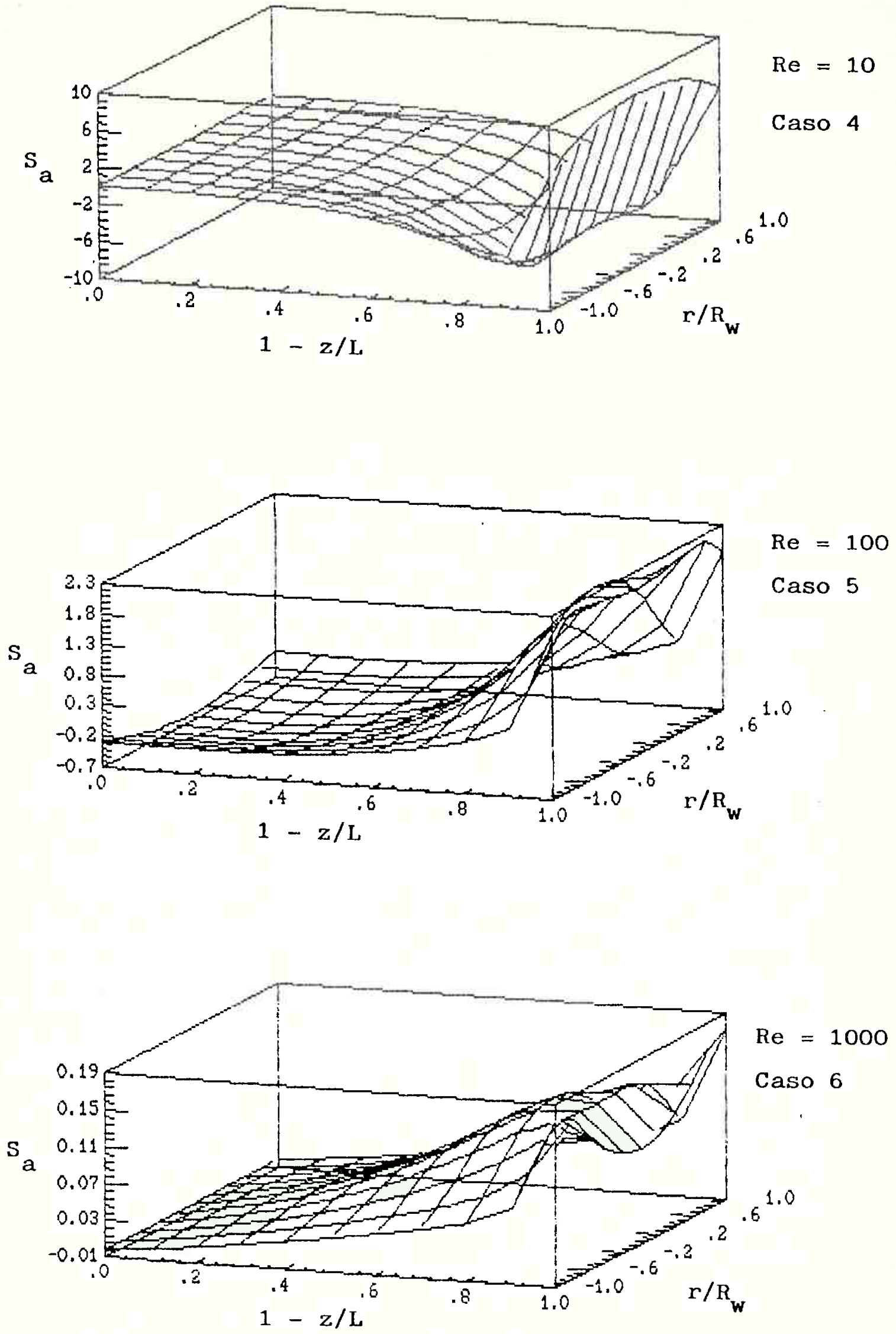

Figura 3.23. Superficies de sensibilidade a $k_{a}$. Casos 4,5 e 6 . 
experimento. A região de maior sensibilidade a $k_{m}$ está praticamente em $z=0$; isto explica a afirmacäo de Dixon et ali (1978) de que seria possivel melhorar a estimacäo de $k_{m}$ medindo com mais precisão o perfil de temperatura em $z=0$. Observa-se também que para maiores Re, menor a sensibilidade a $k_{m}$ o que é esperado pois o termo de dispersäo axial $k \partial^{2} \mathrm{~T} / \partial \mathrm{z}^{2}$ tende a tornarse menos importante que o termo convectivo $G c_{p} \partial T / \partial z$.

De uma forma geral para os casos simulados neste trabalho. para Re muito baixos $(\operatorname{Re}=10$ ) há uma região de maior sensibilidade a $k_{r}$ e hrpróximo à entrada da secão térmica $(z=0)$, sendo $5_{r}$ maior na região central e $S_{w}$ maior junto à parede. Esta região de máxima sensibilidade a $k_{r} e h_{w}$ desloca-se no sentido de $z$ crescente d̀ medida que Re aumenta.

Pode-se perceber ainda que a distribuifão $e$ os valores numéricos de sensibilidades dependem das condicoes experimentais e do valor dos parâmetros, como também fora observado por Sklivaniotis et alii (1988) para o modelo sem dispersão axial. Pode-se, dessa forma, estender algumas das suas conclusôes ao modelo com dispersão estudado no presente trabalho: a localizacão ótima dos termopares no leito para un experimento de estimacäo de parâmetros só pode ser obtida por un procedimento iterativa, após obter uma primeira estimativa dos parâmetros; no entanto podem ocorrer dificuldades de caráter prático ao se tentar locar sensores em determinadas posicöes do reator. Por outro lado, o conhecimento da distribuicăo de sensibilidade permite ponderar com menores pesos as medidas tomadas em locais de pequena sensibilidade, diminuindo a influência dos erros experimentais e melhorando a confiabilidade das est imativas. 


\subsection{Uodelo Teórico para a Sensor Anelar de Temperatura}

Nos itens 3.2 .1 e 3.6 foi proposto e testado experimentalmente un tipo de sensor de temperatura em forma de anel que permite filtrar as flutuacóes angulares de temperatura. Neste item este dispositivo é analisado teoricamente.

Cada sensor consiste de un anel metálico colocado coaxialmente ao reator a uma pequena distância acima do leito. Cada ponto do anel, a uma diferente posicăo angular, troca calor com uma corrente de gás saindo do leito, correntes estas que apresentan variacões de velocidade e de temperatura- Deseja-se medir uma temperatura média em determinada posicáo radial em que o anel se encontra. Un termopar esta soldado a um ponto do ane1, registrando portanto a temperatura deste ponto.

Considerando-se o fio metálico que forma o anel seja suficientemente fino de tal modo que se possa desprezar a variacáo de temperatura ao longo do raio do fio, a seguinte equacão rege a distribuicão de temperatura $t(\theta)$ ao longo da posicão angular $\theta$ no anel:

$$
\frac{k}{R_{m}=} \frac{d^{2} t}{d \theta^{2}}=h_{\infty} \frac{4}{D}\left(t-T_{\infty}\right)
$$

com as condicões de contorno (continuidade do fio)

$$
\begin{gathered}
t(\theta=\theta)=t(\theta=2 \pi) \\
d t / d \theta(\theta=\theta)=d t / d \theta \quad(\theta:=2 \pi)
\end{gathered}
$$

o coeficiente de transferência de calor $h_{m}$ entre o gás $a$ fio foi calculado pela correlação na forma $N u_{0}=f\left(R E_{0}\right)$, con $R_{0}=$ $u \rho_{+} D / \mu_{\text {r }} e N u_{0}=h_{-} D / k$, sendo a funçäo descrita graficamente na figura 3.24 (Welty et alii, 1976), válida para escoamento perpendicular a cilindros. Portanto além da velocidade $u$ e da temperatura To também $h_{n}$ foi considerado variar localmente. 


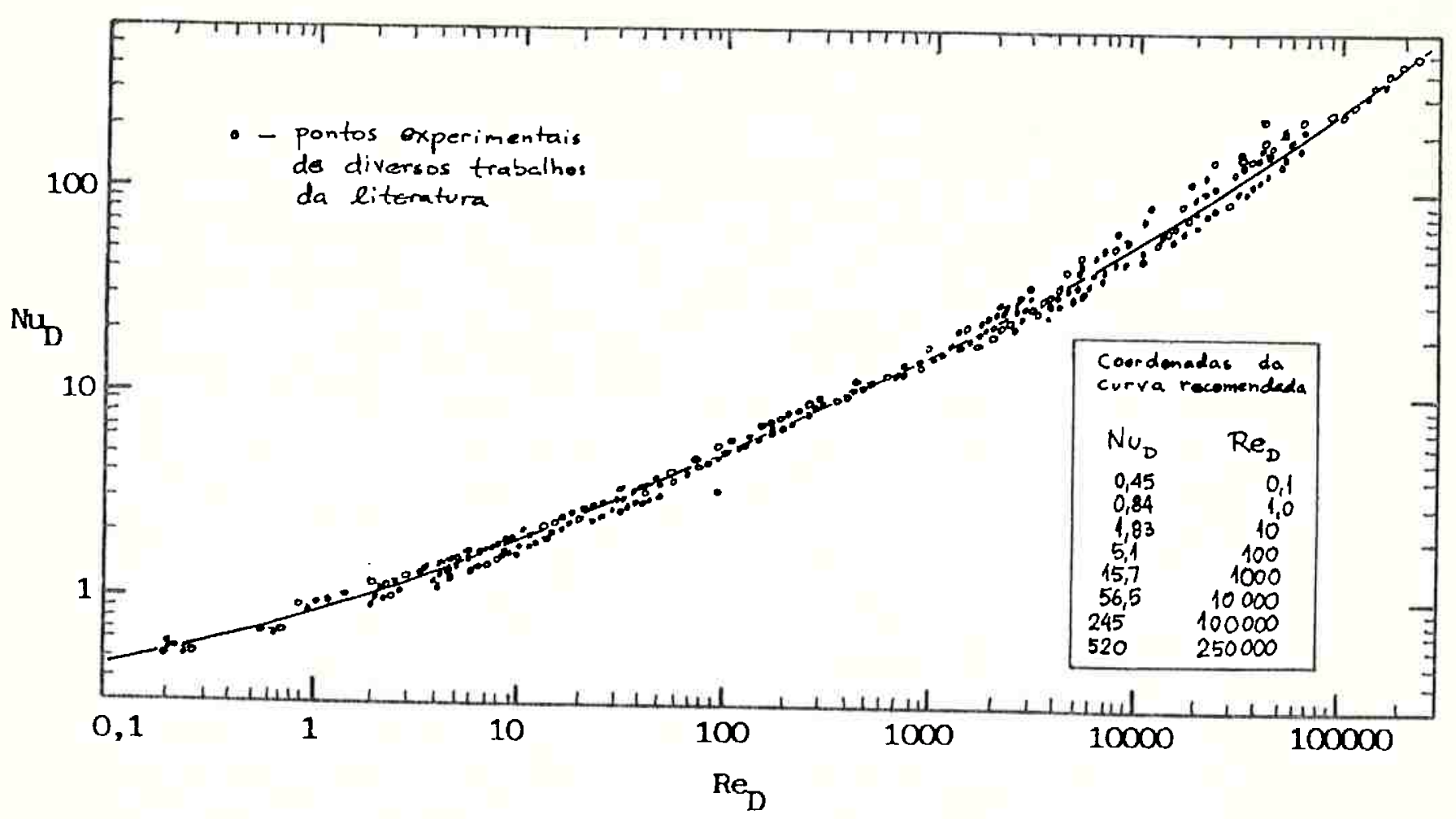

iFigura 3.24. $N u_{D}\left(=h_{a} D / k_{f}\right)$ versus $R e_{D}\left(=\rho_{f} u D / \mu_{f}\right)$ para escoamento normal a um cilindro (extraido de Welty et alii, 1976). 
A equacão foi discretizada pelo mécodo de diferencas finitas e o sistema linear resultante foi resolvido pelo método de el im inacão de Gauss (detalhes no Apêndice B).

Resultados tipicos para um anel de cobre (k=380 $\left.\mathrm{H} / \mathrm{m}^{\circ} \mathrm{C}\right)$ com raio $R_{m}=0.02 \mathrm{~m}$ e diâmetro do fio $D=0.002$ m sấo mostrados nas figuras 3.25 e 3.26. Para as simulafófes realizadas adotou-se um perfil angular de temperatura, cuja distribuicão e amplitude foi baseada nas observacōes experimentais descritas no item 3.7, e um perfil de velocidade do gás baseado em resultados experimentais descritos na literatura (Mariovet et alii, 1974; Ziolkowsk \& Ziolkowski, 1988; Drahos \& Cermak, 1986). Os dois casos apresentados referem-se à situacão onde os máximos de temperatura coincidem com os máximos do perfil de velocidade, $e$ onde os máximos de um perfil coincidem com os miminos do outro.

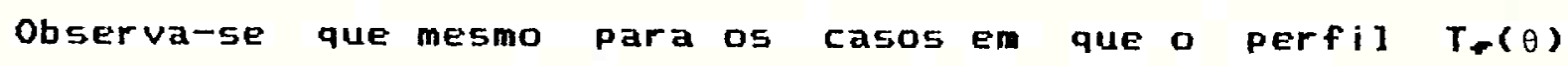
apresenta grandes variacões, $t(\theta)$ se mantém bastante uniformizado, sem flutuacões significativas, com valores praticamente iguais à temperatura média do gás. A comparacão destes valores dada na Tabela 3.12; a temperatura do gás foi suposta ter variacōes de até $15^{\circ} \mathrm{C} e$ a máxima diferenca de temperatura entre dais pontos do anel foi $0,3^{\circ} \mathrm{C}$. O valor de temperatura emalquer ponto no anel difere menos de $x^{\circ} \mathrm{C}$ do valor médio da temperatura do gás.

Tabela 3.12 Valores obtidos com o modelo do sensor anelar de temperatura.

\begin{tabular}{|c|c|c|c|}
\hline $\begin{array}{l}\text { perfis de } \\
\text { velocidade e de } \\
\text { temperatura }\end{array}$ & $\begin{array}{l}T-\left({ }^{\circ} \mathrm{C}\right) \\
\text { máx.- } \\
\text { min. }\end{array}$ & $\begin{array}{l}t(\infty \mathrm{C}) \\
\text { máx. } \\
\text { min. }\end{array}$ & $\left\langle T_{-}\right\rangle=\frac{\int T_{*} u d \theta}{\int u d \theta}$ \\
\hline figura 3.25 & $98,6 / 83,6$ & $90,7 / 90,4$ & 90,7 \\
\hline figura 3.26 & $98,0 / 83,0$ & $90,4 / 90,1$ & 89,8 \\
\hline
\end{tabular}




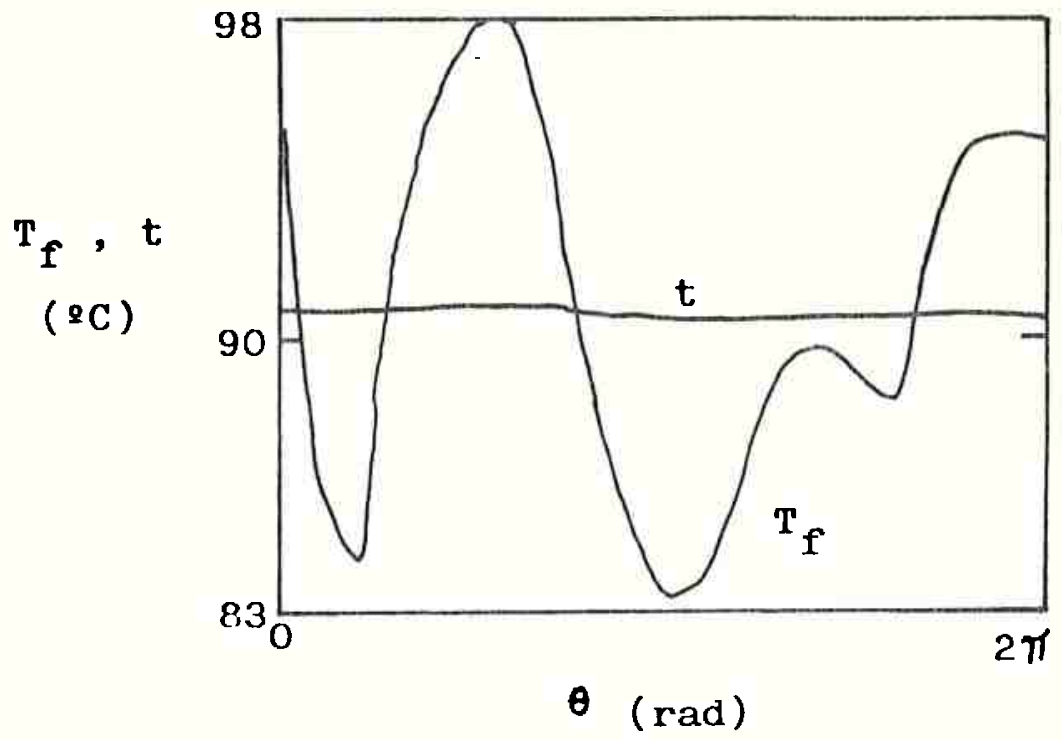

(a)

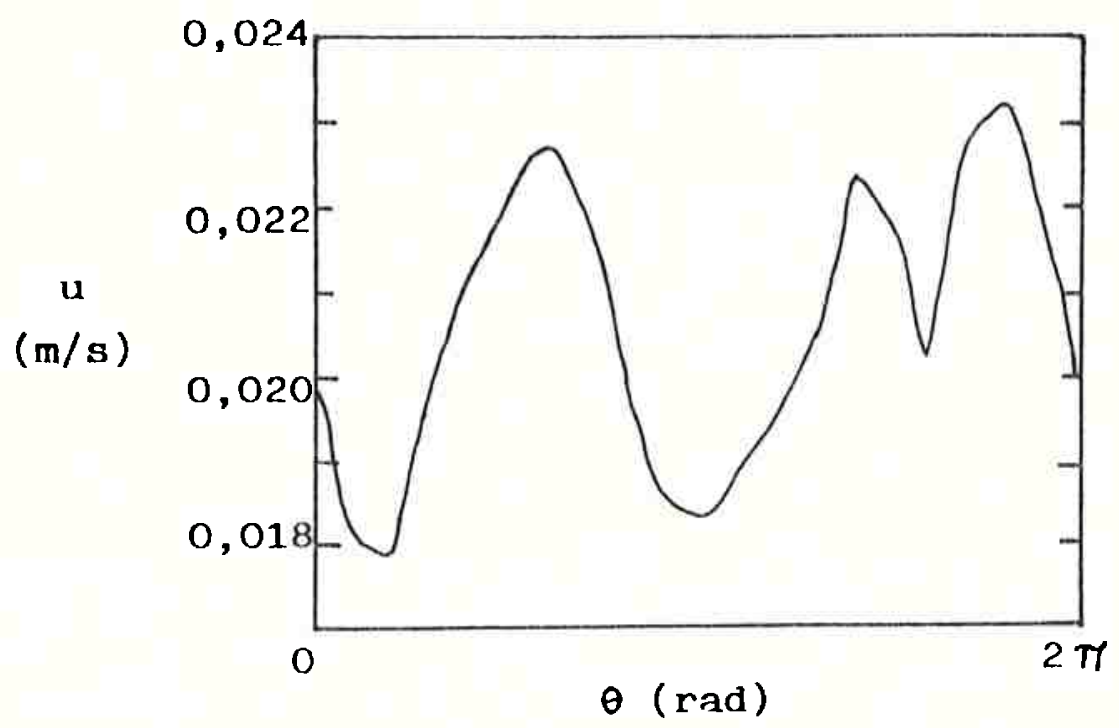

(b)

Figura 3.25. Resultados do modelo do sensor anelar de temperatura (a) perfis de temperatura no gás e no anel; (b) perfil de velocidade do gás. 


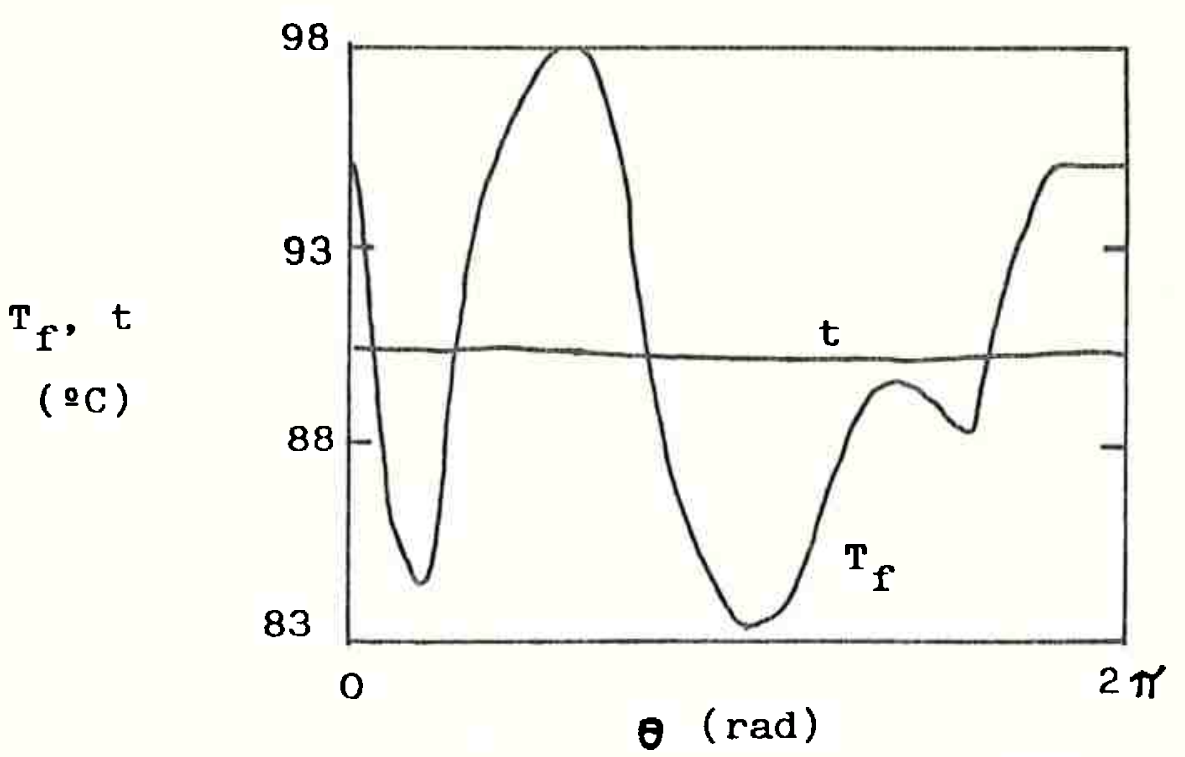

(a)

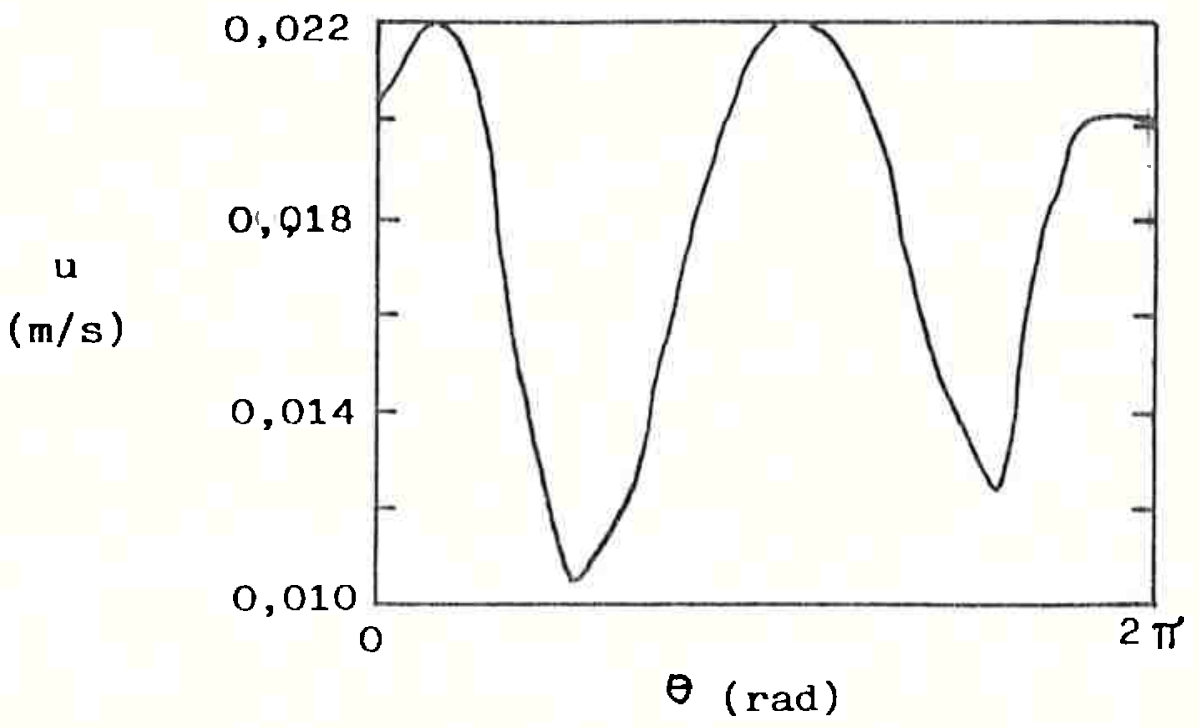

(b)

Figura 3.26. Resultados do modelo do sensor anelar de temperatura (a) perfis de temperatura no gás e no anel, (b) perfil de velocidade do gás. 
As previsões teóricas do modelo apresentado confirmam a idéia de que $a$ anel de material de alta condutividade filtra adequadamente as flutuacōes de temperatura angulares que ocorrem nos experimentos de transferência de calor en leito fixo.

\subsection{Conclusões do estudo de transferência de calor}

A Partir do estudo de transferencia de calor em leito fixo apresentado neste Capitulo, foram obtidas as seguintes conclusões:

- o sensor anelar de temperatura proposto neste trabalho é de fácil construç̃o: testado experimentalmente apresentou bons resultados quanto à capacidade de filtrar as flutuacões de temperatura que são observadas em reatores de leito fixo; estes resultados foram também verificados a partir de uma análise teórica do sensar;

- dentre os modelos testados para a estimacão de parâmetros, o modelo com dispersão axial e condicốes de contorno no infinito (modelo I) mostrou ser o que melhor descreve os perfis de temperatura medidos e foi o usado para tratar os dados; o modelo que inclui um perfil de temperatura como condicão de contorno em $z=0$ (modelo III) também apresentoubons resultados $e$ pode ser aperfeicoado:

- a análise de sensibilidade paramétrica do modelo com dispersão axial (modelo I) mostrou que os valores de sensibilidade dependew fortemente das condicóes experimentais e do valor dos parâmetros; mostrou ainda que a sensibilidade ao coeficiente de dispersão axial é bastante pequena, o que explica o ajuste pobre que este parämetro costuma apresentar;

- os parâmetras térmicos obtidos apresentam comportamento e valores coerentes com resultados da literatura. 


\section{Capítulo 4}

\section{MODELAGEM MATEMATICA DO REATOR CATALITICO DE LEITO FIXO}

\subsection{Introducão}

Neste Capitulo é apresentada a modelagem matemática do reator catalitico de leito fixo. O processo de protucăo de ixido de eteno foi escolnido por se tratar de um exemplotipico de reacão de oxidafão industrial onde o problema da ocorrencia de pontos quentes é critico, além de sua grande importância industrial.

Foram elaborados o seguintes modelos para a operacão Estacionária do reator:

- um modelo unidimensional pseudo-homogêneo (modelo 1), empregado para estudar a previsão de pontos quentes e para uma análise preliminar da influência das variáveis de processo no comportamento do reator e para o estudo de estratégias de diluifáo do leito visando prevenir a ocorrência de pontos quentes;

- um modelo bidimensional pseudo-homogèneo (modelo 2 ), empregado para a verificagâo mais apurada das previsóes sob condicốs mais severas e para verificar efeitos da inclusáo de năo un iformidades radiais no modelo.

Foram consideradas, em princípio, as três principais reacōes que podem ocorrer no processo de oxidacăo de eteno:

$$
\begin{aligned}
& \mathrm{C}_{2} \mathrm{H}_{4}+1 / 2 \mathrm{O}_{2} \longrightarrow \mathrm{C}_{2} \mathrm{H}_{4} \mathrm{O} \quad \Delta \mathrm{H}=-1,17 \times 10^{\circ} \mathrm{J} / \mathrm{kmol} \text { ( } \mathrm{r} 1 \text { ) } \\
& \mathrm{C}_{2} \mathrm{H}_{1}+3 \mathrm{O}_{2} \longrightarrow 2 \mathrm{CO}_{2}+2 \mathrm{H}_{2} \mathrm{O} \Delta \mathrm{H}=-1,334 \times 10^{\circ} \mathrm{J} / \mathrm{kmol}(\mathrm{r} 2) \\
& \mathrm{C}_{2} \mathrm{H}_{4} \mathrm{O}+5 / 2 \mathrm{O}_{2} \longrightarrow 2 \mathrm{CO}_{2}+2 \mathrm{H}_{2} \mathrm{O} \Delta \mathrm{H}=-1,217 \times 10^{4} \mathrm{~J} / \mathrm{kmol} \text { (r3) }
\end{aligned}
$$

A matriz dos coeficientes $\alpha x \mu$ mostrada na Tabela 4.1, tem característica ("rank") igual a 2 , sendo que a reacão (r3) pode ser escrita como combinafão 1 inear de ( 1 ) e: (r2). Assim, havendo 
apenas duas equaçöes estequiométricas linearmente independentes, basta escrever equacóes diferenciais de balanco de massa para duas espécies, sendo que as quantidades das demais espécies são obtidas por relacões estequiométricas.

Tabela 4.1. Matriz dos coeficientes estequiométricos.

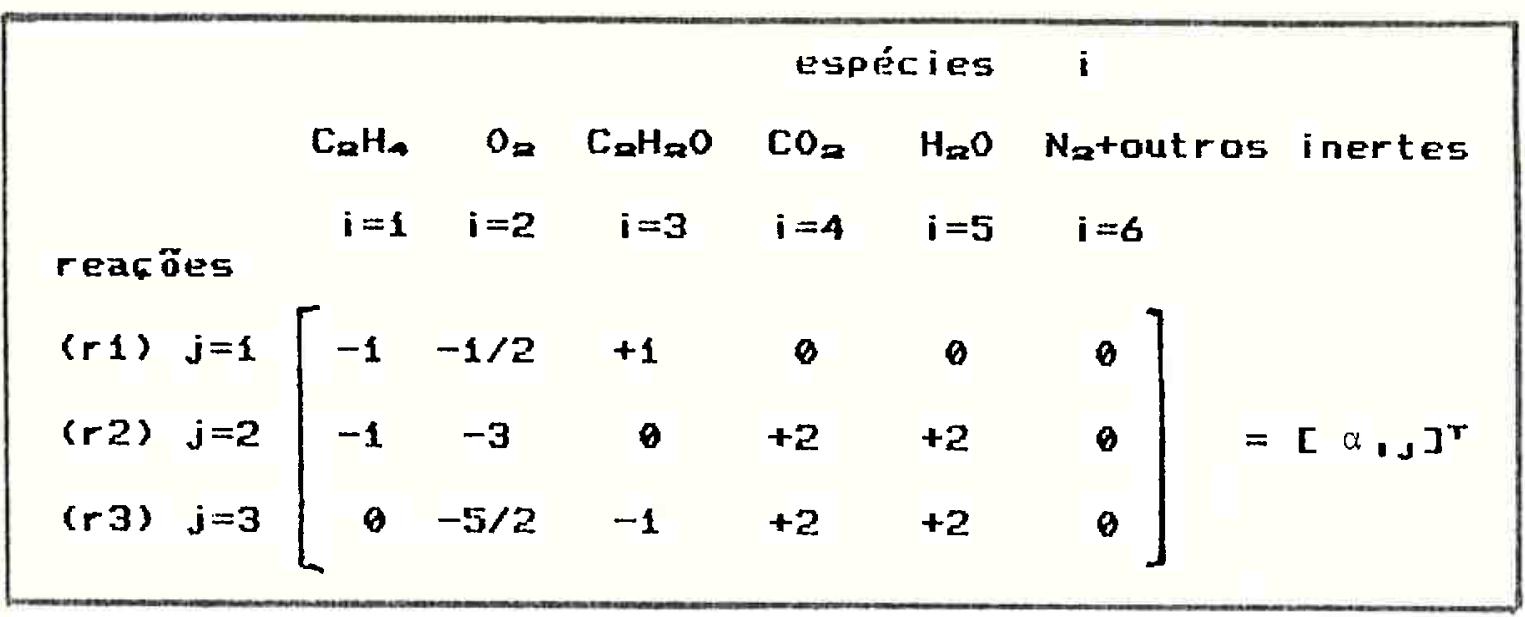

\subsection{Modelo 1 - unidimensional. pseudo-homogêneo. Estático}

As principais hipóteses adotadas na elaboraçäo deste modelo ธão:

- modelo unidimensional, isto é as variafóes de propriedades sáo consideradas somente na direfäo axial do reacor parcialmente justificada pelo fato de os tubos serem relativamente estreitos; a validade desta hipotese é verificada posteriormente Por comparafáo com os resultados do modelo 2;

- tratamento pseudo-homogêneo, ou sejar não se faz distincão entre as fases sólida e gasosa, utilizando-se parâmetros cinéticos e térmicos "efetivos";

- estado estacionário;

- não se considera a dispersão axial de calor e massa, por serem estes termos despreziveis frente aos termos convectivos para 
condicões industriais típicas $\left.\left(L / d_{p}\right) 500\right) ; 0$ escoamento é pistonado ("plug-flow") ;

- todos os tubos do reator estão sujeitos às mesmas condicốes de resfriamento pelo fluido da carcaca;

- temperatura do fluido refrigerante e da parede dos tubos constante; dados reportados na literatura - Piccinini \& Levy (1984) - mostram que a variacão na temperatura do fluido refrigerante é pequena nos reatores industriais, mesmo quando refrigerados por fluido monofásico:

- propriedades físicas constantes com a temperatura, já que a variacão de temperatura é pequena; exceqão feita para a densidade da fase gasosa, onde foi suposto o comportamento de gás ideal Capesar de a pressáo de operacáo ser razoavelmente elevada, a hipotese de gás ideal não é muito restritiva pois as expressões cinéticas utilizadas no modelo säo coerentes con esta consideracão; outras hipótoses do modelo são mais restritivas).

As equacões diferenciais de balancos de massa, energia e queda de pressão para o modelo 1 são=

$$
\begin{aligned}
& \frac{d X_{E T}}{d z}=\frac{A \rho_{0} a\left(-R_{1}-R_{2}\right)}{\left(F_{E T}\right)} \\
& \frac{d X_{\text {Or }}}{d z}=\frac{A \rho_{b} a\left(+R_{1}-R_{z}\right)}{\left(F_{E T}\right)_{0}} \\
& \frac{d T}{d z}=\frac{1}{G C_{m}}\left[-\rho_{D} a \sum_{j=1}^{3}\left(-\Delta H_{J}\right) R_{J}-\frac{4 U}{d t}\left(T-T_{\infty}\right)\right] \\
& \frac{d P}{d z}=\frac{-f G u}{d_{r}}
\end{aligned}
$$

com condiçăo inicial

$$
z=0 \quad X_{\text {ext }}=6 \quad X_{\text {OEx }}=0 \quad T=T_{0} \quad P=P_{0}
$$


As equacões de balanco de massa säo escritas em termos da conversão total do eteno $X_{\text {er }} e$ da conversão de eteno a óxido de eteno $X_{0}=$ As vazões molares dos componentes são calculadas a partir de relacões estequiométricas por:

$$
\begin{aligned}
& F_{1}=F_{K T}=\left(F_{K T}\right)_{0}\left(1-X_{K T}\right) \\
& F_{z}=F_{02}=\left(F_{O R}\right)_{0}+\left(5 / 2 X_{\text {OF }}-3 X_{F T}\right)\left(F_{\text {KT }}\right)_{0}
\end{aligned}
$$

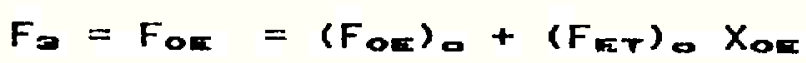

$$
\begin{aligned}
& F_{A}=F_{\text {COZ }}=\left(F_{\text {coz }}\right)_{0}+\left(-2 X_{\text {OK }}+2 X_{\text {RT }}\right)\left(F_{\text {er }}\right)_{0} \\
& F=F_{\text {HPO }}=\left(F_{\text {HPO }}\right)_{0}+\left(-2 X_{O E}+2 X_{E T}\right)\left(F_{k T}\right)_{0} \\
& F_{\Delta}=F_{N 2}=\left(F_{N 2}\right)_{0} \\
& \text { Frotal }=\sum_{i=1}^{6} F_{1}
\end{aligned}
$$

e as fracóes molares e pressóes parciais dos componentes são definidas por:

$$
\begin{aligned}
& y_{1}=F_{1} / F_{\text {rotal }} \\
& p_{1}=y_{1} P
\end{aligned}
$$

- fator de atrito f para leito fixo foi calculado pela equacão de Ergun:

$$
f=\left[1.75+\frac{150(1-E)}{\operatorname{Re}}\right]\left(\frac{1-\varepsilon}{\varepsilon 3}\right)
$$

onde $\operatorname{Re}=G \mathrm{~d} / \mu$.

o coeficiente global de troca térmica ( $U$ ) foi obtido a partir do valor de condutividade térmica efeitiva radial, obtida por (Gunn et ali $i, 1987)=$

$$
\frac{G C_{p r} d_{p}}{k_{r}}=\frac{1}{10}+\frac{8}{\operatorname{RePr}}
$$


onde $\operatorname{Pr}=0,74$, do coeficiente de transferencia de calor parede-1eito, obtido a partir de (Dixon \& Creswe11, 1979)=

$$
\frac{h_{\omega} R_{m}}{k_{r}}=3,6\left(R_{00} / d_{m}\right) R^{-\infty}
$$

sendo combinados na forma:

$$
\frac{1}{U}=\frac{1}{h_{\infty}}+\frac{d_{t}}{8 k_{\sigma}}
$$

As correlacổes utilizadas são tipicamente encontradas na literatura e suas previsões não diferem muito dos valores obtidos experimentalmente neste trabalho, apresentados no Capitulo 3.

As equacões para o cálculo das velocidades das reacóes ("modelo cinetico") foram calculadas pelas expressöes propostas por Westerterp Ptasinski (1984)=

$$
\begin{aligned}
& R_{2}=k_{2} \exp \left(-E_{1} / R_{0} T\right) P_{0 R} \\
& R_{2}=k_{2} \exp \left(-E_{2} / R_{0} T\right) \text { poa } \\
& R_{\mathbf{l}}=0 .
\end{aligned}
$$

e as constantes cinét icass são:

$$
\begin{aligned}
& k_{1}=70,4\left(\mathrm{~m}^{3}\right)\left(\mathrm{kg}(\mathrm{at})^{-2}(\mathrm{~s})^{-1}, \quad E_{1} / R_{3}=7200 \mathrm{k}^{-1}\right. \\
& k_{z}=29400\left(\mathrm{~m}^{3}\right)(\mathrm{kg} \text { (at })^{-1}(5)^{-2}, \quad E_{z 2} / R_{g}=10800 \mathrm{~K}^{-1}
\end{aligned}
$$

A seletividade a óxido de eteno é definida por

$$
\text { Sor }=X_{\text {ore }} / X_{\text {ret }}
$$

Os valores dos demais parâmetros constantes utilizadas na simuląão sáo mostrados na Tabela 4.2 .

o sistema de equacóes diferenciais ordinárias (4.1) a (4.4) foi resolvido numericamente pelo método de Runge-kutta-Gill de 4m ordem. 
Tabela 4.2. Valores dos parâmetros usados na simulacăo.

\begin{tabular}{|c|c|}
\hline parâmetro & símbolo e valor \\
\hline $\begin{array}{l}\text { calor especifico médio dos gases } \\
\text { viscosidade dos gases } \\
\text { porosidade média do leito } \\
\text { diametro médio de particula } \\
\text { diametro interno dos tubos } \\
\text { comprimento dos tubos } \\
\text { número de tubos } \\
\text { densidade aparente do catalisador }\end{array}$ & $\begin{array}{l}c_{p+}=1050 \mathrm{~J} \mathrm{~kg}^{-x} \mathrm{~K}^{-1} \\
\mu=3 \times 10^{-5} \mathrm{~kg} \mathrm{~m}^{-x} \mathrm{~s}^{-x} \\
\varepsilon=0.5 \\
d_{p}=6.008 \mathrm{~m} \\
d_{t}=0.04 \mathrm{~m} \\
L_{t}=9 \mathrm{~m} \\
n_{t}=4000 \\
\rho_{p}=850 \mathrm{~kg} / \mathrm{m}^{3}\end{array}$ \\
\hline
\end{tabular}

\subsection{Resultados da simulacân obtidos com a modelo 1}

Para verificar a influencia das variaveis de processo na resposta do reator, foi escolhido um conjunto base de condicões operacionais e depois cada parämetro sofreu uma variacão, mantendo-se os outros constantes. Esse conjunto base de condicões operacionais é mostrado na Tabela 4.3.

Tabela 4.3. Conjunto base de condicões operacionais.

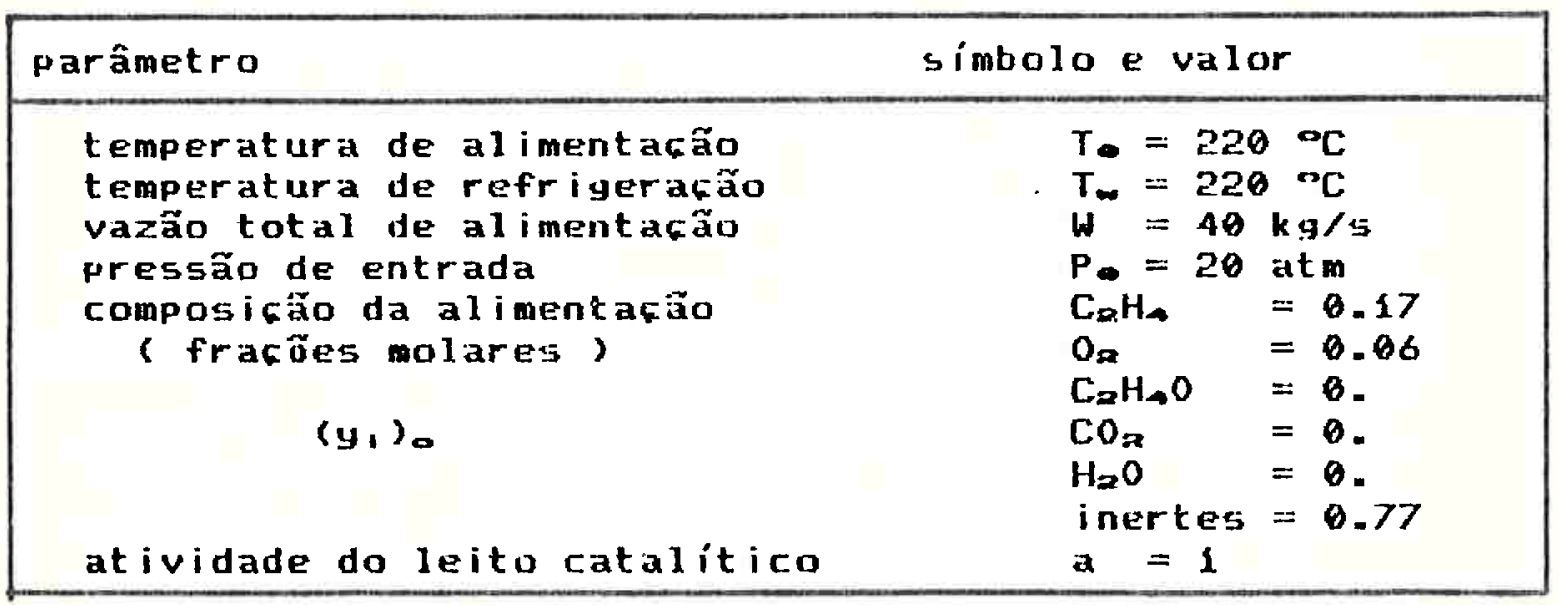

\subsubsection{Influência da temperatura de alimentacãa Ia e da temperatura da parede do tubo $T_{w}$}

Ambas as temperaturas (de alimentación e do fluido refrigerante) sấo importantes variáveis para a operação do reator, como pode ser observado nas figuras 4.1 e 4.2 . Em ambos os casos 

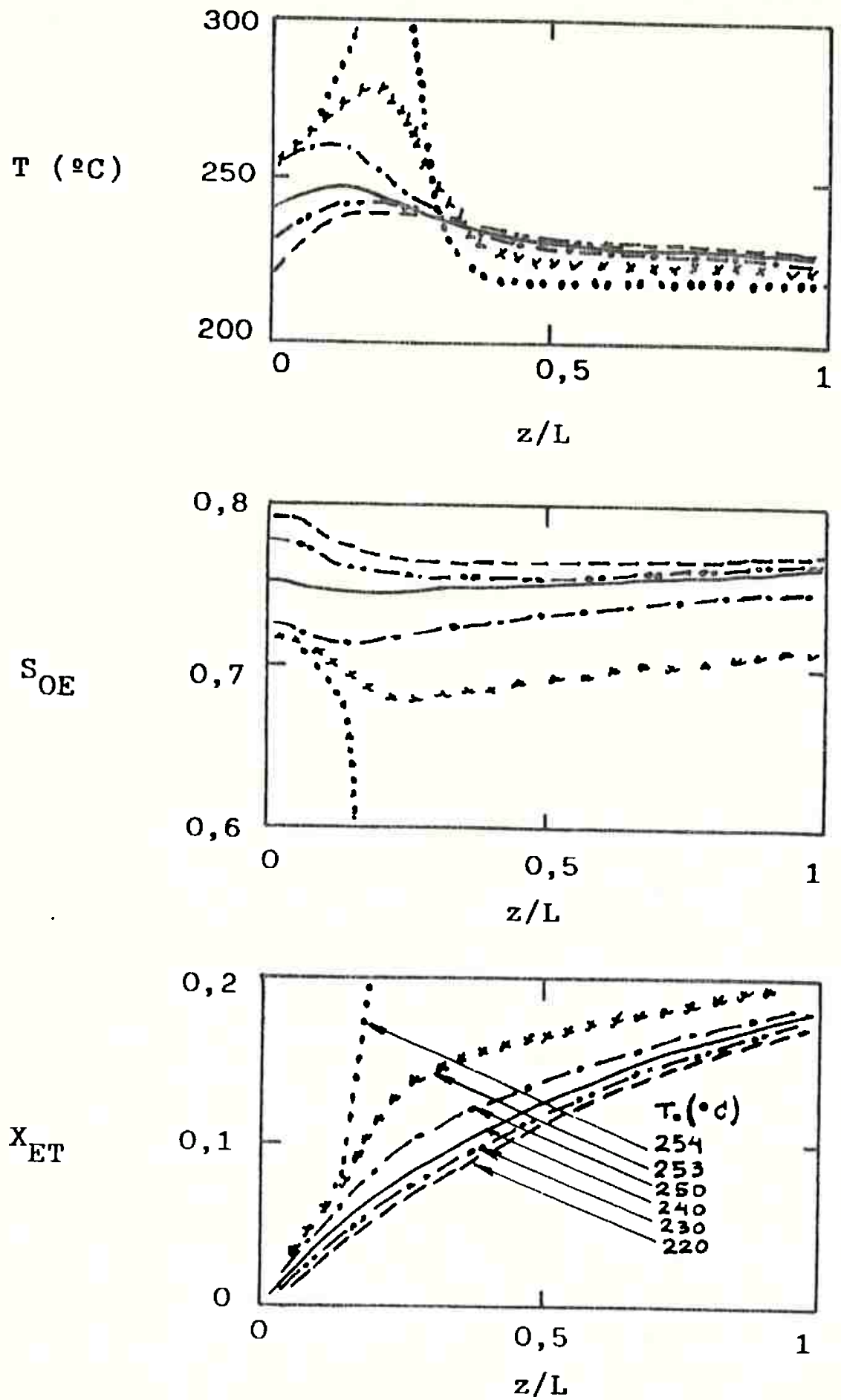

Figura 4.1. Influência da temperatura da alimentação sobre o comportamento do reator. 

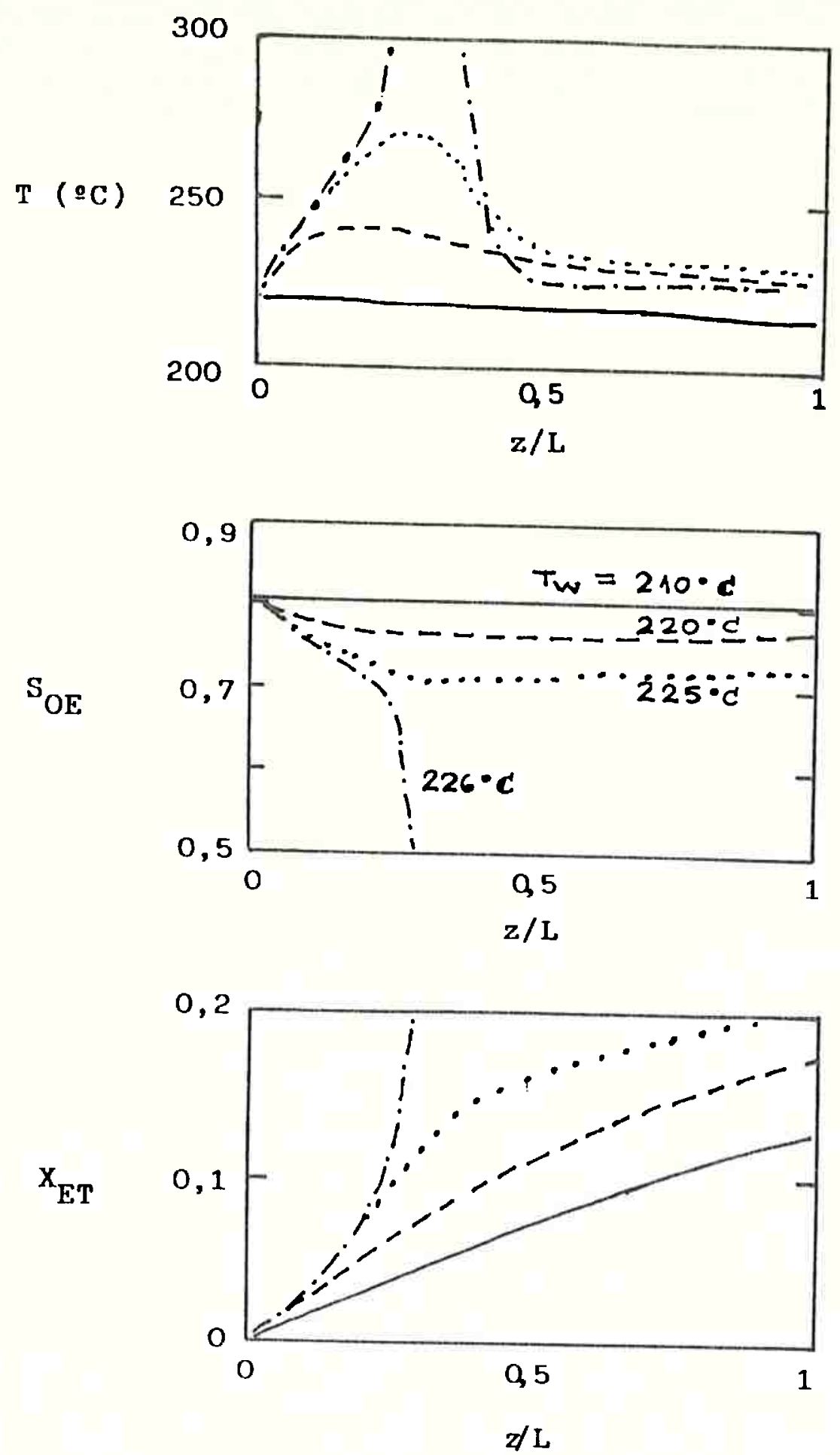

Figura 4.2 Influência da temperatura do fluido refrigerante. 
uma elevacão excessiva de To ou Tw pode elevar a sensibilidade paramétrica e provocar disparo de temperatura ("pontos quentes") no reat or.

\subsubsection{Influência da concentracäo de reagentes}

Observa-se na figura 4.3 que um aumento da concentracão de reagente limitante (oxigênio) provoca um aumento na conversão, como esperado. Para as condicões simuladas observa-se que esta variável deve ser mantida dentro de faixa estreita para que se obtenha uma conversão razoável mas sem o risco de ocorrência de disparos de temperatura.

Nas simulacăo foram ut ilizadas expressöes simplificadas para a cinética das reacões, válidas para condicóes cipicamente encontradas em reatores de oxidacão de eteno com oxigênio. Nestas condicões o etileno está presente en grande excesso em relacão ao oxigênio, e por isso a cinética passa a praticamente náo depender da concentracão de eteno.

\subsubsection{Influência da vazäo de alimentacäo}

Foram feitos dois tipos de considerafão nesta análise:

- coeficiente global de troca térmica calculado em funcão da vazåo de alimentacão, como apresentado no item 4.2;

- coeficiente global de troca térmica mantido constante; esta segunda abordagem é frequentemente encontrada na literatura.

Em ambos os casos, mostrados nas figuras 4.4 e 4.5 , o aumento da vazão de alimentacão provoca uma diminuicão da conversăo de eteno, como consequência da diminuicão do tempo de résidência dos gases no reator.

Quando se fixa o valor do coeficiente de troca térmica $U$, observa-se uma mudanca substancial de comporkamento das previsães 

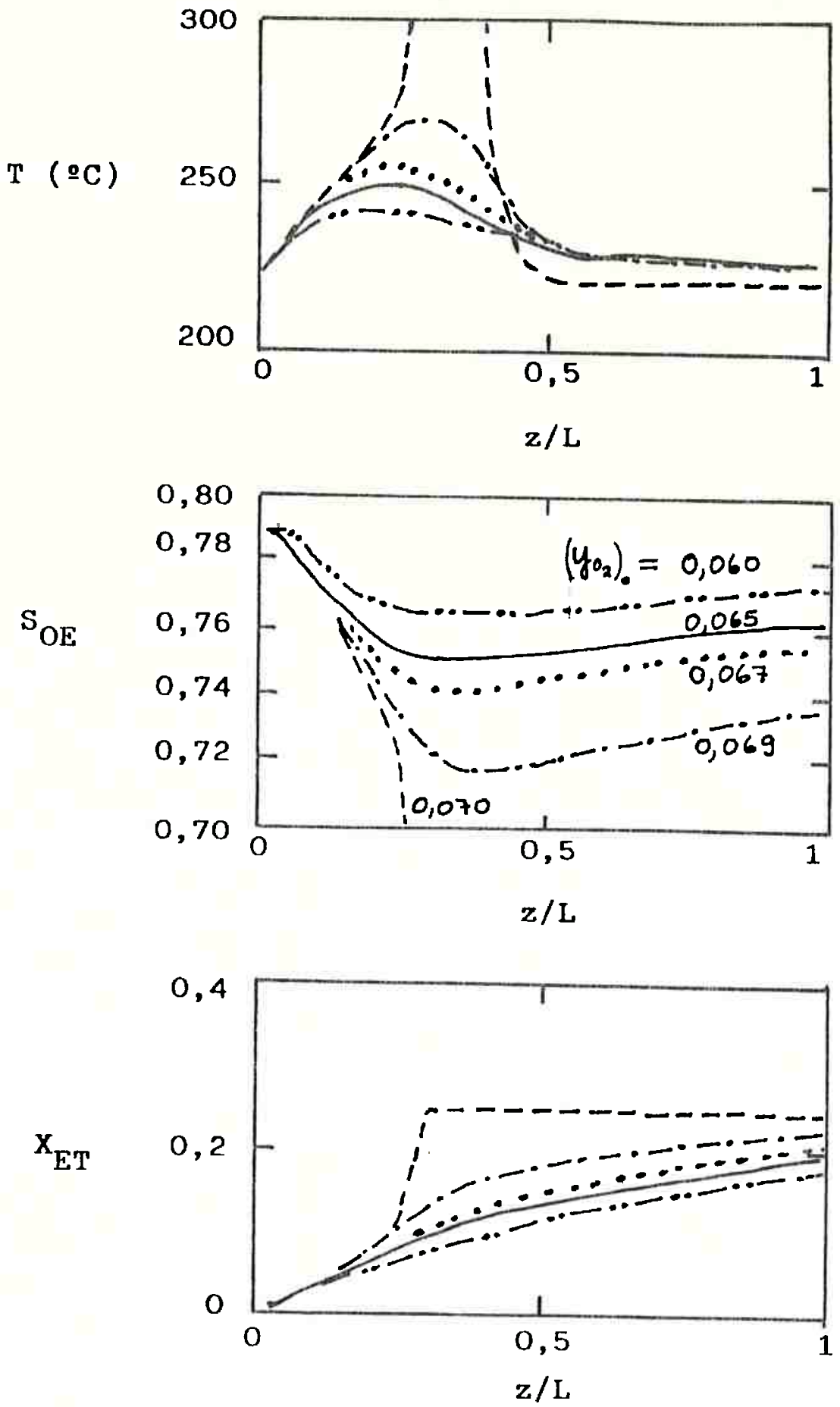

Figura 4.3. Influência da concentração do oxigênio na alimentação. 
T (ㄷ)
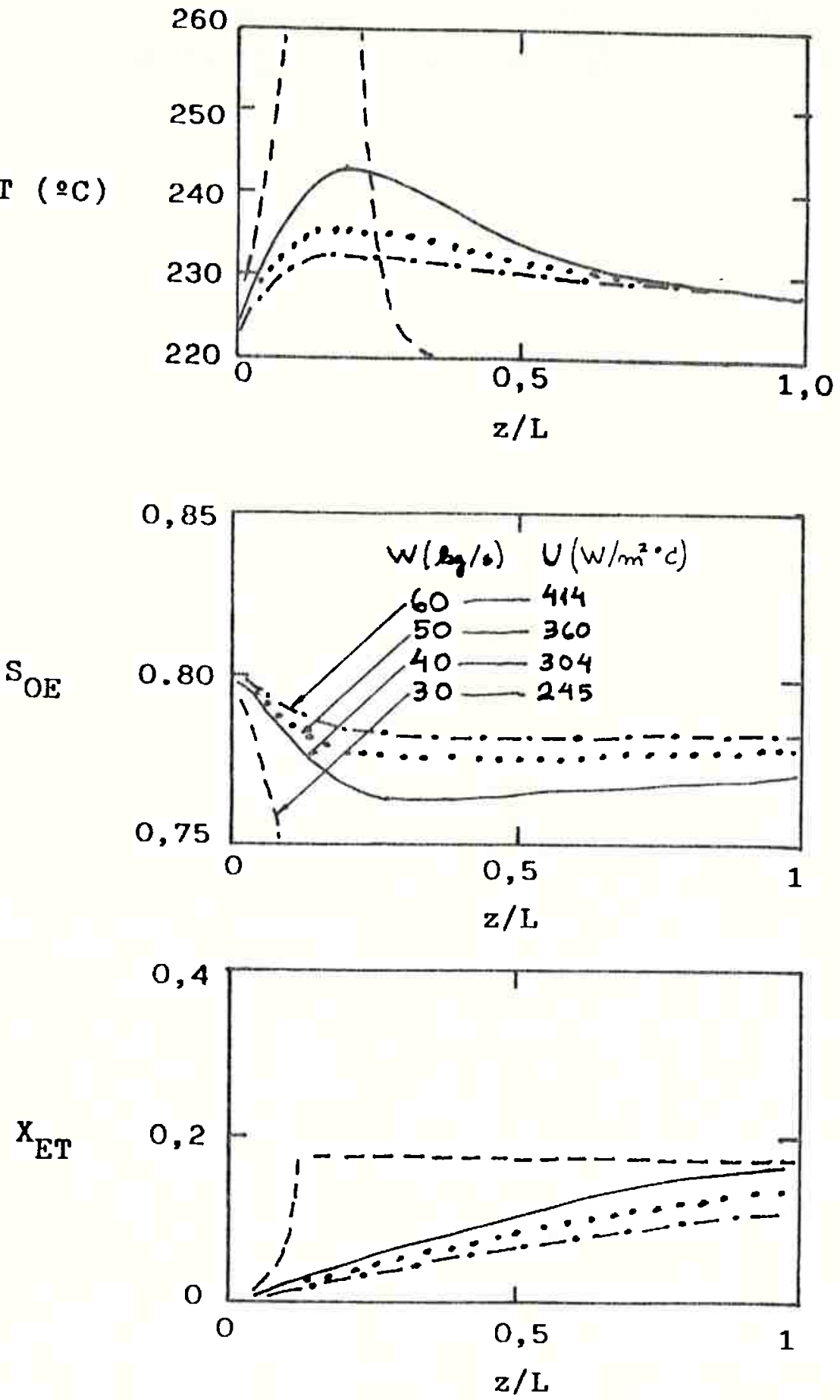

Figura 4.4. Influência da vazão de alimentação. o coeficiente de troca térmica é calculado em função da vazão. 

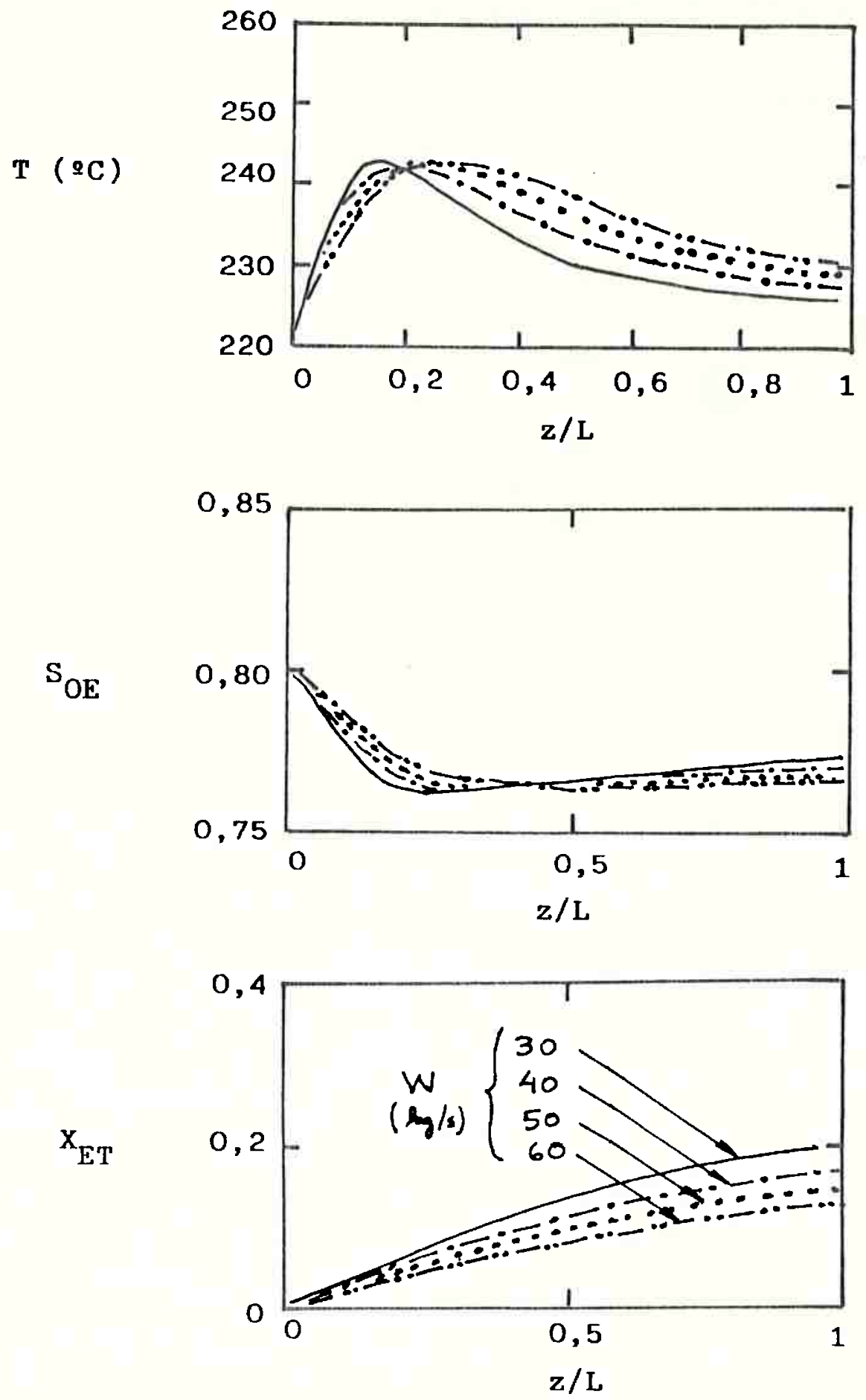

Figura 4.5. Influência da vazão de alimentação quando o coeficiente de transferência de calor é considerado constante $\left(U-304 \mathrm{~W} / \mathrm{m}^{2} \mathrm{o} \mathrm{C}\right)$. 
frente a uma variacão da vazão de alimentacão. Ao aumentar-se a vazão de alimentacão a temperatura do ponto quente permanece praticamente a mesma e sua localizacão varia, deslocando-se mais para dentro do reator, como ilustra a figura 4.5. Este tipo de análise é frequentemente encontrada na literatura (p.ex. Rutzler. 1986) e indicaria que a vazão influi muito pouco na temperatura de ponto quente, mudando apenas a sua localizacão dentro do reator.

Contudo, quando se considera que a coeficiente de transferência de calor depende da vazão, observa-se que mudancas de vazão também podem levar a mudancas de temperatura máxima no reator, como mostrado na figura 4.4. Estas observacôes podea ser explicadas pela análise das equacóes usadas para o cálculo do coeficiente de transferência de calor.

Portanto, tem-se duas previsões de comportamento bastante distintas. O coeficiente global de troca térmica é um parâmetro que deve ser conhecido com bastante precisấ para uma boa previsäo do comportamento do reator.

\subsubsection{Influência da pressäo}

Pela figura 4.6 verifica-se que quanto maior a pressão, até um certo limite, maior a conversăo de etileno, com pouca mudanca na seletividade a óxido de eteno. Uma elevacão execessivã de pressão pode entretanto levar a disparos de temperatura. A escolha da pressáo de operacão decorre, entretanto, de uma análise econômica que envolve o custo de compressão dos gases, recuperafäo do produto e custo do reator.

Pela simulacão verificou-se que também que a queda de pressão no leito é pequena (cerca de 5 a $10 x$ da pressão na entrada). Se reduzir o tempo de processamento do programa for importante 0 balanco de quantidade de movimento pode ser desconsiderado pois 

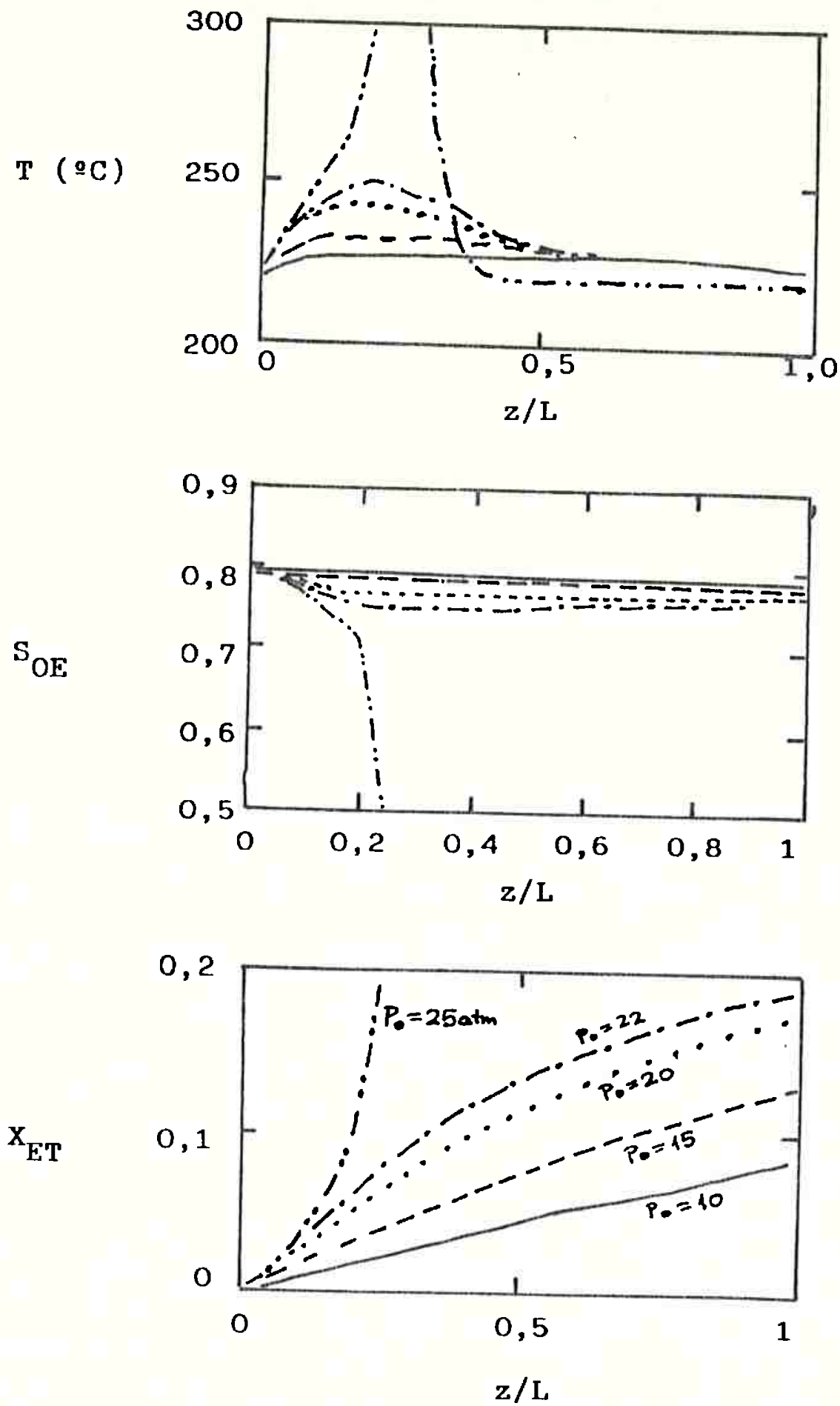

Figura 4.6. Influência da pressão de operação. 
afeta muito pouco o resultado final da simulação, nas condicões estudadas.

\subsubsection{Influência da atividade catalítica do leito}

Como era esperado, quanto maior a atividade catalitica do leito, maiores serão a conversão e a temperatura. 0s resultados mostrados na figura 4.7 sugerem que se possa obter uma estratégia de distribuicão de atividade catalitica no leito a fim de se conter a conversão na entrada do reator $e$, consequentemente, reduzir a temperatura do ponto quente. Este assunto é abordado no Capítulo 5 deste trabalho.

\subsubsection{Influência da cinética da reacăo}

Além do modelo cinético de westerterp \& ptasinski(1984), equacóes (4.22.a) a (4.22.c), tambén foram experimentados outros modelos cinéticos, como o de Heggs \& Assaf (1981), representado por:

$$
\begin{aligned}
& R_{1}=k_{1} \exp \left(-E_{k} / R_{g} T\right) \text { PkT } .+0 \text { POP } \\
& R_{2}=k_{2} \exp \left(-E_{2} / R g T\right) P_{E T^{2-1}} \text { pop-104 } \\
& \mathbf{R}_{\mathbf{3}}=0 \text {. } \\
& (4.24 .-a) \\
& \text { (4.24.b) } \\
& (4.24 . c) \\
& k_{2}=18,0(k m o l)\left(k g(a t)^{-2}(s)^{-1} ; E_{2} / R_{2}=7461 \mathrm{k}^{-x}\right. \\
& k_{z}=713,9(\mathrm{kmol})\left(\mathrm{kg}(\mathrm{cat})^{-x}(5)^{-1} ; E_{z / R_{2}}=8747^{-1}\right.
\end{aligned}
$$

e o de Dogu (1981), expresso na forma:

$$
\begin{aligned}
& R_{1}=k_{2} \exp \left(-E_{1} / R g T\right) C_{E T} 1 / 2 C_{02} \\
& R_{z}=k=\exp \left(-E_{z} / R_{g T}\right) C_{E T} \times / 2 C_{0 z} \\
& \mathbf{R}_{\mathbf{a}}=0 \text {. } \\
& (4.25 . a) \\
& (4.25 . b) \\
& (4.25 . c) \\
& k_{1}=3,04 \times 10^{\circ}(k m a l)(k g c a t)^{-1}(5)^{-1} ; E_{a} / R_{0}=7461 \mathrm{k}^{-1} \\
& k_{z}=3.73 \times 10^{120}(\mathrm{kmol})(\mathrm{kg} \text { cat })^{-x}(s)^{-k} ; E_{a} / R_{0}=8747 \mathrm{~K}^{-1}
\end{aligned}
$$



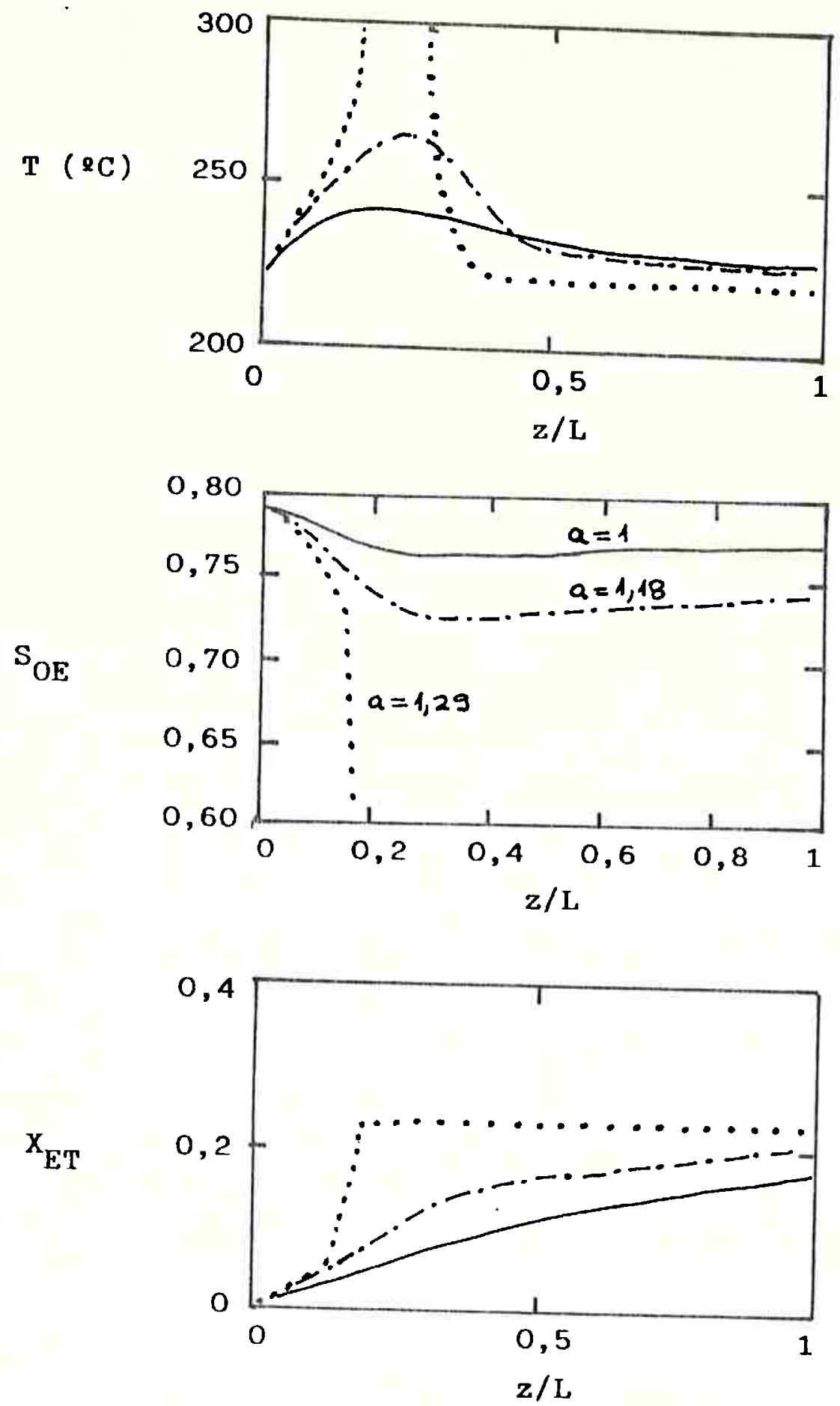

Figura 4.7. Influência da atividade catalítica do leito. 
e o de Buntin (1962)=

$$
\begin{aligned}
& R_{2}=\frac{k_{1} \exp \left(-E_{2} / R g T\right) P_{02} / 2 \text { PET }}{K\left(1+K_{\text {ET PET }}\right)} \\
& R_{2}=\frac{k_{2} \exp \left(-E_{2} / R_{g T}\right) P_{0 z^{2} / 2} P_{k T}}{K\left(1+K_{E T} P_{E T}\right)\left(1+K_{0 z} P_{0 z}{ }^{2 / 2}\right)} \\
& R_{\mathbf{s}}=0
\end{aligned}
$$

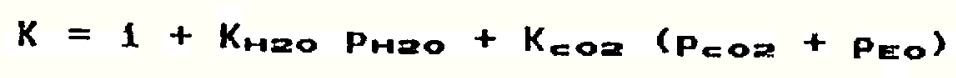

com

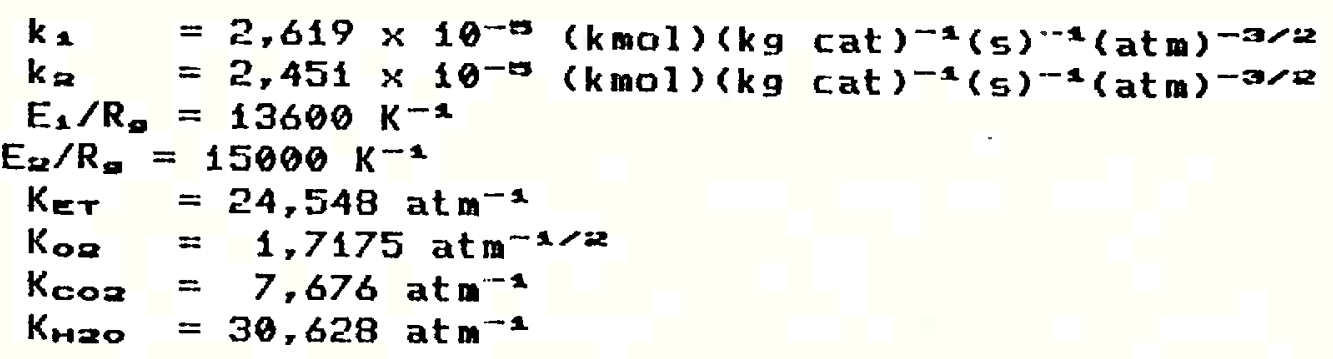

Testes comparativos das previsöes destas três cinéticas foram realizados e mostraram que as previsôes do modelo são fortemente dependentes da expressão da modelo cinético e do valor de seus parâmetros. As expressões acima apresentam previsöes bastante diferentes: esta variedade é decorrente do fato de tais expressões terem sido obtidas a partir de ensaios cinéticos com catalisadores a base de prata de diferentes formulacóes. Isto mostra que boas previsôes quantitativas da simulacão dependem de un adequado conhecimento da cinética das reacöes. Também deve ser enfatizada a necessidade de uma estimaça correta de parâmetros cinéticos, aos quais o modelo é bastante sensivel.

\subsection{Godelo 2 -bidimensional. pseudo-homogêneo estático}

o modelo 2 difere do modelo 1 na hipótese do mímero de dimensões consideradas. No modelo 2 , bidimerisional, são consideradas variacōes radiais, além das longitudinais no reator. Este maior nivel de detalhamento do reator é importante para 
estudar o perfil radial de temperatura, que pode ser bastante acentuado, ou seja, podem ocorrer diferencas significativas de temperatura entre o centro e a parede do reacor.

o modelo pode ser representado pelas seguintes equacões diferenciais parciais de balancos de massa e energia na forma adimensional dada por Carberry (1979):

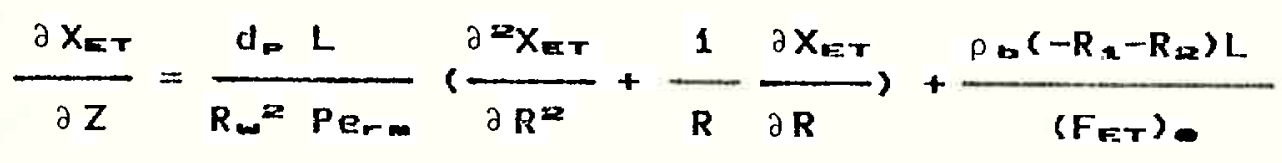

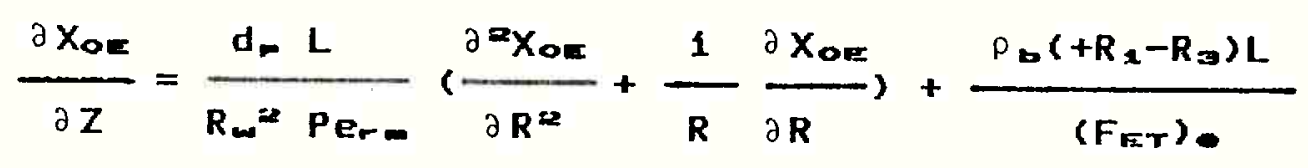

$$
\begin{aligned}
& \frac{\partial T}{\partial Z}=\frac{d_{P} L}{R_{\infty}=P_{E_{-}}}\left(\frac{\partial \geq T}{\partial R^{2}}+\frac{1}{R} \frac{\partial T}{\partial R}\right)+\frac{\rho_{D} \Sigma\left(-\Delta H_{J}\right) R_{J} L}{G C_{F} T_{-}}
\end{aligned}
$$

com as seguintes condicões de contorno:

$$
\begin{aligned}
& R=0 \quad\left(\partial X_{E T} / \partial R\right)=0 \quad\left(\partial X_{O E} / \partial R\right)=0 \quad(\partial T / \partial R)=0 \\
& R=1 \quad\left(\partial X_{\mathbf{L} T} / \partial R\right)=0 \quad\left(\partial X_{\text {OEE }} / \partial R\right)=0 \quad-(\partial T / \partial R)=B i\left(T-T_{\omega}\right) \\
& Z=0 \quad X_{E T}=0 \quad T=T_{0}
\end{aligned}
$$

onde foram utilizadas as seguintes variáveis e parâmetros ad imensionais:

$$
\begin{aligned}
& Z=z / L \quad R=r / R_{\omega} \\
& \operatorname{Pe}_{-}=G C_{m} / d_{m} / k_{r} \\
& \operatorname{Perm}_{r}=d_{p} u / D_{r} \\
& \text { Bi }=h_{\omega} R_{\omega} / k_{r}
\end{aligned}
$$

Neste caso não foi incluido o balanco de quantidade de movimento (para calcular a queda de pressão ao longo do leito) em funcão dos resultados apresentados no item 4.3 , onde se mostra que Esta nåo é uma simplificacão drástica. No entanto näo há qual quer dificuldade conceitual ou de resolucão em se incluir neste modelo a equacão (4.4) para o cálculo da queda de pressão. 
As equacỗes (4.19) a (4.20) foram utilizadas para o cálculo dos números de Peclet radial de calor Pere $e$ de Biot Bi, respectivamente. Para o nimero de Peclet radial de massa utilizouse o seguinte valor, recomendado por Carberry(1979):

$$
\text { Perm }=10
$$

As equacóes diferenciais parciais (4.27) a (4.32) foram resolvidas numericamente utilizando-se os métodos do colocacão ortogonal e Runge-Kutta-Gili. O método de colocacáo ortogonal (Finlayson, 1980) foi aplicado às derivadas radiais (N pontos de colocafão internos), resultando no seguinte sistema de $3 N$ equacões diferenciais ordinárias:

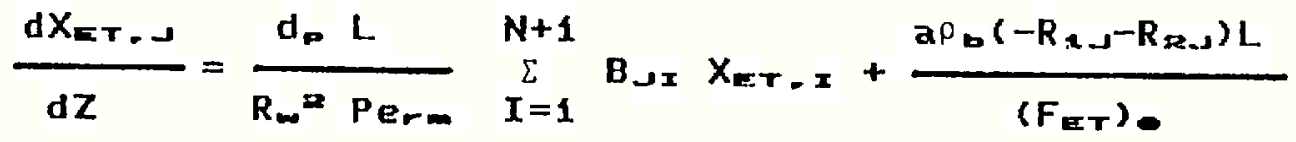

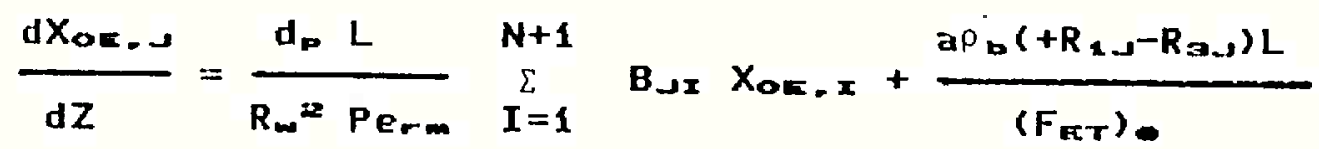

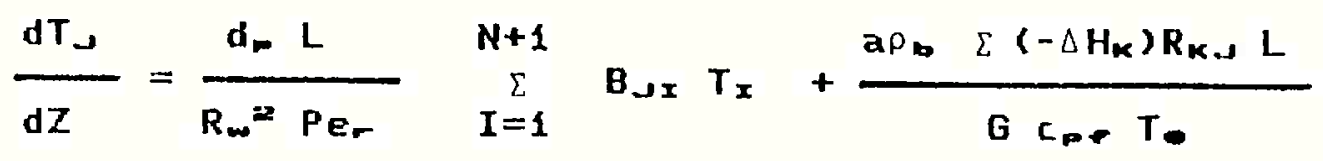

$$
\begin{aligned}
& \rfloor=1,2, \ldots N
\end{aligned}
$$

que foram resolvidas pelo método de Runge-Kutta-Gill. As condicões de contorno $\mathrm{em} R=0$ estão automaticamente satisfeitas quando se usam polinômios ortogonais de grau par, e as condicões de contorno em $R=1$ ficam na forma:

$$
\begin{aligned}
& N+1 \\
& \sum_{I=1} A_{N+1, x} X_{E T, X}=0 \\
& N+1 \\
& \sum_{I=1} A_{N+1, x} X_{\text {On. }}=0 \\
& N+1 \\
& -\sum_{I=1} A_{N+1.1} T_{x}=B i\left(T_{N+2}-T_{\infty}\right)
\end{aligned}
$$


Os valores médios radiais em cada posicäo axial foram calculados a partir dos pesos de quadratura WW do método de colocação ortogonal:

$$
\begin{aligned}
& \bar{X}_{E T}=\sum_{I=1}^{N+1} \quad W W_{x} X_{E T-x} \\
& \bar{X}_{\text {ox }}=\sum_{I=1}^{N+1} \text { WWI } X_{\text {or }}=x \\
& \vec{T}=\sum_{I=1}^{N+1} W W_{x} T_{x}
\end{aligned}
$$

Para efeito de comparacão, foram utilizadas as mesmas condicôes operacionais $e$ os mesmos parâuetros do modelo un id imensional.

\subsection{Besultados obtidos com a modelo bidimensional}

A discretizacão das equacôes do modelo bidimensional aplicando o método de colocacão ortogonal às derivadas radiais pode levar a desvios na resposta numérica. Esses desvios säo minimizados à medida em que se aumenta o numero de pontos internos de colocacão. Entretanto, se utilizamos un número wuito grande de pontos internos de colocacáo o numero de equacöes diferenciais ordinárias a serem integradas cresce bastante e, consequentemente, a tempo de processamento computacional também.

Além disso, com o aumento do número de pontos de colocacáo radial é necessário diminuir o passo de integracão axial do método de Runge-Kutta, pois aumenta a tendência do sistema de equacäes ser tornar rígido ("stiff") (Finlayson, 1980).

A figura 4.8 apresenta perfis radiais de temperaturana posicão axial de máxima temperatura, perfis estes obtidos com diferentes números de pontos de colocafão. Observa-se que uma boa 


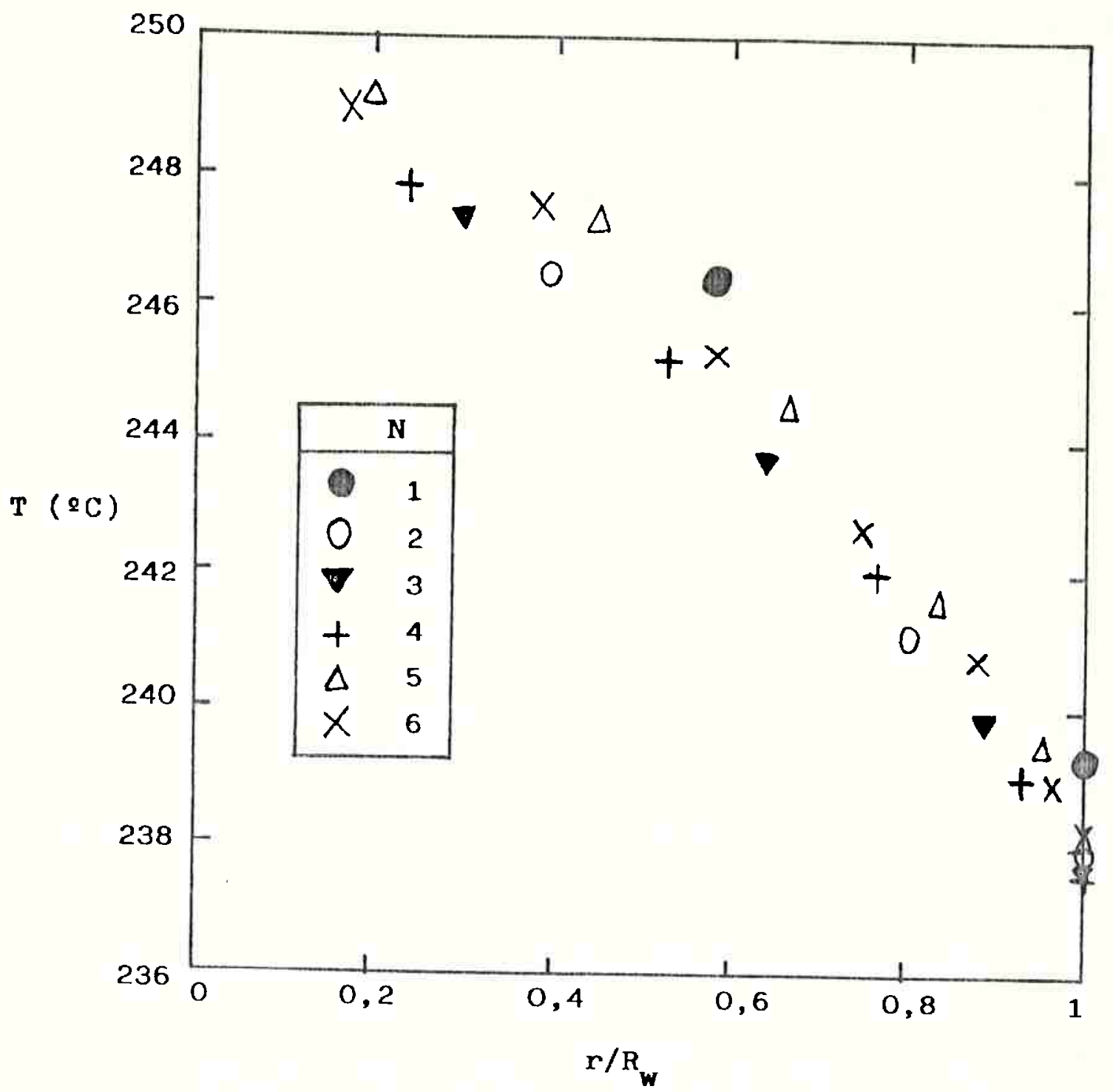

Figura 4. 8. Influência do número de pontos de colocação internos sobre as previsões do modelo. Condições mesmas da Tabela 4.3 , caso base. Perfil radial de temperatura na posição axial de máxima temperatura. 
solucão de compromisso entre precisão e tempo de processamento é conseguida ut ilizando-se dois pontos internos de colocacão.

Un típico resultado comparativo entre as previsões do modelo bidimensional e as do unidimensional está mostrado na figura 4.9. Foi observado que os valores de temperatura no centro do reator sempre foram superiores às correspondentes temperaturas previstas pelo modelo unidimensional. O modelo unidimensional é, portanto, menos conservativo que o bidimensional.

Dessa forma, para a simulacäo de condicōes mais severas de operacão, seria mais recomendável utilizar o modelo bidimensional.

A análise paramétrica do sistema quando realizada en torno de tipicas condicões de operacão industrial mostra que as condicöes práticas estäo bastante afastadas das regiőes onde podem ocorrer instabilidades no processo spor exemplo longe de condicões onde pode haver disparo de temperatura no reator). Nestas condicốes, o estudo da influência das variáveis de processo com o modelo bidimensional leva às mesmas conclusöes qualitativas apresentadas com base no modelo unidimensional, uma vez que, neste caso os valores médios obtidos com o modelo bidimensional são praticamente iguais aos obtidos com o modelo unidimensional.

\subsection{Inclusäo de perfil radial de velocidade no modelo 2}

Como discutido no capitulo 2 , uma hipótese muito frequentemente adotada é a de que o perfil radial de velocidade é plano (escoamento pistonado). Neste item são apresentados resultados referentes a testes sobre a influência da presenca de perfis radiais de velocidade e de porosidade não achatados sobre as previsões do modelo.

Para incluir um perfil radial no modelo bidimensional pode-se recorrer a duas abordagens: (1) impor un perfil de velocidade u(r) 


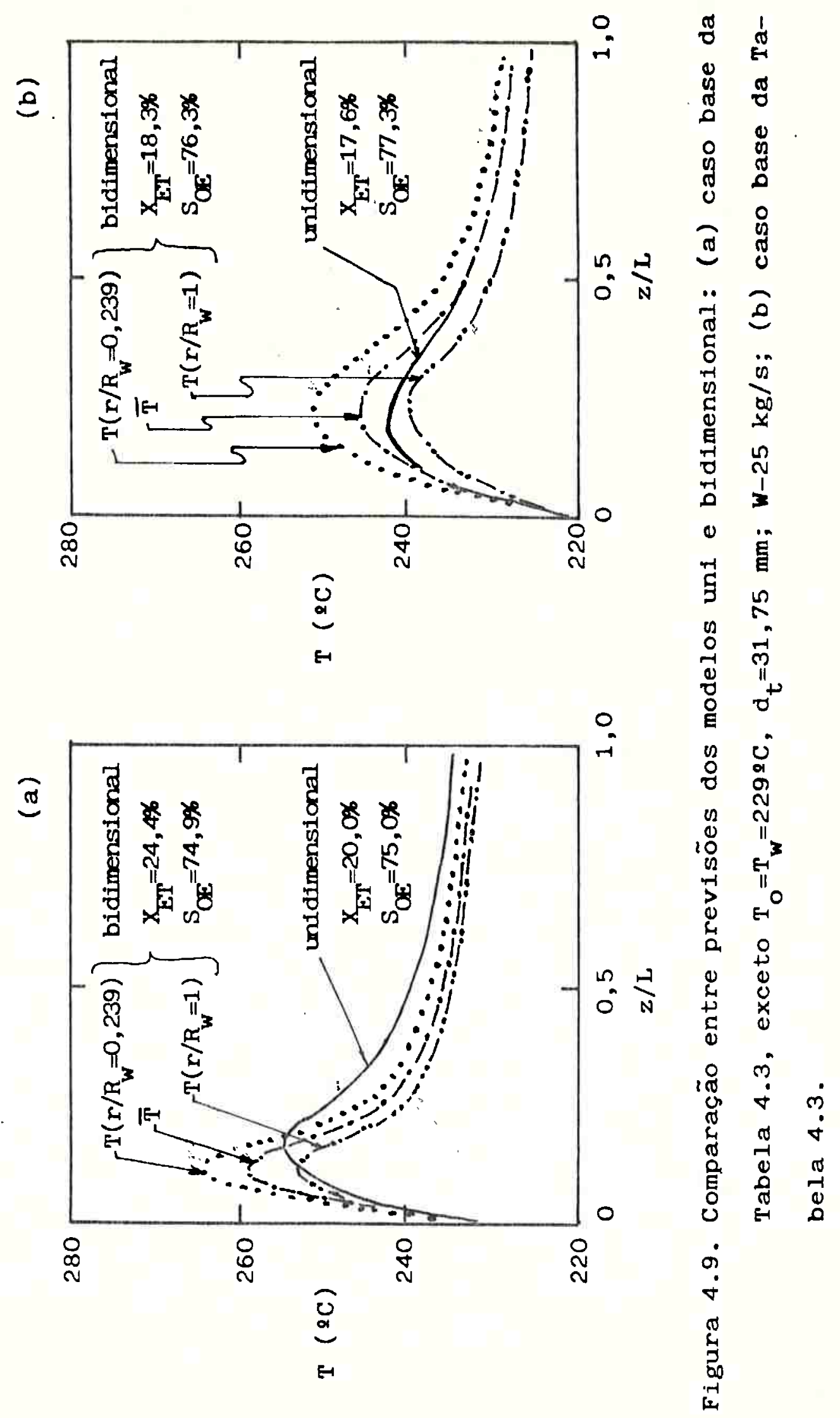


conhecido a priori e resolver as equacóes de massa e energia sujeitas a este escoawento (p-ex. Eigenberg, 1984), ou (2) acrescentar no modelo una equacão diferencial de balanco de quantidade de movimento bidimensional capaz de prever o perfil $u(r)$ (p.ex. Delmas \& Froment, 1988). Esta última abordagem, mais rigorosa, permite considerar a influência da temperatura sobre o perfil de velocidade, porém aumenta consideravelmente a complexidade da simulacão.

A dificuldade de ambas as abordagens está no pouco conhecimento existente sobre as não-uniformidades radiais de leitos fixos.

Seguindo a primeira abordagem, usou-se o perfil de velocidade obtido teoricamente por Vortmeger \& schuster (1983), por solucão numérica da equacão de Brinkman extendida cbalanco diferencial de quantidade de movimento incluindo o termo de atrito com o leito), que foi posteriormente correlacionado na forma:

$$
\left.u / u_{0}=B C 1-\exp \left[a Q\left(1-r / R_{m}\right)\right]\left[1-m Q\left(1-r / R_{m}\right)\right]\right] \text { (4.47) }
$$

onde

$$
\begin{aligned}
& B=\frac{Q^{2}}{2}\left[\frac{Q^{2}}{2}-\frac{(m Q-1)(a Q+1)}{a^{2}}+m\left(\frac{Q^{2}}{a}+\frac{2 Q}{a^{2}}+\frac{2}{a^{3}}\right)\right. \\
& \left.-\frac{\exp (a \theta)}{a^{2}}\left(1-m+\frac{2 m}{a}\right)\right]^{-1} \\
& Q=R_{w} / d_{p} \\
& a=4 m /(4-m) \\
& m=112,5-26,31 R e^{2}+10,97 \mathrm{Re}^{2}-0,1804 R \mathrm{e}^{3} \\
& 0,1<\operatorname{Re}<1 \\
& (4.48 .0) \\
& m=-1863+201,62(\ln R e+4)-3737(1 n R e+4) 1 / 2 \\
& +5399(\ln R e+4) * 13 \\
& m=27 \\
& 1<\operatorname{Re}<1000 \\
& \text { (4. } 49 . b) \\
& \text { Re> } 1000 \\
& (4.49 . C)
\end{aligned}
$$


Esta equacão prevê perfis de velocidade com um máximo bastante acentuado a uma distancia aproximada de 0,25 do da parede, conforme ilustra a figura 4.10.

Além do perfil de velocidade, também a variacão radial de fracão de vazios deve ser incluida no modelo. Isto se reflete nas velocidades de reacão, que deven ser multiplicadas pelo fator $[1-\varepsilon(r)] /[1-\bar{\varepsilon}]$, que corrige o fato de as reacóes ocorrerem apenas na fase sólida. O perfil de porosidade $\varepsilon(r)$ foi calculado usando a seguinte equacão usada por Votmeyer \& Schuster (1983):

$$
\varepsilon(r)=\bar{E}\left[1+\exp \left[1,5\left(d_{t} / d_{m}\right)\left(2 r / d_{t}-1\right)\right]\right]
$$

Com a inclusăo dos perfis radiais de velocidade e de fracão de vazios, as equacōes $(4.26)$ a (4.28) ficam:

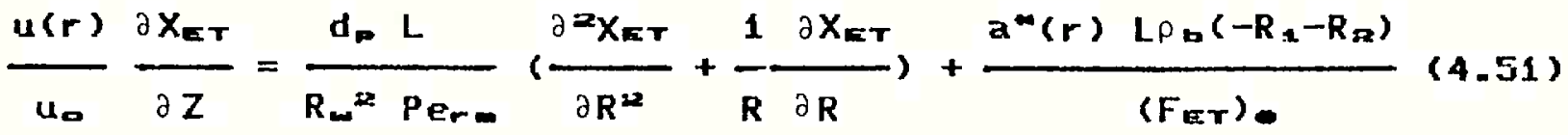

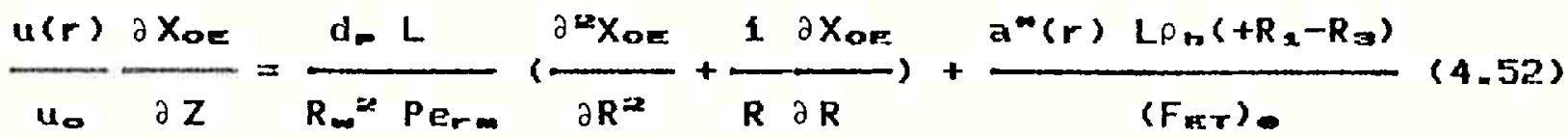

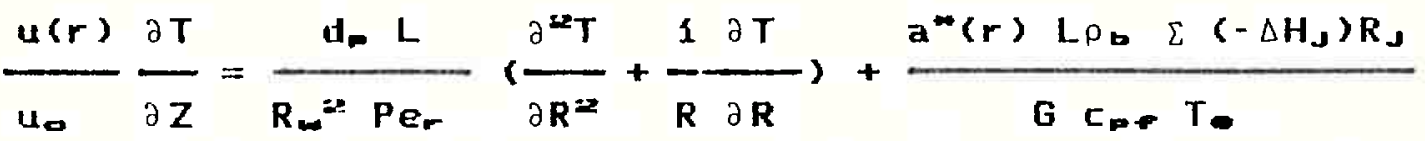

onde

$$
a^{\omega}(r)=a[1-\varepsilon(r)] /[1-\bar{\varepsilon}]
$$

Para a solucảo destas equacões, com as mesmas condicổes de contorno (4.30) a (4.32), foi usado também o método de colocacão ortogonal para a direcão radial e o método de Runge-Kutta-Gill para a integracão na direcäo axial. No entanto, neste caso, para que o perfil u(r) fosse razoavelmente bem representado, foi 

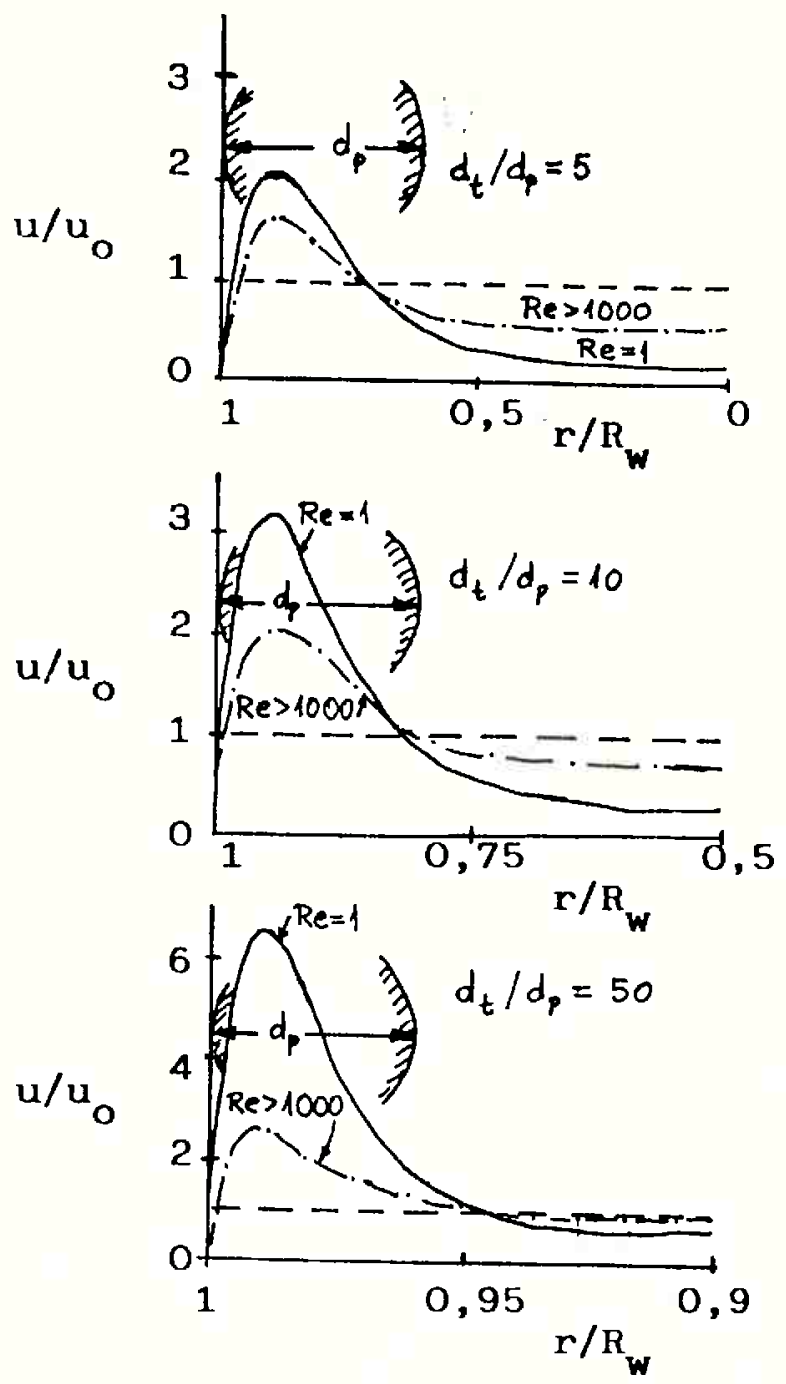

Figura 4.10. Perfis radiais de velocidade em leitos fixos de esferas, conforme as previsões de Vortmeyer \& Schuster (1983), equações (4.47) a (4.49) (extraido de Tsotsas \& Schlunder, 1988). 
preciso considerar um maior número de pontos de colocacão radial; testes mostraram ser necessários no minimo 4 pontos internos.

Resultado deste modelo modificado estão mostrados nas figura 4.11 e 4.12, em comparacão com as previsōes do modelo bidimensional convencional. Observa-se que o modelo que inclui perfis de velocidade e porosidade mais conservativo que o modelo bidimensional convencional, prevendo temperaturas de ponto quente maiores. Sob condicōes mais extremas, como na figura 4.12, 0 modelo comperfis radiais prevé disparos de temperatura enquanto que o modelo convencional não o prevê.

\subsection{Comentários gerais}

Neste Capitulo foram estudados alguns modelos para a simulacão do reator catalitico de leito fixo para produçấo de óxido de eteno. Os modelos de diferentes graus de complexidade for am estudados, mostrando-se, em cada caso, situacöes em que se podem obter informacôes importantes a partir da simulaçáo.

Os estudos de simulacão evidenciam a necessidade de um bom conhecimento de certos parametros do mode10, tais como parâmetros cinéticos $e$ de transferencia de calor. Mesmo o modelo mais simples, o unidimensional pseudo-homogêneo, pode ter grande utilidade em estudas do processo, como se mostra no capitulo 5. Para que certas deficiências do modelo, como as estudadas neste Capitulo 4, possam ser corrigidas, faz-se necessário uma identificacáo do modelo com dados do processo, de modo que aqueles parâmetros mais importantes possam ser ajustados. Este procedimento de identificakão do modelo é estudado no Capitulo 6. 


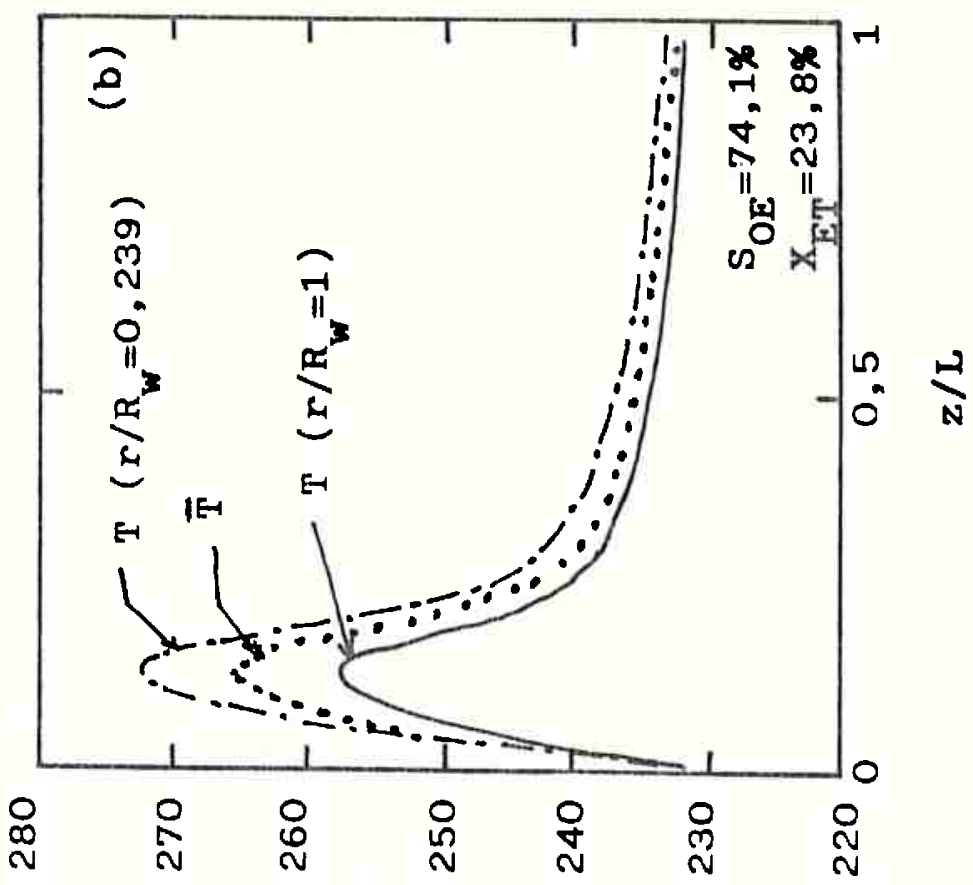

엉

엉

(3)

告

先

0
0
0
0
0
0
0
0
0
0
0
0

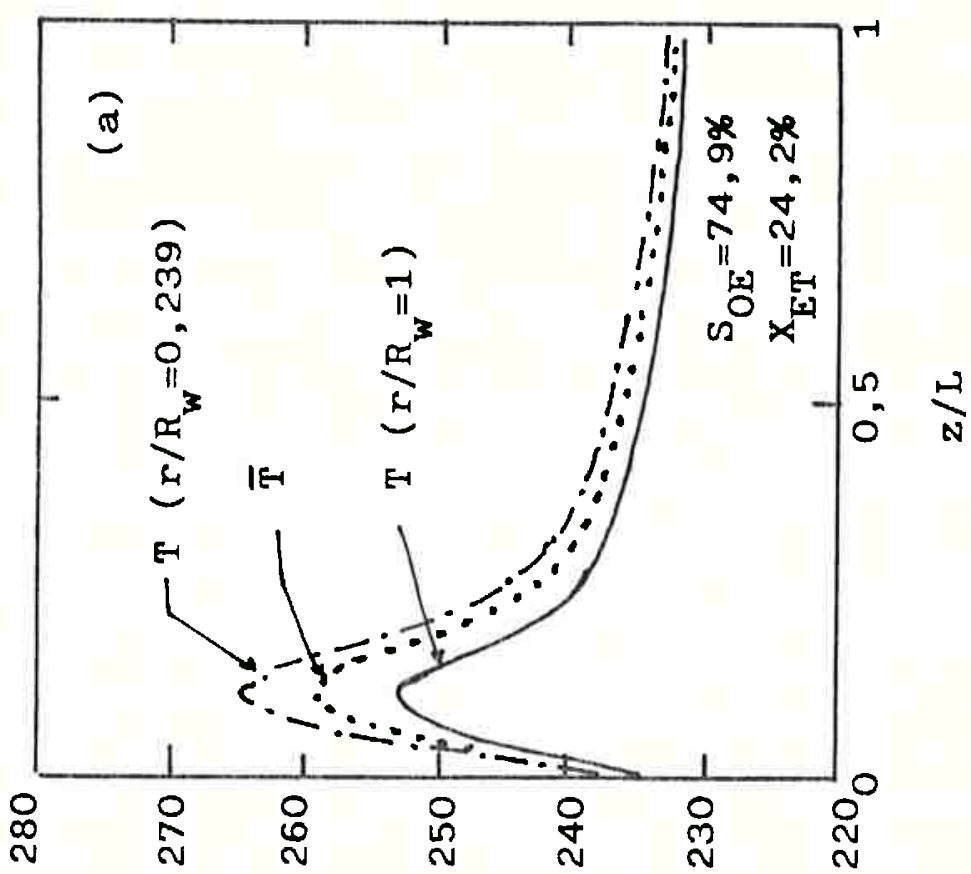

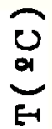

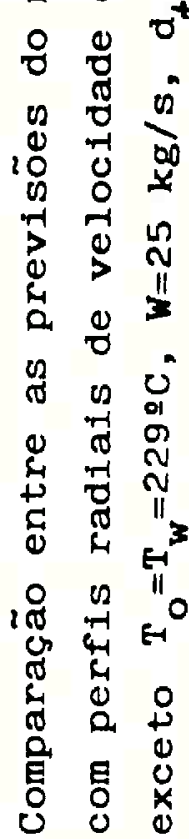

-

$\mathfrak{c}_{\substack{\infty \\ 0-1}}^{\infty}$ 


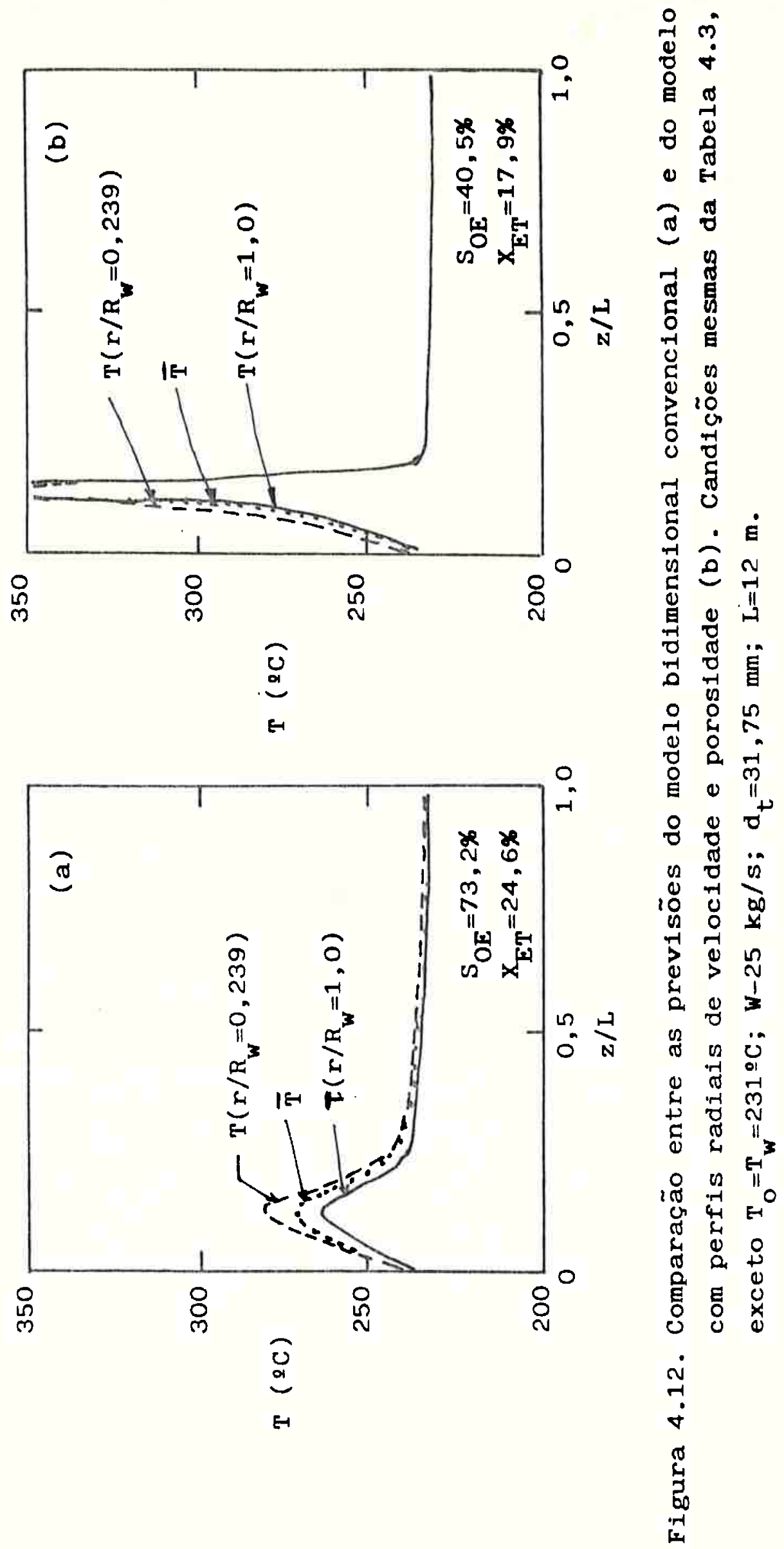




\section{Capitulo 5}

\section{ESTUDO DE ESTRATÉgIAS DE DILUICÁO DO LEITO CATALÍTICO}

\subsection{Introducão}

Neste Capítulo sáo apresentados resultados de um estudo sobre a viabilidade de se utilizar estratégias de diluicão do leito catalitico do reator de producäo de óxido de eteno, visando diminuir ou evitar pontos quentes, reduzir a sensibilidade do reator às condicôes de processo e aumentar a faixa de operacão segura.

Para tanto foi usado o modelo unidimensional pseudo-homogêneo ao qual foram incluidos diferentes perfis de atividade catalitica do leito. Também foi verificada a possibilidade de ocorrência de pontos quentes localizados quando a diluigáo do leito feita por mistura de particulas ativas e inertes.

\subsection{Modelo matemaitico empregado}

o modelo utilizado neste estudo é o unidimensional pseudohomogêneo sem dispersão axial, já descrito e testado no Capitulo 4 (modelo 1). As principais equacöes são a seguir reproduzidas:

$$
\begin{aligned}
& \frac{d X_{E T}}{d z}=\frac{A \rho_{b}\left(-R_{2}-R_{z}\right) a}{\left(F_{E T}\right)_{-}} \\
& \frac{d X_{0 E}}{d z}=\frac{A \rho_{b}\left(+R_{2}-R_{B}\right) a}{\left(F_{E T}\right)_{0}} \\
& \frac{d T}{d z}=\frac{-\rho_{b} \sum\left(-\Delta H_{J}\right) R_{J} a-U\left(4 / d_{t}\right)(T-T w)}{G C_{m}} \\
& \frac{d P}{d z}=\frac{-f G U}{d_{m}}
\end{aligned}
$$


onde a atividade do leito catalítico é, neste estudo, uma funcão da posicão, ou seja, $a=a(z)$.

- fator de atrito foi calculado pela equacão de Ergun (4.18) e o coeficiente global de transferencia de calor pelas equacöes $(4.19),(4.26)$ e $(4.21)$.

As velocidades das reacopes foram calculadas pelo modelo cinético de Westerterp \& Ptasinski (1984):

$$
\begin{array}{ll}
R_{1}=k_{1} \exp \left(-E_{1} / R_{-} T\right) \text { Co2 } & (4.22 . a) \\
R_{\mathbf{a}}=k_{\mathbf{2}} \exp \left(-E_{2} / R_{\mathbf{0}} T\right) \operatorname{Cog} & (4.22 . b) \\
R_{3}=0 & (4.22 . c)
\end{array}
$$

onde $k_{1}=76.4\left(\mathrm{~m}^{3}\right)\left(\mathrm{kg} \mathrm{cat}^{-1}(5)^{-1}, E_{k} / R_{9}=7200 \mathrm{~K}^{-1}\right.$,

$k_{2}=29400\left(m^{30}\right)\left(k g(a t)^{-1}(s)^{-1}, E_{2} / R_{g}=10800 \mathrm{~K}^{-1}\right.$

Tipicamente as condicôes utilizadas em reator industrial de oxidacão de eteno com oxigênio, a concentracăo de eteno na alimentacão éda ordem de $17 x$ molar, bastante superior à de oxigênio (em torno de $6 x$ molar), o que explica as expressöes

\begin{tabular}{|c|c|}
\hline Parâmetro & símbolo e valor \\
\hline 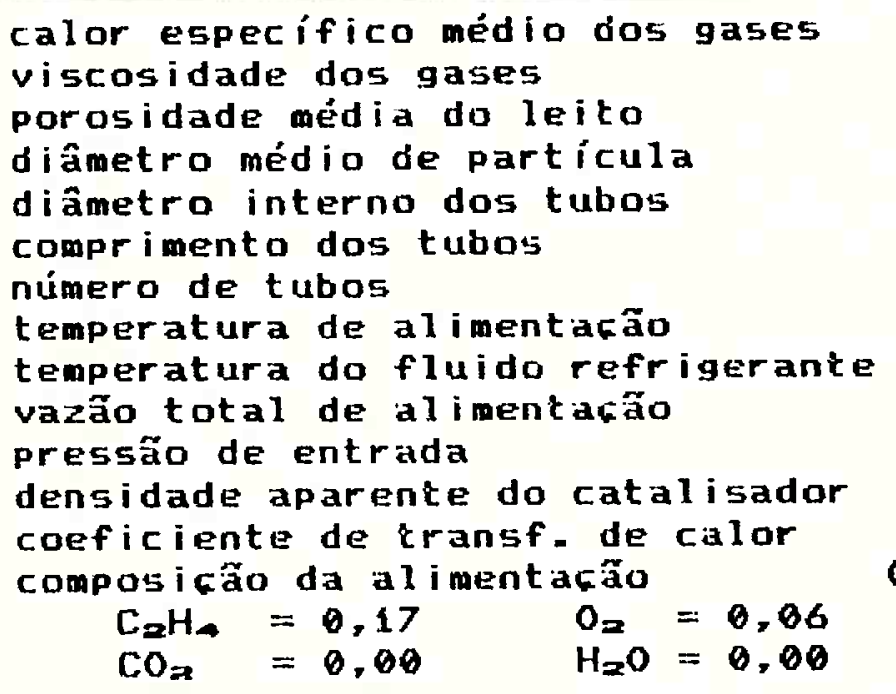 & 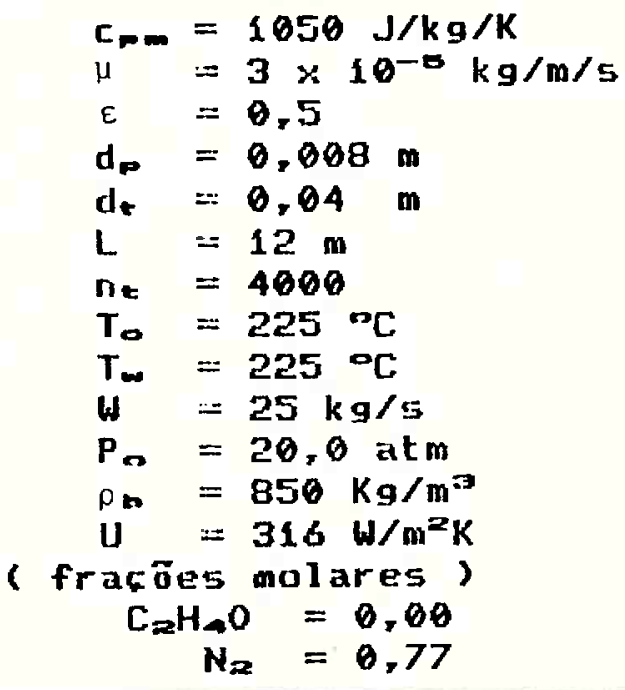 \\
\hline
\end{tabular}
cinéticas (5.1) e (5.2) utilizadas. Os valores dos parâmetros $e$ condicões utilizadas na simulacão são mostrados na Tabela 5.1.

Tabela 5.1. Valores dos parâmetros usados na simulacão conjunto base de condicôes operacionais. 


\subsection{Resultados da simulacăo}

As variáveis de operacăo utilizadas para analisar a sensibilidade paramétrica do modelo foram a temperatura, a composicão e a vazão da alimentacão. Como nos reatores industriais existe uma secão de pré-aquecimento, ew wuitos dos casos simulados a temperatura de alimentacáo foi considerada igual à da parede dos tubos.

Para un reator de leito catalitico de atividade uniforme a influência da temperatura e concentraçăo de oxigênio na al imentacão sobre os perfis de temperatura é mostrada na Tabela 5.2 e na figura 5.1. Observa-se que há uma limitaçăo nas condicôes de entrada para que não ocorra disparo de temperatura no leito.

Tabela 5.2. Efeito da temperatura de alimentacão e do fluido refrigerante e da concentracão de $o_{2}$ na alimentacáo no desempento do reator para un leito com atividade un i forme

\begin{tabular}{|c|c|c|c|c|c|}
\hline$T_{0}=T_{\infty}\left({ }^{\circ} C_{0}\right)$ & yoz & $T_{H E}\left({ }^{\circ} C\right)$ & $Z_{\text {He }}$ & $x_{E}+(x)$ & Sorn $(Z)$ \\
\hline $\begin{array}{l}220 \\
225 \\
230 \\
232 \\
233 \\
234\end{array}$ & $\begin{array}{l}0.060 \\
0.060 \\
0.060 \\
0.060 \\
0.060 \\
0.060\end{array}$ & $\begin{array}{c}233,1 \\
243,2 \\
258,5 \\
270,8 \\
287,5 \\
\text { disparo }\end{array}$ & $\begin{array}{l}0,15 \\
0,15 \\
0,16 \\
0,18 \\
0,21 \\
-\end{array}$ & $\begin{array}{l}16,2 \\
18,4 \\
20,4 \\
21,3 \\
21,9 \\
20,0\end{array}$ & $\begin{array}{l}78,6 \\
76,8 \\
74,4 \\
72,7 \\
70,4 \\
47,6\end{array}$ \\
\hline $\begin{array}{l}225 \\
225 \\
225 \\
225\end{array}$ & $\begin{array}{l}0,060 \\
0,070 \\
0,075 \\
0,076\end{array}$ & $\begin{array}{c}243,2 \\
253,5 \\
278,5 \\
\text { disparo }\end{array}$ & $\begin{array}{l}0,15 \\
0,18 \\
0,26 \\
--\infty\end{array}$ & $\begin{array}{l}18,4 \\
22,5 \\
25,8 \\
25,2\end{array}$ & $\begin{array}{l}76,8 \\
75,5 \\
72,3 \\
47,9\end{array}$ \\
\hline
\end{tabular}

Considerando como 1 imite aceitável que a seletividade em óxido de eteno não deva ser menor que 70x, verifica-se que os I imites de operação são muito estreitos quando se usa um leito de at ividade un iforme- 

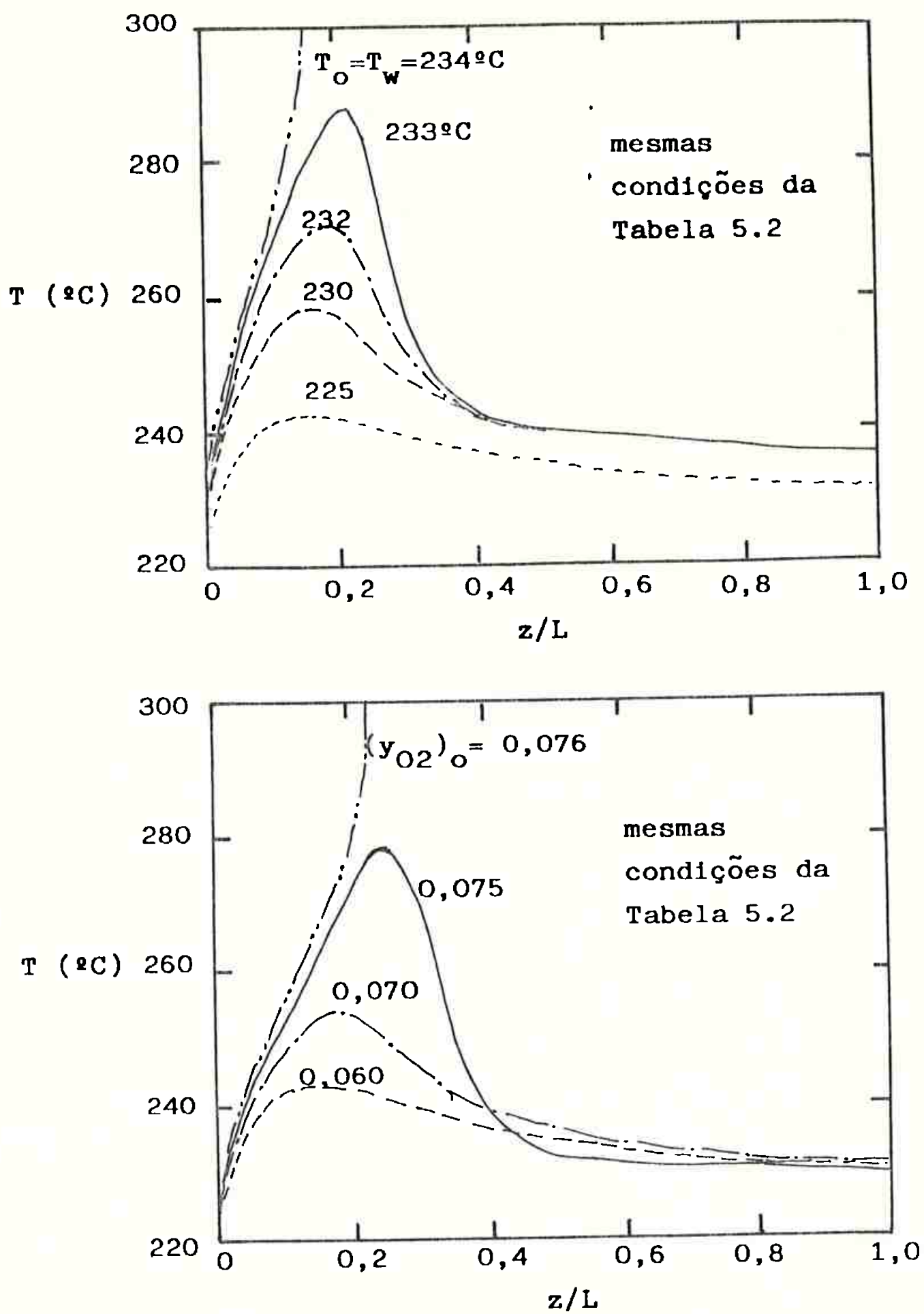

Figura 5.1. Influência das temperaturas de alimentação e de refrigeração, e da concentração de oxigênio na alimentação sobre o comportamento de um leito de atividade uniforme. 
Algumas estratégias de diluicão de leito podén ser propostas para que se possa ampliar os limites de operabilidade do reator. A diluifão do leito pode ser implantada, em princípio, variando-se a quantidade de sitios ativos dentro da particula de catalisador cou a quantidade de prata no suporte de alumina, no caso da reacão em estudo) ou constituindo o leito com uma mistura de partículas cataliticas ativas com partículas de material inerte (por exemplo alumina)

A primeira estratégia de diluicáo estudada foi a descrita por Pirkle \& Wachs (1987) camposta de dois patamares de atividade, formalmente expressa por:

$$
a=\left\{\begin{array}{lll}
a_{1} & \text { para } & 0<z / L<Z_{1} \\
a_{2} & \text { para } & Z_{2}<z / L<1
\end{array}\right.
$$

caracterizada, portanto, por trés parâmetros (a, $\left.a_{a}, Z_{1}\right)$.

Como ilustram a Tabela 5.3 e a figura $5.2(a)$, fixando-se as $=1$ e $Z_{1}=0,25$ e variando a. observa-se que valores elevados de $a_{1}(p-e x .0,95)$ conduzem a uma elevacáo de temperatura no início do reator. Um valor excessivamente baixo de $a_{1}(p . e x=0,1)$ provoca uma pequena conversão na primeira parte do leito porém un pico de temperatura ra segunda sefão. Este fenômeno é dito sensibilidade reversa (Pirkle \& Wachs, 1987). Para uma condicăo intermediária $\left(a_{1}=0,75\right)$ é observada a máxima seletividade e o menor pico de temperatura. Isto mostra claramente a ocorrência de um problema de ot imização.

Fixando $a_{x}=0,75 ; a_{z}=1$ e aumentando $Z_{x}$, observa-se uma diminuicão da temperatura máxima e uma elevacia da seletividade. Entretanto, como o leito está com uma atividade global menor, a conversão total também diminui apreciavelmente. A Tabela 5.4 e a figura $5.2(b)$ mostram alguns resultados simulados. 

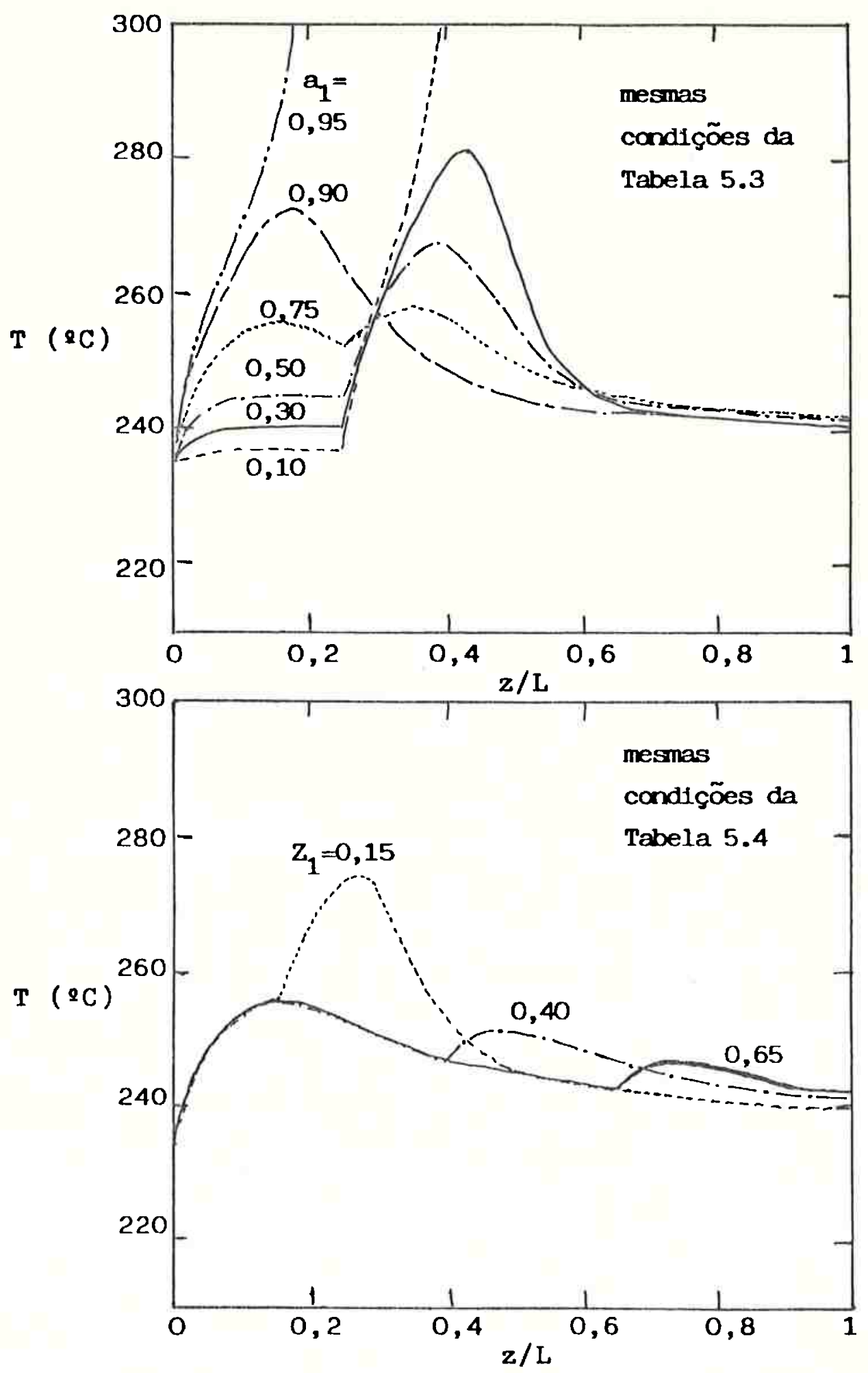

Figura 5.2. Influência dos parâmetros $a_{1}$ e $Z_{1}$ sobre o comportamento de um leito com estratégia de diluição. 
Tabela 5.3. Influência da atividade $a_{1}$ da primeira secão de leito para $Z_{2}=0,25 ; a_{2}=1 ; T_{0}=T_{\omega}=235$ o $;$ yet $=0,17$; yoz $=0,06$

\begin{tabular}{|c|c|c|c|c|}
\hline$a_{1}$ & $T_{H e}\left({ }^{\circ} \mathrm{C}\right)$ & $Z_{\text {He }}$ & $X_{E r r}(Z)$ & Sore $(z)$ \\
\hline $\begin{array}{l}0,10 \\
0,30 \\
0,50 \\
0,70 \\
0,75 \\
0,80 \\
0,85 \\
0,90 \\
0,95\end{array}$ & $\begin{array}{c}\text { disparo } \\
281,7 \\
267,6 \\
260,5 \\
259,3 \\
259,5 \\
264,5 \\
272,8 \\
\text { di isparo }\end{array}$ & $\begin{array}{l}0,-43 \\
0,38 \\
0,345 \\
0,33 \\
0,16 \\
0,16 \\
0,18 \\
-\end{array}$ & $\begin{array}{l}20.1 \\
20.8 \\
20.7 \\
21.1 \\
21.2 \\
21.4 \\
21.5 \\
21.7 \\
21.1\end{array}$ & $\begin{array}{l}48,3 \\
71,0 \\
72,8 \\
73,2 \\
73,2 \\
73,1 \\
72,7 \\
72,0 \\
52,9\end{array}$ \\
\hline
\end{tabular}

Tabela 5.4. Influência do tamanho $Z_{2}$ da primeira seçäo de leito para a. $=0,75 ; a_{2 x}=1 ; T_{0}=T_{0}=235 \circ \mathrm{C} ;$ yer $=0,17$; $y_{02}=0,06$

\begin{tabular}{|c|c|c|c|c|}
\hline$Z_{2}$ & $T_{H=}\left({ }^{\circ} \mathrm{C}\right)$ & $Z_{\text {HE }}$ & $X_{E T}(X)$ & $S_{\text {orm }}(x)$ \\
\hline $\begin{array}{l}0,15 \\
0,40 \\
0,65 \\
0,80\end{array}$ & $\begin{array}{l}273,7 \\
255,9 \\
255,9 \\
255,9\end{array}$ & $\begin{array}{l}0,26 \\
0,145 \\
0,145 \\
0,145\end{array}$ & $\begin{array}{l}21.8 \\
20.6 \\
19.6 \\
19.0\end{array}$ & $\begin{array}{l}71,9 \\
73,6 \\
73,9 \\
73,9\end{array}$ \\
\hline
\end{tabular}

Uma caracteristica interessante do leito diluido com o perfil dado Pela equacão (5.1) é mostrada na Tabela 5.5. Fixando-se a temperatura do fluido refrigerante, uma diminuigáo da cemperatura cie alimentaçáo provoca um aumento na tendência de disparo de temperatura, comporfamento oposto ao observado para leito un iforme. Este fenômeno é outro caso de sensibilidade reversa, também foi observado por Pirkle \& Wachs (1987). Este fenômeno pode ser explicado quamo se analisam os valores de conversä́o temperatura na entrada da segunda secáo do leito cestes valores também estão reportados na Tabela 5.5). Quanto menor a temperatura de al imentacão, maior a temperatura e menor a conversão na entrada da segunda secão de leito, favorecendo, nesta, a ocorrência de disparo de temperatura. 
0s dois casos de sensibilidade reversa observados mostran a necessidade de estudos cuidadosos para uma implantacão prática da diluicão do leito catalitico, para que se delimite bea sua faixa adequada de operacão.

Tabela 5.5. Influência da temperatura da alimentacáo sobre o desempenho do reator com leito diluido, para temperatura do fluido refrigerante mantida constante em $T_{\omega}=240{ }^{\circ} \mathrm{C}$ F $z_{1}=0,25 ; a_{1}=0,75 ; a_{2}=1 ; y_{\mathrm{kr}}=0,17 ; y_{02}=0,06$

\begin{tabular}{|c|c|c|c|c|c|c|}
\hline$T_{0}\left({ }^{\circ} \mathrm{C}\right)$ & $T_{H O}\left({ }^{\circ} \mathrm{C}\right)$ & $Z_{H E}$ & $x_{\text {ET }}(x)$ & Soer $(z)$ & $\begin{array}{c}\text { valores } \mathrm{em} \\
\text { T(OC) }\end{array}$ & $\begin{array}{l}z=0,25 \\
x_{E}(x)\end{array}$ \\
\hline $\begin{array}{l}240 \\
220 \\
200 \\
180 \\
150 \\
100\end{array}$ & $\begin{array}{r}274,8 \\
275,8 \\
281,2 \\
286,7 \\
298,6 \\
\text { disparo }\end{array}$ & $\begin{array}{l}0,16 \\
0,31 \\
0,33 \\
0,33 \\
0,36 \\
----\end{array}$ & $\begin{array}{l}22,5 \\
22,6 \\
22,6 \\
22,6 \\
22,8 \\
22,4\end{array}$ & $\begin{array}{l}70,5 \\
70,4 \\
70,1 \\
69,6 \\
68,3 \\
55,6\end{array}$ & $\begin{array}{l}266,6 \\
268,3 \\
269,4 \\
270,1 \\
270,8 \\
271,2\end{array}$ & $\begin{array}{l}9,8 \\
9,6 \\
8,5 \\
8,1 \\
7,7 \\
7,3\end{array}$ \\
\hline
\end{tabular}

As vantagens de se aplicar a diluicăo do leito catalítico ficam evidentes no exemplo mostrado a seguir. Para ua perfil de at ividades dado por $a_{1}=0,75 ; a_{2}=1$ e $Z_{2}=0,25$ os resultados da Tabela 5.6 e figuras $5.3(a)$ (b) mostram que os limites operacionais podem ser substancialmente ampliados em relacäo à operação com atividade do leito uniforme.

Tabela 5.6. Influência da temperatura da alimentaçáo e do fluido refrigerante e da fraçäo molar de $O_{2}$ na alimentação no desempenho do reator com leito diluido: a1 $=0,75$; $a_{2}=1 ; Z_{2}=0,25 ; y_{\varepsilon T}=0,17$

\begin{tabular}{|c|c|c|c|c|c|}
\hline$T_{0}=T_{-}\left({ }^{\circ} \mathrm{C}\right)$ & YOx & $T_{H D}\left({ }^{\circ} \mathrm{C}\right)$ & $Z_{H e}$ & $x_{\in} \in r(x)$ & $S_{\text {OEE }}(X)$ \\
\hline $\begin{array}{l}233 \\
235 \\
238 \\
240 \\
242 \\
243\end{array}$ & $\begin{array}{l}0.060 \\
0.060 \\
0.060 \\
0.060 \\
0.060 \\
0.060\end{array}$ & $\begin{array}{r}254,9 \\
259,3 \\
265,7 \\
274,8 \\
305,4 \\
\text { disparo }\end{array}$ & $\begin{array}{l}0,33 \\
0,33 \\
0,31 \\
0,16 \\
0,215 \\
-\end{array}$ & $\begin{array}{l}20.5 \\
21,2 \\
22,1 \\
22,5 \\
22,7 \\
19,0\end{array}$ & $\begin{array}{l}74,1 \\
73,2 \\
71,7 \\
76,5 \\
66,3 \\
45,5\end{array}$ \\
\hline $\begin{array}{l}225 \\
225 \\
225 \\
225 \\
225 \\
225\end{array}$ & $\begin{array}{l}0,060 \\
0,070 \\
0.080 \\
0,085 \\
0,087 \\
0,088\end{array}$ & $\begin{array}{c}239,4 \\
244,5 \\
253,2 \\
263,3 \\
279,4 \\
\text { disparo }\end{array}$ & $\begin{array}{l}0,34 \\
0,345 \\
0,36 \\
0,38 \\
0,43 \\
---\end{array}$ & $\begin{array}{l}17,4 \\
21,2 \\
25,6 \\
28,3 \\
30,4 \\
34,3\end{array}$ & $\begin{array}{l}77,1 \\
76,4 \\
75,3 \\
74,1 \\
72,3 \\
50,9\end{array}$ \\
\hline
\end{tabular}




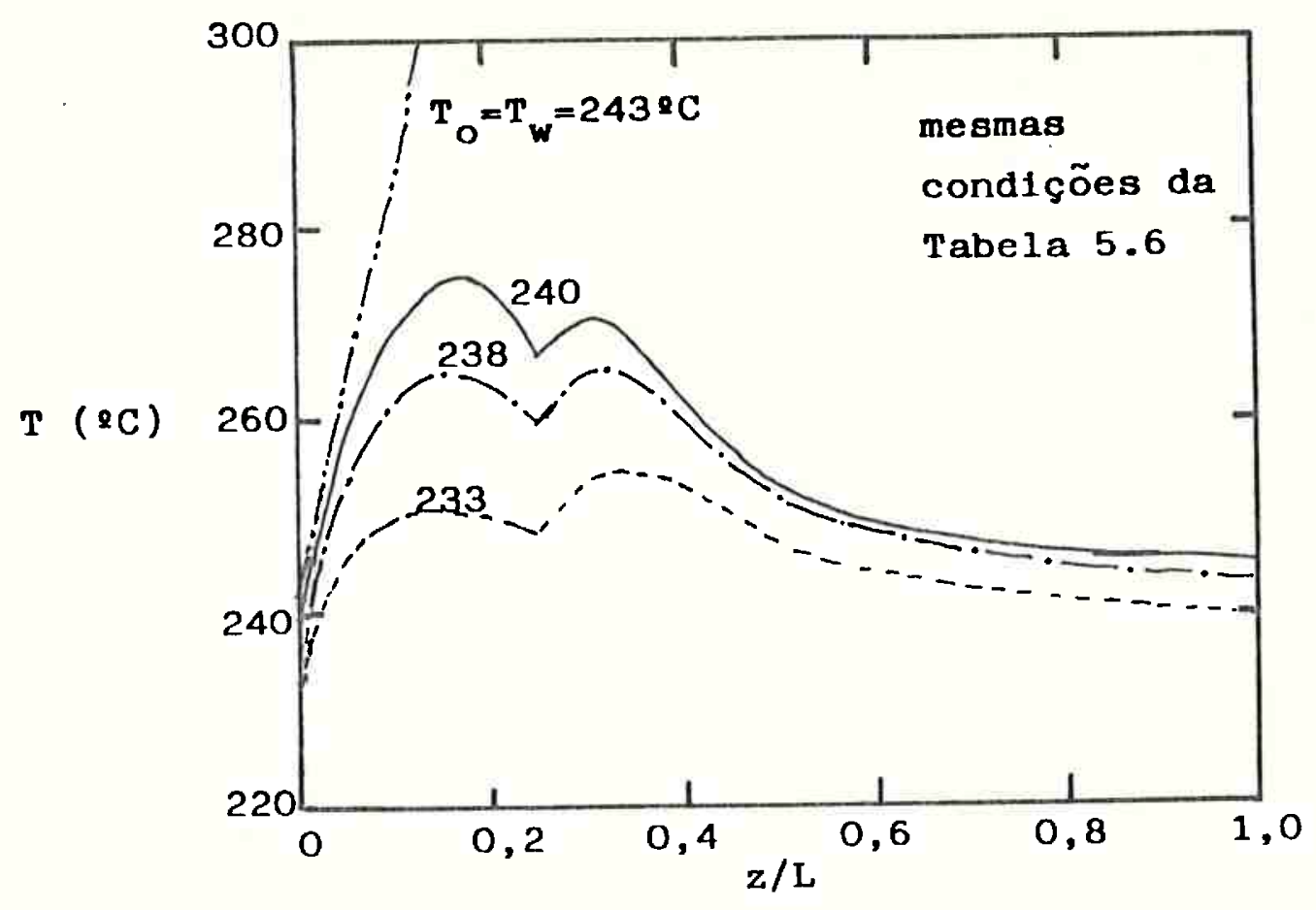

(a)

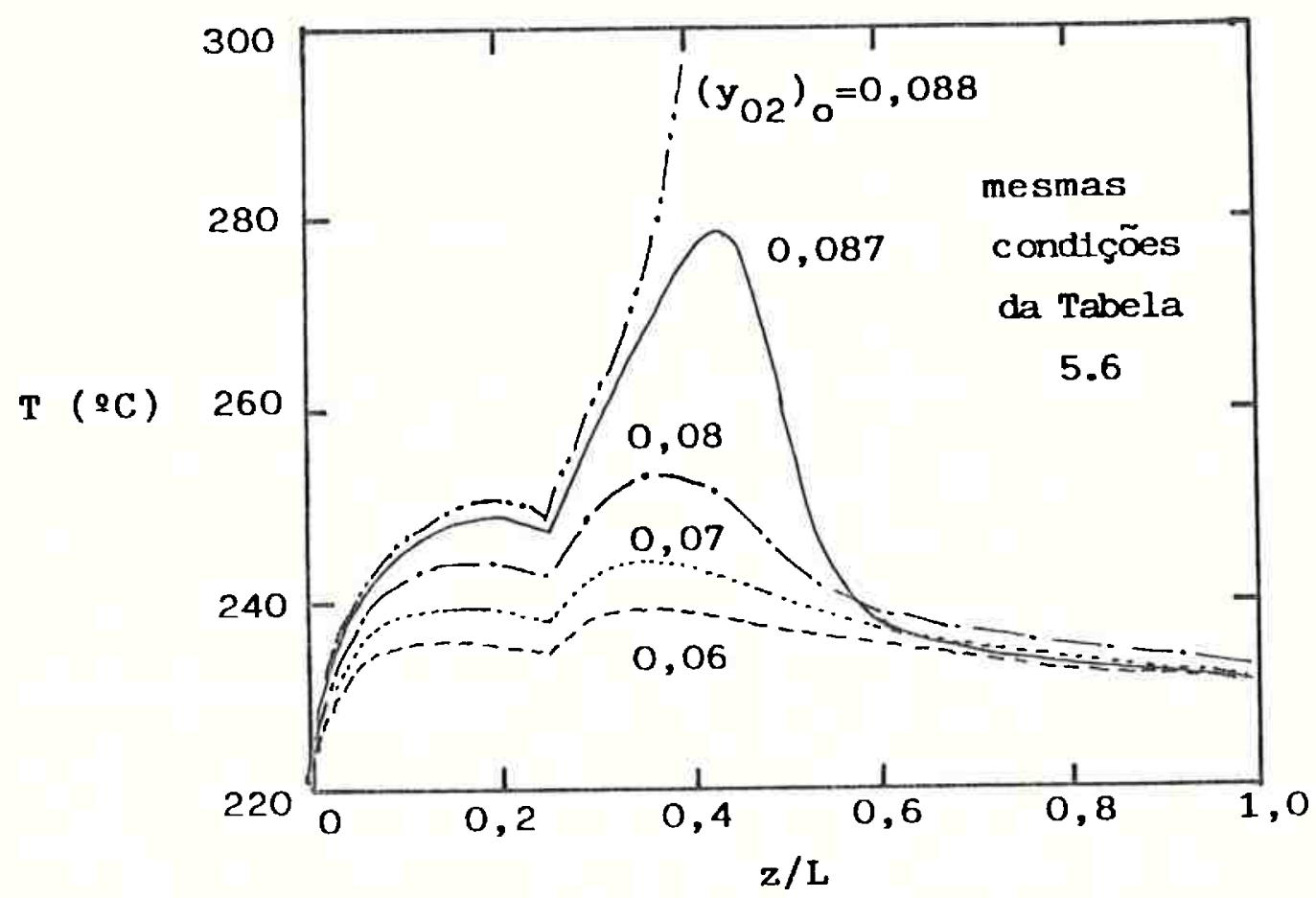

(b)

Figura 5.3. Influência das temperaturas de alimentação e de refrigeração (a) e da concentração de oxigênio na alimentação (b) sobre o comportamento de um reator com leito diluído $\left(a_{1}=0,75 ; a_{2}=1,0 ; z_{1}=0,25\right)$. 
Com o leito diluido, para $T_{0}=T_{\omega}=225{ }^{\circ} \mathrm{C}$, a fracão molar de oxigênio na alimentaço pode chegar até 0,087 sem que ocorra disparo de temperatura (temperaturas excessivamente elevadas) enquanto que para o leito uniforme o limite máximo \& 6,075. Para yoz $=0,06$ na al imentacão o 1 imite da temperatura de entrada para uma seletividade acima de $70 x$ sobe de $23^{\circ} \mathrm{C}$ (leito un iforme) para $240^{\circ} \mathrm{C}$ (leito com diluigão).

Nas figuras $5.4(a)$ (b) apresentam-se a conversăo tatal e a seletividade em funcão da fracão molar de oxigênio e da temperatura da alimentacão e de refrigeração. Nelas podemos definir claramente onde comeca haver disparo de temperatura no reator e também comparar o desempenho do leito diluido com o leito uniforme. A ampliatão dos limites de operabilidade conseguida com a diluicão do leito é bastante significativa.

o efeito do número de patamares de atividade do leito catalitico na performance do reator é ilustrado na Tabela 5.7 e figura 5.5. Nesta outra estratégia de diluicão tentou-se preservar uma atividade global média unitária com um aumento do nível de atividade gradativo ao longo do reator. Assim, para o comprimento total do leito dividido em N patamares, operfil de atividade seria dado por

$$
a(z)=(2 i-1) / N \quad(i-1) / N<Z<i / N
$$

que resulta em atividade média unitária. A situaçăo limice para $N$ tendendo a infinito leva a uma funcão linear de aumento de atividade no leito $\operatorname{com} Z$, isto $a(Z)=2 Z$.

Para os casos simulados, nota-se que um aumento do número de patamares permitiu diminuir a máxima temperatura do reator. No entanto um número excessivo de patamares pode levar a maiares temperaturas e menores seletividades, situacão esta que, embora 

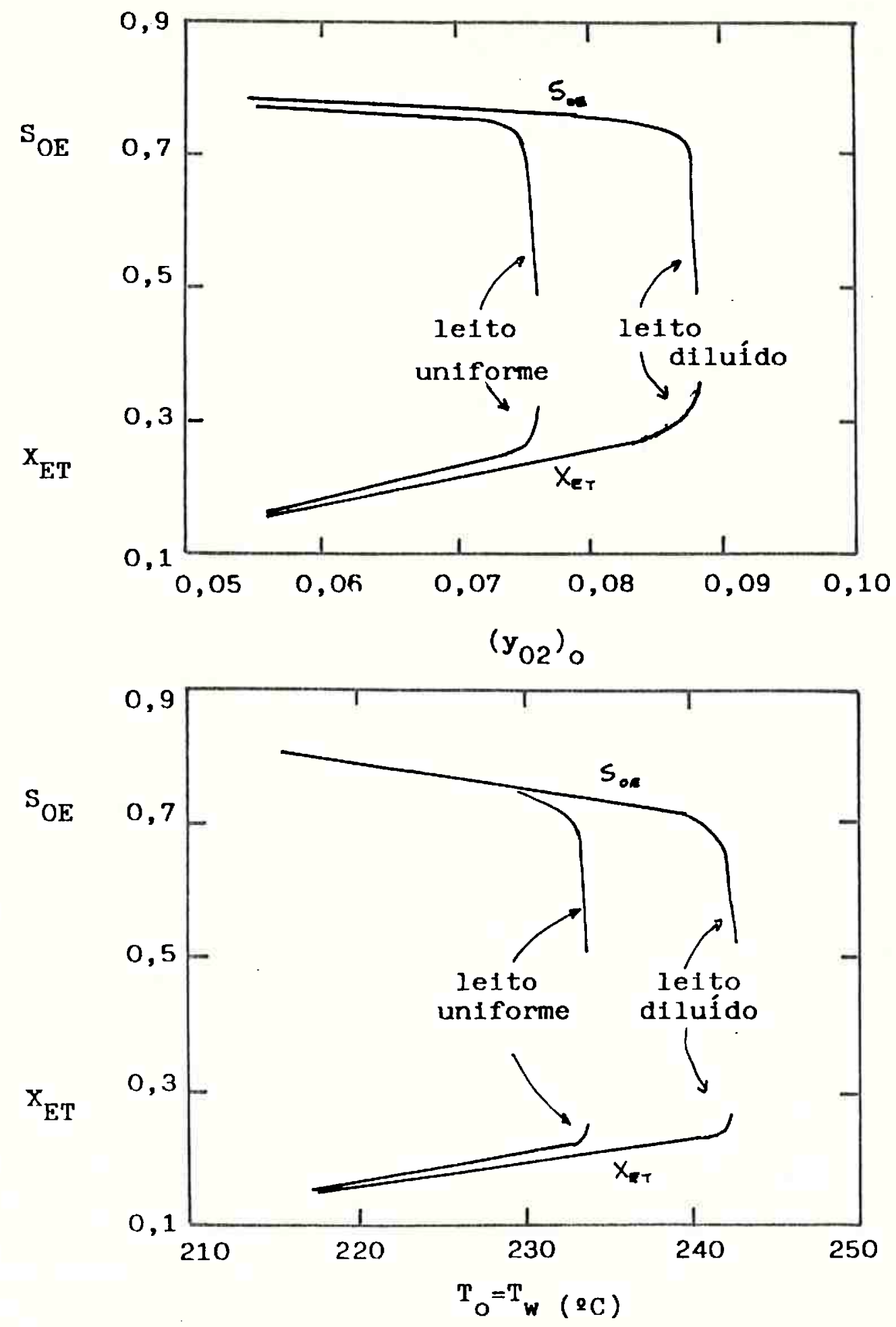

Figura 5.4. Influência das temperaturas de alimentação e de refrigeraçāo sobre a seletividade a óxido de eteno e sobre a conversão do eteno, para leito da atividade uniforme 1,0 e leito diluido $\left(a_{1}=0,75 ; a_{2}=1,0 ; z_{1}=0,25\right)$. 

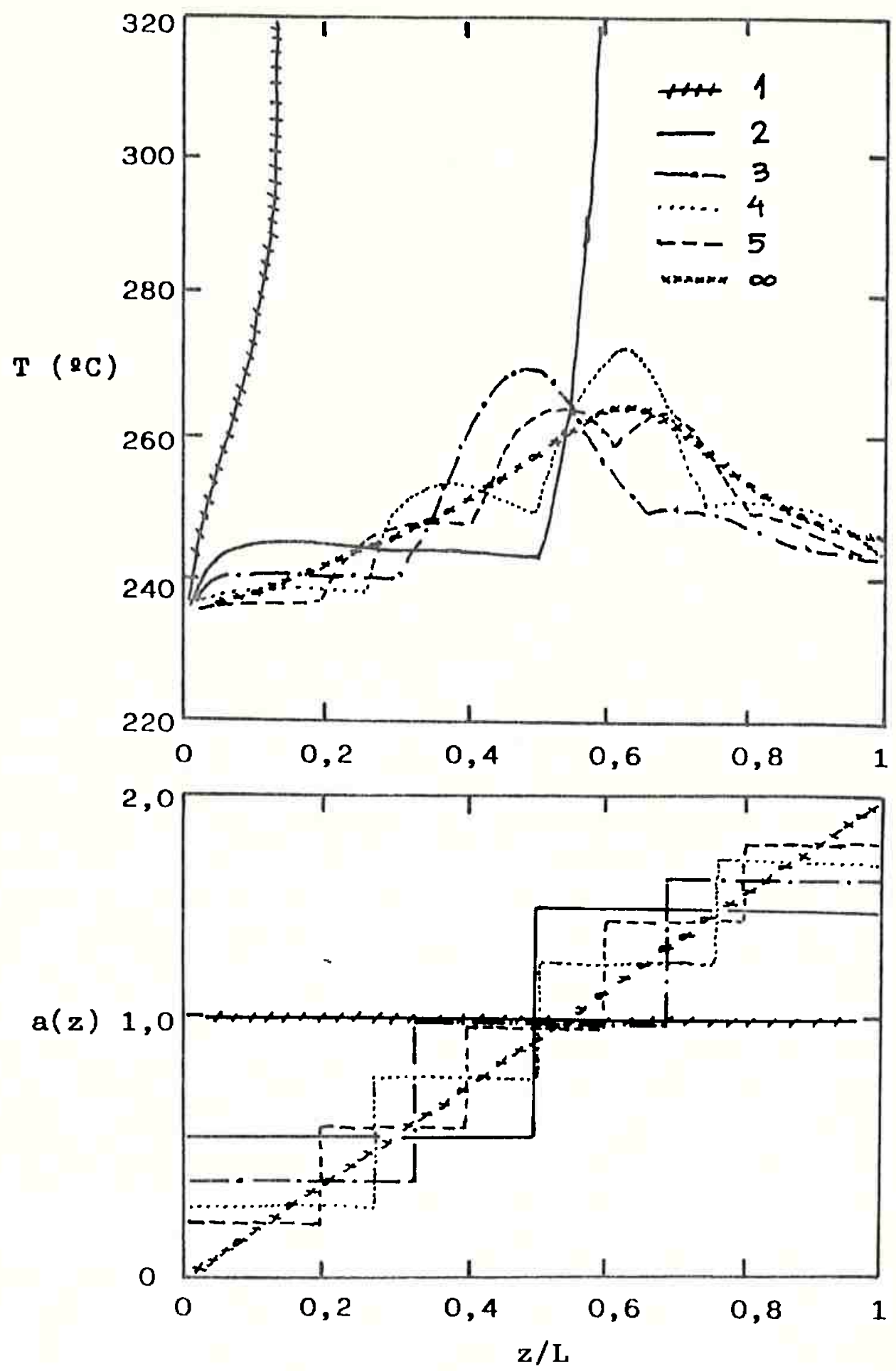

Figura 5.5. Influência do número de patamares de atividade catalítica no leito. Condições mesmas da Tabela 5.7. 
não esteja clara na Tabela 5.7, já fora observada sob outras situaçós (Yamamoto et alii, 1990).

Tabela 5.7. Influência do número de patamares com intervalos igualmente espacados e atividade global média unitária sobre o desempento do reator: $y_{\text {at }}=0,17 ; y_{02}=0,06 ; T_{0}=T_{\omega}=235{ }^{\circ} \mathrm{C}$

\begin{tabular}{|c|c|c|c|c|}
\hline$N$ & $T_{\mu}\left({ }^{\circ} \mathrm{C}\right)$ & $Z_{H}=$ & $x_{-T}(x)$ & $S_{0 \pi}(x)$ \\
\hline $\begin{array}{c}1 \\
2 \\
3 \\
4 \\
5 \\
10 \\
\text { infinit } 0^{*}\end{array}$ & $\begin{array}{c}\text { d i sparo } \\
\text { d i sparo } \\
270,6 \\
273,9 \\
264,6 \\
265,3 \\
265.1\end{array}$ & $\begin{array}{l}---1 \\
0.48 \\
0.61 \\
0.66 \\
0,63 \\
0.61\end{array}$ & $\begin{array}{l}20,6 \\
21,9 \\
21,4 \\
23,1 \\
23,0 \\
23,1 \\
23,1\end{array}$ & $\begin{array}{l}41,6 \\
54,9 \\
72,3 \\
71,9 \\
72,3 \\
72,2 \\
72,2\end{array}$ \\
\hline
\end{tabular}

* corresponde a perfil de atividade linear a( $Z)=2 Z$

\subsection{Verificacão da ocorrência de pontos quentes locais quando a diluicão de atividade catalítica é feita eor mistura de particulas at ivas e inertes}

A diluicăo do leito catalitico pode ser feita na prática basicamente de duas maneiras. Uma técnica seria usar catalisadores com diferentes atividades, isto $\dot{*}$, diferentes quantidades de sitios ativos, e estas diferentes formulacóes seriam distribuidas ao longo do tubo segundo a estratégia desejada. Outro modo seria fazer o leito com uma mistura de particulas cataliticas ativase particulas, inertes, variando a proporkão entre ambas conforme se deseje um leito mais ou menos ativo. No caso do reator de dxido de eteno, a primeira técnica consistiria em usar catalisadores com diferentes atividades (por exemplo com diferentes porcentagens de prata na formulacão), enquanto a segunda técnica corresponderia a misturar particulas inertes de alumina (suporte) sem prata às partículas cataliticas.

No caso da utilização desta segunda técnica, surge uma preocupacão quanto do grau de "homogeneidade" do leito, isto é na distribuicão aleatória de particulas ativas e inertes pelo leito 
poderiam ocorrer aglomerados de particulas ativas que se comportariam como uma pequena porfão de leito com maior atividade. Com isso poderiam ocorrer pontos quentes localizados no reator, os quais não seriam previstos quando se considera um valor médio de atividade de uma dada mistura de particulas.

Para estudar esta "wicro-heterogeneidade" espacial de atividade catalitica do leito, foi adaptado ao modelo bidimensional pseudo-homogêneo apresentado no Capítulo 4 uma distribuicão estocástica de atividades "locais", correspondentes as particulas ativas e inertes aleatoriamente distribuidas, de modo discreto, ao longo do raio e do comprimento do reator. As previsôes deste modelo foram comparadas com as obtidas supondo uma distribuicão continua de atividade, de valor constante e igual ao valor médio de atividade do leito.

A soluç̃o do modelo discreto foi obtida usando os métodos de diferencas finitas para a direção radial e integracão por RungeKutta-Gill na direcão axial.

Alguns dos resultados obtidos estão ilustrados nas figuras 5.6. $e$ indicam que as "micro-heterogeneidades" podem ser importantes, levando a formacä́o de pontos quentes locais, quando ocorrer aglomerados de particulas ativas. Nos casos testados. muito embora o comportamento do modelo de distribuicão discreta estocástica apresente oscilaçōes en torno da previsão do modelo de distribuicão contínua de atividade, foram obtidos valores locais com até $20^{\circ} \mathrm{C}$ acima da temperatura prevista usando uma atividade contínua média da mistura de particulas. A distribuicão local de atividade pode afetar os resultados médios globais do reator, como mostra a Tabela 5.8. 


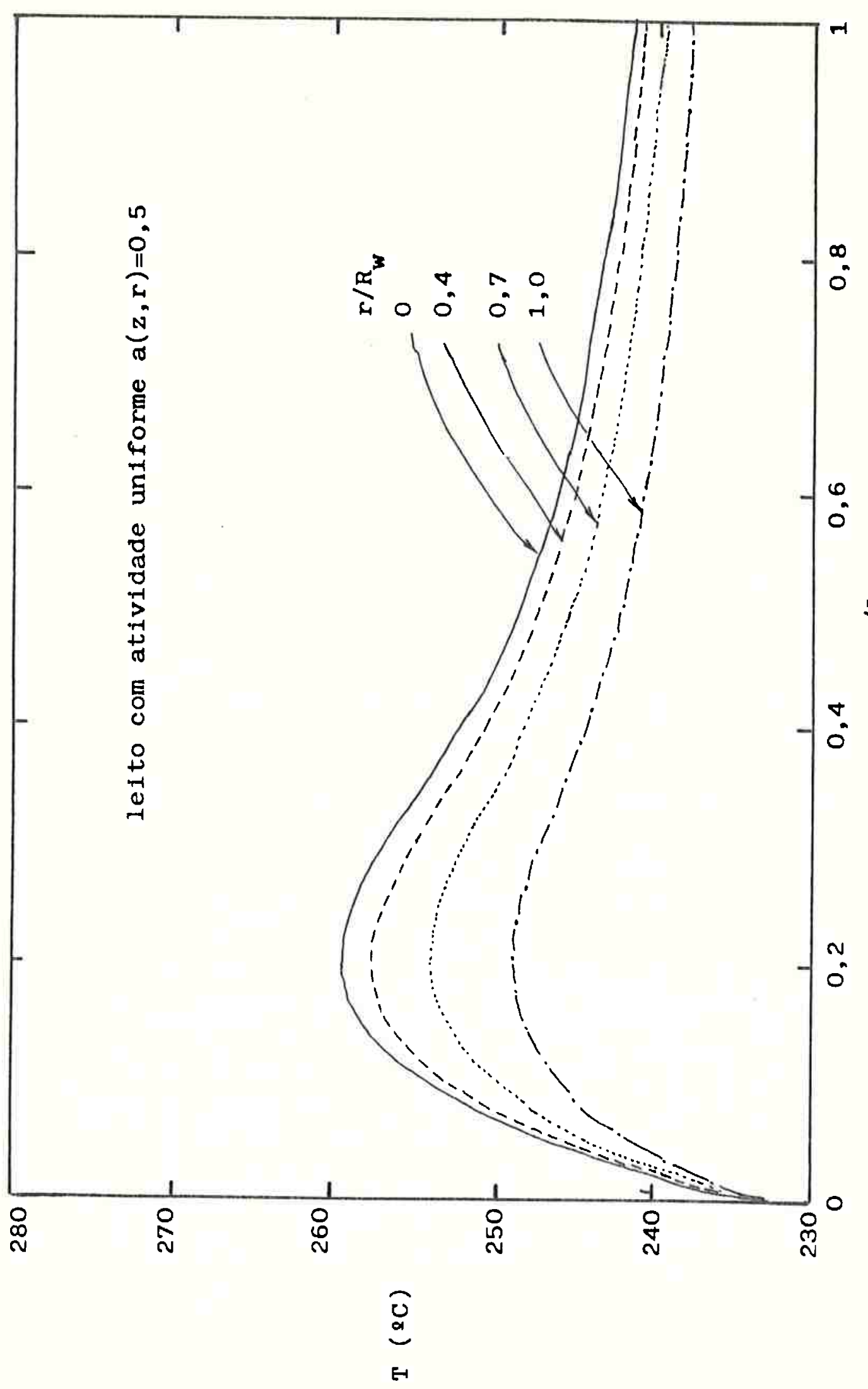

ช

i

告

$\stackrel{N}{N}$

क्ष

E

응

$\begin{array}{ll}0 & 0 \\ 0 & 0 \\ 0 & 0 \\ 0 & 0 \\ -1 & +3 \\ 0 & -1 \\ 0 & 5 \\ 0 & 0 \\ 0 & 0 \\ 0 & 0 \\ 4 & 0 \\ 0 & 0 \\ 0 & 0\end{array}$

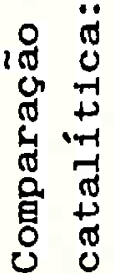

i 


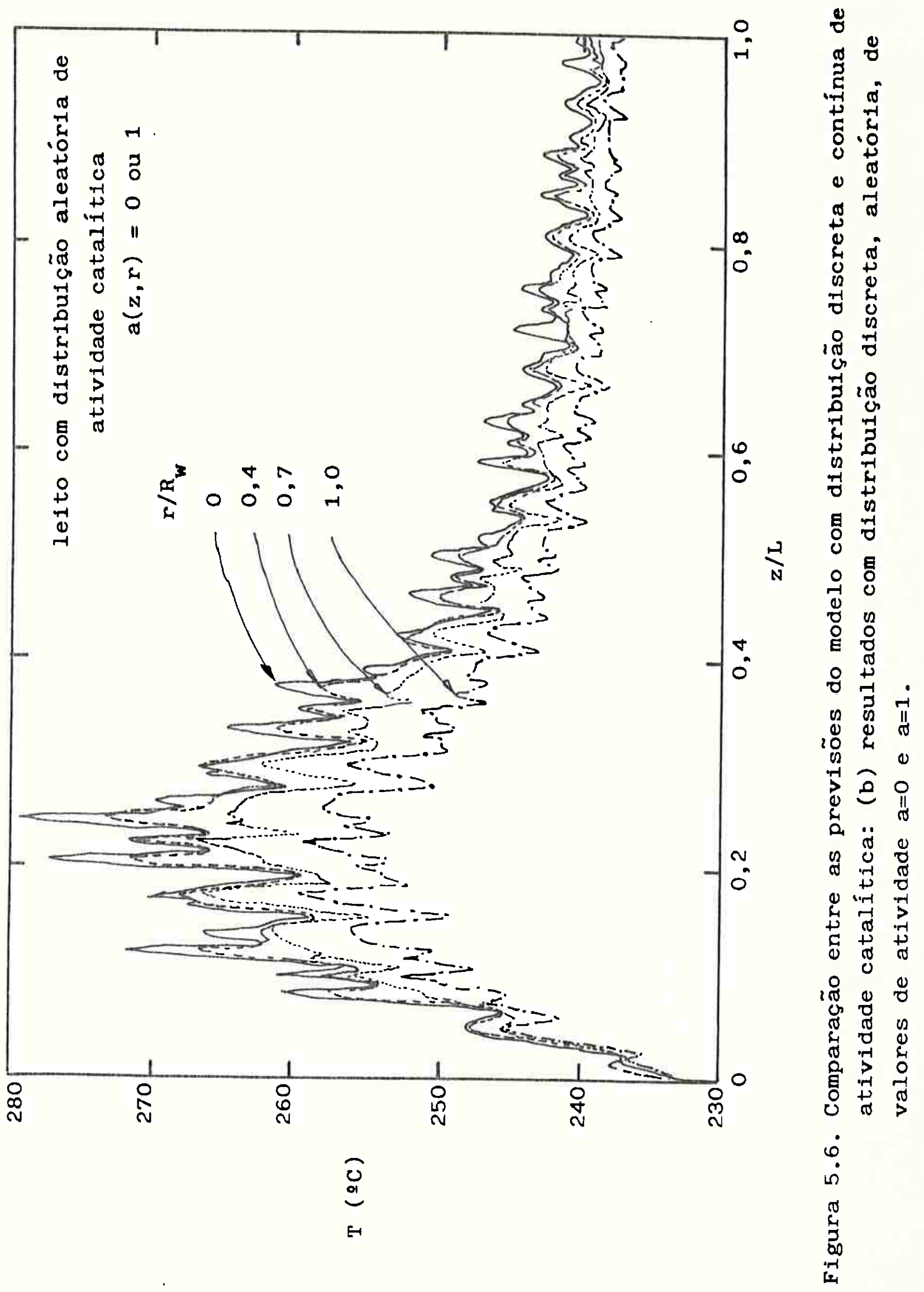


Tabela 5.8. Comparacão dos resultados da simulacão usando modelo com distribuicão discreta $e$ modelo com distribuicão contínua de at ividade catalitica.

condicoes utilizadas na simulacão:

$W=35 \mathrm{~kg} / \mathrm{s} \quad T_{0}=T_{\omega}=232 \circ \mathrm{C} \quad \mathrm{d}_{\mathrm{t}}=0.04 \mathrm{~m}$

$\mathrm{L}=8 . \quad P_{0}=20$ atm $\quad \mathrm{d}_{F}=0,008 \mathrm{~m}$

demais condicoes são as mesmas do caso base da Tabela 5.1

\begin{tabular}{|c|c|c|c|c|}
\hline distr. & $a(z, r)$ & $T_{H=}\left({ }^{\circ} C\right)$ & $X_{E=T}(X)$ & $S_{\text {on }}(x)$ \\
\hline $\begin{array}{l}\text { cont inua } \\
\text { discreta }\end{array}$ & 1 ou 0 \% & $\begin{array}{l}259,4 \\
279,1\end{array}$ & $\begin{array}{l}15,02 \\
17,00\end{array}$ & $\begin{array}{l}70,88 \\
69,72\end{array}$ \\
\hline
\end{tabular}

* distribuicão aleatória (média 0,5 ).

\subsection{Comentários Gerais e Conclusōes}

Estratégias de diluicão mais elaboradas do que as dadas pelas equacỗes (5.1) e (5.2) podem ser propostas e testadas usando a metodologia aqui estudada, e assim obter perfis de temperatura mais suavizados ou entäo permitir utilizar condicöes mais severas de operacấo do reator que proporcionem maiores conversões. No entanto, estratégias mais simples são recomendadas devido a facilidade de sua implantacão prática en reatores industriais mult itubulares.

Para otimizar a estratégia de diluicão do leito catalitico deve ser feita uma avaliacăo econômica do processo ut ilizando como parámetros a estratégia de diluicáo do leito (ak,arar $Z_{a}$, a temperatura de entrada $e$ do fluido refrigerante $\left(T_{\infty}, T_{\infty}\right), a$ concentracão de oxigênio da alimentacão (yoa) e a vazão dos gases (w). Deve considerar nesta otimizacão as interrelacoes entre o reator $e$ as outras unidades do circuito industrial, por exemplo o trocador de calor que pré-aquece a alimentacão com os gases de saida do reator, as torres absorvedoras de óxido de eteno $e$ de gás carbônico, o compressor que movimenta o gás no circuito, etc. Maiores produtividades poder-se-iam obter entäo através de 
mudancas de condicões de operacão aliada a eficientes estratégias de diluicão de catalisador.

Pelos resultados apresentados, a estratégia de diluicão do catalisador parece ser uma alternativa bastante promissora na ampliacão da faixa de operabilidade do reator, possibilitando diminuir a sensibilidade parametrica do mesmo. Dependendo da estratégia proposta é possivel ocorrer sensibilidade reversa quanto a algumas variáveis, o que pode ser previsto através da simulaç̃o. É possível estudar a otimizacão da estratégia de diluicão do leito catalítico, selecionando as melhores estratégias para serem testadas na prática. A diluicåo baseada em mistura de partículas inertes com particulas cataliticas ativas pode levar a formacão de pontos quentes localizados se houver má distribuicão das particulas ativas ao longo do leito. 
Capitula 6

IDENTIFICACAOO DE MODELO DE REATOR DE LEITO FIXO

\subsection{Introducão}

Neste Capitulo é apresentado un estudo sobre identificacáo de modelo de reator catalítico de leito fixo.

Este assunto é de utilidade no controle otimizado de processos envolvendo este tipo de reator. O esquema simplificado do controle ot imizado é mostrado na figura 6.1. Dados medidos no processo, após serem tratados e reconciliados, sáo usados para a identificacão de um modelo estático, ajustando-se parâmetros deste para que se obtenha uma adequada representacão do comportamento estacionário do processo. O modelo identificado é então utilizado para a etapa de otimização estática, em que se determinam os valores das variáveis de processo que maximizam ou minimizam uma dada funcäo objetivo, sujeita a restrifões inerentes ao processo. Estas informacỗes são enviadas como sendo os "set-points" do módulo de controle que monitora o processo. 0 controlador se utiliza ainda de uma etapa de identificacão de um modelo dinâmico simplificado, com o qual é possivel estabelecer, dentro da etapa de regulaço, o caminho mais adequado para a mudanca dos "setpoints" de seus valores atuais para os valores ótimos, sem violar restricões do processo durante este perído transitório.

As etapas de identificacão dinâmica e de atuaçăo do controlador devem ser feitas em linha ("on-line"), em tempo real, e por isso frequentemente o modelo dinâmico simplificado. As etapas de identificacão do modelo estático e de otimizacão do processo são feitas năo em tempo real, com uma frequência menor, permitindo o uso de modelos mais rigorosos. 


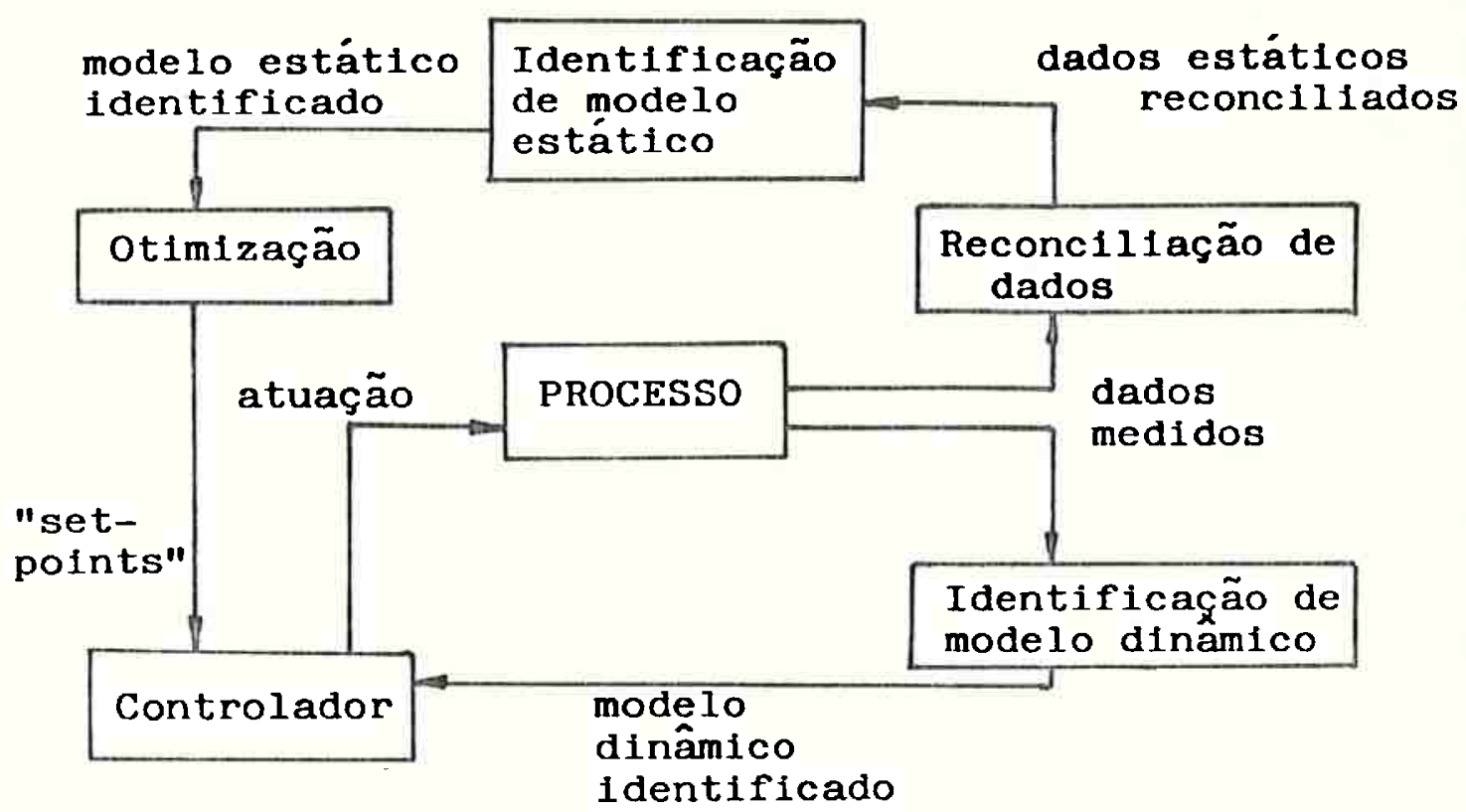

Figura 6.1. Esquema simplificado de controle com otimização.

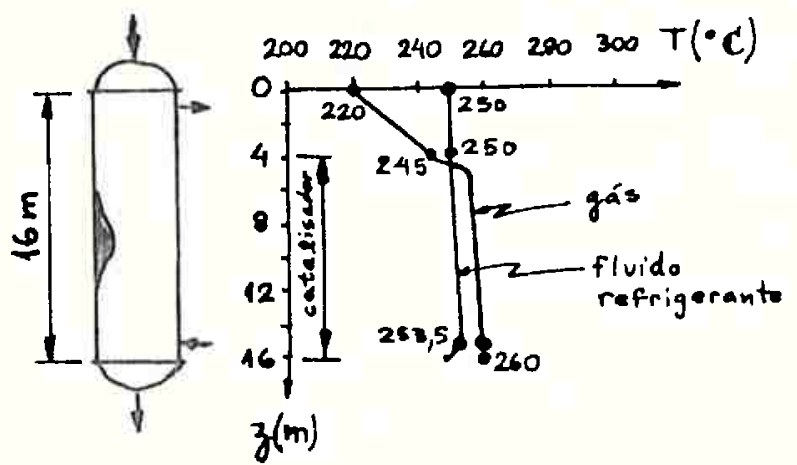

Figura 6.2. Perfil de temperatura no reator de óxido de eteno (extraído de Piccinini \& Levy, 1984). 
Entretanto dois aspectos limitas o uso de modelos muito sofist icados:

- as variáveis medidas experimentalmente, com as quais se faz a identificacão do modelo normalmente não são muito detalhadas especialmente em reatores industriais (modelos muito sofisticados normalmente requeren medidas detalihadas para ajuste de seus Parâmetros);

- o modelo identificado é utilizado em rotina de ot imizacão onde são efetuados cálculos repetitivos com o modelor dificultando o uso de modelos que impliquem ew grande tempo de processamento.

\subsection{Oproblema de ident ificacão}

Tipicamente os dados disponíveis para um procedimento de identificacão estática de reator tubular, seja en escala de bancada, piloto ou industrial, sấo medidas do perfil axial de temperatura $T(z)$, a temperatura do meio externo rese e medidas de composicão da corrente de entrada e da de saida do reator. Eventualmente, mas não usualmente, pode-se dispor do perfil axial de composicão; estas medidas podem ser mais facilmente encontradas para reatores de laboratório em escala de bancada ou menor, sendo raras em reatores piloto e mais raras ainda em reatores industriais.

o modelo empregado tipicamente é o unidimensional pseudohomogêneo, que representa um bom compromisso entre uma representacão razoável do reator, frente às medidas disponíveis, e um adequado tempo de processamento. Para o caso do reator de óxido de eteno, o modelo é dado por:

$$
\begin{aligned}
& \left(F_{E T}\right)_{0}\left(d X_{E T} / d z\right)=\rho_{b} A\left(a_{2} R_{2}+a_{2} R_{z}\right) \\
& \left(F_{E T}\right)_{0}\left(d X_{\text {OKK }} / d z\right)=\rho_{0} A a_{1} R_{1}
\end{aligned}
$$




$$
G c_{m} \frac{d T}{d z}=P_{b} \sum_{j=1}^{3} a_{J} R_{\lrcorner}\left(-\Delta H_{J}\right)-U\left(4 / \sigma_{t}\right)\left(T-T_{\text {met }}\right)
$$

com condicões iniciais conhecidas e com expressões para a velocidade de reacão em função da temperatura e composição.

O5 Parâmetros considerados ajustáveis neste modelo foram as

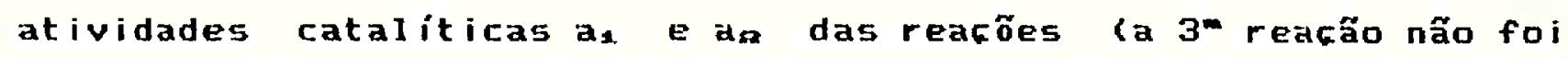
considerada) e o coeficiente de transferencia de calor $U$. Os valores destes parâmetros cinéticos e térmico devem ser ajustados, usando regressão não-linear, de maneira a fazer com que o modelo represente o mais fielmente possivel as medidas experimentais. 0 critério normalmente utilizado éminimizar a funcão objetivo soma dos quadrados dos residuos:

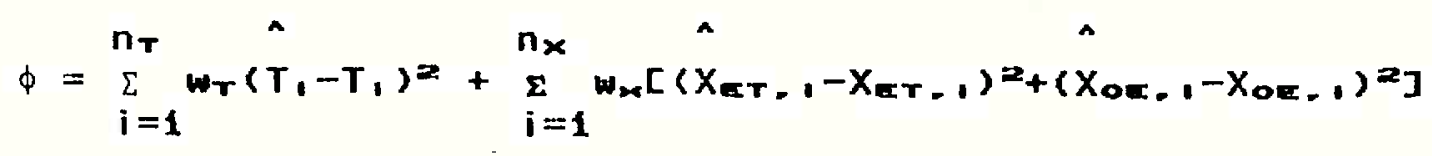

A identificąão do modelo constitui portanto um problema de ot imizacão. Os valores calculados provêm da solucão numérica das equacoes (6.1) a (6.3), pelo método de Runge-Kutta-Gill. Estimativas iniciais dos parâmetros ajustáveis devem ser fornecidas e o método de ot imizacâo de Marquardt (1963) foi usado para o ajuste.

\subsection{Aplicacão ao reator de éxido de eteno}

Uma pesquisa da literatura aberta mostrou que dados medidos em reatores industriais do processo de oxidacăo de eteno são raramente publicados.

Foram encontrados dois trabalhos que trazem dados relativos ao processo. O primeiro é o de Montalvo-Robles et ali i (1973), em que säo mostrados dados relativos a um reator industrial de 
oxidacão de eteno com ar- Os autores usam estes dados para comparafão com resultados de simulacão do reator. Entretanto nenhuma informacão sobre a geometria do reator foi fornecida (número de tubos, diâmetro e comprimento dos tubos, etc.) o que impede a utilizacão destes dados para os fins de identificacão.

Outro trabalho é o de Piccinini \& Levy (1984), que traz um estudo sobre análise de seguranca do processo para o projeto do sistema de refrigeracão do reator de óxido de eteno. Neste trabalho são apresentados dados de operação de un reator. Estes dados apresentam-se razoavelmente detalhados $e$ foram usados no presente trabalho para teste da rotina de idencificacão do modelo do reator.

Os dados geométricos e operacionais referentes a este reator piloto são dadas na Tabela 6.1. Além dos dados relativos às correntes de entrada e de saida nostrados na Tabela 6.1, também é apresentado un esboco do perfil de temperatura ao longo do leito, reproduzido na figura 6.2 .

Estes dados foram utilizados para a identificacão do modelo do reator. Ao modelo formado pelas equacōes (6.1) a (6.3), devem ser acrescidas expressōes para a cinética das reacöes. Dois "modelos cinéticos" foram considerados:

(a) o de Westerterp \& Ptasinski (1984), representado por:

$$
\begin{array}{lll}
\mathbf{R}_{2}=70.4 \exp (-7200 / \mathrm{T}) C_{02} & (6.5 . a) \\
\mathbf{R}_{\mathbf{0}}=24700 \exp (-10800 / \mathrm{T}) C_{02} & (6.5 .6) \\
\mathbf{R}_{\mathbf{3}}=0 & & (6.5 . \mathrm{C})
\end{array}
$$


(b) o de Bunt in (1962), representado por:

$$
\begin{aligned}
& R_{1}=\frac{2,619 \times 10^{-0} \exp (-13600 / T) P_{E T} P_{02}{ }^{1 / 2}}{K(1+24,548 \text { PET })} \quad(6.6 . a)
\end{aligned}
$$

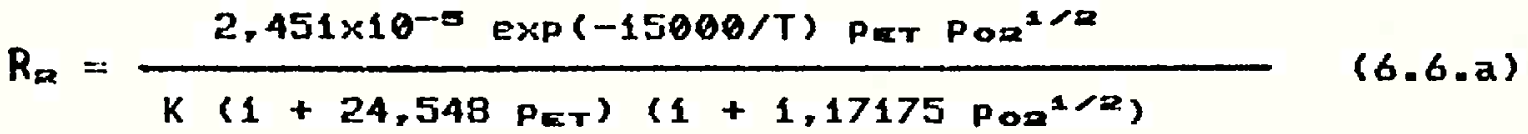

$$
\begin{aligned}
& R_{\mathbf{0}}=0 \\
& (6.6 .5) \\
& \left.K=1+36,628 \text { Phe0 }+7,676 \text { (Pcoz }+P_{\text {om }}\right)
\end{aligned}
$$

Tabela 6.1. Caracteristicas condicões de operacão do reator para a producão de óxido de eteno cextraídas de Piccinini \& Levy, 1994).

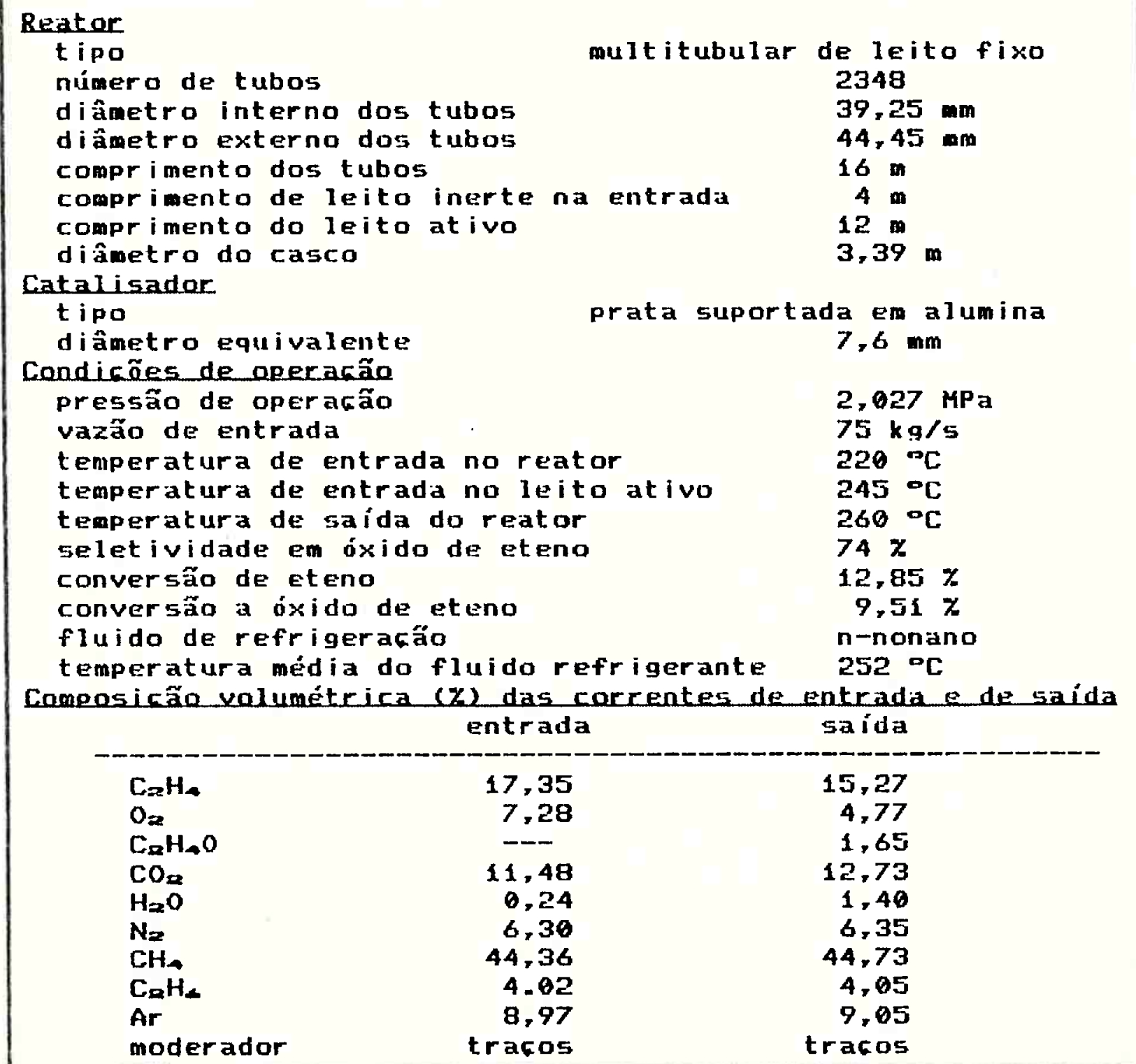


Dois critérios de ajuste foram testados. Un critério de minimos quadrados absolutos, em que se minimiza a funcão objetivo \$ dada pela equacão (6.4), com pesos unitários, e un critério de minimos quadrados relativos, na forma

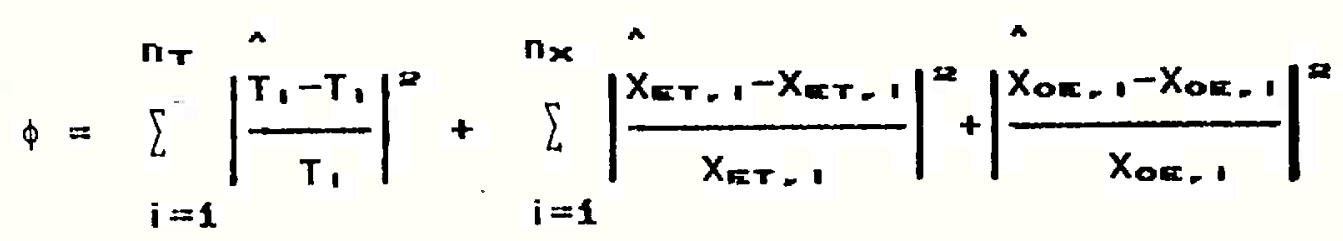

\subsubsection{Identificacão usando apenas a temperatura e conversões de saída do reator}

Nesta parte foram considerados conhecidos apenas os dados relativos as correntes de entrada e de saida do leito catalitico ativo. Neste caso fica-se com un número de parâmetros (3) igual ao numero de pontos experimentais, portanto sem nenhum grau de liberdade estat istico.

Os parâmetros ajustados estão apresentados na Tabela 6.2 . Observa-se que nesta situafăo, para cada cinérica considerada, ambos os critérios (mínimos quadrados absoluto e relativo) levaram ao mesmo valor dos parâmetros ajustados.

A figura 6.3 mostra os perfis de temperatura e conversós calculados pelo modelo e os pontos experimentais utilizados, mostrando um bom ajuste, tanto com a cinética de westerterp \& Ptasinski (1984), equacão (6.5), como com a cinética de Buntin (1962), equação (6.6). As conversöes (e a composicão obtida a partir destas) e temperatura na saida do reator calculadas praticamente coincidem com os valores experimentais. O perfil de temperatura calculado difere algo do suposto perfil experimental (mostrado na figura 6.2), porém as diferencas não ultrapassam $10^{\circ} \mathrm{C}$, e pode ser considerado aceitável, uma vez que este ajuste 


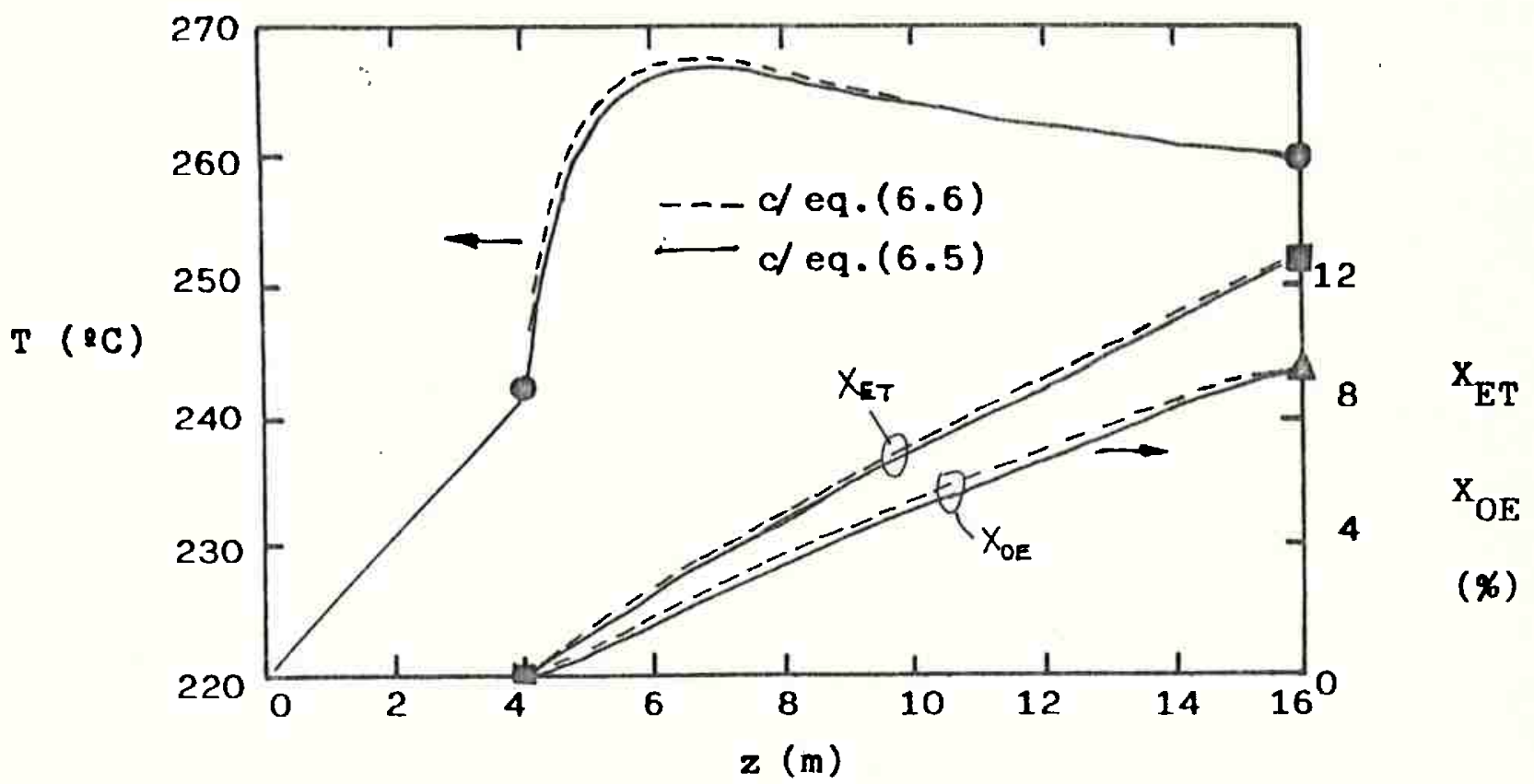

Figura 6.3. Comparação dos perfis ajustados com os pontos experimentais. Ajuste obtido usando apenas a temperatura e conver sões na saída do reator.

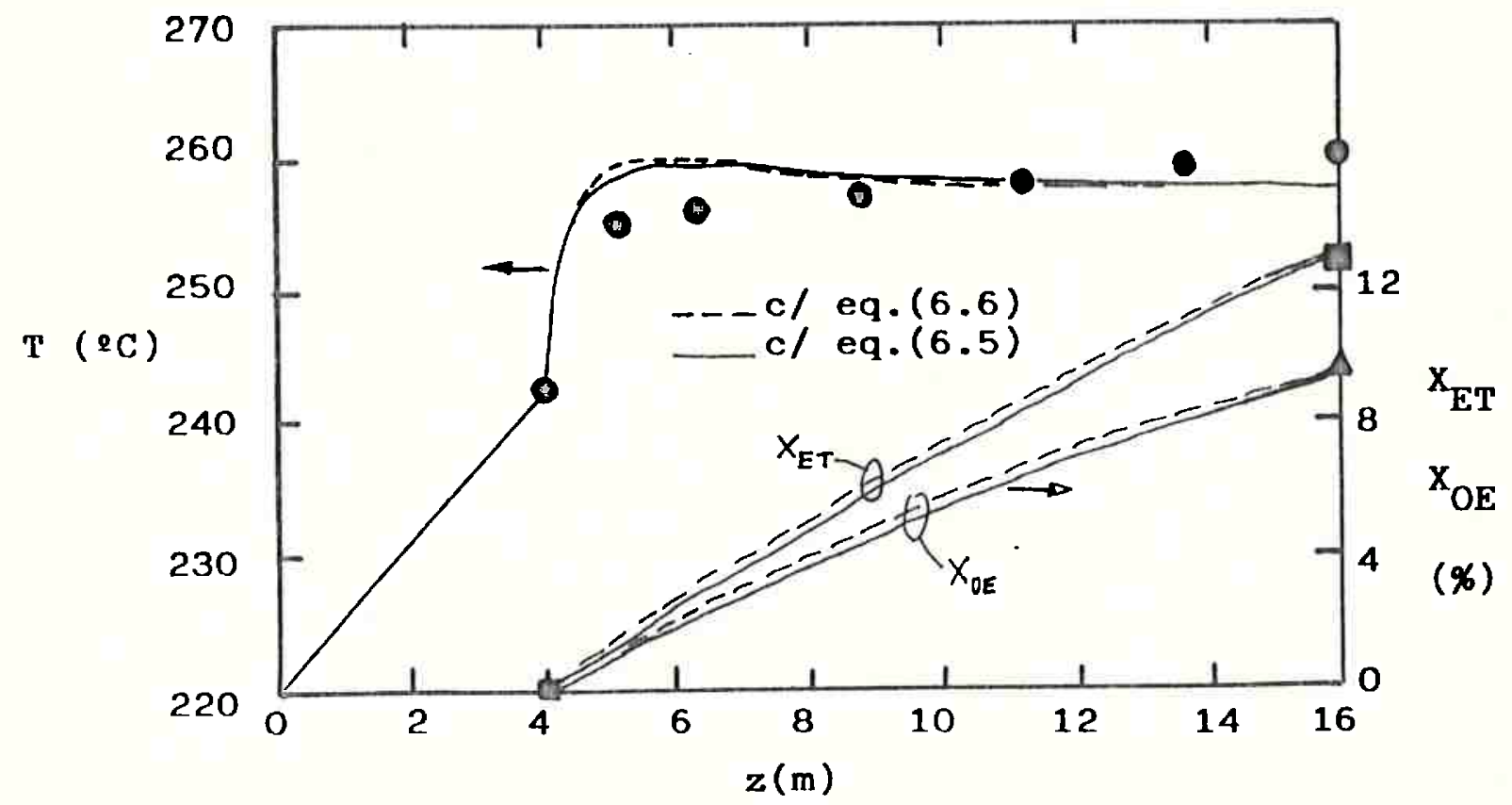

Fıgura 6.4. Comparação dos perfis ajustados com os pontos experimentais. Ajuste obtido usando o perfil de temperatura (0) e as conversões na saída ( $\Delta \mathrm{x}_{\mathrm{ET}}, \Delta \mathrm{x}_{\mathrm{OE}}$ ), com o critério relatıvo, equação $(6.7)$. 
foi baseado apenas nas medidas de entrada e saida do reator, sem qualquer informacão relativa a pontos internos ao leito.

Tabela 6.2. Resultados do ajuste obtidos usando apenas a temperatura e conversöes na saída do reator.

\begin{tabular}{|c|c|c|c|c|c|}
\hline \multirow{2}{*}{$\frac{\text { expressão cinética }}{\text { criterio de ajuste }}$} & \multicolumn{2}{|c|}{ equaç̃o (6.5) } & \multicolumn{2}{|c|}{ equação $(6.6)$} & \multirow{2}{*}{$\begin{array}{l}\text { valor } \\
\text { exp. }\end{array}$} \\
\hline & absoluto & relativo & absoluto & relativo & \\
\hline \multicolumn{6}{|l|}{ parámetros } \\
\hline $\mathbf{a}_{1}$ & 0.2142 & 6,2142 & 7,508 & 7,509 & -- \\
\hline & 0,1769 & 0.1769 & 7,646 & 7,638 & -- \\
\hline$U\left(W / \mathrm{ra}^{2} / K\right)$ & 509.6 & 509,6 & 498,0 & 497,9 & -- \\
\hline \multicolumn{6}{|c|}{ resultados (corrente de saida) } \\
\hline$T \quad\left({ }^{\circ}[)\right.$ & 260,0 & 260,0 & 260,0 & 260,0 & 260 \\
\hline $\begin{array}{l}X_{E=T}(z) \\
X_{\text {or }}(z)\end{array}$ & $\begin{array}{l}12,86 \\
9,513\end{array}$ & $\begin{array}{l}12,86 \\
9,513\end{array}$ & $\begin{array}{l}12,85 \\
9,508\end{array}$ & $\begin{array}{r}12,85 \\
9,51\end{array}$ & $\begin{array}{r}12,85 \\
9,51\end{array}$ \\
\hline$x \mathrm{C} 2 \mathrm{HA}$ & 15,25 & 15,25 & 15,25 & 15,25 & 15,27 \\
\hline$x 02$ & 4,75 & 4.75 & 4,75 & 4,75 & 4,77 \\
\hline$x \quad \mathrm{C} 2 \mathrm{H} 40$ & 1.66 & 1,66 & 1,66 & 1,66 & 1,65 \\
\hline$x \operatorname{co2}$ & 12,74 & 12,74 & 12,74 & 12,74 & 12,73 \\
\hline $\mathrm{xH20}$ & 1,41 & 1,41 & 1,41 & 1,41 & 1,40 \\
\hline$z$ outros & 64,19 & 64,19 & 64,19 & 64,19 & 64,18 \\
\hline
\end{tabular}

\subsubsection{Identificacão usanda a perfil de temperatura e as conversöes na saida do reator}

Neste caso além das medidas feitas na corrente de saída do reator foram incluídos como "medidas" cinco valores de temperatura tomados ao longo do leito ativo, obtidos a partir do esboco do perfil de temperatura apresentado no trabalho de Piccinini \& Levy (1984). Os pontos utilizados säo mostrados na Tabela 6.3.

Tabela 6.3. Pontos intermediários $e$ de saída utilizados para a ident if icacão do modelo.

\begin{tabular}{|l|rllllll|}
\hline$z / L$ & 0 & 0,1 & 0,2 & 0,4 & 0,6 & 0,8 & 1,0 \\
\hline$T(\circ C)$ & 245 & 255 & 256 & 257 & 258 & 259 & 260 \\
$X_{E T}(\%)$ & 0 & --- & --- & --- & --- & $-0-$ & 12,85 \\
$X_{0=}(\%)$ & 0 & -- & -- & -- & --- & -- & 9,51 \\
\hline
\end{tabular}

Os parâmetros ajustados para este caso estăio mostrados na Tabela 6.4. Observa-se que neste caso há uma forte influência do 
critério de ajuste utilizado sobre o valor dos parâmetros. A figura 6.4 mostra a comparacão entre os perfis ajustados pelo critério de mínimos quadrados relativo es pontos experimentais. Na figura 6.5 a mesma comparacão é feita com o ajuste pelo critério de minimos quadrados absoluto. Observa-se que o ajuste pelo critério relativo é adequado, o que náo acontece com o critério absoluto. Usando o critério absoluto obtem-se uma representacão adequada para o perfil de temperatura, mas não para os valores de conversão. Com isso, a composicáo da corrente de saída calculada pelo critério absoluto difere apreciavelmente da composicão experimental, como mostrado na Tabela 6.4. Também como decorrência destes aspectos, ocorrew diferencas apreciaveis entre os valores do coeficiente de troca de calor 4 ajustados pelos dois critérios.

A explicafão para estas observacôes está no fato de que as variáveis dependentes apresentam diferentes ordens de grandeza. Ats conversôes Xer e Xoer expressas em porcentagens, tem ordem de grandeza 16, ao passo que as temperaturas, medidas em o $\mathrm{C}$, tem ordem de grandeza 100 . Diferencas absolutas aceitáveis entre o valor experimental e o calculado para as conversốcs säo da ordem de 0,1 ou menores, enquanto que para temperaturas são de orden de 1 a $2^{\circ} \mathrm{C}$, ou menores. Isto leva a diferencas relativas da mesma ordem de grandeza, em torno de 0.01 , tanto para temperaturas como para conversóes.

Usando o critério absoluto, só as temperaturas são razoavelmente ajustadas, já que a funcão objetivo torna-se pouco sensivel às diferencas absolutas en conversões, e como reflexo disto, as conversőes são mal ajustadas. Por outro lado o critério relativo procura ajustar igualmente bem tanto as temperaturas como 


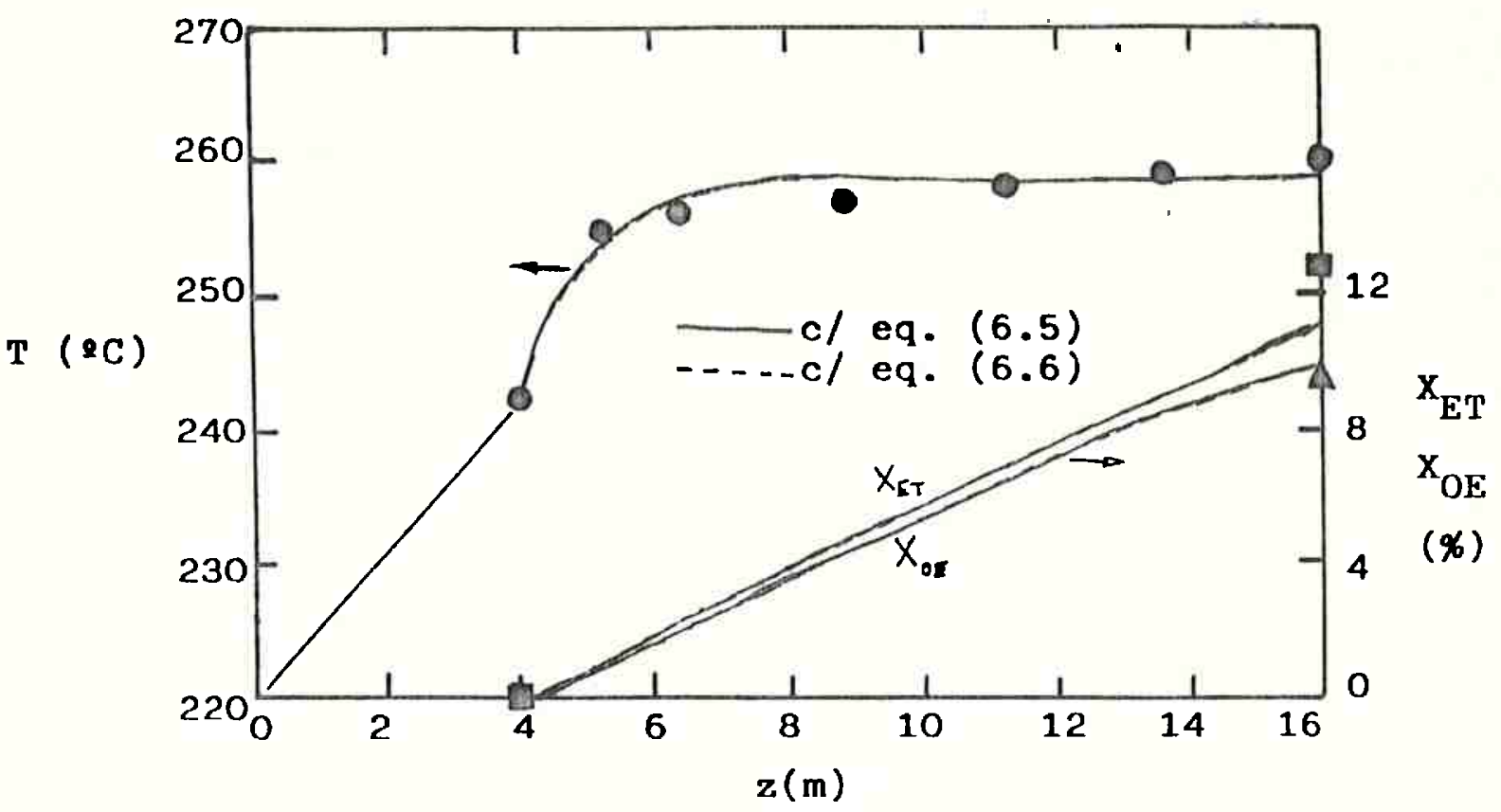

Figura 6.5. Comparação dos perfis ajustados com os pontos experimentais. Ajuste obtido usando o perfil de temperatura ( $\bullet$ ) $e$ as conversões na saída ( $\sim \mathrm{x}_{\mathrm{ET}}, \Delta \mathrm{x}_{\mathrm{OE}}$ ), com o critério absoluto, equação $(6.4)$.

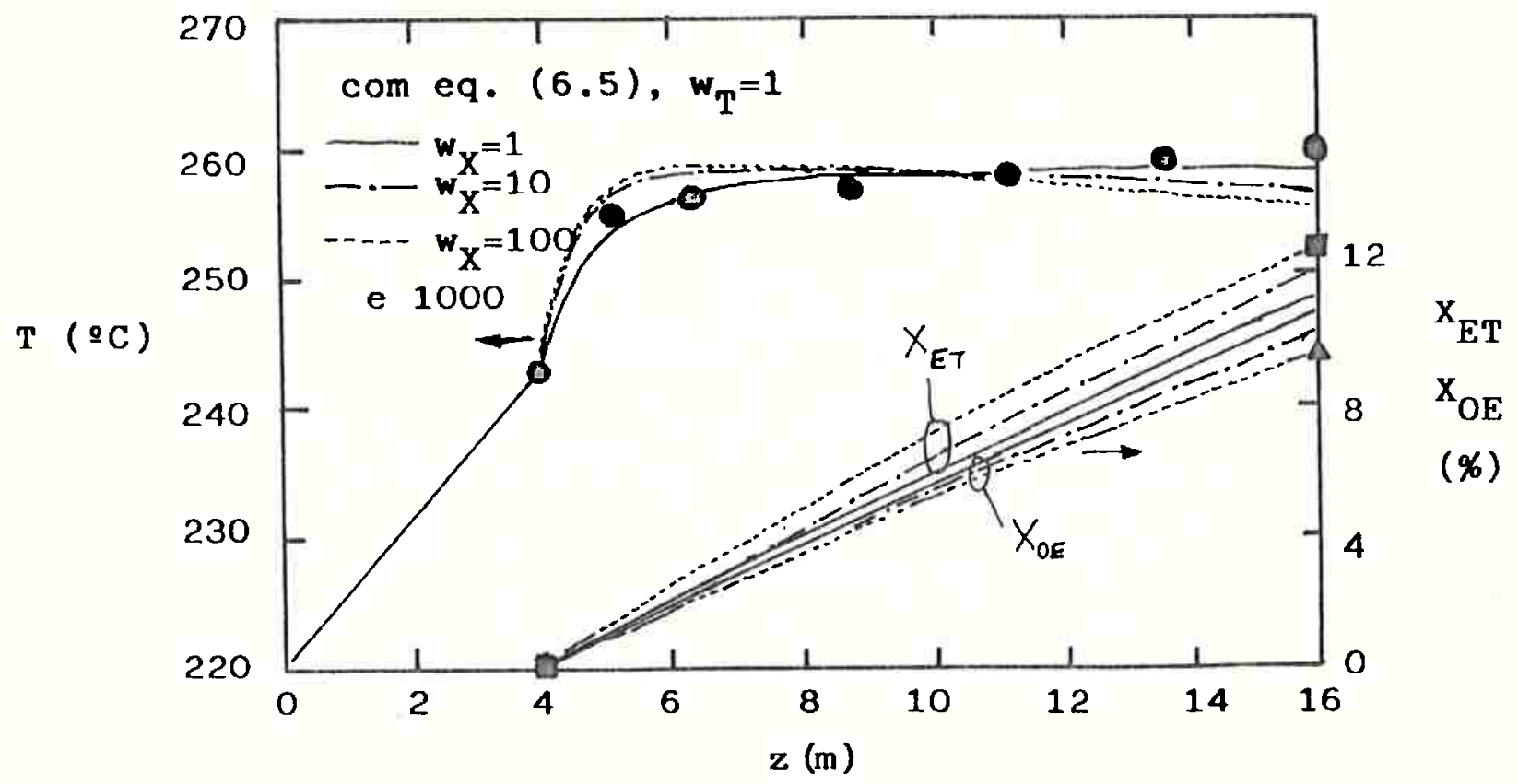

Figura 6.6. Influência dos pesos $w_{X}$ e $w_{T}$ sobre o ajuste usando o critério absoluto, equação (6.4). 
as conversōes, levando a uma representação adequada do comportamento do reator.

Tabela 6.4. Resultados do ajuste usando perfil de temperatura e conversões na saida do reator.

\begin{tabular}{|c|c|c|c|c|c|}
\hline \multirow{2}{*}{$\begin{array}{l}\text { expressão cinética } \\
\text { critério de ajuste }\end{array}$} & \multicolumn{2}{|c|}{ equacão $(6-5)$} & \multicolumn{2}{|c|}{ equaçän $(6.6)$} & \multirow{2}{*}{$\begin{array}{l}\text { valor } \\
\text { exp. }\end{array}$} \\
\hline & absoluto & relativo & absoluto & relativo & \\
\hline \multicolumn{6}{|l|}{ parámetros } \\
\hline $\mathbf{a}_{1}$ & 0,2461 & 0.2468 & 7,861 & 8,794 & -- \\
\hline $\begin{array}{l}a_{2} \\
\text { U) }\left(w / m^{2} / K\right)\end{array}$ & $\begin{array}{l}0,2163 \\
263,0\end{array}$ & $\begin{array}{l}0,2186 \\
967,8\end{array}$ & $\begin{array}{l}0,5735 \\
238,7\end{array}$ & $\begin{array}{l}9,632 \\
1005\end{array}$ & -- \\
\hline \multicolumn{6}{|c|}{ resultados (corrente de saida) } \\
\hline$T\left({ }^{\circ} \mathrm{C}\right)$ & 258,0 & 255,4 & 257,8 & 255,1 & 260 \\
\hline $\begin{array}{l}x_{E T}(x) \\
x_{\text {OEx }}(z)\end{array}$ & $\begin{array}{l}11,27 \\
10,90\end{array}$ & $\begin{array}{r}12,83 \\
9,52\end{array}$ & $\begin{array}{l}11,15 \\
10,89\end{array}$ & $\begin{array}{r}12,84 \\
9,52\end{array}$ & $\begin{array}{r}12,85 \\
9,51\end{array}$ \\
\hline х С2H4 & 15,54 & 15,25 & 15,56 & 15,25 & 15,27 \\
\hline$x 02$ & 6,20 & 4,77 & 6,26 & 4,77 & 4,77 \\
\hline Z $\mathrm{C} 2 \mathrm{H} 4 \mathrm{O}$ & 1,91 & 1,67 & 1,91 & 1,67 & 1,65 \\
\hline$x \cos$ & 11,74 & 12,74 & 11,68 & 12,74 & 12,73 \\
\hline 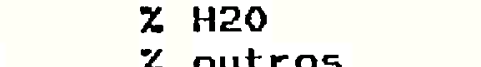 & 0,37 & 1,40 & $\begin{array}{r}0,33 \\
64,26\end{array}$ & $\begin{array}{r}1,40 \\
64,17\end{array}$ & $\begin{array}{r}1,40 \\
64,18\end{array}$ \\
\hline$x$ ou & 64,24 & & & & \\
\hline
\end{tabular}

\subsubsection{Influência dos pesos no aiuste pelo critério de} mínimos quadrados absolutos ponderados

Pode-se corrigir o efeito citado no item anterior usando pesos adequados no critério absoluto. Os pesos wre seriam feitos maiores que os wr, o que faz com que o critério se torne igualmente sensivel às diferencas em $X e$ em $T$. Particularmente se se escolhe o peso de cada ponto como inversamente proporcional ao quadrado do valor experimental da medida considerada, obtem-se o critério de minimos quadrados relativo. Oefeito do valor dos pesos wx e wr no critério absoluto é ilustrado na Tabela $6.5 e$ figura 6.6. Fixado o valor de wt $=1$ e aumentando-se o valor de wx, observa-se como esperado um ajuste cada vez melhor de conversões, em detrimento do ajuste das temperaturas. Para wx= 100 w $\omega_{T}=1$ obteve-se um ajuste semelhante ao obtido com o critério relativo. 
Ao se usar o critério absoluto, os pesos devem ser usados não só para compensar diferencas de "qualidade" das medidas, mas também diferencas de ordens de grandeza das variáveis dependentes. Parece ser preferivel usar o critério relativo, reservando os pesos para ponderar os pontos conforme a "qualidade" das medidas experimentais, ou seja, usar pesos menores para os pontos sujeitos a maiores erros de medicão ou maiores graus de dispersão estat istica.

Tabela 6.5. Influência dos pesos wx $e$ wr sobre o ajuste usando o critério absoluto.

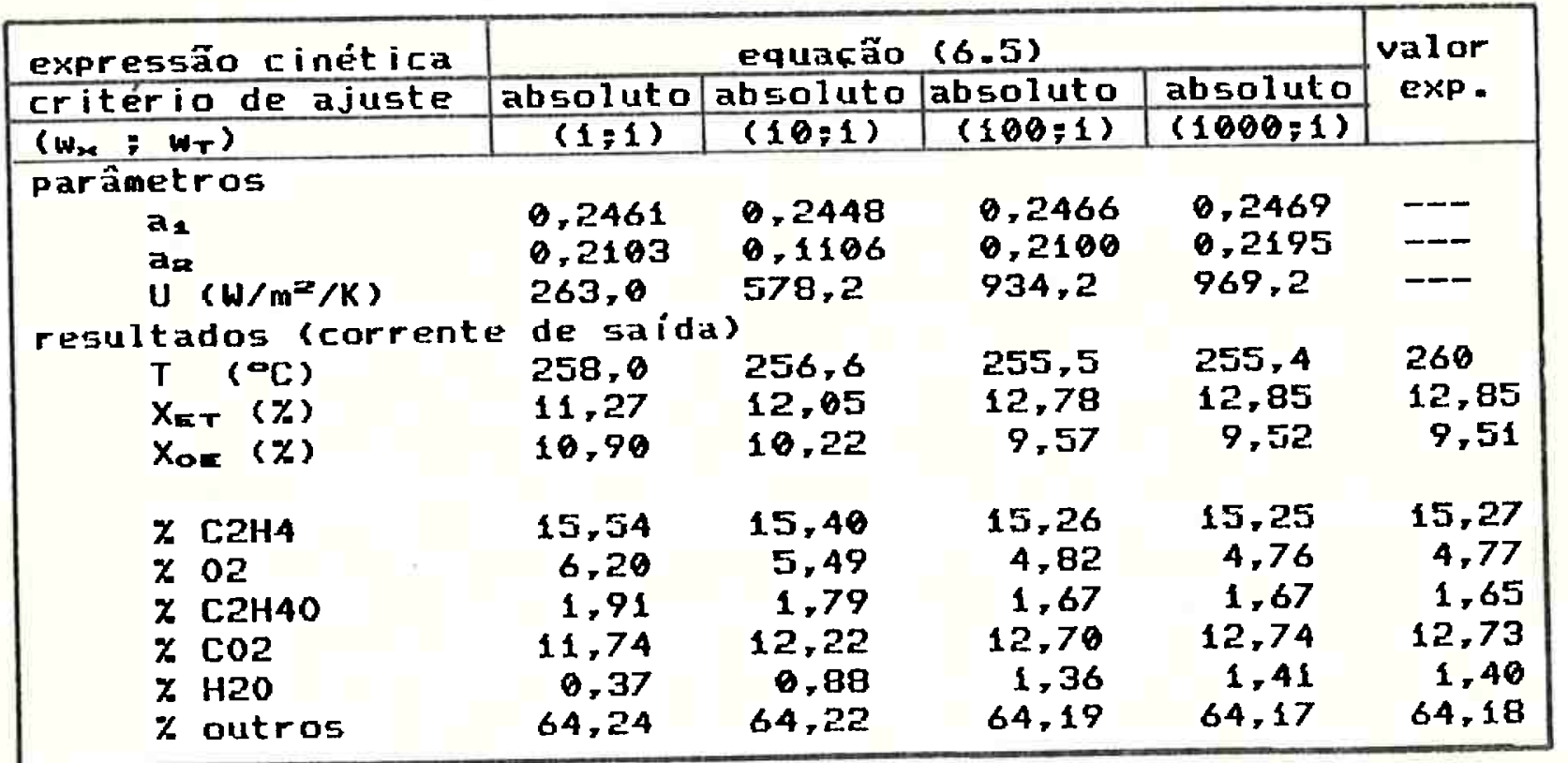

\subsection{Comentários e discussão}

A partir dos resultados apresentados neste Capitulo verificase que o problema de identificacão de modelo de reator de leito fixo é influenciado pelo critério de ajuste utilizado. Ao se usar - critério de minimos quadrados absolutos os pesos devem ser cuidadosamente escolhidos para que o ajuste não negligencie as variáveis cujos valores apresentem menor ordem de grandeza. o uso do critério de mínimos quadrados relativos é recomendado como forma de evitar esta escolha- Isto resguarda aos pesos sua funcăo 
de fatores de ponderacão relacionados a "qualidade" dos pontas experimentais, quando se conhece a estrutura de distribuicão de erros sobre as variáveis experimentais.

- modelo unidimensianal pseudo-homogêneo mostrou-se adequado a representação dos dados disponíveis do reator industrial de oxidacăo de eteno.

Também ambos os modelos cinéticos usados, mesmo oriundos de diferentes fontes e possivelmente relativas a catalisadores de diferentes formulacōes, possibilitaram uma boa representacão do reator, fazendo-se ajuste apenas das atividades catalíticas (a, e $a_{2}$, sem a necessidade de incluir como parâmetros ajustáveis outras constantes cinéticas, como por exemplo as energias de ativação. Entretanto esta conclusão não pode ser generalizada para outras situacōes, uma vez que só foram testados dados referentes a um particular reator e catalisador. Para outras situacões pode ser necessairio un melhor conhecimento da cinética do processo. 


\section{Capitulo 7}

\section{CONCLUSÕES E RECOMENDACõES}

Neste Capitulo é feita uma apresentacão das conclusões obtidas ao longo do desenvolvimento do trabalho. Também são apresentadas algumas recomendacőes e sugestôes de futuros trabalhos para cont inuidade da pesquisa.

\subsection{Conclusôes}

Quanto ao estudo experimental de transferência de calor em reatores de leito fixo, conclue-se que:

- o sensor anelar de temperatura proposto é de fácil construcão e apresentou boa capacidade de filtrar as flutuacóts de temperatura observadas em leitos fixos, o que permite diminuir o trabalho experimental de medicões neste tipo de experimento eliminando a influência da posicão angular na medida de temperatura; estes resultados foram também verificados por uma análise teórica do funcionamento do sensor:

- dentre alguns modelos testados, a modelo cam dispersão axial condicốes de contorno no infinito (modelo I) foi a que melhor representou os perfis de temperatura medidos; a despeito do fato de o coeficiente de dispersão térmica axial ser um parânetro de ajuste sem um significado físico claro, este modelo foi usado para a estimacão dos parâmetros térmicos radiais, condutividade radial efetiva e coeficiente de transferencia parede-leito:

- a análise de sensibilidade paramétrica do modelo utilizado mostrou que os valores de sensibilidade dependem fortemente das 
condicões experimentais $e$ do valor dos parâmetros; mostrou ainda que a sensibilidade ao coeficiente de dispersão axidl é bastante pequena, o que explica o ajuste pobre que este parâmetro costuma apresent ar;

- os parâmetros térmicos obtidos para os materiais ensaiados apresentam comportamento e valores coerentes con resultados de literatura; não foi possivel, entretanto, obter correlacōes gerais para os parâmetros térmicos devido ao pequeno número de materiais ensaiados, os quais näo permitiram variar independentemente a forma, o tamanho e tipo de material -

Quanto à modelagem matemática do reator catalitico de leito fixo para a producão de óxido de eteno, as conclusões são:

- os estudos realizados com modelos de diferentes graus de complexidade mostraram que o modelo bidimensional É mais conservativo que o unidimensional, e que o modelo que considera a existência de perfis radiais de velocidade e de porosidade no leito é mais conservativo que o modelo bidimensional convencional; a utilizacão do modelo com perfis de velocidade e porosidade é dificultada por algum aumento de complexidade computacional, mas principalmente pela carencia de conhecimento existente sobre tais não-uniformidades radias do leito, menos ainda sobre como interferem, por exemplo, nos parâmetros térmicos do reator;

- o estudo de estratégias de diluicáo do leito catalítico permitem obter condicőes operacionais de menor sensibilidader com ámpliação da faixa de operaçáo segura do reator, como se observou em uma das estratégias estudadas, baseada em dois patamares de atividade diferentes no reator; esta estratégia pode levar a situacôes de sensibilidade reversa, que podem, no entanto, ser detectadas através de estudo de simulacão; 
- estratégias de diluicão da atividade do leito por mistura de particulas ativas $e$ inertes podem levar a pontos quentes localizados junto a eventuais aglomerados de particulas ativas; este um comportamento diferente do que seria previsto supondo uma atividade catalitica média daquela wistura de partículas;

- os estudos de simulacáo evidenciam a necessidade de um bom conhecimento de certos parâmetros, tais como parâmetros térmicos e cinéticos; o ajuste de tais parâmetros permite corrigir certas deficiências do modelo unidimensional, obtendo-se assim um modelo computacionalmente mais simples $e$ ainda suficientemente representativo do processo; isto foi verificado fazendo a identificacào do modelo com dados de operacáo de un reator industrial de óxido de eteno, obtidos na literatura;

- para a identificacão do modelo, é recomendado que se disponha de medidas de temperatura ao longo do leito, além das medidas de temperatura e composicão de entrada e saida do reator;

- na identificacão feita com base no critério de minimos quadrados absolutos, devem ser escolhidos adequadamente pesos para as diferentes variáveis, para que o ajuste do modelo seja sensivel tanto aos valores de temperaturas como aos de conversóes; o uso do critério de mínimos quadrados relativos evita esta dificuldade reserva aos pesos sua funcão relacionada apenas à "qualidade" dos pontos experimentais.

\subsection{Sugestões para cont inuacáo dos trabalhos}

Quanto a sugestôes para cont inuidade das pesquisas sobre os assuntas abordados neste trabalho, pode-se citar:

(a) no estudo de transferência de calor, trabalhar cor um maior número de materiais, com diferentes tamanhos, formas $t$ ipo 
de material, de modo que a influência destas caracteristicas possam ser estudadas independentemente e quant ificadas;

(b) pesquisar outra forma de medir o perfil radial de temperatura na entrada da seçáo térmica, de maneira a melhor caracterizar os efeitos de entrada sobre a medicão dos parâmetros térmicos:

(c) pesquisar um modelo mais adequado para a estimaçáo de parámetros térmicos, sem a necessidade de ajustar parämetros de pouca sensibilidade e sem significado físico claro como $k$ mo modelo I (Capitulo 3). O modelo III, que infere um tipo de perfil de temperatura na entrada da seçao térmica, apresentou resultados interessantes e parece poder ser aperfeicoado para esta finalidade. Este estudo dependerá da pesquisa citada em (b);

(d) estudar estratégias de diluicão de atividade catalítica que permita otimizar as vantagens observadas no presente estudo;

(e) estudar experimentalmente estratégias de diluicão da atividade catalitica, en reator de bancada e piloto (em condicões de processo industrial);

(f) pesquisar, experimental e teoricamente, outras possíveis formas de quantificar as não-uniformidades radiais em leitos fixos e suas consequências sobre os parâmetros e sobre o comportamento de reatores;

(g) testar o programa de identificafão de reator com um maior número de reatores e situacôes, e aplicar o programa na etapa de identificacão de modelo estático de un esquema de controle com ot im izacão. 
APÊNDICE A

MĚTODO DE OTIMIZACEO DE MARQUARDT

Em problema de estimaç̃o de parâmetros de modelos matemáticos $\mathbf{Y}=\mathbf{f}(\boldsymbol{X}, \mathbf{h})$

o critério mais usual é o de mínimos quadrados, isto é, os parâmetros são ajustados de maneira a minimizar a funcäo:

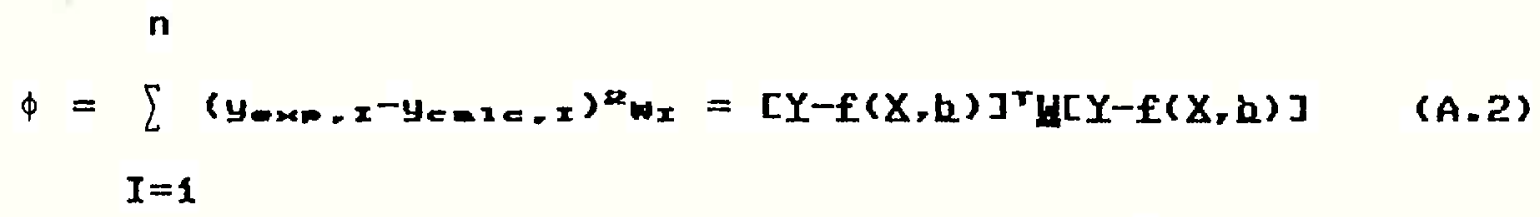

Conforme Himmelblau (1970), dentre os métodos que usam derivadas, o método de Newton-Gauss, ou Gauss-Seidel, baseia-se na linearização do modelo, por expansão em série de Taylor truncada nos termos de derivada primeira, ao redor da estimativa bo. A Partir deste ponto a procura segue o seguinte algoritmo:

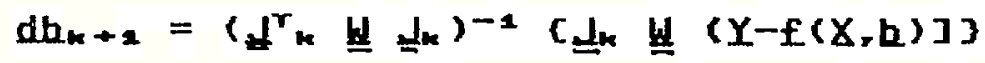

$$
\begin{aligned}
& b_{k+1}=b_{k}+g d b_{k+1}
\end{aligned}
$$

onde $k$ é o número da iteração, $\underline{\underline{l}}$ a matriz jacobiana:

$$
J_{k}=\left(J_{x+1} J_{k}=\left[\partial f\left(x_{x}, b_{k}\right) / \partial \text { bis }\right]\right.
$$

e $g$ um fator de amortecimento. 0 método de Gauss-Seidel corresponde a solucão do sistema normal de equacóes náo lineares pelo método de Newton-Raphson multivariável.

Outro método é o do gradiente, o qual baseia-se na linearização da funçáo objetivo $\phi$. Seu algoritmo tem a forma:

$$
\begin{gathered}
d b_{k+1}=\left[-\nabla \phi\left(b_{k}\right)\right] /\left[\sum_{j=1}^{p}\left(-\partial \phi / \partial b_{j}\right)=\right]^{k / 2} \\
b_{k+1}=b_{k}+g d_{k+1}
\end{gathered}
$$


Enquanto o método de Gauss-seidel mostra-se rápido e convergente para estimativas próximas da solucão, mas pode falhar para estimativas iniciais pobres de $h$, o método do gradiente mostra-se efetivo longe da solucão mas apresenta certas dificuldades próxino a solufão para certos tipos de problema.

- método de Marquardt (1963) apresenta un algoritmo que combina as direcôes de procura dos métodos de Gauss-Seidel e do gradiente, aproveitando melhor as vantagens de cada um durante a procura do mínimo. O método pode ser representado pela equacão:

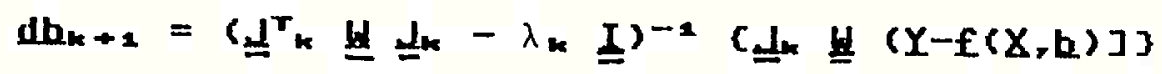

$$
\begin{aligned}
& b_{k+1}=b_{k}+g d h_{k+1}
\end{aligned}
$$

onde $I \dot{E}$ a matriz identidade $e \lambda_{*} \dot{e}$ um fator que adapta $e$ controla a direcão e o tamanho do passo. Para $\lambda_{k}=0$ tem-se o método de Gauss-Seidel e para $\lambda_{k} \rightarrow \infty$ tem-se o método do gradiente. 0 algoritmo para a mudanca do valor de $l_{k}$ durante a procura pode ser resumido na forma:

- inicialmente toma-se $\lambda_{0}=10^{-2} \mathrm{e} v=(2$ a 5$)$;

- para a iteracão $k$, tenta-se $\lambda=\lambda_{k-1} / v$ e calcula-se $\phi(\lambda)$;

- se $\phi(\lambda)<\phi_{k-1}$, então o passo f́aceito, senão tenta-se sucessivamente $\lambda=\lambda-v$ até que $\phi(\lambda)<\phi_{k-1}$, quando entäo a iteração é aceita.

0s programas usados para a estimacáo de parâmetros de modelo representado por equacão algébrica não linear cdeterminacão dos parâmetros térmicos no Capítulo 3 ) e equacões diferenciais ordinärias (identificacão do modelo do reator no Capítulo 6) utilizam o método de Marquardt. Os programas foram desenvolvidos pelo autor do presente trabalho para fazer parte da biblioteca de subrotinas de otimizaçáo do SIMPRo - simulador de Processos da Industria Quimica, em projeto conjunto desenvolvido pela USP, UFSCar, UNICAMP e UFUberlândia. 
APÊNDICE B

SOLUCZO NUMÉRICA DO MODELO DO SENSOR ANELAR

- modelo do sensor anelar de temperatura, apresentado no item 3.10, é representado pelas equacōes:

$$
\begin{aligned}
& \frac{k}{R_{m}=} \frac{d=t}{d \theta^{2}}=h=\frac{4}{D}\left(t-T_{-}\right) \\
& t(\theta=\theta)=t(\theta=2 \pi) \\
& d t / d \theta(\theta=\theta)=d t / d \theta(\theta=2 \pi)
\end{aligned}
$$

onde $h_{m}=h_{m}(0)$ e $T_{-}=T_{f}(0)$ são funcões da posicão angular $\theta$. Discretizando a equacão (3.25) aproximando a derivada segunda por fórmula de diferenca central, obtem-se:

$$
\frac{t_{J+2}-2 t_{\lrcorner}+t_{\lrcorner-2}}{(\Delta \theta)^{2}}=\left(\frac{4 h_{m} R_{m}}{k D}\right)\left(t_{J}-T_{-J}\right), j=1,2,3, \ldots N-1 \quad(A, 1)
$$

onde $\Delta \theta=2 \pi / N$ representa o espacamento entre os $N$ pontos de discret izakão.

Das condicôes de contorno decorre (vide figura A.1)

"to" $t_{0} t_{N}, t_{1}=t_{N+1}, t_{2}=" t_{N+2} "$

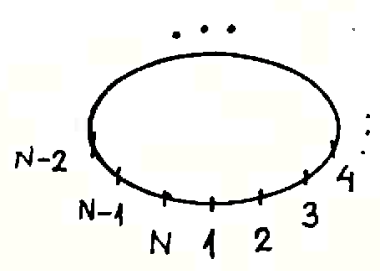

Figura A.1. Esquema da numeracão dos pontos de discretizacăo. 
Aplicando a equacâo (A.1) aos N pontos de discretizacáo considerando a equaçäo $(A .2)$, chega-se a:

$\left(\frac{d^{2} t}{d \theta^{2}}\right)_{1}=\frac{t_{z}-2 t_{1}+t_{m}}{(\Delta \theta)^{2}}=\frac{4 R_{m}^{2}}{k D} h_{m 2}\left(t_{2}-T_{+2}\right) \quad j=1$

$\left(\frac{d^{2} t}{d \theta^{2}}\right)_{J}=\frac{t_{J+1}-2 t_{\lrcorner}+t_{J-1}}{(\Delta \theta)^{4}}=\frac{4 R_{m}^{2}}{k D} h_{-J}\left(t_{J}-T_{-J}\right) \quad j=2 . . N-1\left(A_{-} 3\right)$

$\left(\frac{d^{2} t}{d \theta^{2}}\right)_{N}=\frac{t_{1}-2 t_{N}+t_{n-2}}{(\Delta \theta)^{2}}=\frac{4 R_{m}^{2}}{k D} h_{m N}\left(t_{N}-T_{N N}\right) \quad j=N$

- rearranjo destas equacões leva ao seguinte sistema linear:

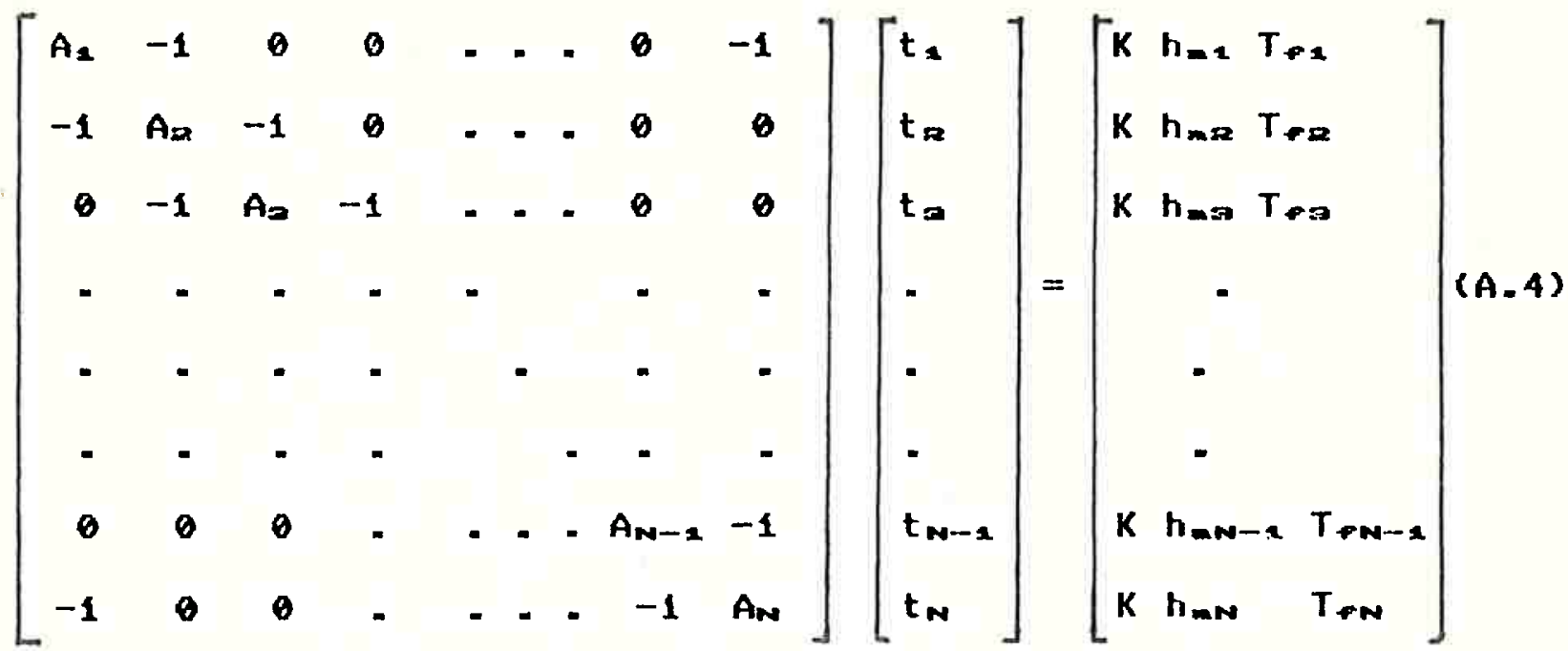

onde

$$
\begin{aligned}
& A_{J}=2+K h_{m J} \\
& K=4 R_{m}=(\Delta \theta)=2 /(k D)
\end{aligned}
$$

A solucão do sistema linear (A.4) foi obtida pelo método de eliminacão de Gauss. O valor de $N$ foi tomado igual a 20 , não havendo diferencas significativas em relacão à escolha $M=40$. 


\section{AP䏍DICE C SOBRE OS PROGRAMAS UTILIZADOS}

Ao longo deste trabalho foram elaborados e utilizados os seguintes programa:s de computador, descritos de modo sucinto:

- programa NT3.FOR: para a estimacáo de parâmetros térmicos do modelo $I$ do Capítulo 3, a partir dos dados experimentais de temperatura $T(r, z)$; este programa faz a estimacão dos parâmetros em equacão algébrica não-linear, usando o método de ot inizacão de Marquardt;

- Programa FBC.FOR: idem para o modelo II do Capitulo 3;

- programa ENT.FOR: iden para o modelo III do Capítulo 3;

- programa MT2.FOR: idem para o modelo IU do Capitulo 3.

- programa SENSIFOR: calcula os valores de sensibilidade paramétrica $S_{w} S_{r}$ E $S_{m}$ ao longo do raio e do comprimento do reator, dados os valores dos parânztros e as condicöes operacionais;

- programa ANEL.FOR: simula o funcionamento do sensor anelar de temperatura, calculando o perfil de temperatura no anel, dados - Perfil de velocidade $e$ o de temperatura do gás ao longo da posicão angular;

- programa UNI.FOR: simula o reator de leito fixo usando o modelo unidimensional pseudo-homogêneo; ten opkão para estudos de algumas estratégias de diluicão da atividade catalítica a(z); solucäo numérica usando o método de Runge-Kutta-Gill de 4n ordem;

- Programa BIDI.FOR: idem usando a modelo inidimensional pseudo-homogêneo; opqão para inclusấo de perfil radial de porosidade e de velocidade no modelop solucăo numérici usando os 
métodos de colocacão ortogonal (direfão radial) E Runge-Kutta-Gill (direfão axial);

- programa BIDGRAD.FOR: simula o reator de leito fixo usando o modelo bidimensional pseudo-homogêneo, com uma distribuicão discreta e aleatória cobtida a partir de um gerador de números aleatórios 0 e 1) de particulas ativas e inertes no leito; solucão numérica usando os métodos de diferencas finitas (direcão radial) e Runge-Kutta-Gill (direcão axial);

- programa IDENT.FOR: faz a identificacão do modelo do reator de leito fixo, usando o modelo unidimensional pseudo-homogêneo (solucão pelo método de Runge-Kutta-Gill), estimando seus parâmetros térmicos e cinéticos ajustáveis pelo método de otimizacão de Marquardt; faz portanto estimacáo de parâmetros em equacôes diferenciais ordinarias de condicăo inicial.

- programa COEFSYM.FOR: gera as matrizes A, B E o vetor WW do método de colocafáo ortogonal para polinômios ortogonais de Jacobi; este último programa foi montado a partir de subrotinas do livro de Villadsen a Michelsen (1978).

Todos as programas foram escritos em 1 inguagem FORTRAN E rodados em microcomputador PC-AT. Cópias dos programas em disquete podem ser solicitadas ao autor ou ao LSCP - Laboratório de Simulacão e Controle de Processos Químicos. Escola Politécnica da USP, Depto. Engenharia Quimica, Conjunto das Químicas Bloco 21, Caixa Postal 61548, CEP 65508, Säo Paulo, SP. 


\section{REFERÊNCIAS BIBLIOGRAFICAS}

ABRAMOWITZ, M. \& STEGUN, I.A. (Ed.) - Handhook of Mathematical Eunctions, Dover, New York, 1965.

ADAMSKA-RUTKOWSKA, D. ; STANK IEWICZ, A. \& LECZCZYNSKI, Z. Simulation of the operational characteristics od largescale multitubular reactor for maleic anhydride production, Comput. Chem. Enge, 12(2/3), 171-175, 1988.

AHMED, M. \& FAHIEN, R.H. - Tubular reactor design - II Twodimensional model, ChemeEng_Sci,, 35, 889-895, 1980.

AHMED, M. \& FAHIEN, R.W. - Tubular reactor design - III: Threedimensional mode1, Chem.Eng.Sci,, 43, 2801-2806, 1988.

ALFANI, F. \& CARBERRY, J.J. - An exploratory kinetic study of ethylene oxidation over an unmoderated supported catalyst, La Chimica \& L'Industria, J2(12), 1192-1196. dec. 1970.

AL-SALEH, M.A.; AL-AHMADI, M.5. \& SHALABI, M.A. - Kinetic study of ethylene oxidation in a Berty reactor, Chemeng.dournal, $37,35-41,1988$.

BALAKRISHNA, A.R. \& PEI, D.C.T. - Heat transfer in gas-solid packed bed systems. 1. A critical review, Ind. Eng. Chem. Pracess Desa Deve, 18(1), 30-39, 1979.

BEEK, J. \& SINGER, E. - A procedure for scaling-up a catalytic react or. Chem. Eng. Progr, 47, 534-546, 1951. 
BENENATI, R.F. \& BROSILOU, G.B. - Void fraction distribution in beds of spheres, A.I.Ch.E, Journal, 8, 359-362, 1962.

BERTY, J.M. - Ethylene oxide synthesis, IN Applied Industrial Catalysis, B.E.Leach (ed.), vol.1, Cap.8, p.207-238, 1983.

BIscaia Jr., E.C. \& DIEGUEZ, L.C. - Influência do número de tubos no comportamento estacionário de reatores cataliticos de leito $f i x o$, Revista Brasileira de Engenharia Quimica, $7(1), 27-30,1983$

BORIO, D.O. ; BUCALA, U.; PORRAS, J.A. \& ROMAGNOLI, J.A. Operabilidad de reactores multitubulares de lecho fijo, XIV Jornadas sobre Investigationes en Ciencias de la Ingenieria Quimica y Quimica Aplicada, Santa Fé, Argentina, Actas, vol. 1, p 411-416, 1987.

BUNTIN, R.R., Phodhesis, Purdue University, 1961 [citado em Montalvo Robles, 19753 .

CAlderbank, P.H. CAlDWELl, A. \& ROSS, G. - The 'diluted-catalyst' fixed-bed reactor for exothermic catalutic reactions, $4^{\text {th }}$ European Symposium on Chemical Reaction Engineering, Brustiels, Proce, p.93-106, 1968.

CARBERRY, J.J. - Chemical Catalutic Reaction Engineering, McGrawHi11, New York, 1979. 
CARBERRY, J.J. \& HHITE, D. - On the role of transport phenomena in catalytic reactor behaviour. Digital simulation of naphtalene oxidation over $\mathrm{V}_{2} \mathrm{O}_{\mathrm{s}}$, Ind. Eng. Chemer 61(7), $27-35,1969$.

CHALBI, M.; CASTRO, J.A.; RODRIGUES, A.E. \& ZOULALIAN, A.- HEat transfer parameters in fixed bed exchangers, Chem. Eng. Journal, 34, 89-97, 1987.

CHEN, C.Y. \& JOSEPH, B. - On-line optimization using a two-phase approach = an application study, Ind. Eng. Chem. Rese, 26, $1924-1930,1987$.

CLEMENT, K. \& JORGENSEN, 5.B. - Experimental investigation of axial and radial thermal dispersion in a packed bed, Chem.Eng.Sci., $38(6), 835-842,1983$.

CRIDER, J.E. \& FOSS, A.S. - Effective wall heat transfer coefficients and thermal resistances in mathematical models of packed beds, A.I.Ch.E. Journal, 11, 1012-1019, 1965.

D'AUILA, S.G. - Oxidacáo catalítica de crotonaldeído a anidrido maleico, Iese de Doutorado, COPPE-UFRJ, 1971.

DELMAS, H. \& FROMENT, G.F. - A simulation model accounting for structural radial nonuniformities in fixed bed reactors, Chem. Enq, Sile, $43(8), 2281-2287,1988$. 
DETTWILER, H.R. ; BAIKER, A. \& RICHARZ, W. - Kinetics of ethylene oxidation on a supported silver catalyst, Helvetia Chinica Acta, 62(2), 1689-1700, 1979.

DE WASCH, A.P. \& FROMENT, G.F. - Heat transfer in packed beds, Chem. Enq. Sci., 27, 567-576, 1972.

DIXON, A.G. \& CRESSWELL, D.L. - Theoretical prediction of effective heat transfer parameters in packed beds, A.I.Ch.E. Jouraal, 25(4), 663-676, 1979.

DIXON, A.G. - PATERSON, W.R. \& CRESSWELL, D.L. - Heat transfer in packed beds of low tubefparticle diameter ratio, ACs Sump. Series, 65, 238-253, 1978.

DIXON, A.G. - Solution of packed-bed heat-exchanger models by orthogonal collocation using piecewise cubic Hermite functions, ACs Sume. Series, 168, 287, 1981.

DIXON, A.G. - Thermal resistance models of packed-bed effective heat transfer parameters, A.I.Ch.E. Journal, 31(5), 826$834,1985(a)$.

DIXON, A.G. - The length effect on packed bed effective heat transfer parameters, Chem. Enge Journal, 31, 163-173, 1985 (b).

DIXON, A-G. - Wall and Particle-shape effects on heat transfer in Packed beds, Chem. Eng_Comme, 71, 217-237, 1988. 
DOGU, G. - The effect of temperature and diffusion limitations on the selectivity of catalytic oxidation of ethylene, 2nd Hor ld Congress Chem. Eng., Canadá, Proce, vol.3, 280-284, 1981.

DORAISWAMY, L.K. \& SHARMA, M.M. - HeterogeneOUS reactions: analusise exameles and reactor desiga. vol. 1: Gas-solid and solid-solid_reactions, Wileg, New York, 1984 .

DRAHOS, J. 8 CERMAK, J. - Analysis of gas discharge from packed beds, IN Encyclopedia of Fluid Mechanics, vol. 3: Gasliquid flows, Gulf Publishing, Houston, 1986.

DRAHOS, J. ; CERMAK, J. ; ZIOLKOWSKA, I. \& ZIOLKOWSKI, D. Statistical analysis of local gas velocities at the exit from a packed bed, Chem. Eng Jaurnal, 24, 71-80, 1982.

EIgenberg, G. - Practical problems in the modelling of chemical reactions in fixed bed reactors, Chem. Eng. Processe. 18, $55-63,1984$.

ELIYAS, A. : PETROU, L. \& SHOPOU, D. - Ethylene oxide oxidations over a supported silver catalyst II. Kinetics of inhibited oxidation, Apllied Catalusis, 41, 39-52, 1988.

FAHIEN, R.H. \& STANKOUIC, I.M. - An equation for the velocity profiles in packed columns, Chem. Eng. Sciar 34, 1350$1354,1979$.

FINLAYSON, B.A. - Packed bed analysis by orthogonal collocation, Chem._Ena_sci., 26, 1681-1091, 1971. 
FINLAYSON, B.A. - NOnlinear Analysis in Chenical Enginefring, McGraw-Hill, New York, 1930.

FOGNANI, F. \& MONTARNAL, R., REY, Inst, Fr. PEtar 14, 191, 1959 [citado em Sacht]er et ali $i$, spor].

FREIRE, J.T. - Transferência de calor en meios porosos, IEsede Doutorado, COPPE-UFR J, 1980.

FREIRE, J.T. - Comunicąăo Pessoal, 1936.

FREGOLENTE, A.L.; NASCIMENTO, C.A.0. \& GIUUICI, R. - TransfErência de calor en reator catalitico de leito fixo II: aspectos. Experimentais, 170 Encontro sobre Escoamento en Meios Porosos, Säo Carlos, 1939.

FFOMENT, G.F. - Fixed bed catalytic reactors, Ind. Eng. Chemm. $59(2), 18-27,1967$.

FROHENT, G.A. \& BISCHOFF, K.E. - Chenical Reactor Analysis-and Design, Wiley, 1979.

GEAR, C. U. - Mumerical initial value problems in ordianu differential_equations, Prent ice-Ha11, Englewood Cliffs, 1971.

GIUDICI, R. \& NASCIMENTO, C.A.O. - Transferéncia de calor en reator catalitico de leito fixo II modelos, 170 Encontro sobre Escoamento en Meios Forosos, São Carlos, 1909. 
GOUINDARAO, U.H.H. \& FROMENT, G.F.- Voidage profiles in packed beds of spheres, Chen. Enq. Sci., 41(3), 533-539, 1986.

GUNN, D.1. ; AHMAD, M.M. \& SABRI, M.N. - Radial heat transfer to fixed bed of particles, Chen. Eng, Sci., 42, 2163-2173, 1997.

GUN, D.J. \& KHALID, M. - Thermal dispersion and wall heat transfer in packed beds, Chem. Eng. Sci, 30, 261-267, 1975.

HEGGS, P.J. \& ASSAF, A.ri. - Investigation of the kinetics of ethylene oxidation over silver catalyst, 2nd World Congress Chem. Eng., Canadá, Eroc., vol.3, 280-284, 1981.

HERCE-UIGIL,UlL- et alii-Experinental determination of heat transfer parameters in catalytic beds, 100 Congresso Interamericano de Engenharia Quimica, Santiago, Chile, Anais, vol. 1, P. 101-105, 1983.

HIMMELBLAU, D.M. - Process Analysis by Statistical Kethods, wiley, NE: York, 1970.

HLAUACEK, U. \& ROMPAY, P.V. - Current problens of multiplicity, stability and sensitivity of states in chenically reacting systens, Chem. Eng. Sci.., 36, 1587-1597, 1901.

HLAVACEK, $U$. \&OTRUBA, J. - Steady-state operation of fixed-bed reactors and monolithic structures, Cap. 6 IN L. Lapidus \& H.R. Amundson (ed.), Chemical Reactor Theory. A Review, Prentice-Hal1. Englewood Cliffs, 1977. 
IMRE, V.L. - Untersuchungen zum Mechanismus der Oxydation von Athylen durch Sauerstoff zu Athylenoxid ann Silber als Katalysat or, Berichte de Bunsen-Gesellschaft, $74(3)$, 220$226,1970$.

KALTHOFF, 0. \& VORTMEYER, D. - Ignition/extinction phenomena in a wall cooled fixed bed reactor. Experiments an model calculations including radial porosity and velocity distributions, Chem. Eng. Scia, 35, 1637-1643, 1980.

KAHANER, D. ; MOLER, C. \& NASH, S. - Numerical methods and sofware, Prentice-Hall, Englewood Cliffs, 1989.

KHANA, R. \& SEINFELD, J.H. - Mathematical modeling of packed bed reactors: numerical solutions and control model development, Advances in Chemical Engineering, vol. 13, P. $113-191,1987$.

KLUGHERZ, P.D. \& HARRIOT, P. - Kinetics of ethylene oxidation on a supported silver catalyst, A.I.Ch_E Journal, $17(4)$, 856866,1971 .

KUR ILENKO, A.I. ; KUL 'KOWA, N.U. ; RYBAKOWA, N.A. \& TEMKIN, M.I., Zh. Fize_Khim., 32, 797, 1958 [citado em Sachtler et alii, $1981 \mathrm{~J}$.

LANDAU, R. \& LIDOU, R.E. - Ethylene oxide, IN Ethylene and its Industrial Derivatives, S.A.Miller (ed.), Ernest Benn, London, 1969. 
LASA, H.de : MOK, L.K. \& SORIA LOPEZ, A. - Oxidation of orthoxylene in a catalytic packed bed reactor. The cross flow operation. The critical row of tube case, $2^{\text {mat }}$ World Congress Chew. Eng., Canadá, Brac., vol.3, 297-300, 1981.

LEROU, J.J. \& FROMENT, G.F. - Velocity, temperature and conversion profiles in fixed bed catalytic reactors, Chem. Eng. Sci., 32, 853-861, 1977.

LEROU, J.J. \& FROMENT, G.F. - Reply to comments by A.G.Dixon and D.L.Cresswell on "Est imation of heat transfer parameters in packed beds from radial temperature profiles". Chem. Eng._Journal, 17, 247-249, 1979.

LEVA, M. - Heat transfer to gases through packed tubes, Ind. Eng. Chem., 46, 857-65, 1947.

LI, C.H. \& FINLAYSON, B.A. - Heat transfer in packed beds - a reevaluat ion, Chem. Ena. Sci., 32, 1055-1066, 1977.

LYCZKOHSKI, R.H. - Modeling of flow nonuniformities in fissured porous media, Can. J. Chem. Eng., 60, 61-75, 1982.

MAKHLIN, U.U. F EUENCHIK, A.S. ; GROSHEU, G.A. \& SLINKO,M.G. Parametric sensitivity, interruption of stationary heat conditions, "decomp", and critical loads of a tubular ethylene oxide synthesis reactor, Khimicheskaya Promushlenaoist, $19(8), 31-35,1987$. 
martuoet, J.; TEOdORIU, P. \& WAJC, S.J. - Porosity, velacity and temperature profiles in cylindrical packed bed, Chem. Eng. Sci., 29, 1836-1840, 1974.

MARQUARDT, D.W. - An algorithm for least squares estimation of nonl inear parameters, L. Soc. Indust. Appl. Mathe. $11(2), 43 i-441,1963$.

MARTIN, H. - Low Peclet number particle-to-fluid heat and mass transfer in packed beds, Chem. Enge Sci., 33, 913-919, 1978 .

MARTINEZ, O.M. ; PEREIRA DUARTE, S.I. \& LEMCOFF, N.0. - Modelling of fixed bed catalytic reactor, Come. Chem. Eng., 9(5), $535-545$, 1985.

MCGREAUY, C. \& DUNBBOBIN, B-R. - Operational flexibility considerations in the design of multitubular reactors, Proc. of 5th International Symposium on Chemical Reaction Engineering, Houston, A.c.S. Sump. Series, 65, 214-222, 1978 [citado em McGreavy et alii, 1988].

MCGREAUY, C. ; FOUMENY, E.A. \& JAUED, K.H. - Characterization of transport properties for fixed bed in terms of local bed structure and flow distribution, Chem. Enge Scie, 41, $787-797,1986$. 
MCGREAUY, C. ; MACIEL FILHO, R. ; CASTRO, J.A.A. \& MOURA, J.C. Processo alternativo para a obtencão do acetaldeído: oxidacão catalitica do álcool etílico, XI Simp. Tberoam. Cat ., Guanajuato, México, Anais, P. 655-663, 1988.

MICHELSEN, M.L. - An efficient general-purpose nethod for the integration of stiff ordinary differential equations, A.I.Ch_E Journal, 22, 594-597, 1976.

MINHAS, S. \& CARBERRY, J.J., Br. Chemenng,, 14(6), 799, 1969 Ccitado em Carberry, 19791.

MORALES, M. ; SPINN, C.W. \& SMITH, J.M. - Velocities and effective thermal conductivities in packed beds, Ind. Enq. Chem. $43(1), 225-232,1951$.

MONTALVo ROBLES, A. - Simulacion de un proceso para la sintesis de oxido de etileno, Baletin Técnico da Petrobrás, $18(3 / 4), 129-144$, jul ./dez. 1975.

MOURA, J.C. - Oxidação de etanol a acetaldeído sobre catalisador de cobre oxidado, Iese de Doutorado, UNICAMP, 1984.

MURRAY, K.E. - Austre fesci. Res, A3, 433, 1950 [citado em Sachtler et alii, 19813 .

OLBRICH, W.E. \& POTTER, O.E. - Heat transfer in small diameter packed beds, Chem. Eng. Sci_, 27, 1723-1732, 1972. 
PATERSON, H.R. \& CARBERRY, J.J. - Fixed bed catalytic reactor modelling - the heat transfer problem, Chem. Eng. Scis, $38(1), 175-180,1983$.

Pereira duarte, S.I.; Barreto, G.F. \& LemCoff, N.0. - Comparison of two-dimensional models for fixed bed catalytic reactors, Chen. Eng. Scie, 39(6), 1617-1024, 1984.

PETrov, L. : ELIYAS, A. \& shopov, D. - Kinetics of etinglene oxidation over a silver catalyst in the presence of dichloethane, Applied Catalysis, 24, 145-165, 1986.

PICCININI, N. \& LeUY, G. - Process safety analysis for better reactor cooling system design in the ethylene oxide reactor, Can_e_chem._Eng., 62, 541-546, 1984

PIRKLE, J.C. \& WACHS, I.E. - Ackivity Profiling in Catalytic Reators, Chem. Eng. Progres5, 83(8), 29-34, Aug. 1987.

PUSZYNSKI, J. ; SNITA, D. ; HLAVACEK, U. \& hOFMAN, H. - A revision of multiplicity and parametric sensitivity concepts in nonisothermal nonadiabatic packed bed chemical reactors, Chem. Eng. Scie, 36(10), 1605-1609, 1981.

RASE, H.F. - Chemical Reactor Design for Process Plants, vol. 2, Case Studies \& Design Data, Wiley, 1977.

RUTZLER, W. - Nonlinear est imation methods for tubular reactors, Ph.b. Thesis, University of Minnesota, 1980. 
SACHTLER, W.M.H. F BACKX, C. \& VAN SANTEN, R.A. - On the mechanism of ethylene Epoxidation, Cat. Rev. Sci. Enge, 23(1/2), $127-149,1981$.

SCHWARTZ, C.E. \& SMITH, J.M. - Flow distribution in packed beds, Ind. Eng. Chen., 45, 1269-1218, 1953.

SILUEIRA, A.M. ; Massarani, G. \& FREIRE, J.T. - Transferência de calor mo escoamento de un líquido em leito fixo, 170 Encontro sobre Escoamento 2 Heios Porosos, São Carlos, 1989.

SKLIVANIOTIS, M. ; CASTRO, J.A.A. \& McGREAUY, C. - Characteristic features of parametric sensitivity in a fixed bed heat exchanger, Chen. Eng. Sci, $43(7), 1517-1522,1988$.

SMITH, T.G. \& CARBERRY, J.J. - Optimization of a non-isothermal, non-adiabatic fixed-bed catalytic reactor model, Advances in Chemical Series, $133,362-375,1974$.

SOOMRO, M.A. - Heat transfer in packed bed reactors, Ph.D.Thesis, University of Salford, 1981 .

STANEK, $V$. \& UYCHODIL, P. - On the length effect of the heat dispersion parameters, Chem. Eng. Communa, 27, 69-78, 1984.

STANKIEWICZ, A. - Advances in modelling and design of multitubular fixed-bed reactors. I. Description of interaction between reactants and coolant, Chem. Eng. Technol,, 12, 113-130, 1989. 
STANKIEWICZ, A. - Advances in modelling and design of multitubular fixed-bed reactors. II. A mathematical model of the cocurrent multitubular reactor system, Cheme. Eng. Iechnol., 12, 170-175, 1989.

SOARES, J.B.P. \& MORI, M. - Análise do reator de leito fixo na cinética de oxidacão de etanol a acetaldeido sobre catalisador de cobre oxidado, $2^{\circ}$ Congresso Latinoamericano de Transferência de Calor e Matéria, São Paulo, Anais, vol. 3, P. 1458-1469, 1986.

STOUKIDES, M. \& VAYENAS, C.G. - Solid-electrolyte-aided study of the ethylene oxidation on polycrystalline silver, Journal of Catalusis, $69(1), 18-31,1981$.

STOUKIDES, M. \& VAYENAS, C.G. - Solid-electrolyte-aided study of ethylene oxide oxidation on silver, Journal of Catalusis, $64,18-28,1980$.

TEMKIN, M.I. - The kinetics of some industrial heterogeneous catalyt ic reactions, Advances in Catalusis, 28, 173-291, 1979.

THOMÉO, J.C. - Análise experimental dos efeitos de entrada térmicos sobre os coeficientes de transferencia de calor em leito fixo, Dissertacán de Mestrado, UFSCar, 1990. 
THOMÉO, J.C. \& FREIRE, J.T. - Transferência de calor em reator tubular em leito fixo, baixa razão L/D e escoamento monofásico, 160 Encontro sobre Escoamento em Meios Porosos, Petrópolis, Anais, vol. 1, P. 122-135, 1988.

THOMÉO, J.C. \& FREIRE, J.T. - Efeitos de entrada térmicos sobre os coeficientes de transferência de calor em leito fixo, $17^{\circ}$ Encontro sobre Escoamento em Meios Porosos, São Carlos, 1989.

TSOTSAS, E. \& SCHLUNDER, E.U. - Some remarks onn channelling and on radial. dispersion in packed beds, Chem. Enge Sci., 43(5), $1200-1203,1988$.

TWIGG, G.H. - The catalytic oxidation of ethylene, Iransw Faraday Soc., $42,284-291,1946$.

VALLE, M.L.L. - O efeito da concentracäo dos reagentes sobre a taxa de processo na oxidacão do etileno - conversảo, seletividade efetividade do catalisador. Lese de Doutorado, COPPE/UFRJ, 1978.

VALLE, M.L.M. \& SCHMALL, M. - Influência da concentração dos reagentes sobre a taxa de oxidacão de etileno, $6^{\circ}$ Simpósio Iberoamericano de Catálise, Anais, vol. 3, 975$993,1978$.

UILLADSEN, J. \& MICHELSEN, M.L. - Solution of differential equation models bu polunomial aperoximation. Prentice-Hal1, Englewood Cliffs, 1978 . 
VORTMEYER, D. \& SCHUSTER, J. - Evalution of steady flow profiles in rectangular and circular packed beds by a variational method, Chen. Eng. Sci., 38, 1691-1699, 1983.

VORTMEYER, D. \& WINTER, R.P. - On the validity limits of packed bed reactor continuum models with respect to tube to particle dianeter ratio, Chem. Eng. Sci., 39(9), 1430-1432, 1984.

YAGI, S. \& KUNII, D. - Studies on effective thermal conductivities in packed beds, A.I.Ch.E, Journal, 3(3), 373-381, 1957.

YAMAMOTO, C.I. ; NASCIMENTO, C.A.O.\& GIUDICI, R. - Simulaç̃o de reator de leito fixo con reacōes de oxidacáo: aplicacão ao processo de oxidacão de etileno, 10 Seminário sobre Aplicacões e Desenvolvimentos em Simuladores de Processo, Petrobrás, Rio de Janeiro, Anais, vol. 2, 1990.

YOUNG, L.C. \& FINLAYSON, B.A. - Axial dispersion in nonisothermal packed bed chemical reactors, Ind. Eng. Chem. Fundama. $12(4), 412-422,1973$.

WAN, S.W. - Oxidation of ethylene to ethylene oxicie, Indeneng. Chem., 45(1), 234-238, 1953.

WELTY, J.R.; WILSON, R.E. \& WICKS, C.E. - Eundamentals of momentum. heat and mass transfer, 2" ed., Wi ley, 1976.

WESTERTERP, K.R. \& PTASINSKI, K.J. - Safe design of cooled tubular reactors for exothermic, multiple reactions; parallel reactions - II ; The design and operation of an ethylene oxide reactor, Chem. Eng. Scie, 39, 245-252, 1984. 
WHITAKER, S. - Advances in theory of fluid motion in porous media, Ind. Eng. Cheme, 61(12), 14-28, 1969.

WYNGAARDEN, R.J. \& WESTERTERP, K.R. - Do the effective heat transfer conductivity and the heat transfer coefficient at the wall inside a packed bed depend on a chemical reaction? Heakness and applicability of current models, Chem. Eng. Sci., 44(8), 1653-1663, 1989.

ZIóLKOWSKI, D. \& LEGAWIEC, B. - Remarks upon thermokinetic parameters of the one- and two-dimensional mathematical models of heat transfer in a tubular flow apparatus with a packed bed, Chem. Eng. Process, 21, 65-76, 1987.

ZIólKouSKA, I. \& ZIólKowsKI, D. - Fluid flow inside packed beds, Chem. Eng. Process., 23, 137-164, 1988.

ZOMERDIJK, J.C. \& HALL, M.W. - Technology for the manufacture of ethylene oxide, Catal.Rev. Sci. Eng., 23(1/2), 163-185, 1981 .

ZOTIN, F.M.Z. - o efeito de parede em colunas de recheio. Dissertacão de Hestrado, UFsCar, Sáo Carlos, 1985.

ZOTIN, F.M.Z. \& FREIRE, J.T. - Efeito de parede em colunas de recheio, IN Tópicos Especiais de Sistemas Particulados, J.T.Freire e J.C.Gubulin (ed.), vol.2, p.289-392, 1986. 